\title{
Integral Data Testing of ENDF/B Fission-Product Data and Comparisons of ENDF/B with Other Fission-Product Data Files
}

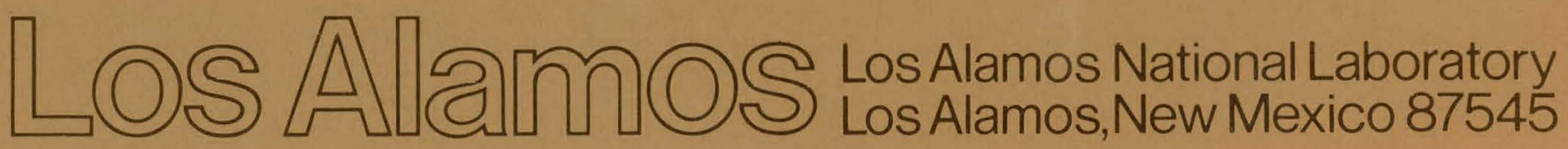




\section{DISCLAIMER}

This report was prepared as an account of work sponsored by an agency of the United States Government. Neither the United States Government nor any agency Thereof, nor any of their employees, makes any warranty, express or implied, or assumes any legal liability or responsibility for the accuracy, completeness, or usefulness of any information, apparatus, product, or process disclosed, or represents that its use would not infringe privately owned rights. Reference herein to any specific commercial product, process, or service by trade name, trademark, manufacturer, or otherwise does not necessarily constitute or imply its endorsement, recommendation, or favoring by the United States Government or any agency thereof. The views and opinions of authors expressed herein do not necessarily state or reflect those of the United States Government or any agency thereof. 


\section{DISCLAIMER}

Portions of this document may be illegible in electronic image products. Images are produced from the best available original document. 


\section{DISCLAIMER}

This report was prepared as an account of work sponsored by an agency of the United States Government. Neither the United States Government nor any agency thereof, nor any of their employees, makes any warranty, express or implied, or assumes any legal liability or responsibility for the accuracy, completeness, or usefulness of any information, apparatus, product, or process disclosed, or represents that its use would not infringe privately owned rights. References herein to any specific commercial product, process, or service by trade name, trademark, manufacturer, or otherwise, does not necessarily constitute or imply its endorsement, recommendation, or favoring by the United States Government or any agency thereof. The views and opinions of authors expressed herein do not necessarily state or reflect those of the United States Government or any agency thereof. 
LA- $9090-M S$

DE82 010041
LA-9090-MS (ENDF-320)

UC-34c

Issued: November 1981

\section{Integral Data Testing of ENDF/B Fission Product Data and Comparisons of ENDF/B with Other Fission Product Data Files}

R. J. LaBauve

T. R. England

D. C. George

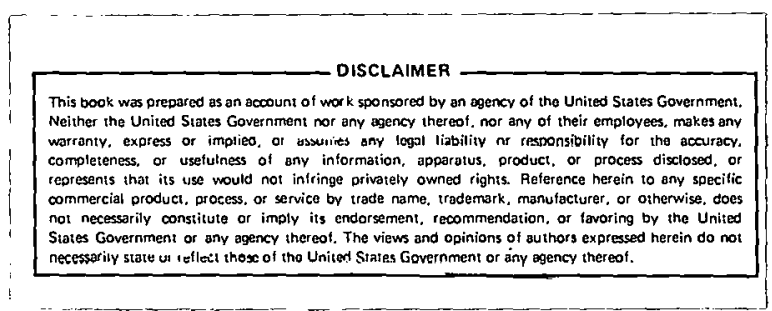


INTEGRAL DATA TESTING OF ENDF/B FISSION PRODUCT DATA AND COMPARISONS OF ENDF/B WITH OTHER FISSION PRODUCT DATA FILES

by

R. J. LaBauve, T. R. England, and D. C. George

\begin{abstract}
Three experiments (one from Oak Ridge and two from Los Alamos), in which samples of $235_{\mathrm{U}}$ and ${ }^{2} 39 \mathrm{Pu}$ were irradiated with thermal neutrons and either the total, gamma-ray, or gamma- and beta-ray fission product decay-energies were measured as functions of cooling time, were selected for comparisons with calculations made using four different fission product data files. The data files used were ( 1 ) the ENDF/B-IV fission product file, (2) the ENDF/B-V. fission product file, (3) a file derived by substituting decay energies from JNDC into the ENDF/B-V file, and (4) a file derived by substituting decay-energies and spectra from the UK data file into the ENDF/B-V file.

Direct summation calculations and spectral comparisons of the experiments were made using these data files as input, and both types of calculational analyses yielded the same results; namely, all data files are deficient, but the JNDC-ENDF/B-V results for the gamma- and beta-ray total decay-energy agree best with experiments. In addition, spectral comparisons with experiment generally indicate that calculated gamma-ray decay-energies are relatively high for early cooling times and small gamma-ray energies; they are low for early cooling times and large gamma-ray energies. The opposite is somewhat the case for the beta-ray decay energies; that is, the calculations are generally low for small beta-ray energies and high for large energies.
\end{abstract}

\title{
I. INTRODUCTION
}

Four different fission product files were used to calculate decay-energies which were then compared to experimental results. These four include two versions of the ENDF/B fission-product files, namely, ENDF/B-IV 1 and ENDF/B-V. ${ }^{2}$ ENDF/B-IV contains data for 824 nuclides and 10 yield sets, whereas ENDF/B-V has been expanded to include 877 nuclides, 20 yield sets, and more evaluated spectral data. Comparisons of the two versions are given in Tables I and II. 
TABLE I

ENDF/B-IV VS ENDF/B-V GROSS COMPARISON OF DATA CONTENT IN FP FILES

Type of Quantity

ENDF/B-IV

ENDF/B-V

General Content

Total nuclides

Nuclides having cross sections

824

877

Stable nuclides

181

196

Unstable nuclides

113

127

Total isomeric states $(>0.1 \mathrm{~s})$

711

750

First isomeric states $(>0.1 \mathrm{~s})$

123

154

Average energies derive $\bar{d}$ from ex

117

148

Delayed neutron precursors

181

317

Fission yield sets

57

105

10

20

Nuclides having detailed spectral data

Beta and/or gamma

Electron related

Photon related

Conversion electron

Positron or EC

Xray

Discrete electron

$\begin{array}{rr}180 & 264 \\ 163\left(\beta^{-} \text {only }\right) & 233 \\ 172(\gamma \text { only }) & 247 \\ 38 & 157 \\ 0 & 12 \\ 0 & 166 \\ 0 & 166\end{array}$

264

233

247

12

166

166

TABLE II

COMPARISON OF. FP YIELDS IN ENDF/B-IV AND ENDF/B-V*

Characteristic Neutron Incident Energy

Target

Nuclide

Th-232

U-233

$\mathrm{U}-235$

$\mathrm{U}-236$

$\mathrm{U}-238$

$\mathrm{Np}-237$

Pu-239

$\mathrm{Pu}-240$

$\mathrm{Pu}-241$

$\mathrm{Pu}-242$

Cf-252
$\mathrm{High}$

(14 MeV)

Spontaneous

Therma1

Fast

5

4,5

4,5

4,5

4,5

5

4,5

5

4,5

4,5

5

4,5 
In addition to the ENDF/B files, data from the Japanese fission product file $(J N D C)^{3}$ and British (UK) fission product file ${ }^{4}$ were also used in the calculational comparisons. In the case of the JNDC file, the average total gamma and beta energies of the individual nuclides were used to replace those in ENDF/B-V where possible; that is, spectra, yields, branching fractions, etc., were from ENDF/B-V. In the case of the UK file, spectra as well as total average energies were used; however, nuclide activities were taken from ENDF/B-V summation runs. A number of experiments at Los Alamos and Oak Ridge, in which nuclear fuel samples were irradiated with thermal neutrons and the decay energy and spectra of the resulting fission products observed, were selected for calculational comparisons. The experiments used in this study include the following.

- Oak Ridge spectral experiments ${ }^{5}, 6$ in which $235_{\mathrm{U}}$ and ${ }^{239} \mathrm{Pu}$ fuels were irradiated with thermal neutrons for times of $1,10,\left(5\right.$ for ${ }^{239} \mathrm{Pu}$ ), and $100 \mathrm{~s}$, and both aggregate fission-product gamma-ray and beta-ray decay-energy spectra were measured for a range of average cooling times from $2.2 \mathrm{~s}$ (for the 1-s irradiation time) to $12000 \mathrm{~s}$ (for the 100-s irradiation time).

- Los Alamos calorimetric experiments ${ }^{7}, 8$ in which ${ }^{23}{ }^{3},{ }^{235} \mathrm{U}$, and ${ }^{239} \mathrm{Pu}$ were irradiated with thermal neutrons for $20000 \mathrm{~s}$ and total decay heat (gamma plus beta) measured for a range of cooling times from 29 to $190000 \mathrm{~s}$.

- Los Alamos spectral experiments ${ }^{9}$ in which fuels, irradiation time, and cooling time ranges were the same as for the calorimetric experiments, but aggregate fission-product gamma-ray decay-energy spectra were measured. All of the experiments were included in formulating the ANSI/ANS-5.1 Decay Power Standard. 10

Two types of calculational analyses were made to compare these integral experiments with results using ENDF/B-IV, ENDF/B-V, JNDC, and UK fission-product data. In the first of these, essentially "direct" calculations of the experiments were made with the CINDER-10 $\operatorname{code}^{1}{ }^{1}$ using fission-product data from the four files as input. The procedure for the second type is as follows.

Step 1: For ENDF/B-IV, ENDF/B-V, JNDC, and UK fission product data files o Using the FPDCYS ${ }^{12}$ code for ENDF/B-IV and UK and the SPEC5 ${ }^{13}$ code for ENDF/B-V data, obtain spectra in fine-group energy bins (about 150 from 0 to $7.5 \mathrm{MeV}$ ) for all unstable fission products. This step is omitted for the JNDC file as spectra are not available; fine group spectra from ENDF/B$V$, normalized to the JNDC total beta and gamma energies, were used instead. 
- Use results from the CINDER-10 code for a thermal neutron pulse input $\left(10^{-4}\right.$ $s$ irradiation time) to obtain fission-product activities for a number of cooling times (at least four per decade in the range 0.1 to $10^{9} \mathrm{~s}$ plus the initial time zero).

o Obtain an aggregate fission-product decay-energy library (PEFPYD ${ }^{14}$ ) for each of the four files in a fine-group structure (approximately 150 groups from 0 to $7.5 \mathrm{MeV}$ ) by using the FPSPEC ${ }^{2}$ code to combine the fission-product activities from CINDER-10 and fission-product spectra from FPDCYS and SPEC5.

- Using the FITPULS ${ }^{15}$ code, rebin the PEFPYD data into the 18 groups (17 beta-ray groups) shown in Table III and fit the results for each group with a sum of exponentials.

The flow of data between codes used in Step 1 is diagrammed in Fig. 1 .

Step 2: For the rebinned experimental data, use an option in FITPULS to reduce data to a pulse and fit each group with a sum of exponentials.

Step 3: Compare the fits to the ENDF/B-IV, JNDC, and UK fission-product data with the fits to the ENDF/B-V data.

Step 4: Compare the fits for the four libraries with the experimental data reduced to a pulse.

We have described these procedures, associated equations, and the utility of the pulse functions in several previous reports ${ }^{14-17}$ and in a recent publication; ${ }^{18}$ these earlier reports used calculations based only on ENDF/B-IV data and an earlier UK data file.

\section{COMPARISONS OF DATA IN THE FISSION-PRODUCT LIBRARIES}

As seen in Table I, only 180 of the 711 unstable nuclides in ENDF/B-IV have spectral data, whereas 264 of the 750 unstable nuclides in ENDF/B-V have spectral data. For applications of the pulse functions to problems involving finite irradiation times, however, it is required that all unstable nuclides have spectra, and for the ENDF/B-IV data, all missing spectra were approximately constructed. This was done for a particular nuclide by assuming that the shape of the fine-group spectrum for the nuclide was approximated by the spectrum shape of the aggregate 180 nuclides with spectra from a pulse irradiation after a cooling time approximately equal to the half-life of the nuclide in question. This shape was normalized to the average gamma or beta decay-energy of the nuclide given in the file. Such constructed spectra, of course, were only used in the aggregate. Further details of this method are given in Refs. 16 and 17. 
TABLE III

GAMMA-RAY ENERGY GROUP STRUCTURE

\begin{tabular}{ccc} 
Group & E-Lo(MeV) & E-Hi(MeV) \\
\cline { 2 - 3 } 1 & 0.0 & 0.1 \\
2 & 0.1 & 0.2 \\
3 & 0.2 & 0.4 \\
4 & 0.4 & 0.6 \\
5 & 0.6 & 0.8 \\
6 & 0.8 & 1.0 \\
7 & 1.0 & 1.2 \\
8 & 1.2 & 1.4 \\
9 & 1.4 & 1.6 \\
10 & 1.6 & 1.8 \\
11 & 1.8 & 2.0 \\
12 & 2.0 & 2.2 \\
13 & 2.2 & 2.4 \\
14 & 2.4 & 2.6 \\
15 & 2.6 & 3.0 \\
16 & 3.0 & 4.0 \\
17 & 4.0 & 5.0 \\
18 & 5.0 & 6.0
\end{tabular}

Note: Because of lack of experimental data, groups 1 and 2 were combined for the $B^{-}$calculations.

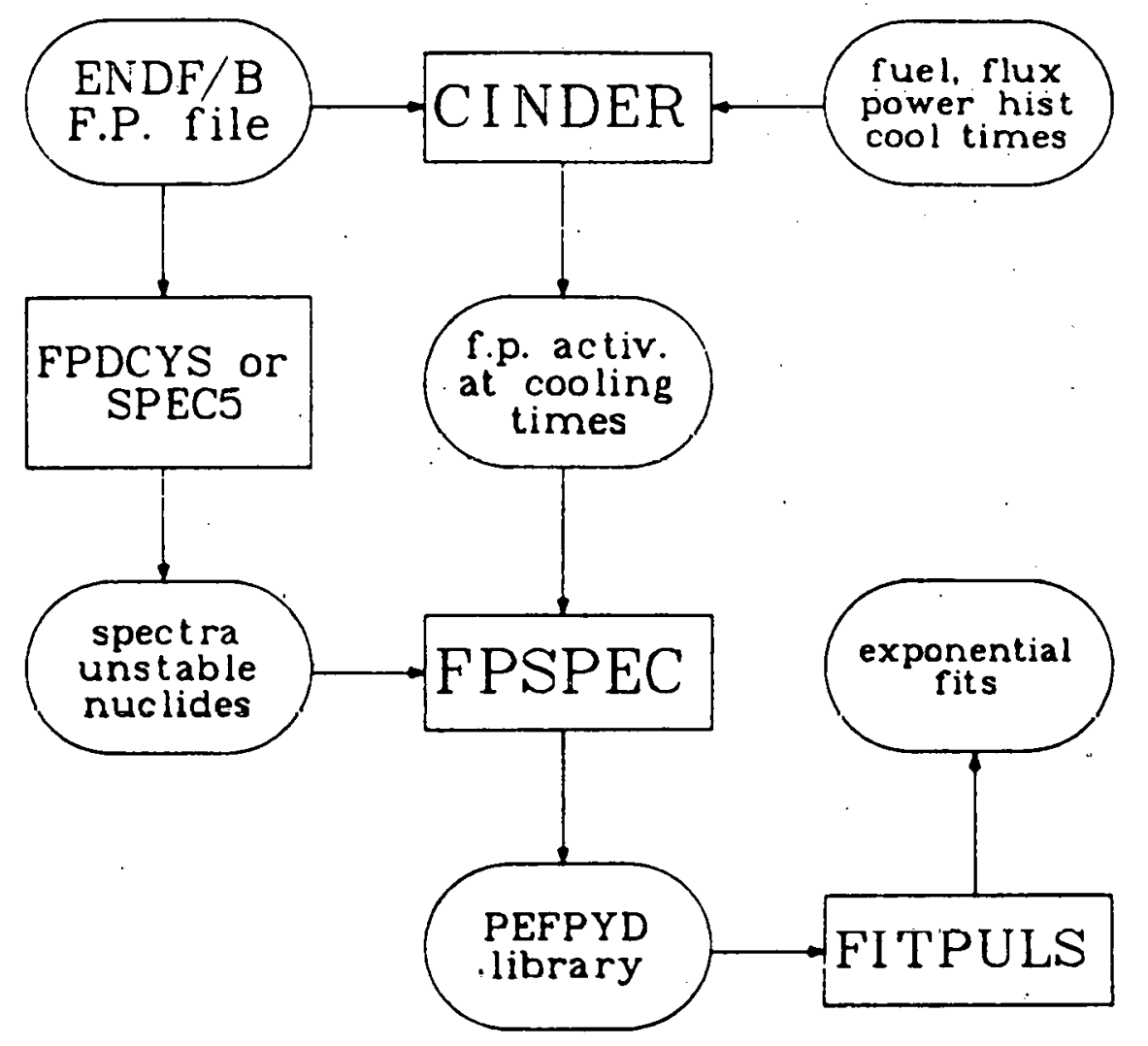

Fig. 1. Codes and data flow for spectral calculations. 
This method was used for the beta spectra in ENDF/B-V, but more care was exercised in providing missing gamma spectra. Gamma-ray line data were taken from other sources, where available, primarily from the GAMDAT-78 data file 19 and Table of Isotopes. ${ }^{20}$ Such data for a particular nuclide, however, were normalized to give the average gamma decay-energy for the nuclide appearing in the ENDF/B-V data file. This made it possible to obtain spectra for many nuclides for which the GAMDAT-78 file and Table of Isotopes give only relative intensities. With this augmentation, the 264 nuclides having gamma-ray spectra in $E N D F / B-V$ were increased to 410 . The spectra of the remaining ENDF/B-V nuclides were constructed as described above.

The JNDC/ENDF file was created by taking the average total gamma and beta energies for individual nuclides from the JNDC file and substituting them into the ENDF/B-V file. Of course, this could not be done completely, as some nuclides in the ENDF/B-V file are not in the JNDC file and vice versa. These differences are shown in Table IV. Also shown in the table are differences between ENDF/B-V and the UK file. The UK file has 371 nuclides with spectral data. Table $V$ shows some significant differences in the ENDF/B-V and JNDC/ENDF files as a function of cooling time.

Figure 2 shows the percentage of the aggregate gamma-ray energy included in the 180 nuclides having spectral data in ENDF/B-IV, the 410 nuclide augmentation of ENDF/B-V, and the 371 UK nuclides with spectra as functions of cooling times. These comparisons are for a pulse irradiation of ${ }^{235} \mathrm{U}$ fuel. Note that for longer cooling times the UK data drops slightly below $100 \%$. This is due to the fact that some nuclides in the ENDF/B-V chains in CINDER-10 are not in the UK file (see Table IV); hence, the energy contributed by these nuclides is missing in the aggregate. Figure 3 shows the aggregate experimental fraction vs time for a ${ }^{235} \mathrm{U}$ fission pulse calculated using original, unaugmented ENDF/B-V data. Values are four to five times larger than those of ENDF/B-IV at $0.1 \mathrm{~s}$ cooling. Figure 4 shows the same for ${ }^{239} \mathrm{Pu}$.

III. PREPARATION OF AGGREGATE MULTIGROUP LIBRARIES

Further processing of these data files was needed to form aggregate finegroup beta- and gamma-ray decay-energy (PEFPYD) libraries for subsequent use in spectral comparisons. Multigroup spectra were obtained for the individual nuclides with the FPDCYS code for the ENDF/B-IV and UK data and with the SPEC5 code for the ENDF/B-V data. The ENDF/B-V spectral data were also used in the 
TABLE IV

COMPARISON OF NUCLIDES IN UK AND JNDC FILES WITH ENDF/B-V

\begin{tabular}{|c|c|c|c|c|c|c|c|c|}
\hline $\begin{array}{l}\mathrm{N} \\
\underline{\mathrm{Z}} \\
\end{array}$ & $\begin{array}{l}\text { lide } \\
\text { Sym }\end{array}$ & A & $\begin{array}{c}\text { State } \\
(\text { see note*) }\end{array}$ & $\begin{array}{l}\text { Half-life } \\
\text { (seconds) }\end{array}$ & $\begin{array}{l}\text { Mean Gamma-Ray } \\
\text { Energy }(\mathrm{MeV})\end{array}$ & $\begin{array}{l}\text { Direct } \\
\text { Yield } \\
\end{array}$ & $\begin{array}{l}U-235 \\
(\%) \\
\end{array}$ & $\begin{array}{c}\text { File from } \\
\text { Which Nuclide } \\
\text { is Missing } \\
\end{array}$ \\
\hline 31 & GA & 72 & 1 & $3.7 \times 10^{-2}$ & $\dot{0} .12$ & $2.7 x$ & $10^{-5}$ & JNDC \& UK \\
\hline 32 & $\mathrm{GE}$ & 79 & 1 & $1.9 \times 10^{1}$ & 0.42 & $4.2 \times$ & $10^{-2}$ & JNDC \\
\hline 33 & AS & 84 & 1 & $6.0 \times 10^{-1}$ & 2.76 & $3.5 \times$ & $10^{-1}$ & JNDC \\
\hline 33 & AS & 90 & 0 & $9.1 \times 10^{2}$ & 5.10 & $4.0 \times$ & $10^{-3}$ & JNDC \\
\hline 34 & $\mathrm{SE}$ & 75 & 0 & $1.0 \times 10^{7}$ & 0.39 & $1.2 \times$ & $10^{-3}$ & UK \\
\hline 36 & $\mathrm{KR}$ & 79 & 0 & $1.3 \times 10^{5}$ & 0.07 & $4.4 \times$ & $10^{-2}$ & UK \\
\hline 36 & $\mathrm{KR}$ & 79 & 1 & $5.0 \times 10^{1}$ & 0.13 & $4.4 \mathrm{x}$ & $10^{-2}$ & UK \\
\hline 38 & SR & 85 & 0 & $5.6 \times 10^{5}$ & 0.05 & 1.3 & & UK \\
\hline 38 & SR & 85 & 1 & $4.1 \times 10^{3}$ & 0.23 & 1.3 & & UK \\
\hline 42 & MO & 93 & 0 & $9.4 \times 10^{10}$ & 0.03 & 6.4 & & UK \\
\hline 42 & MO & 93 & 1 & $2.5 \times 10^{4}$ & 2.42 & 6.4 & & UK \\
\hline 44 & RU & 97 & 0 & $2.5 \times 10^{5}$ & 0.23 & 6.0 & & UK \\
\hline 44 & $\mathrm{RU}$ & 109 & 1 & $1.3 \times 10^{1}$ & 0.82 & $2.8 x$ & $10^{-2}$ & JNDC \\
\hline 45 & $\mathrm{RH}$ & 109 & 1 & $5.0 \times 10^{1}$ & 0.05 & $2.8 x$ & $10^{-2}$ & JNDC \\
\hline 47 & $\mathrm{AG}$ & 107 & 1 & $4.4 \times 10^{1}$ & 0.09 & $1.8 \mathrm{x}$ & $10^{-1}$ & UK \\
\hline 48 & $\mathrm{CD}$ & 107 & 0 & $2: 3 \times 10^{4}$ & 0.00 & $1.8 \mathrm{x}$ & $10^{-1}$ & UK \\
\hline 49 & IN & 133 & 0 & $1.1 \times 10^{1}$ & 3.89 & $4.4 \mathrm{x}$ & $10^{-4}$ & JNDC \\
\hline 50 & SN & 113 & 0 & $9.9 \times 10^{6}$ & 0.00 & $1.2 \mathrm{x}$ & $10^{-2}$ & UK \\
\hline 50 & SN & 113 & 1 & $1.3 \times 10^{3}$ & 0.07 & $1.2 x$ & $10^{-2}$ & UK \\
\hline 51 & SB & 126 & 2 & $1.1 \times 10^{1}$ & 0.00 & $6.2 \times$ & $10^{-2}$ & JNDC \\
\hline 52 & $\mathrm{TE}$ & 121 & 0 & $1.5 \times 10^{6}$ & 0.56 & $1.4 \mathrm{x}$ & $10^{-2}$ & UK \\
\hline 52 & $\mathrm{TE}$ & 121 & 1 & $1.3 \times 10^{7}$ & 0.26 & $1.4 \mathrm{x}$ & $10^{-2}$ & UK \\
\hline 53 & I & 132 & 1 & $5.0 \times 10^{3}$ & 0.04 & 4.3 & & UK \\
\hline 53 & $\bar{I}$ & 143 & 0 & $4.0 \times 10^{-1}$ & 2.06 & $7.8 x$ & $10^{-5}$ & JNDC \\
\hline 53 & I & 144 & 0 & $1.5 \times 10^{-1}$ & 3.48 & $2.7 \times$ & $10^{-6}$ & JNDC \\
\hline 53 & I & 145 & 0 & $1.9 \times 10^{-3}$ & 2.63 & 0.0 & & JNDC \\
\hline 54 & $\mathrm{XE}$ & 125 & 0 & $6.1 \times 10^{4}$ & 0.24 & $3.0 \times$ & $10^{-2}$ & $\mathrm{UK}$ \\
\hline 54 & $\mathrm{XE}$ & 125 & 1 & $5.7 \times 10^{1}$ & 0.25 & $3.0 \mathrm{x}$ & $10^{-2}$ & UK \\
\hline 54 & $X E$ & 127 & 0 & $3.1 \times 10^{6}$ & 0.28 & $1.3 x$ & $10^{-1}$ & $\mathrm{UK}$ \\
\hline 54 & $\mathrm{XE}$ & 127 & 1 & $6.9 \times 10^{1}$ & 0.30 & $1.3 \mathrm{x}$ & $10^{-1}$ & UK \\
\hline 54 & $\mathrm{XE}$ & 143 & 1 & $3.0 \times 10^{-1}$ & 1.99 & $5.4 \mathrm{x}$ & $10^{-2}$ & JNDC \& UK \\
\hline 54 & $\mathrm{XE}$ & 147 & 0 & $2.0 \times 10^{-1}$ & 2.70 & $2.4 \mathrm{x}$ & $10^{-7}$ & JNDC \\
\hline 55 & $\overline{C S}$ & 136 & 1 & $1.9 \times 10^{1}$ & 0.05 & 6.3 & & $\mathrm{JNDC} \& \mathrm{UK}$ \\
\hline 55 & CS & 149 & 0 & $2.4 \times 10^{-1}$ & 2.55 & 0.0 & & JNDC \\
\hline 56 & $\mathrm{BA}$ & 151 & 0 & $3.3 \times 10^{-1}$ & 2.29 & 0.0 & & JNDC \\
\hline 57 & LA & 155 & 0 & $1.5 \times 10^{-1}$ & 3.20 & 0.0 & & JNDC \\
\hline 58 & $\mathrm{CE}$ & 155 & 0 & $5.3 \times 10^{-1}$ & 2.04 & $4.3 \times$ & $10^{-6}$ & JNDC \\
\hline 59 & PR & 142 & 1 & $8.8 \times 10^{2}$ & 0.00 & 5.9 & & JNDC \\
\hline
\end{tabular}

* 0 denotes ground, 1 denotes $1^{\text {st }}$ isomeric, 2 denotes $2^{\text {nd }}$ isomeric states 
ENDF/B-V vS ENDF/B-V + JNDC SHOWING SIGNIFICANT BETA

OR GAMMA ENERGY RATES IN SUMMATION CALCULATIONS

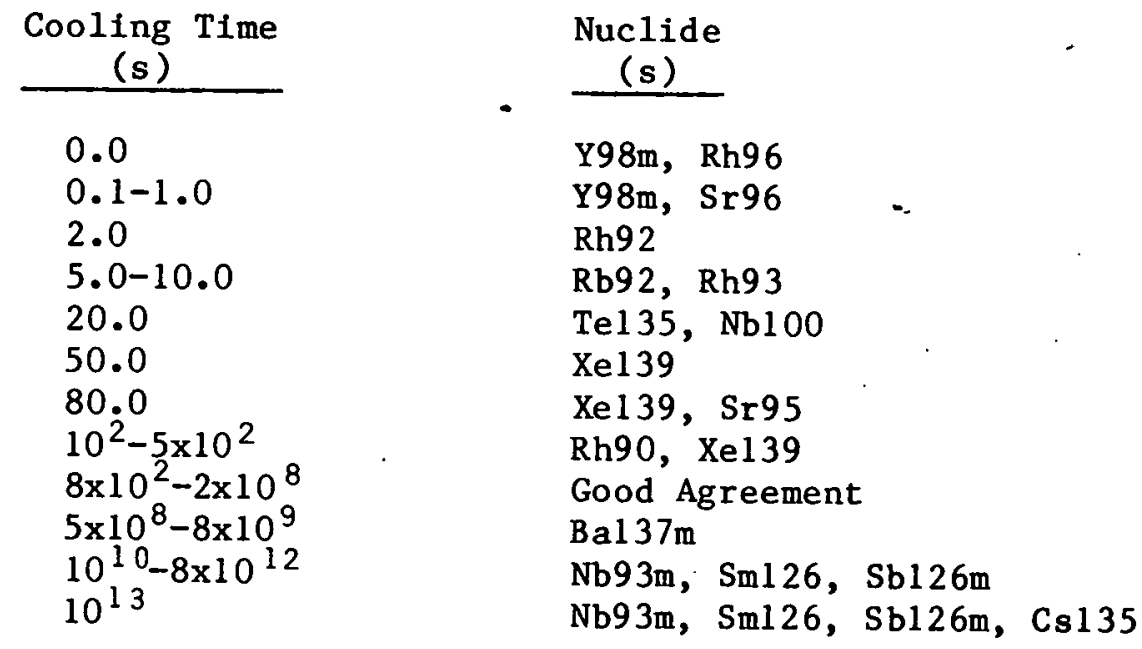

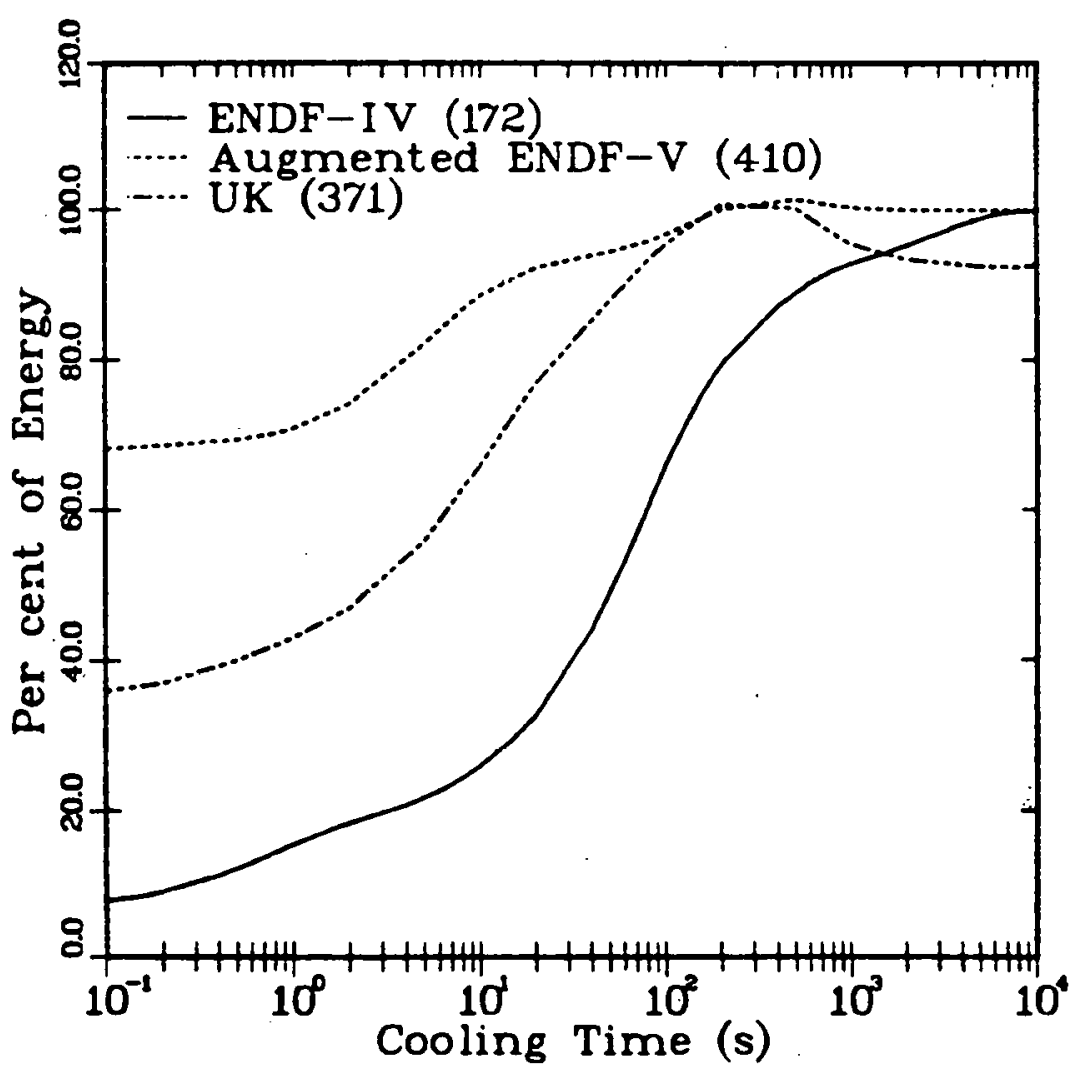

Fig. 2. Percentage aggregate gamma-ray energy from nuclides with spectra after thermal pulse irradiation of $235 \mathrm{U}$. 

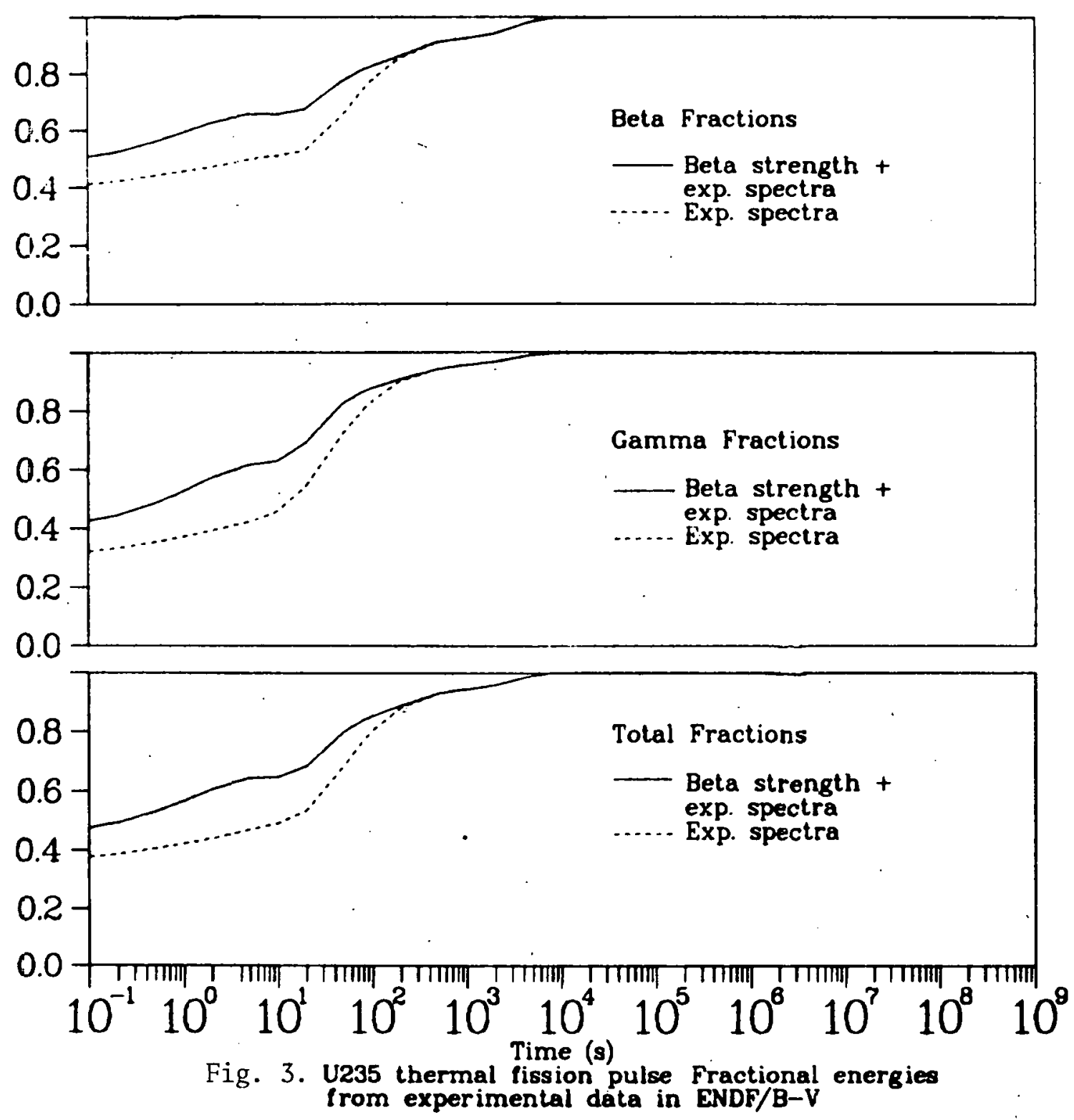


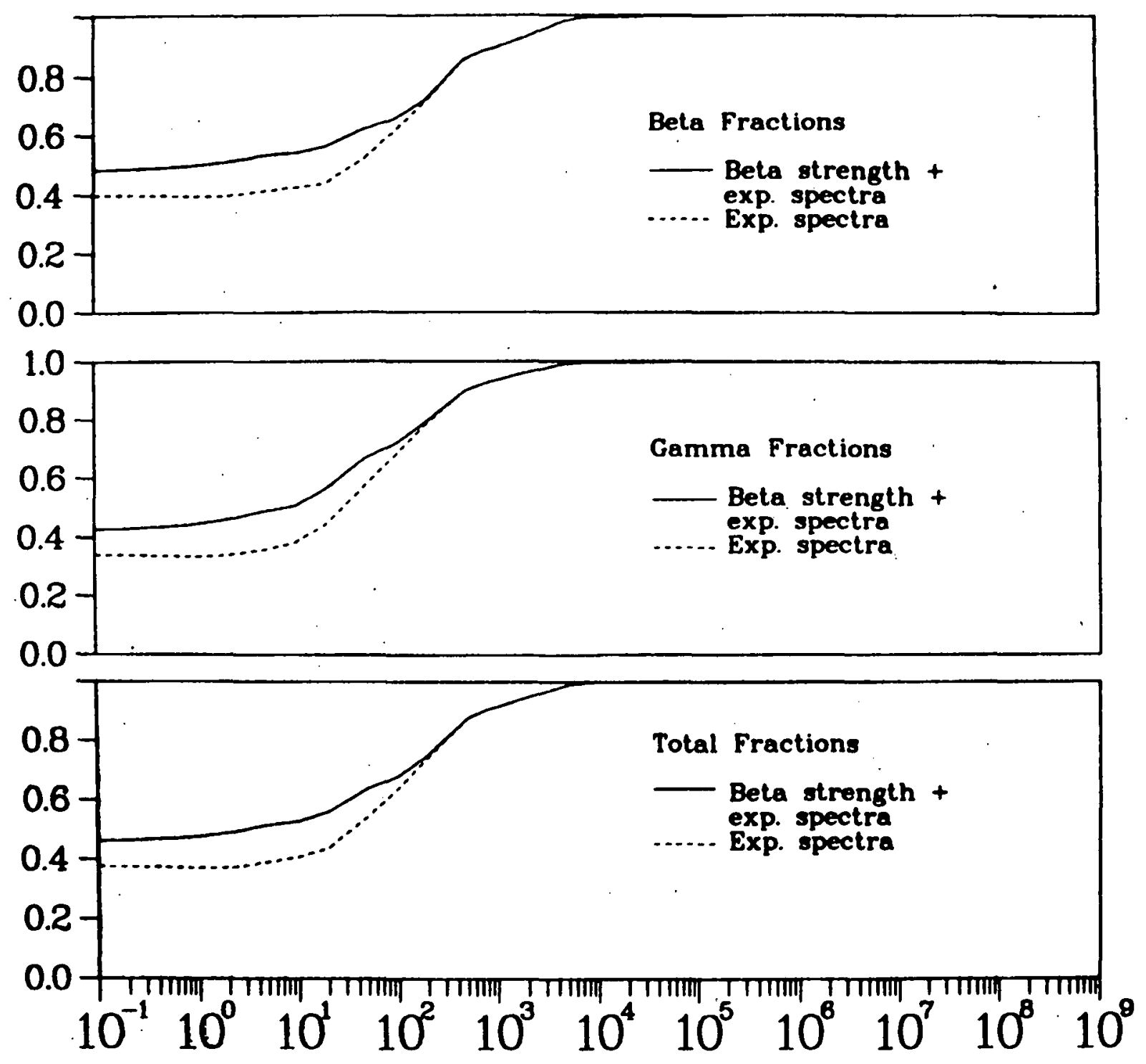

Fig. 4 PUz39 thermal fission pulse. Fractional energies from exper imental data in ENDF/B-V 
JNDC/ENDF calculations. The multigroup spectra were generated in 150 fine groups from 0 to $7.5 \mathrm{MeV}$ for ENDF/B-IV, each group having a bin width of 0.05 $\mathrm{MeV}$. The bin widths used for the ENDF/B-V and UK data were also constant $(0.05$ $\mathrm{MeV}$ ) from 0.1 to $7.5 \mathrm{MeV}$, but a finer width $(0.01 \mathrm{MeV})$ was used below $0.1 \mathrm{MeV}$, which resulted in 158 rather than 150. groups. This was done to better describe the low-energy data ( $\mathrm{x}$ ray) available in ENDF/B-V but not in ENDF/B-IV.

Nuclide activities needed in preparing the aggregate fine-group decayenergy (PEFPYD) libraries were obtained from CINDER-10 problems in which thermal pulse irradiations of ${ }^{235} \mathrm{U}$ and ${ }^{239} \mathrm{Pu}$ fuels were specified. These.problems were run using ENDF/B-IV, ENDF/B-V, and JNDC/ENDF fission-product data. The problem using ENDF/B-IV data for the thermal pulse irradiation of $235_{\mathrm{U}}$ was run at sixpoints-per-decade over a cooling time interval from shutdown to $10^{13} \mathrm{~s}$. All other problems were run for the same cooling time interval, but at four-pointsper-decade. Note that no separate CINDER-10 problem was run using the UK data.

Aggregate fine-group fission-product decay libraries (PEFPYD) were then obtained by multiplying the activity and the beta-ray (gamma-ray) energy for each nuclide at each energy group and then summing these products over the nuclides. This was done with the FPSPEC code, resulting in four PEFPYD libraries, one each for the ENDF/B-IV, ENDF/B-V, JNDC/ENDF, and UK data. In constructing the PEFPYD library for the UK data, activities from the CINDER-10 runs with the ENDF/B-V data were used.

The ENDF/B-IV, ENDF/B-V, and JNDC/ENDF PEFPYD 1ibraries that were assembled contain beta- and gamma-ray data for both ${ }^{235} \mathrm{U}$ and ${ }^{239} \mathrm{Pu}$. The UK PEFPYD library contains beta- and gamma-ray data for only $235_{\mathrm{U}}$ to date. These libraries were subsequently processed with the FITPULS code as described in Sec. V.

\section{RESULTS OF DIRECT CINDER-10 CALCULATIONS}

To date, direct CINDER-10 calculations that have used fission-product data from both ENDF/B-IV and ENDF/B-V have Included (a) thermal pulse $\left(10^{-4} \mathrm{~s}\right)$ irradiation of ${ }^{235} \mathrm{U}$ and ${ }^{239} \mathrm{Pu}$; (b) "infinite" thermal irradiation time (10 $\left.13 . \mathrm{s}\right)$ of $235_{\mathrm{U}}$ and ${ }^{239} \mathrm{Pu}$; (c) $20000 \mathrm{~s}$ irradiation times for ${ }^{233} \mathrm{U}, .{ }^{239} \mathrm{Pu}$, and $235_{\mathrm{U}}$ to simulate the Los Alamos calorimetric experiment; (d) 1, 5, 10, and $100 \mathrm{~s}$ irradiation times to simulate the ORNL ${ }^{235} \mathrm{U}$ and ${ }^{239} \mathrm{Pu}$ experiments. Also, calculations to simulate all experiments reduced to an equivalent pulse were made using the JNDC/ENDF data file. 
Results of this first type of "direct" calculations can be displayed in a number of ways as shown in Figs. $5-21$. Figures 5 through 8 give comparisons for pulse and infinite irradiations as ratios to calculations using ENDF/B-IV data. These are given for both ${ }^{235} \mathrm{U}$ and ${ }^{239} \mathrm{Pu}$ thermal fission, and several ratios are compared to ENDF/B-IV, namely the ANS 5.1 Decay Heat Standard, ENDF/$B-V$ beta, ENDF/B-V gamma, and ENDF/B-V total $\left(B^{-}+\gamma\right)$.

In Figures 9 through 15 results are displayed for the calculations for the Los Alamos calorimetric experiments. Figures 9, 10, and 11 show the ratios of experiment to ENDF/B-V and ENDF/B-IV calculations for ${ }^{235} \mathrm{U},{ }^{239} \mathrm{Pu}$, and ${ }^{233} \mathrm{U}$, respectively. These same ratios are given for all three nuclides but for each data base in Figs. 12 and 13. Figures 14 and 15 give ratios of the values for $23{ }^{9} \mathrm{Pu}$ and $233_{\mathrm{U}}$ to those for $235_{\mathrm{U}}$ for ENDF/B-V and ENDF/B-IV.

Results for the "direct" calculations of the Oak Ridge ${ }^{235} \mathrm{U}$ experiments are displayed in Figs. 16, 17, and 18. In these figures, both the gamma- and beta-ray comparisons are shown. The same comparisons for $239 \mathrm{Pu}$ are shown in Figs. 19, 20, and 21 .

Direct comparisons of the JNDC/ENDF data and the ENDF/B data are shown in Figs. 22 - 27. In Fig. 22 the ratio of a calculation of the $235 \mathrm{U}$ thermal fission pulse using the JNDC/ENDF data to the same calculation using ENDF/B-V data is shown for both beta- and gamma-ray energies. This same comparison for $2{ }^{39} \mathrm{Pu}$ is shown in Fig. 25.

In Figs. 23 and 24 for ${ }^{235} \mathrm{U}$ and Figs. 26 and 27 for ${ }^{239} \mathrm{Pu}$ beta- and gammaray energies, direct calculations for a thermal-fission pulse using the different libraries are compared. Also displayed in these figures are the three ORNL experiments reduced to a pulse, using the method described in Refs. 5 and/or 6; as noted in Ref. 5, the method is more accurate for times longer than the shorter irradiation periods used in the ORNL experiments.

No direct calculations to date have been made using the UK data file. The following are evident from Figs. 5 through 27:

- ENDF/B-V does not seem to be an improvement over ENDF/B-IV and, in fact, ENDF/B-V seems worse at early cooling times.

- Remarkable agreement with the experiment is achieved using the JNDC/ENDF combined file. 


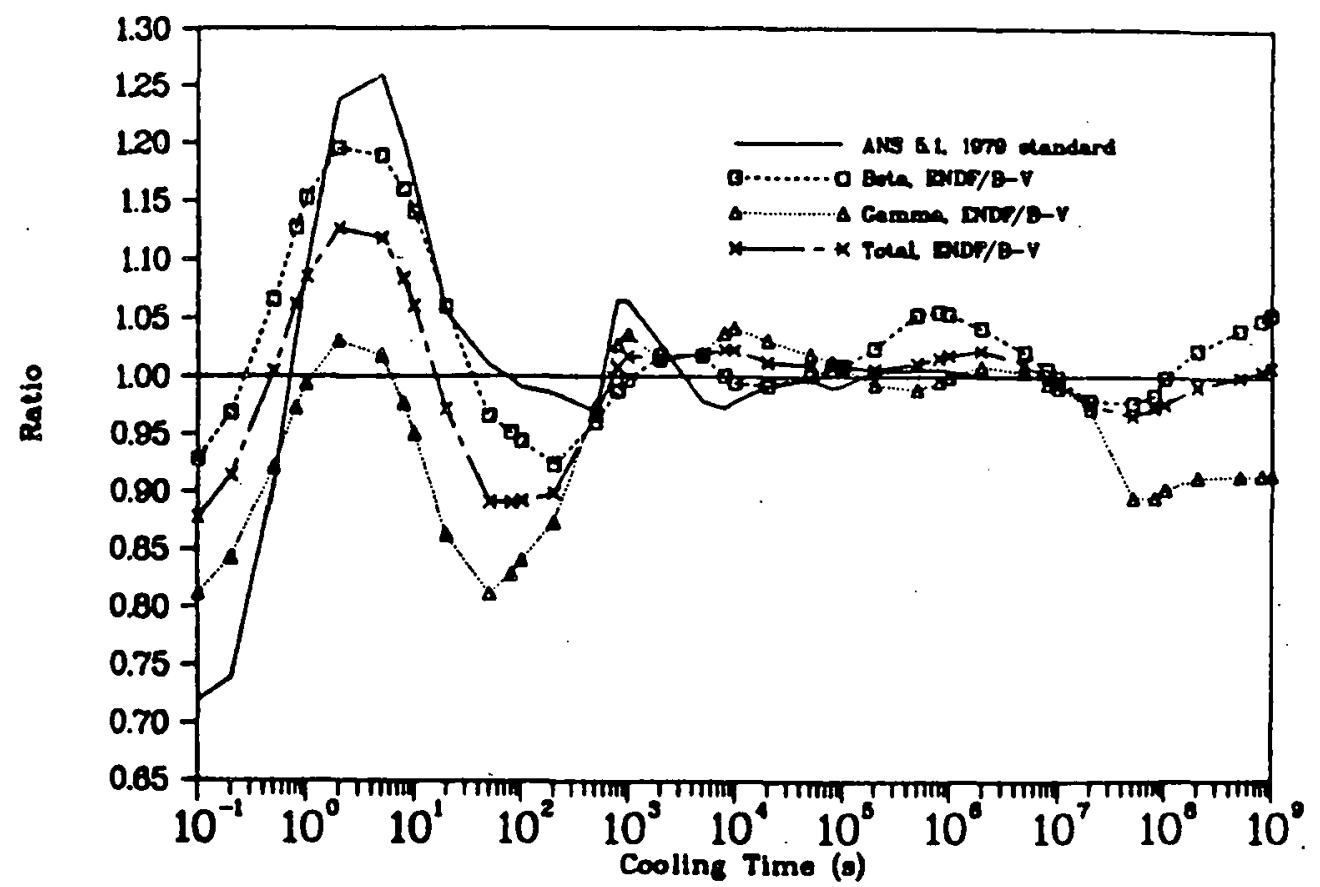

Fig. 5. UZ35 thermal fisolon pulse comparison of ANS 5.1 and calculated ENDF/B-Y fission-product decay powera as a ratio to ENDS/B-IV.

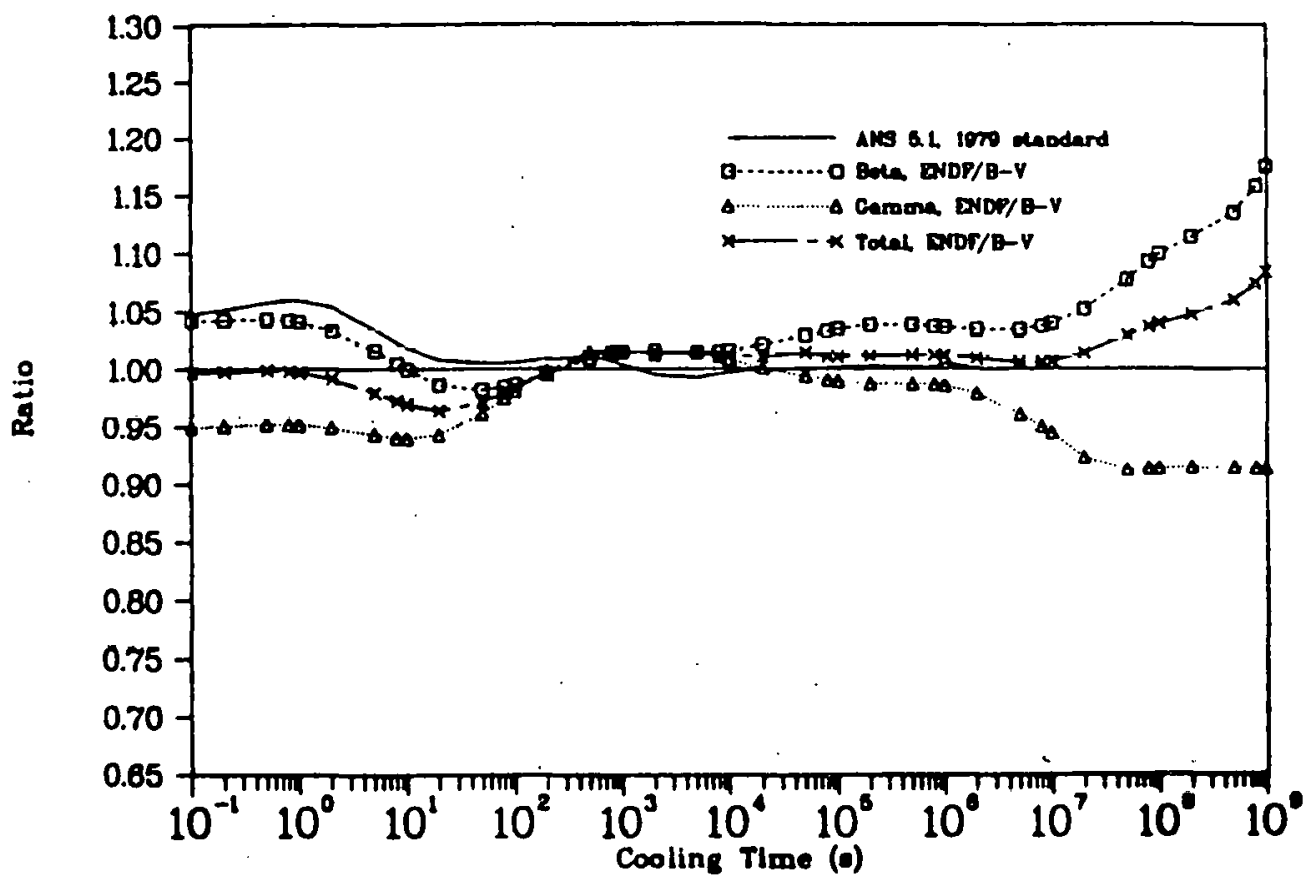

Fig. 6. Uzss thermal floton Infinite comparteon of ANS 51 and calculated ENDF/B-V fionion-product decay powarn as a

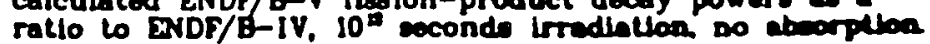




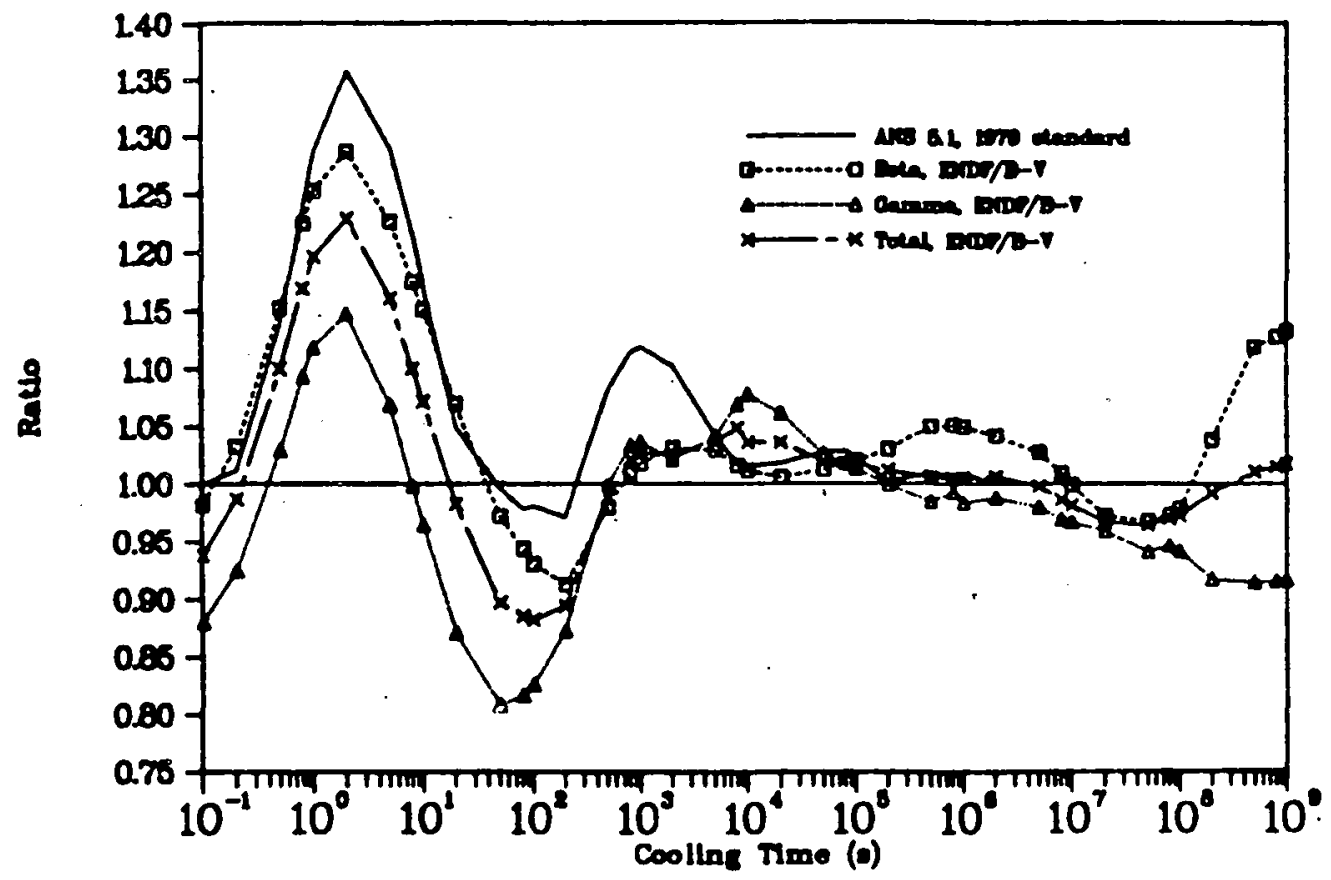

Fig. 7. PUzso thormal finlon putso compartoon of ANS 6.1 and calculated BNDF/B-Y fieton-product decay powers as - rello lo DNDH/B-IV.

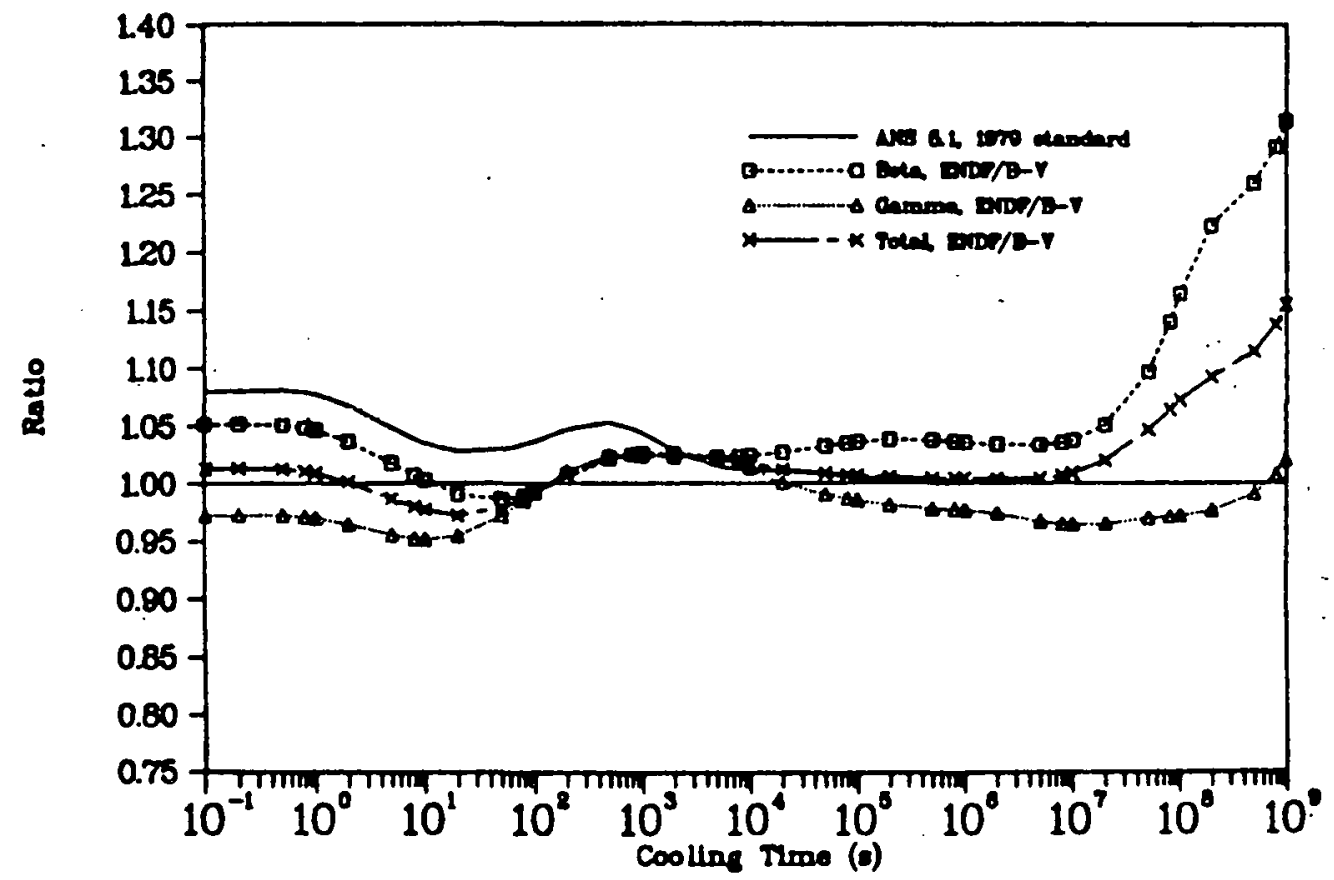

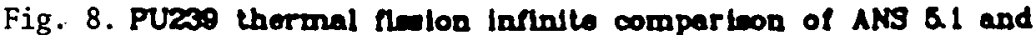
caloulated BNDF/B-Y ficion-product decay powors as a ratio to ENDP/E-IV. $10^{\prime}$ sconds irradintion, no absorption. 


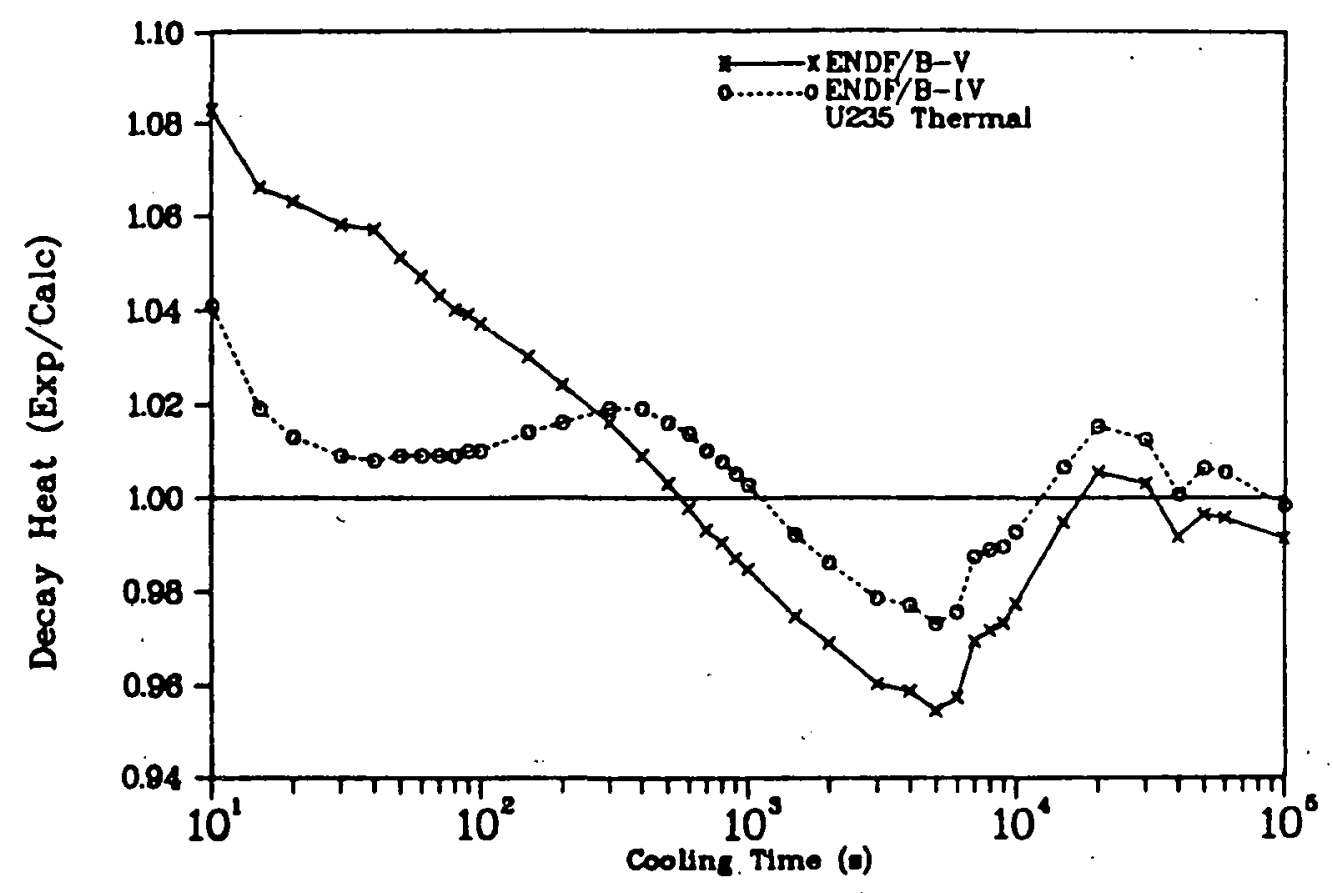

Fig. 9. Ratlo of experimegtal to calculated decay

heat for a $2 \times 10^{4}$ irradiation at contant nur

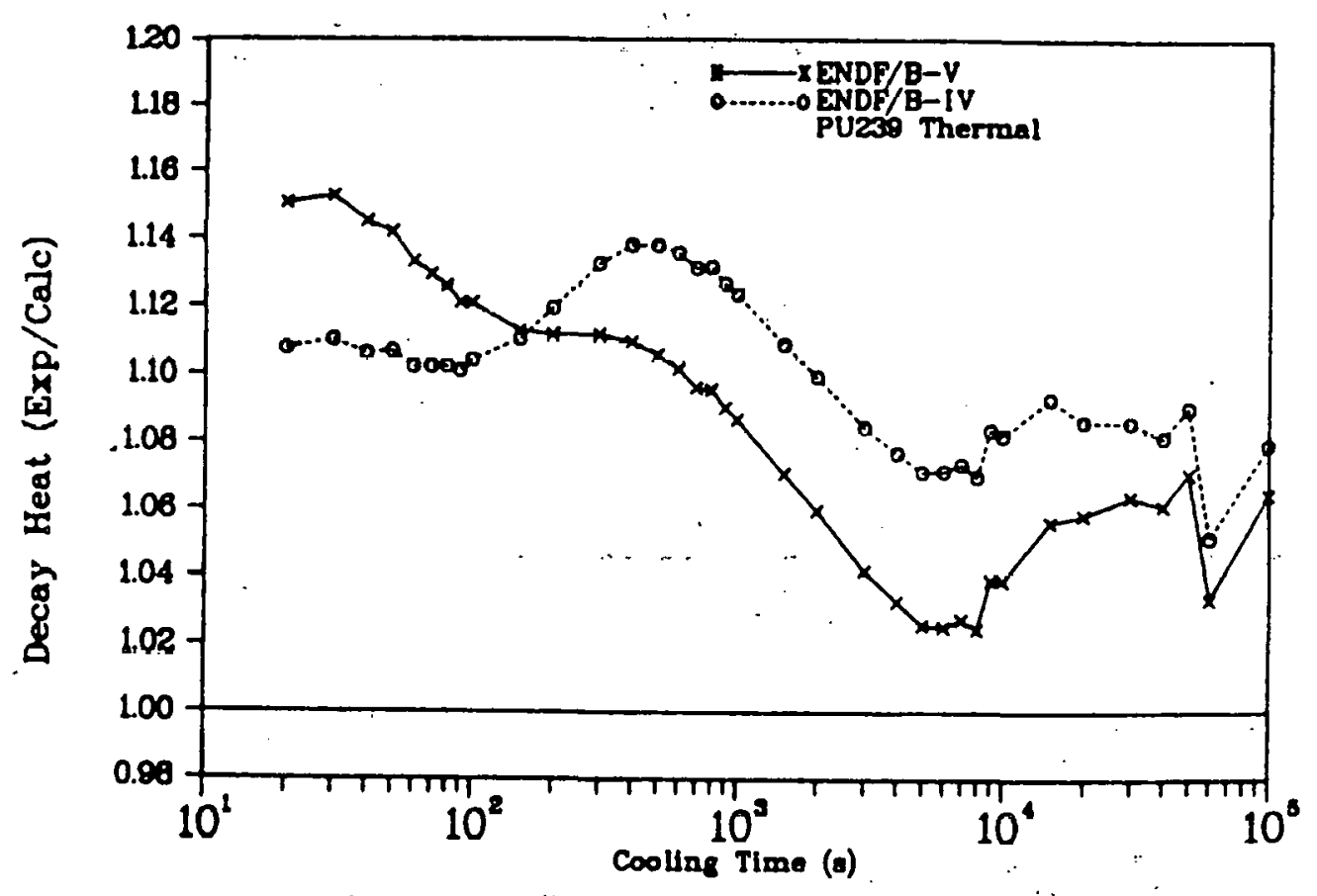

Fig. 10. Ratio" of experimental to calculated decay heat for a $2 \times 10^{\circ}$ a Irrediation at constant nux. 


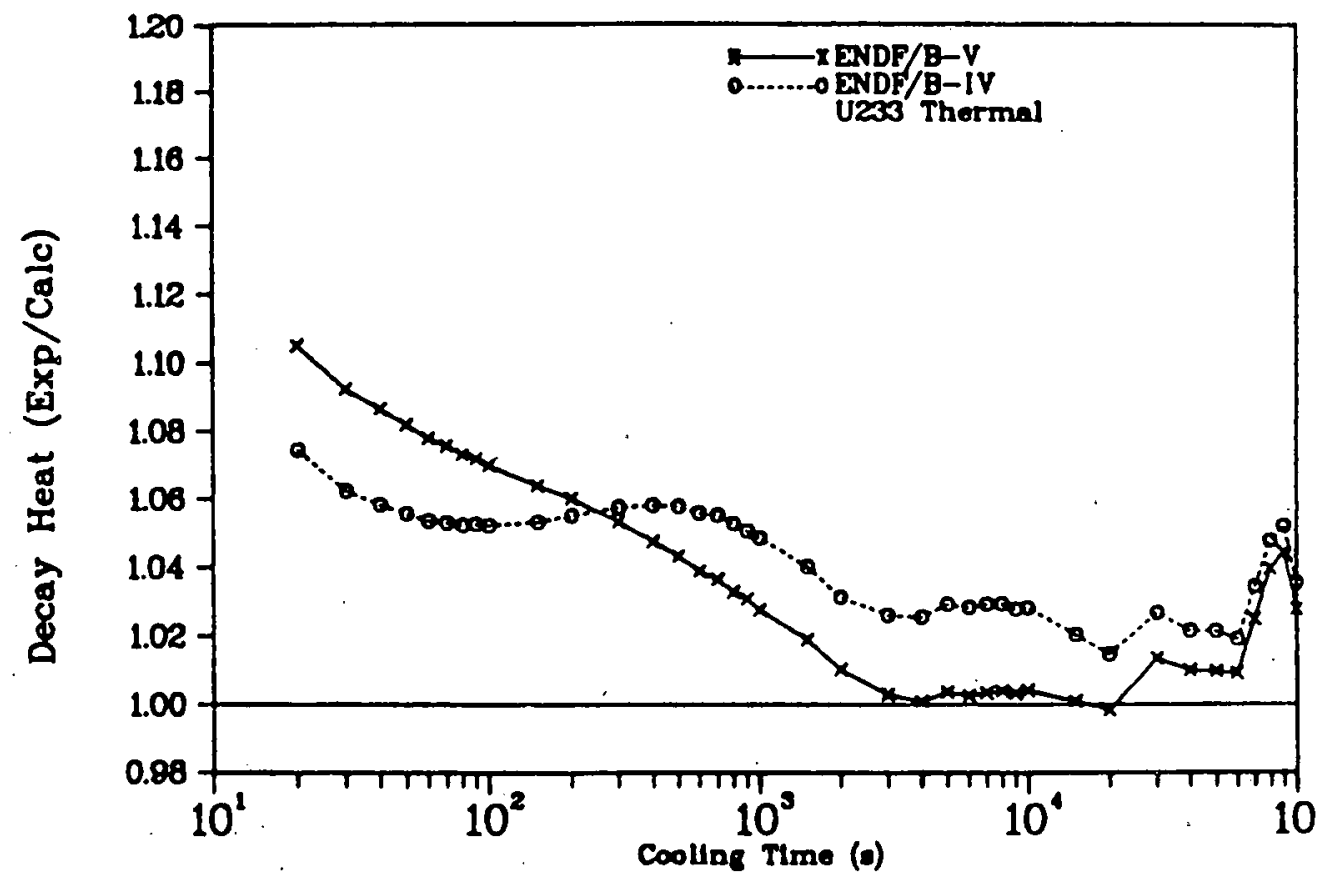

Fig. 11. Ratlo of experimental to calculated decay héat for a $2 \times 10^{4}$ irradiation at constant flux

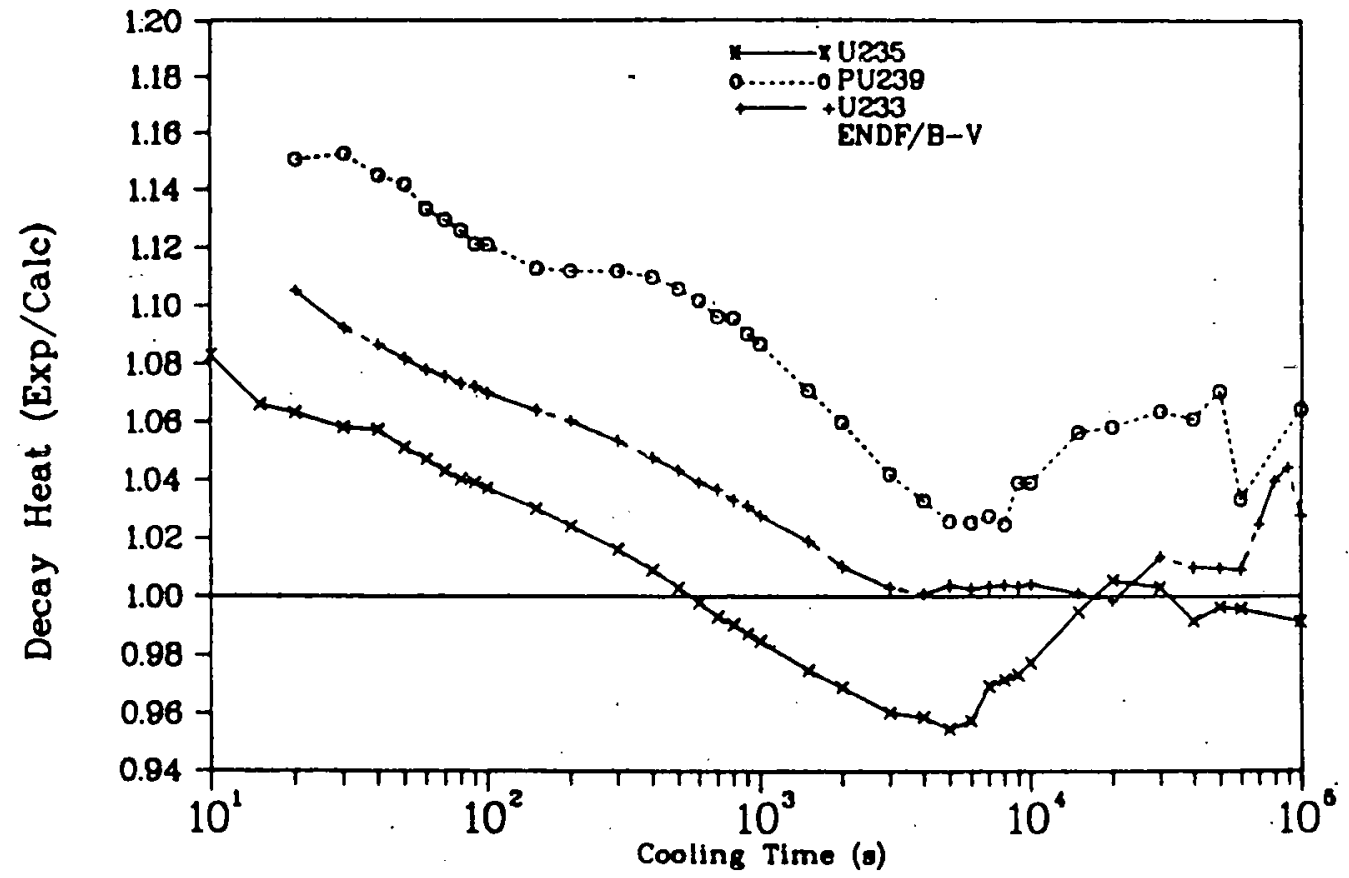

Fig. 12. Ratlo of experimental to calculated decoy heat for a $2 \times 10^{4} \mathrm{~s}$ irradiation at constant flux. 


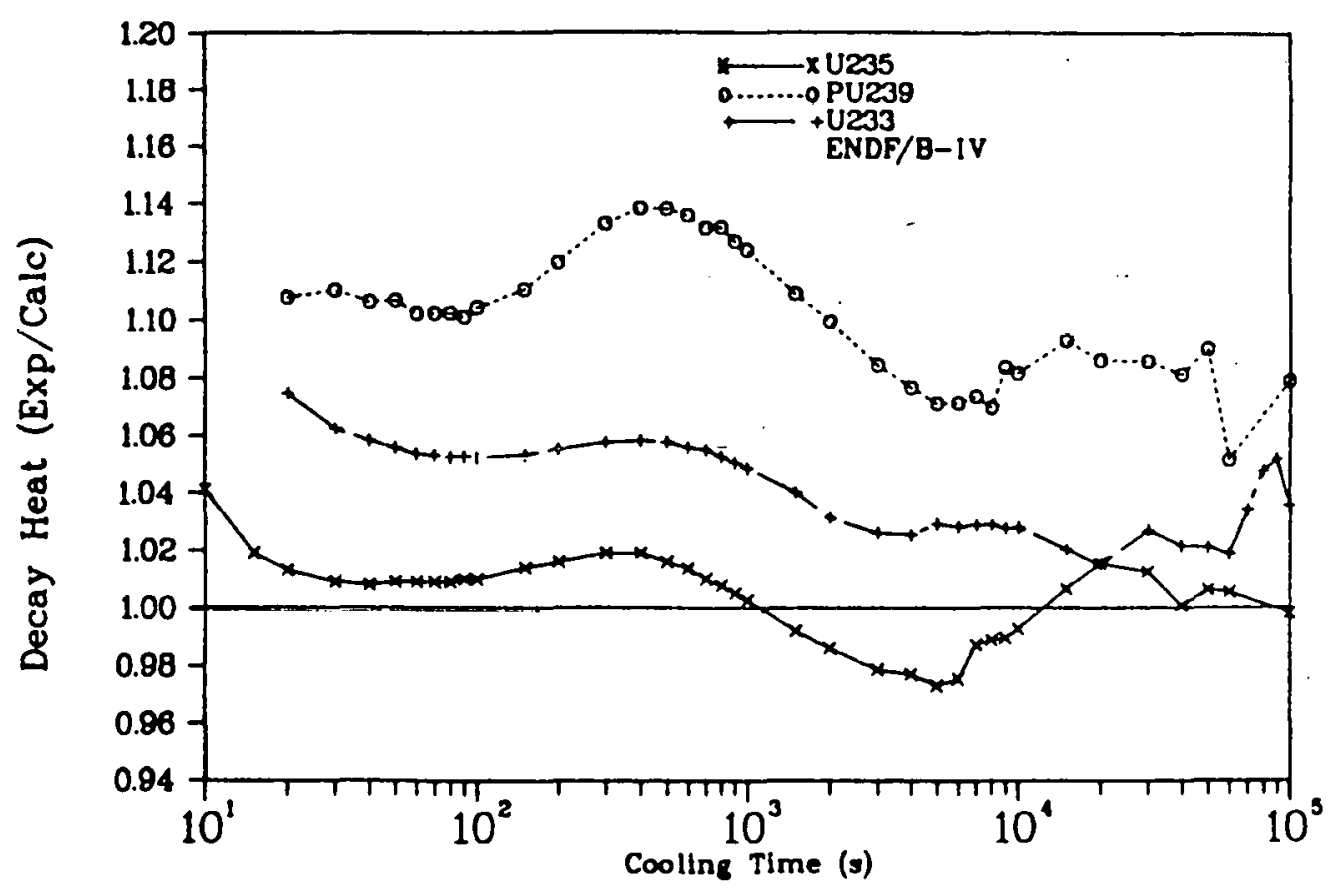

Fig. 13. Ratlo of experimental to calculated decay hoot for a $2 \times 10^{4}$ irradiation at constant flux.

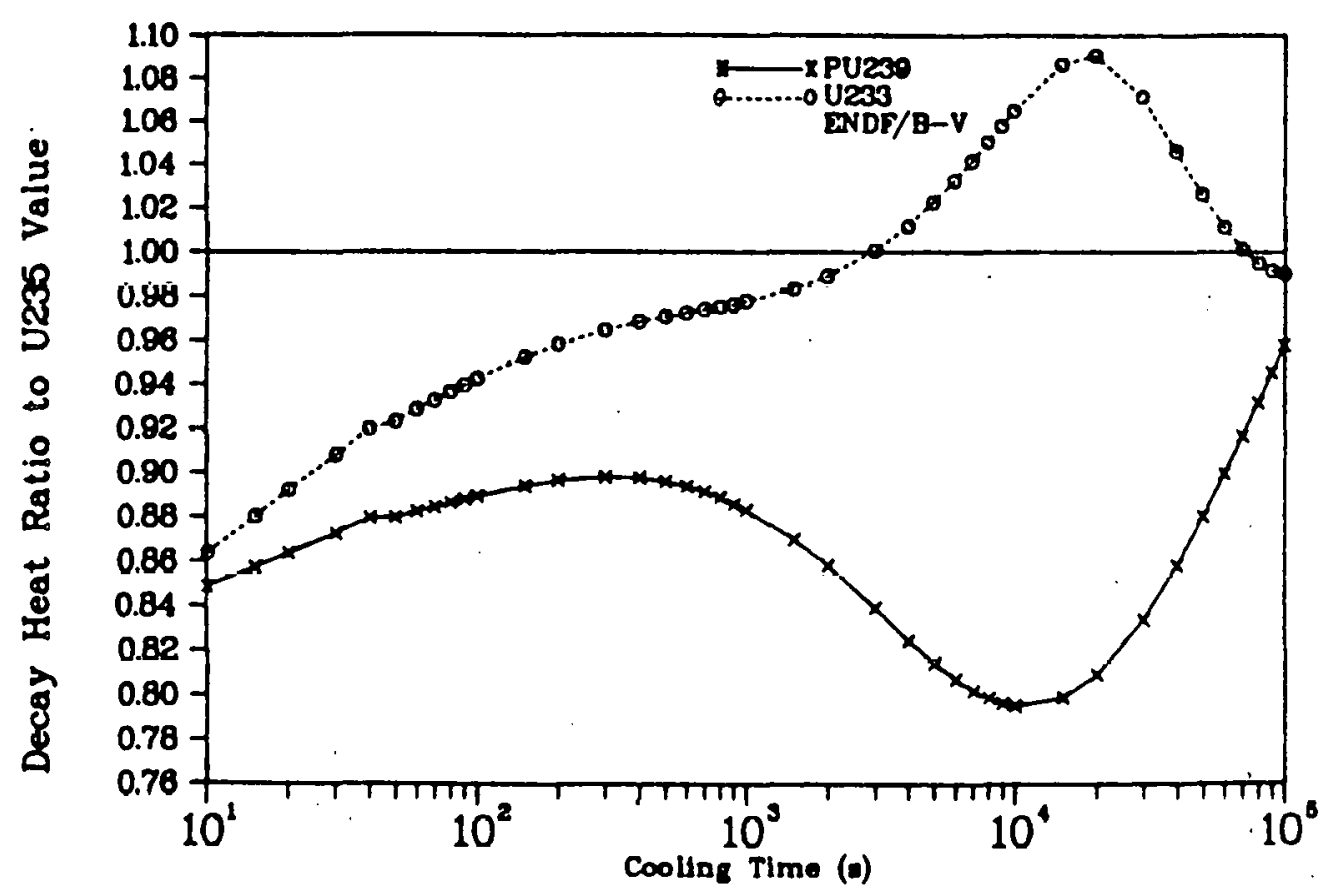

Fig. 14. Rat1o of calculated PU239 and U233 to U235 decay heat for $2 \times 10^{4}$ irratiation at constant flux. 


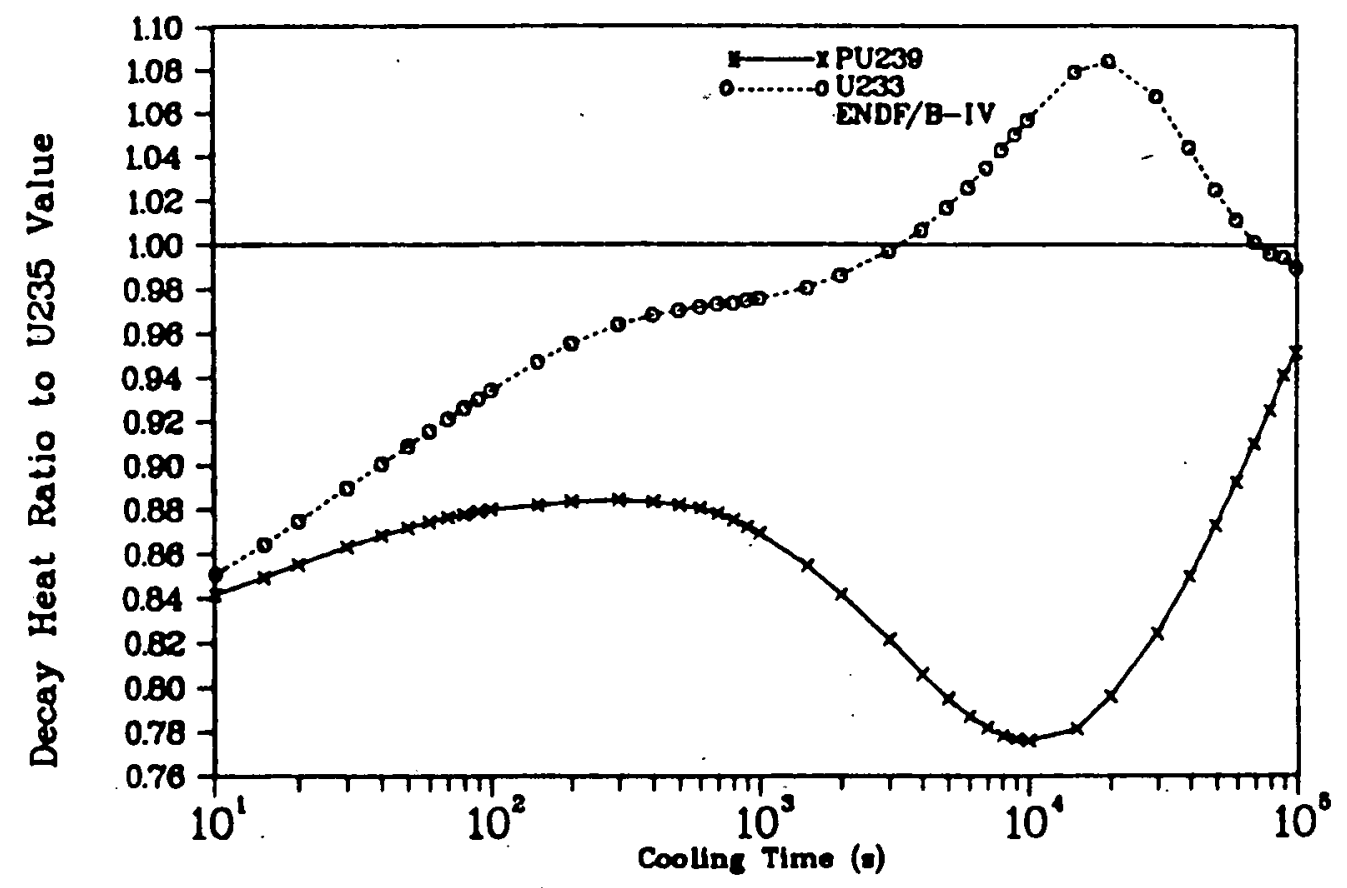

Fig. 15. Ratio of calculated PU239 and U233 to U235

decay heat for $2 \times 10^{4}$ s irradiation at constant flux,

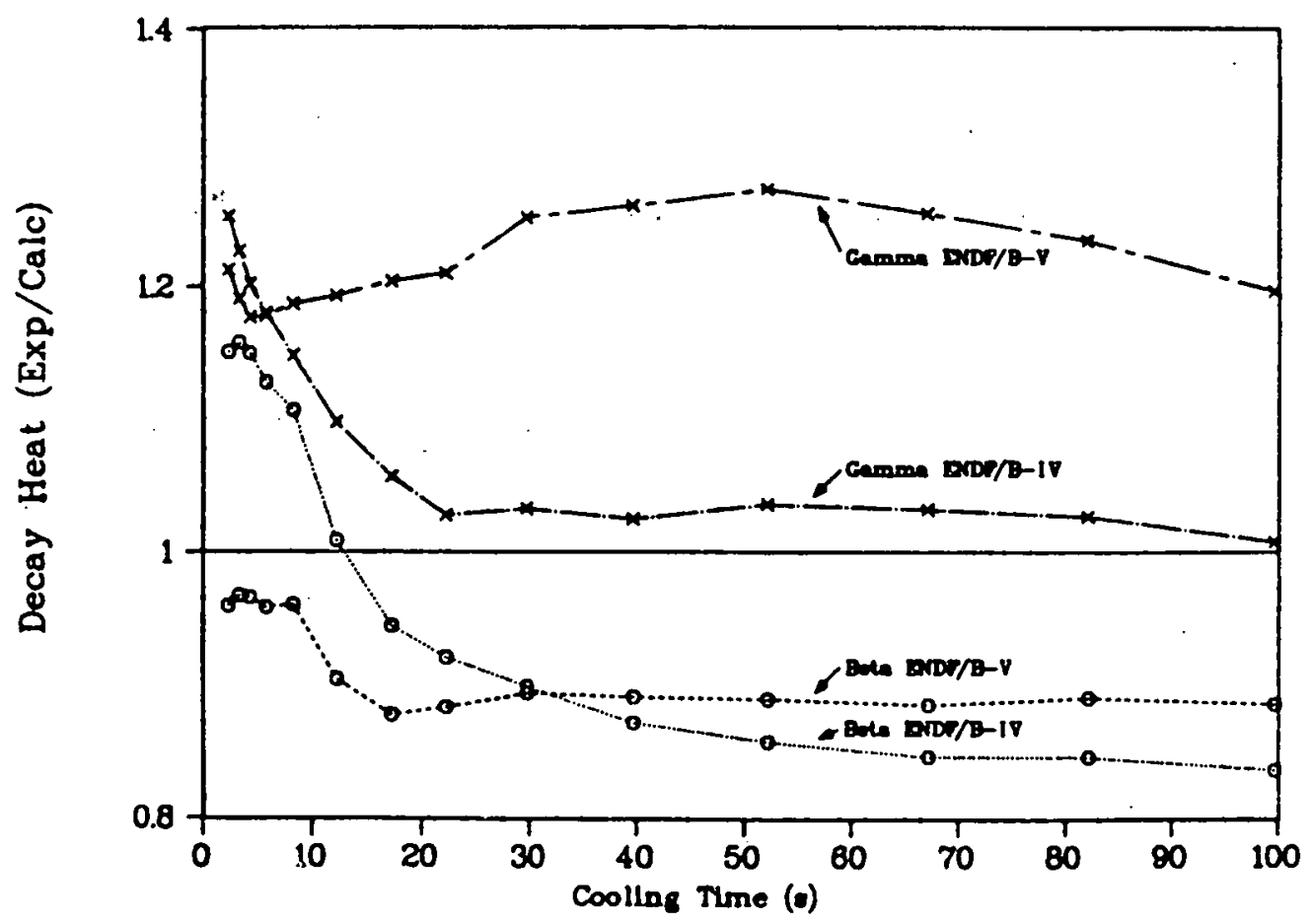

Fig. 16. Ratio of experiment to calculated decay heat for a $1 \mathrm{~s}$ irradiation of U235 at constant flux. 


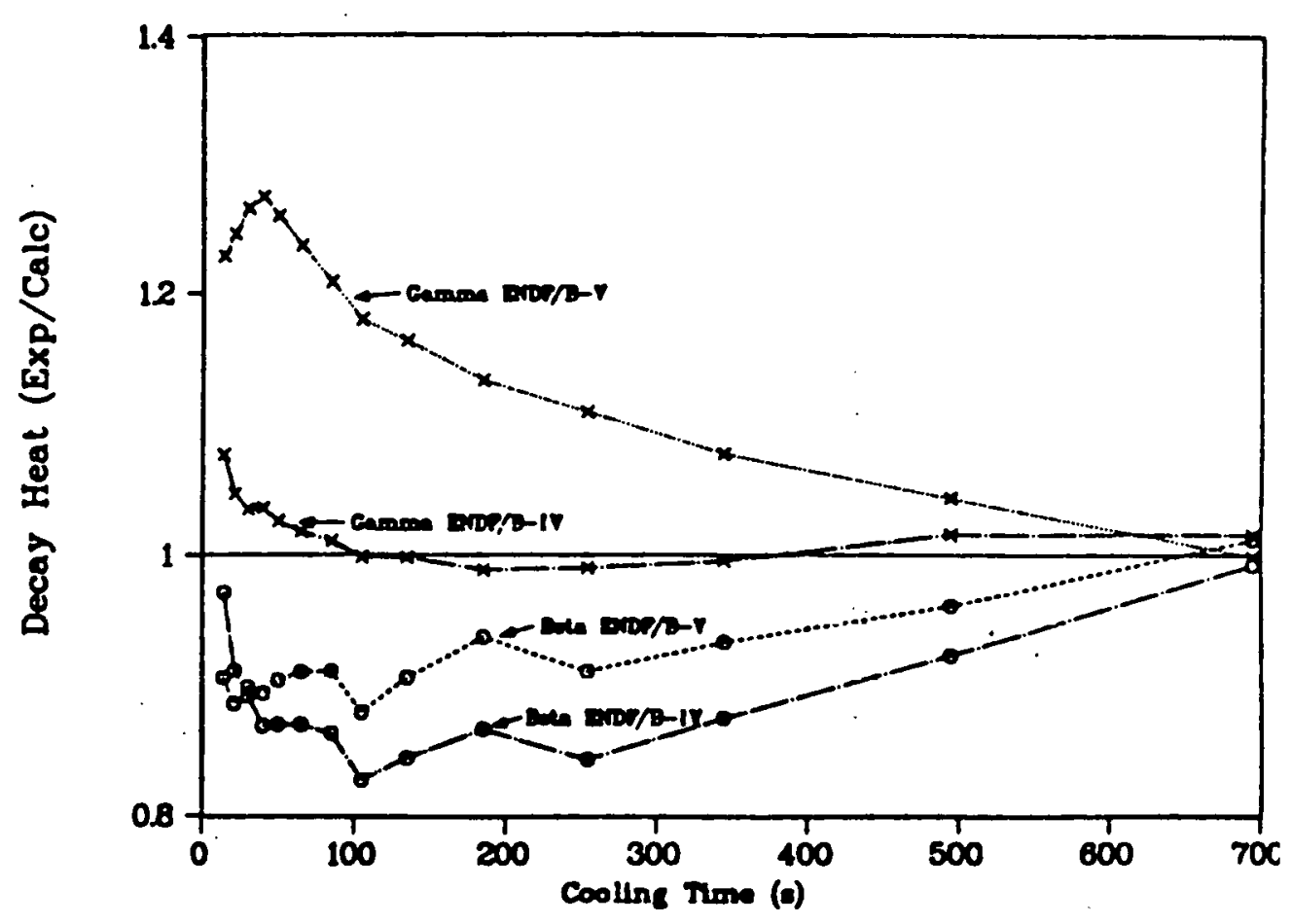

Fig. 17. Ratio of experiment to calculated decay heat for a 10-s irradiation of U235 at constant flux.

(Experimental data from ORNL/NUREG-14)

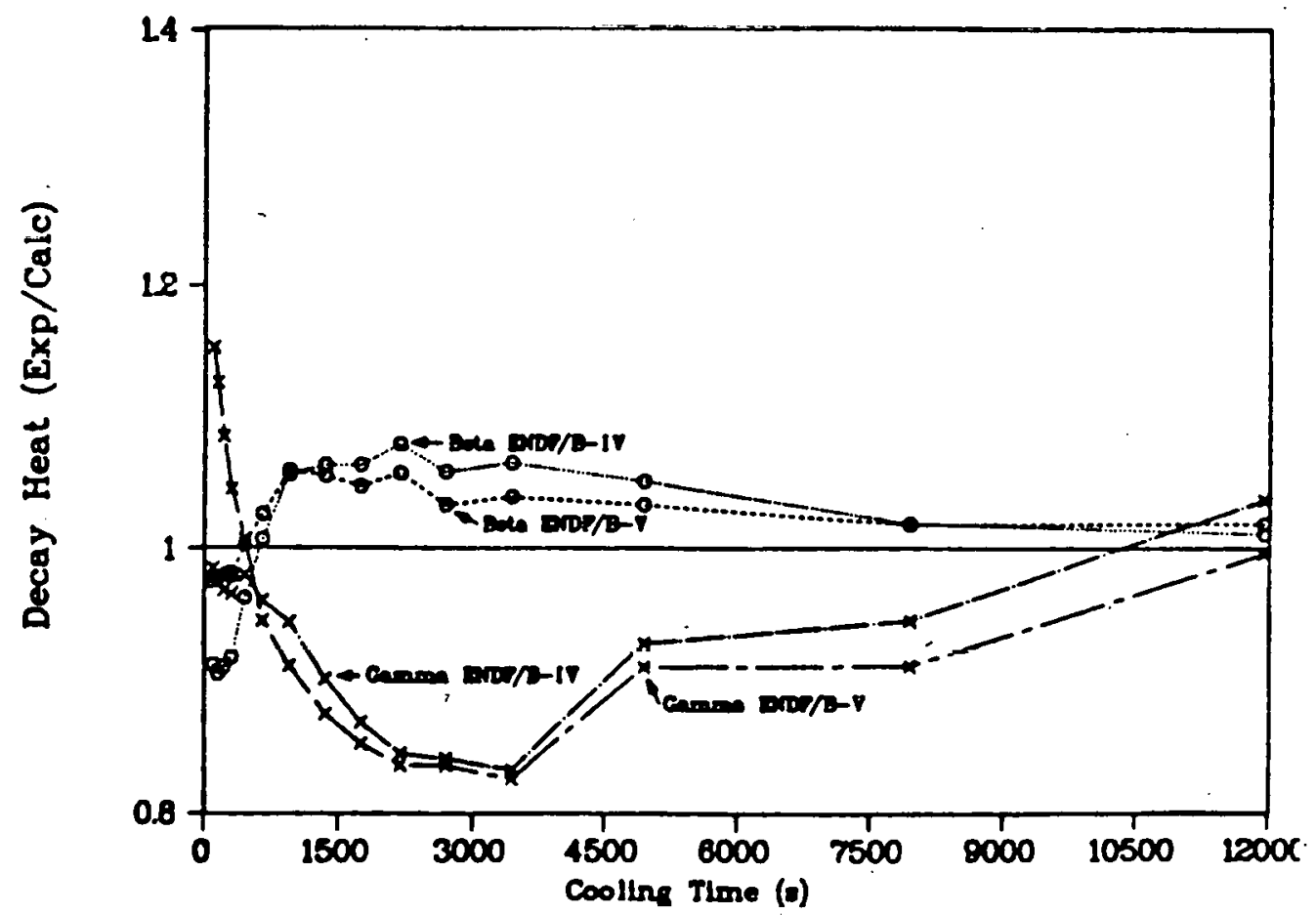

Fig. 18. Ratio of experiment to calculated decay heat for a 100-s irradiation of U235 at constant flux. (Experimental data from ORNL/NUREG-14) 


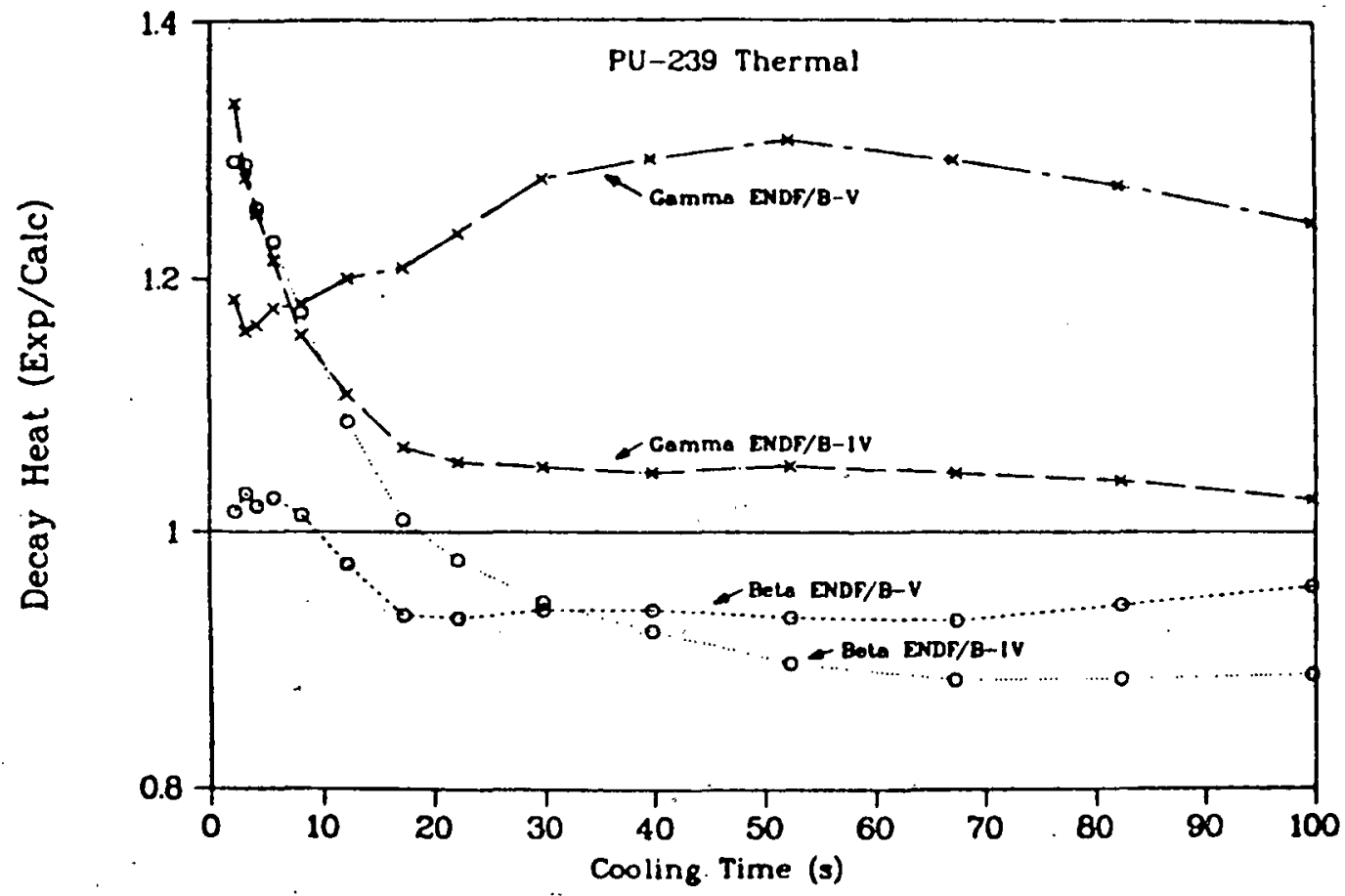

Fig. 19. Ratio of experimental to calculated decay heat for a l-s irradiation at constant flux. (Experimental data from ORNL exp, Dickens, ORNL/NUREG-34, April 1978).

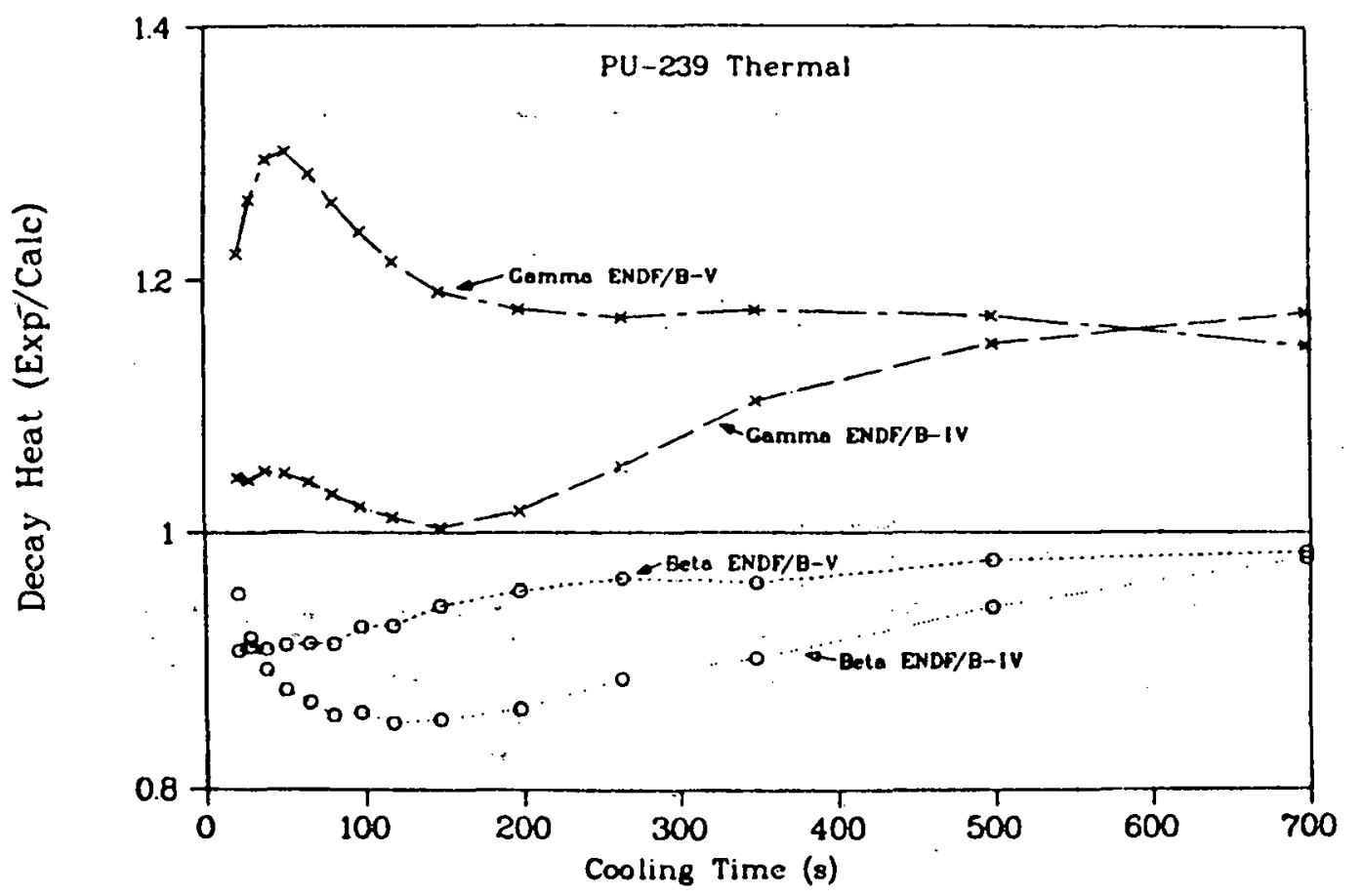

Fig. 20. Ratio of experimental to calculated decay heat for a 5-s irradiation at constant flux. (Experimental data from ORNL exp, Dickene, ORNL/NUREG-34, April 1978). 


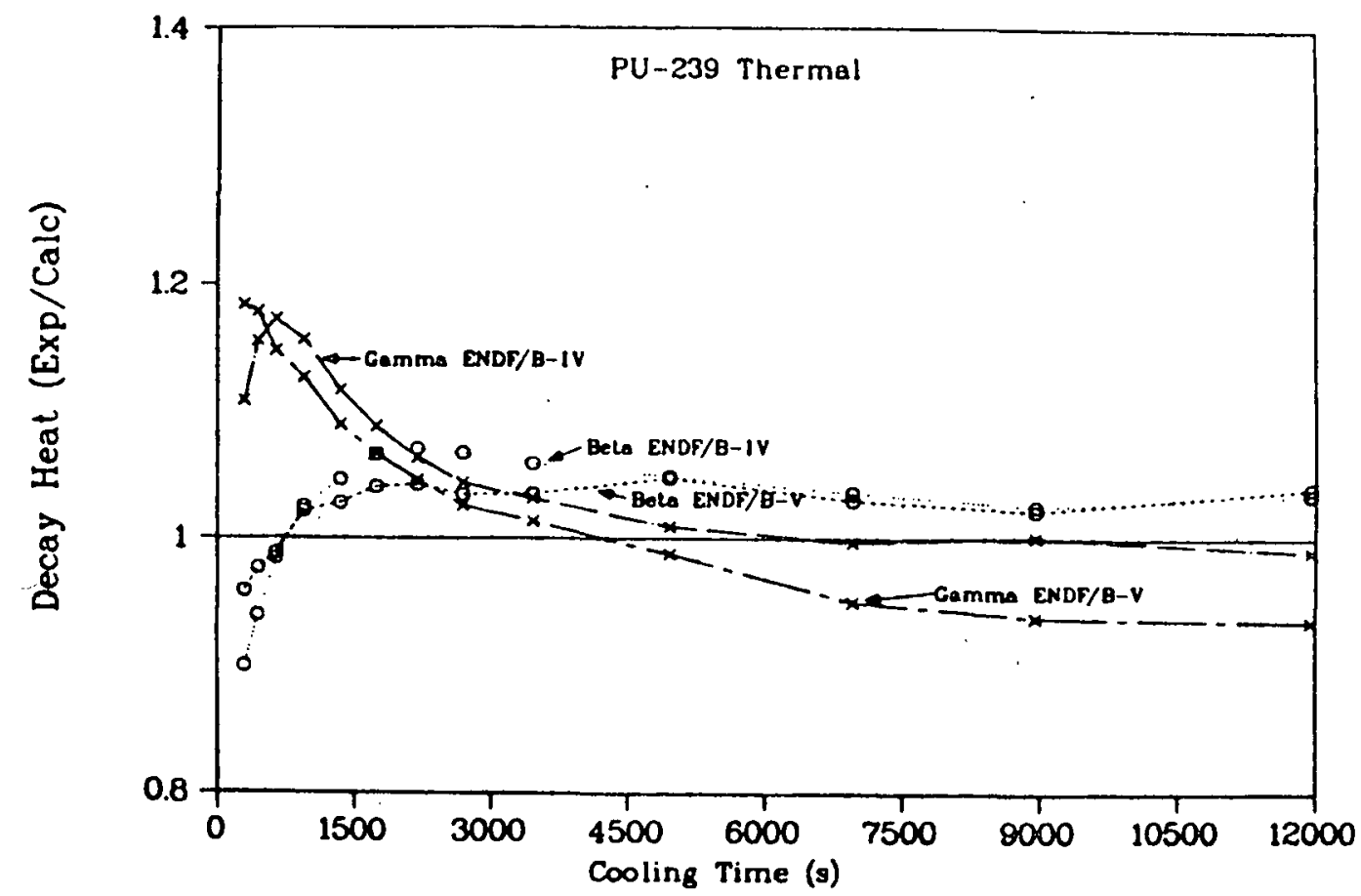

Fig. 21. Ratio of experimental to calculated decay heat for a 100-s irradiation at constant flux. (Experimental data from ORNL exp, Dickens, ORNL/NUREG-34, April 1978)

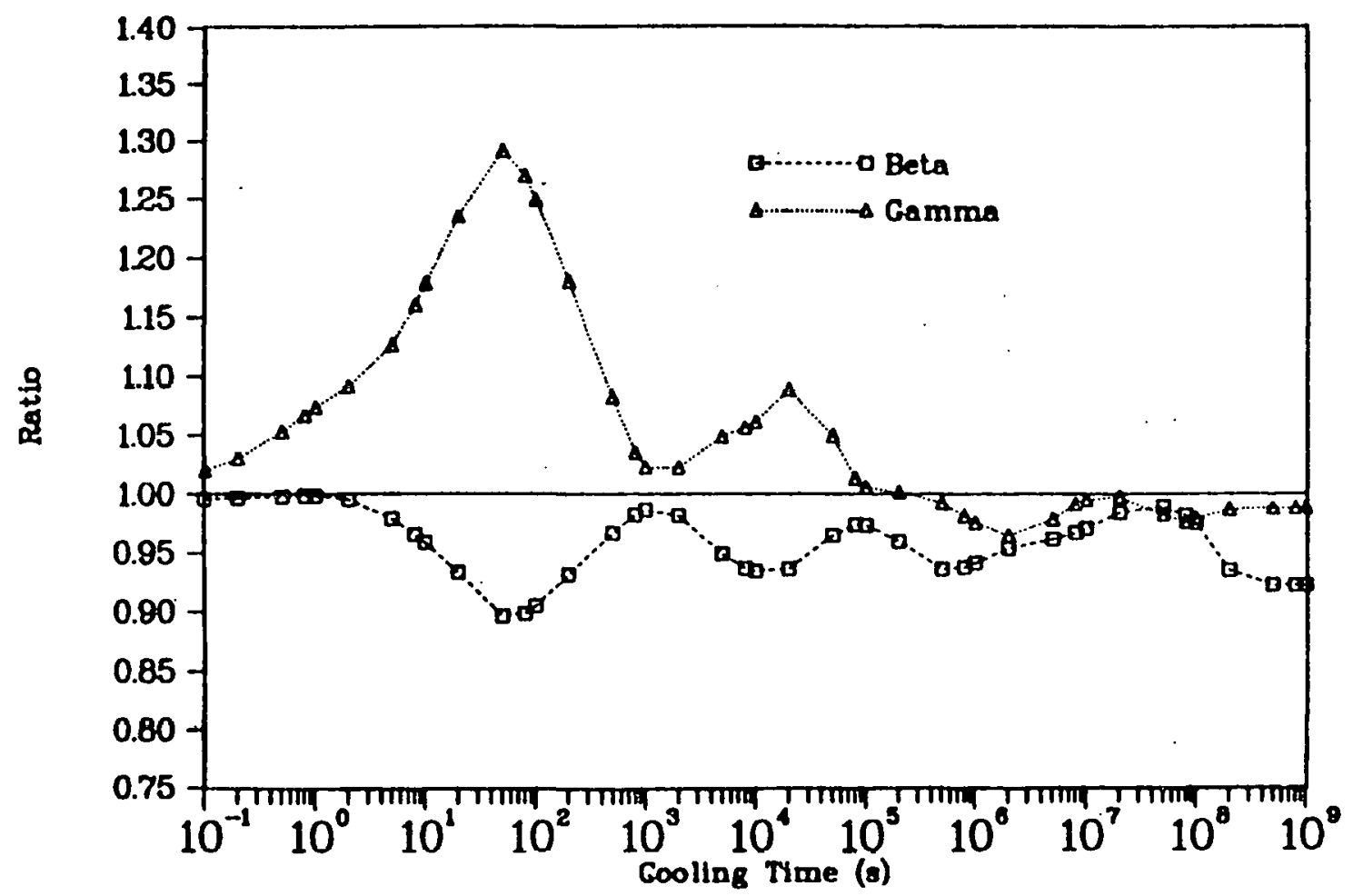

Fig. 22. U235 calculated thermal fission pulse using ENDF/B-V with JNDC energies as a ratio to results using only ENDF/B-V data. 


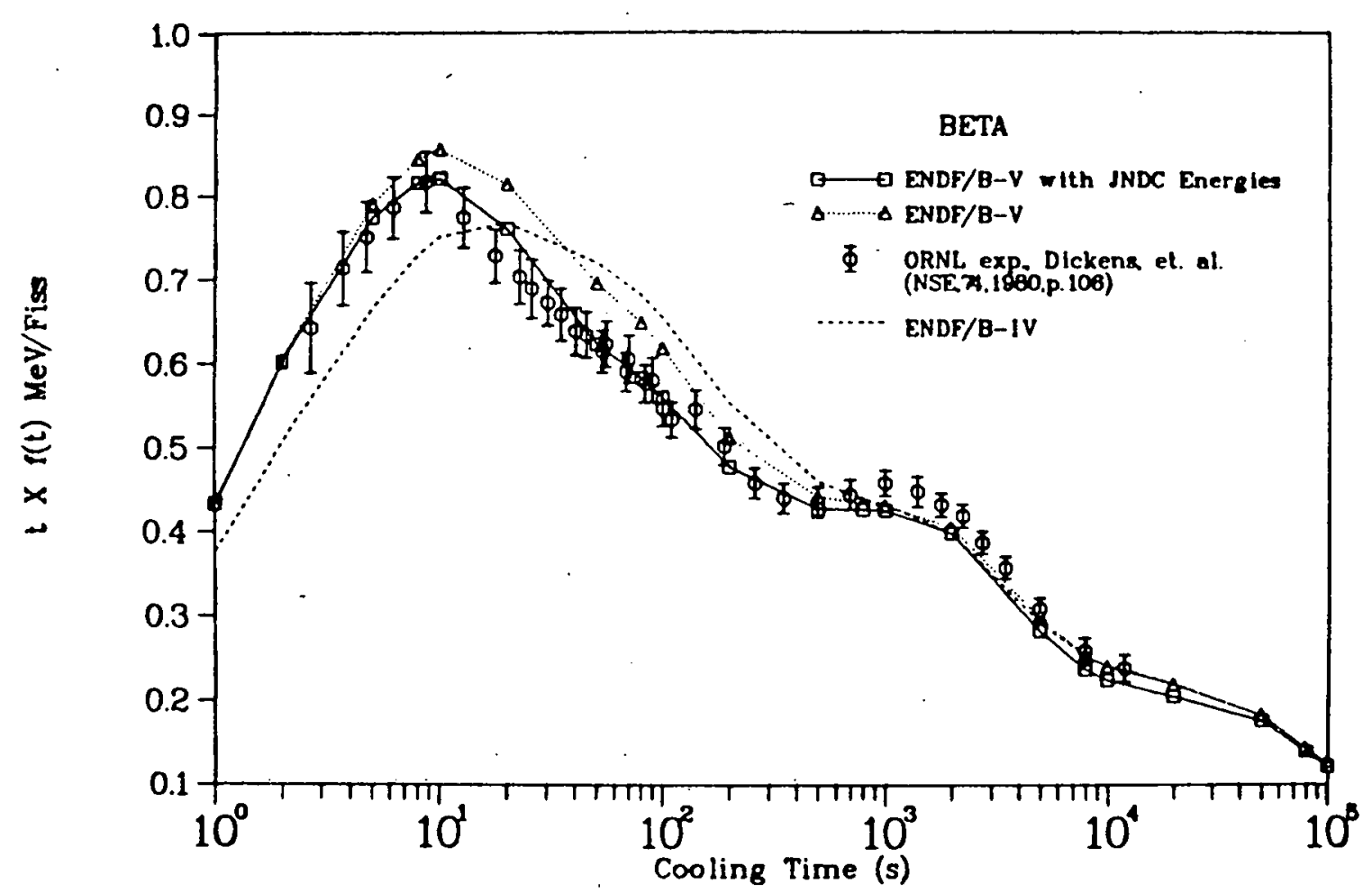

Fig. 23. U235 thermal fission pulse comparisons.

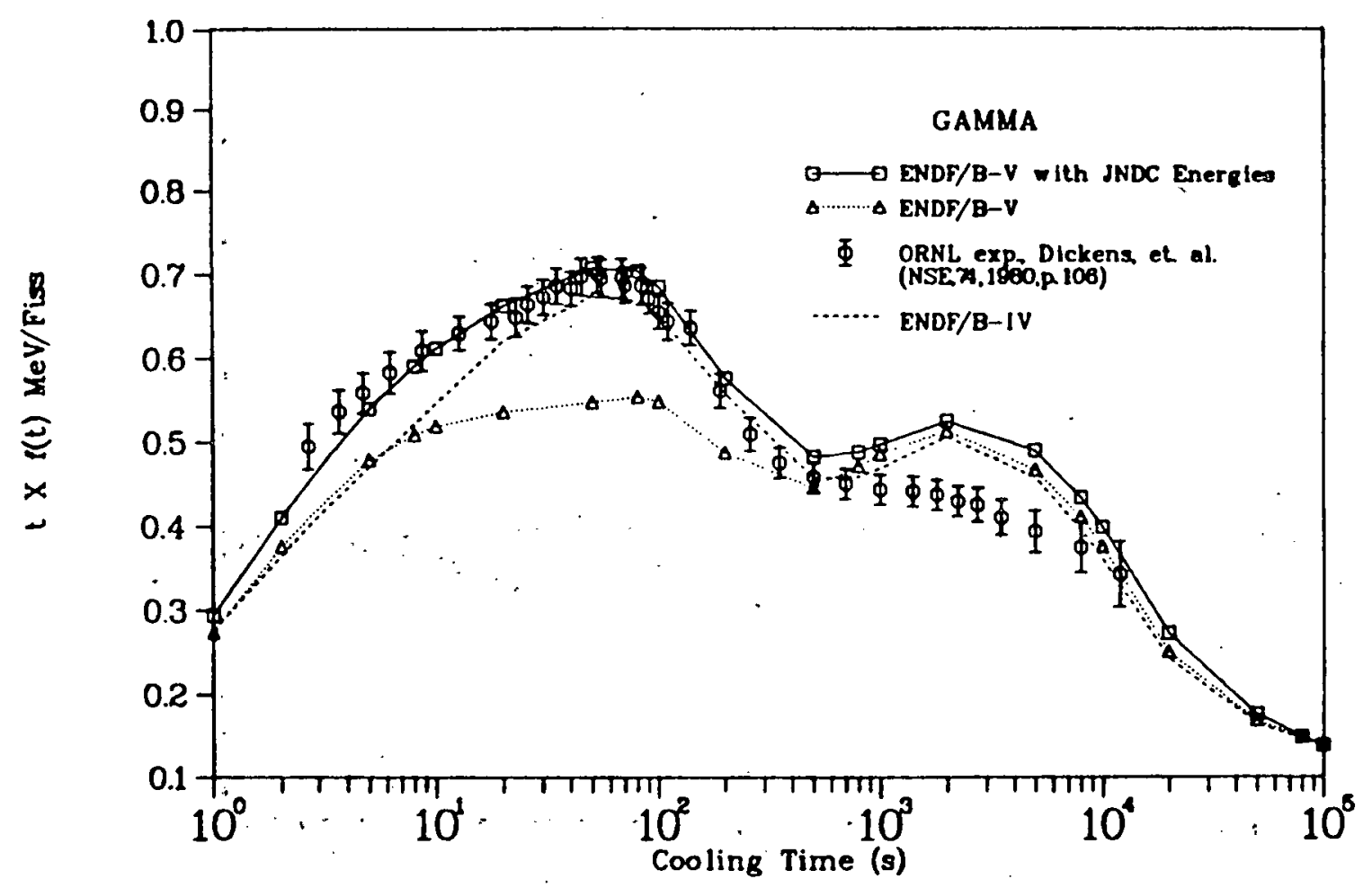

Fig. 24. U235 thermal fission pulse comparisons. 


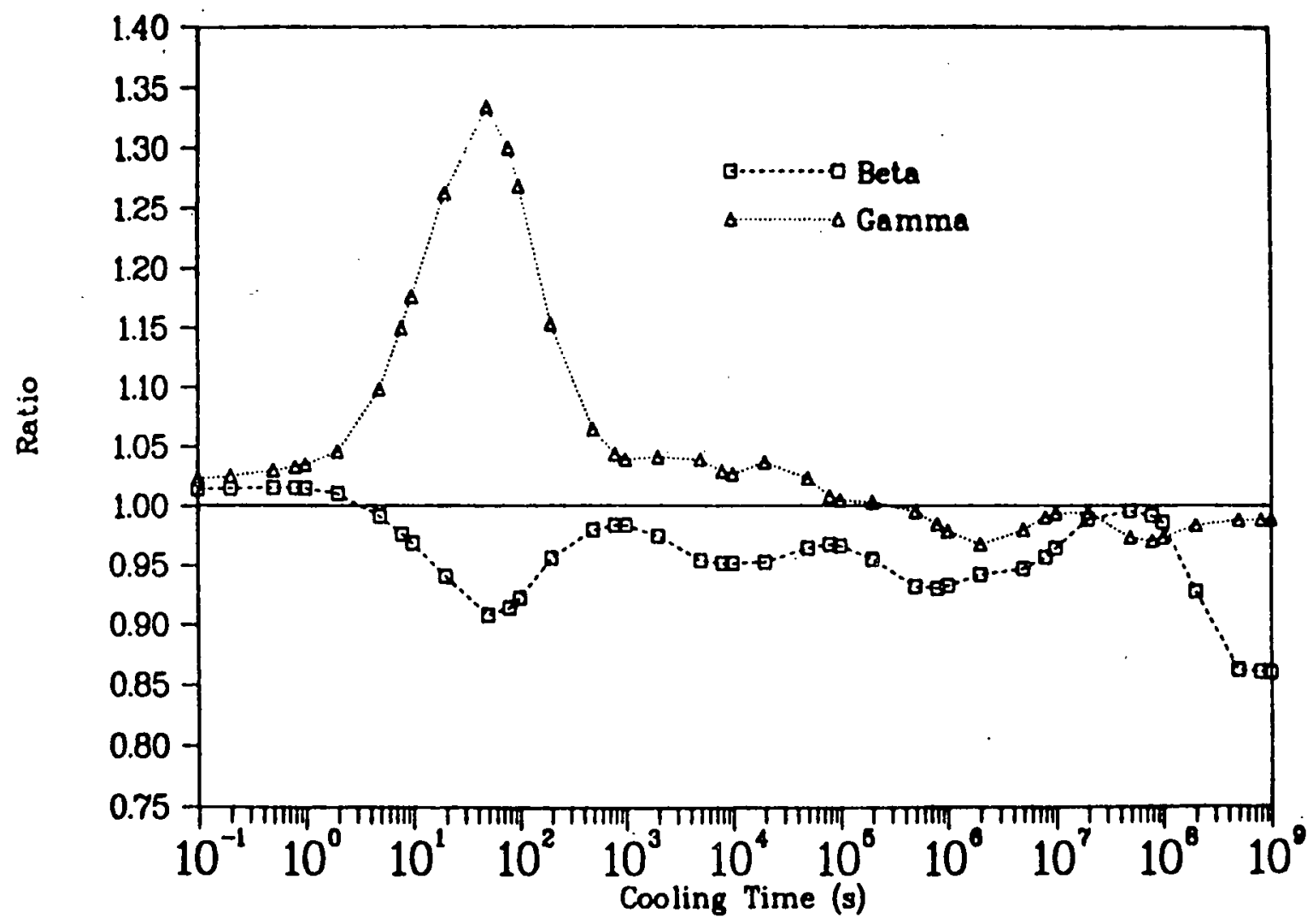

Fig. 25. PU239 calculated thermal fission pulse using ENDF/B-V with JNDC energies as a ratio to results using only ENDF/B-V data.

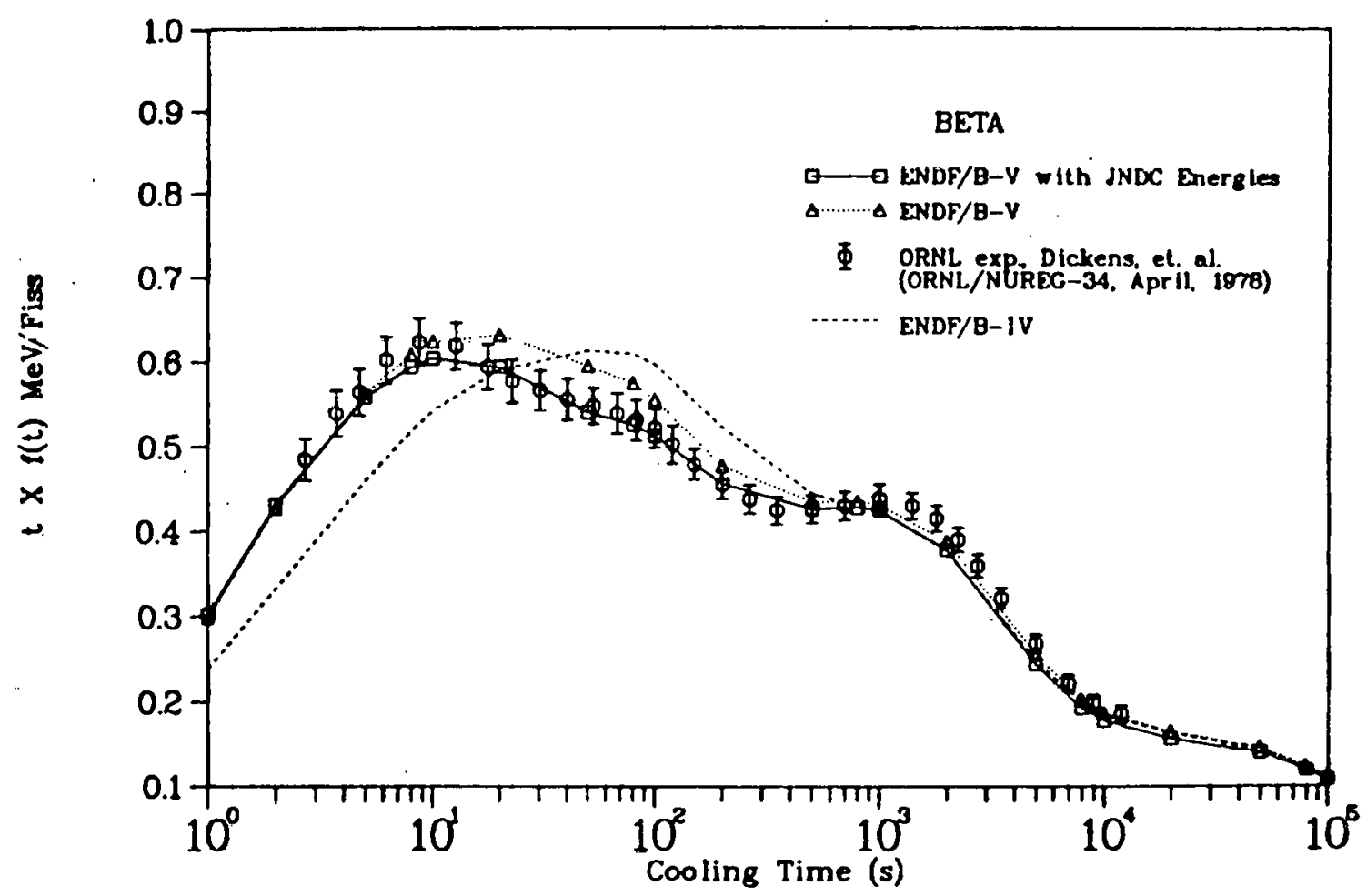

Fig. 26. PU239 thermal fission pulse comparisons. 


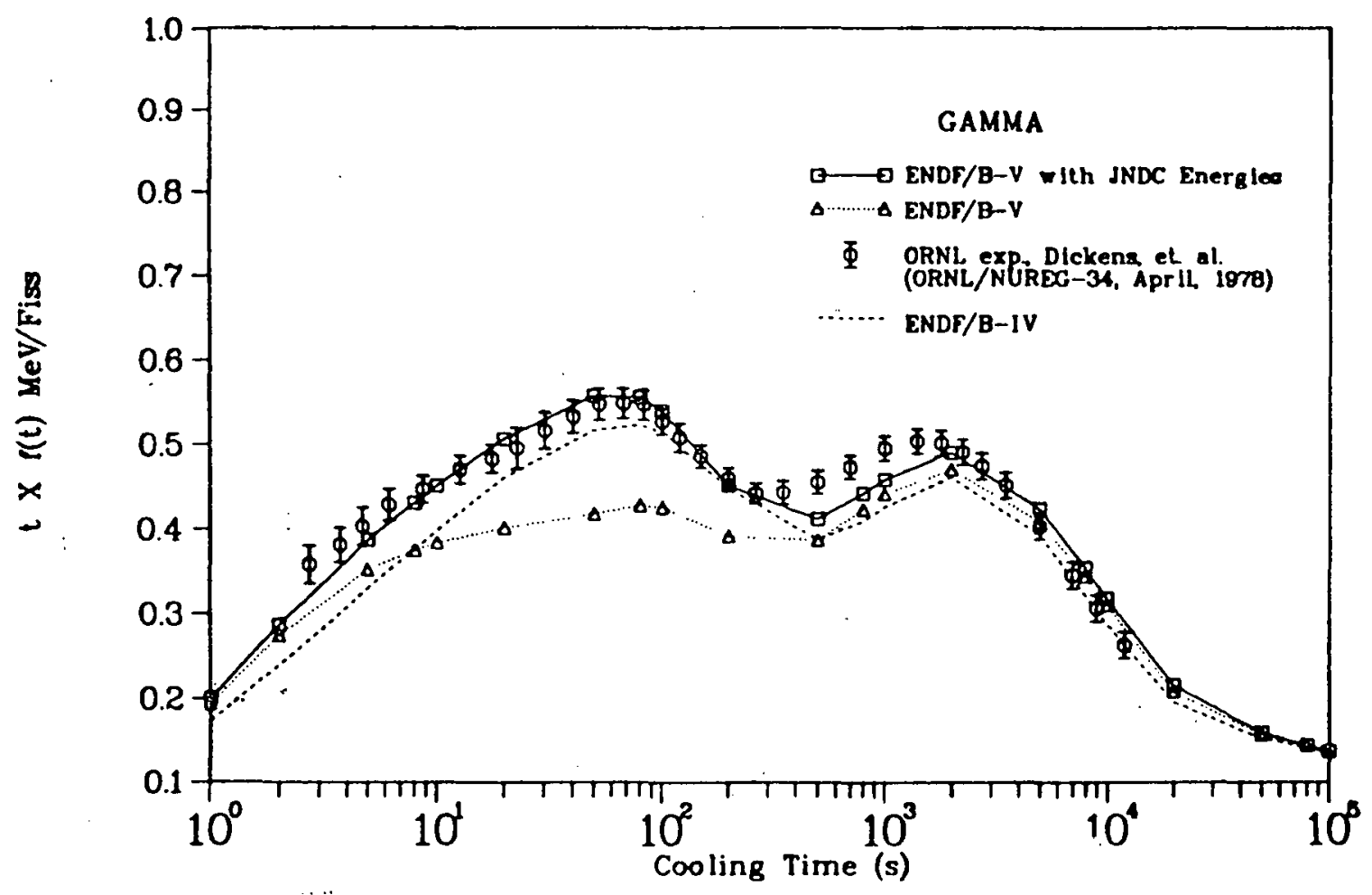

Fig. 27. PU239 thermal fission pulse comparisons. 
Very few errors (none that are significant to the aggregate decay power) have been found in the ENDF/B-V files. The CINDER-10 code ${ }^{1} 1$ library based on processing these files has been extensively checked for errors, and pulse calculations have been independently verified.2l One is forced to conclude that experimental decay energies for the individual nuclides, because of their dominant contribution, are likely deficient. This has already been assumed in compiling the 1981 Japanese data $\mathrm{file}^{22}$ in which it is noted "that the complex beta-decay schemes based on gamma-ray peak analysis and intensity balance should be regarded as doubtful from the viewpoint of completeness." For nuclides having Q-values > $5 \mathrm{MeV}$, they used fitted parameters in a model based on the gross theory of beta decay to replace $\beta^{-}$and $\gamma$ experimental energies. In Figs. 23 to 27 , we have used the JNDC energies with, otherwise, all ENDF/B-V decay parameters. The improved agreement with these sensitive pulse cases for two fuels differing greatly in fission-yield distributions is remarkable. These results strongly indicate that yield and decay parameters in ENDF/B-V, other than some decay energies of short-lived nuclides, are very good. We anticipate making an improvement in aggregate decay-energies similar to the result from the JNDC file, using model calculations and possibly using a recent unpublished code. 23

V. FISSION-PRODUCT DECAY-ENERGY SPECTRAL COMPARISONS OF THE FOUR LIBRARIES The FITPULS code was used to rebin the fine-group aggregate data into the 18-group gamma-ray and 17-group beta-ray energy-group structure shown in Table III and to fit results to a sum of exponentials,

$$
f(t)=\sum_{i=1}^{n} \alpha_{i} e^{-\lambda_{i} t} \quad(\mathrm{MeV} / \mathrm{flss}-\mathrm{s})
$$

The fits were made within $\pm 5 \%$ for all groups for all four aggregate fission-product decay-energy libraries; that is, any calculation using a set of fitted alphas and lambdas in the above "pulse" equation would be within $5 \%$ of the original data point. The cnnling time range of the fits was taken from $1 \mathrm{~s}$ to $2 \times 10^{5} \mathrm{~s}$, which covers all experimental points. The parameters (alphas and lambdas) for all fits are given in Appendix A.

The aggregate gamma-ray energy-fits for a ${ }^{235} \mathrm{U}$ thermal fission pulse derived from ENDF/B-IV, JNDC/ENDF, and UK fission-product decay libraries are compared to those derived from ENDF/B-V in Figs. 28 through 46; that is, the 
ratios of ENDF/B-IV, JNDC/ENDF, and UK, all over ENDF/B-V are plotted as a function of cooling time. Figure 28 shows the comparison for the sum over all energies; Figs. 29 through 46 show the spectral comparisons for each of the groups of the 18-group gamma-energy group structure. Figures $47-64$ display the same comparisons for the beta-ray energies.

Note in Fig. 28, the comparison for the sum, that the most significant difference between $E N D F / B-I V$ and $E N D F / B-V$ is in the cooling time region from about 20 to $200 \mathrm{~s}$, where ENDF/B-IV results are $15-20 \%$ higher than those from ENDF/B-V. As indicated by the following spectral comparisons, this seems to be due to fission-product data with average gamma-decay energies from about $1 \mathrm{MeV}$ to $5 \mathrm{MeV}$ (groups 7 through 17). Further examination of Figs. 29 through 46 reveals that, except for Group $1(0-100 \mathrm{keV})$, ENDF/B-IV and ENDF/B-V fits are in good agreement above the $200 \mathrm{~s}$ cooling time for energies up to about $2.5 \mathrm{MeV}$ (Group 14). The large Group 1 differences are due to the fact that substantial additional low-energy ( $x-r$ ay) data not in ENDF/B-IV were included in ENDF/B-V. Also, changes were made in many $E N D F / B-V, h i g h$-energy spectra, accounting for the differences seen in Figs. 42 through 46.

It should also be noted that for the sums (Figs. 28 and 47), the UK file is in good agreement with ENDF/B-V, but the JNDC-ENDF file is generally higher for the gamma-ray energies and lower for the beta-ray energies. This latter observation is also noted above in Sec. IV. Although not displayed here with this type of figure, similar comparisons are evident for aggregate fissionproduct decay-energy spectra from thermal fissioning of $239 \mathrm{Pu}$.

VI. FITTING THE EXPERIMENTAL DATA

The FITPULS code contains an option for fitting data with functions of the type

$$
\sum_{i=1}^{n} \frac{\alpha_{i}}{\lambda_{i}} e^{-\lambda_{i} t}\left(1-e^{-\lambda_{i} \mathrm{~T}}\right) \quad(\mathrm{MeV} / \mathrm{fis})
$$

thus allowing a determination of alphas and lambdas for an experiment with irradiation time $T$ and cooling time $t$. This procedure is valid only if absorption effects are negligible, that is, only for relatively low-fluence and short irradiation and/or cooling times. This is discussed more completely in Refs. 16 and 17. The set of alphas and lambdas so determined is said to represent an "equivalent pulse" for the experiment, or one can say the experiment has been reduced to an "equivalent pulse." An equivalent set of "experimental points" 


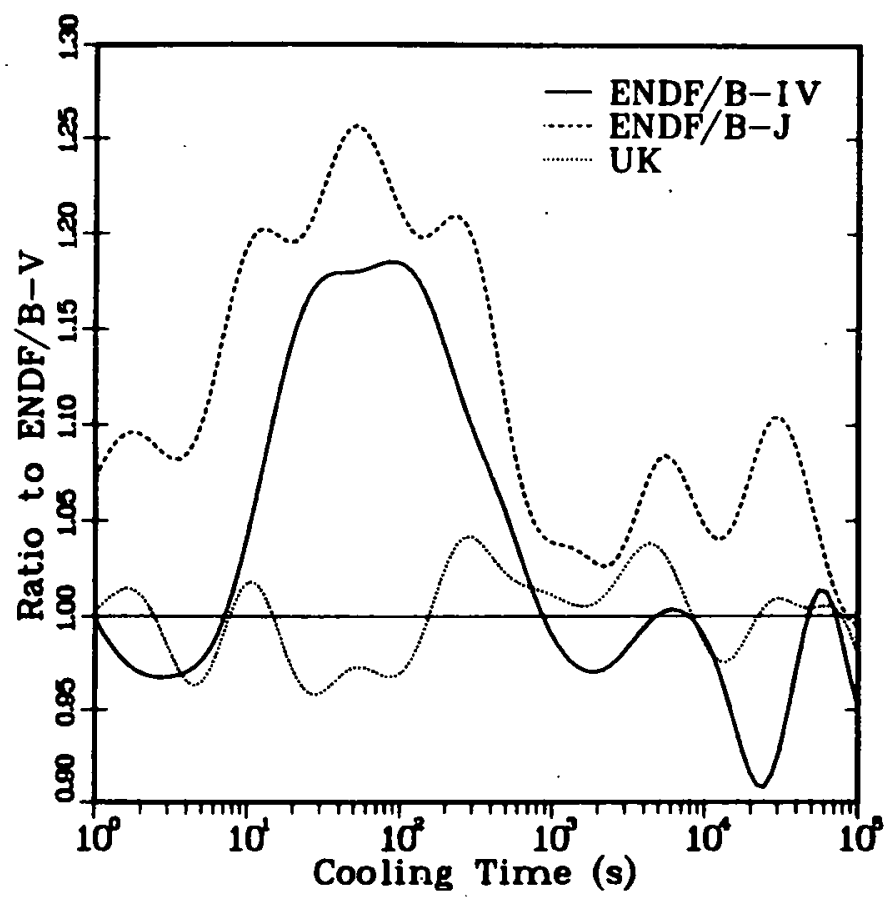

Fig. 28 .

$235_{\mathrm{U}}$ thermal pulse, gamma fit comparison, total over all groups.

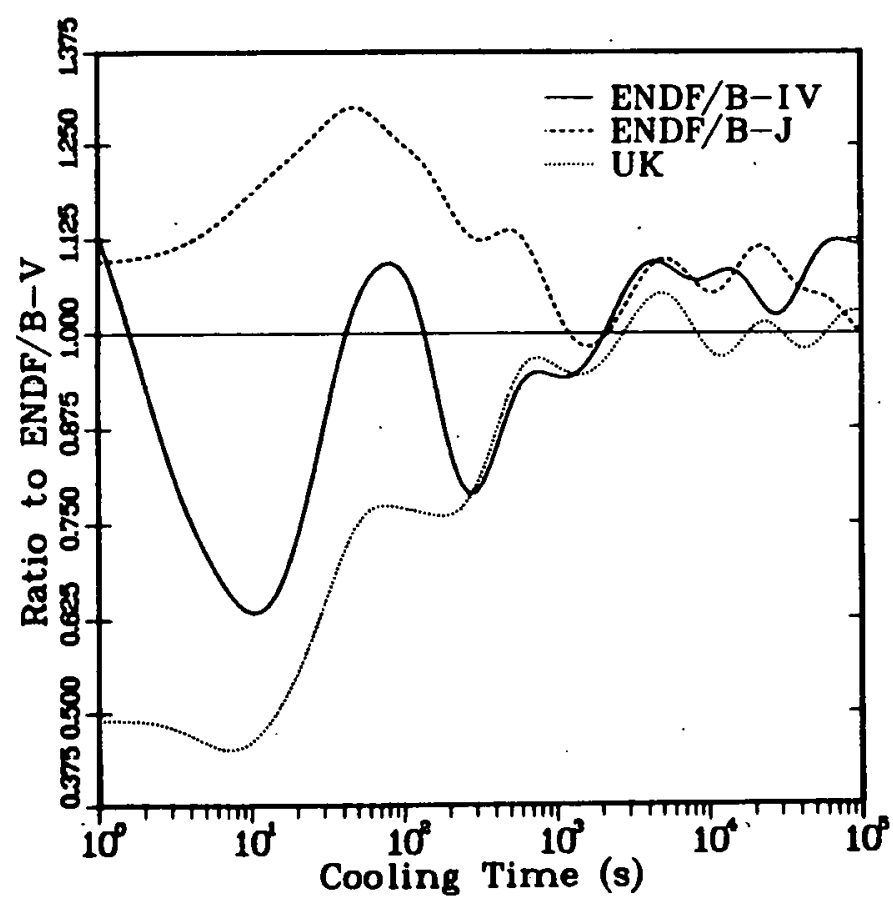

Fig. 30 .

$235_{U}$ thermal pulcc, gamma fit comparison, Group 2 (0.1 - 0.2 MeV).

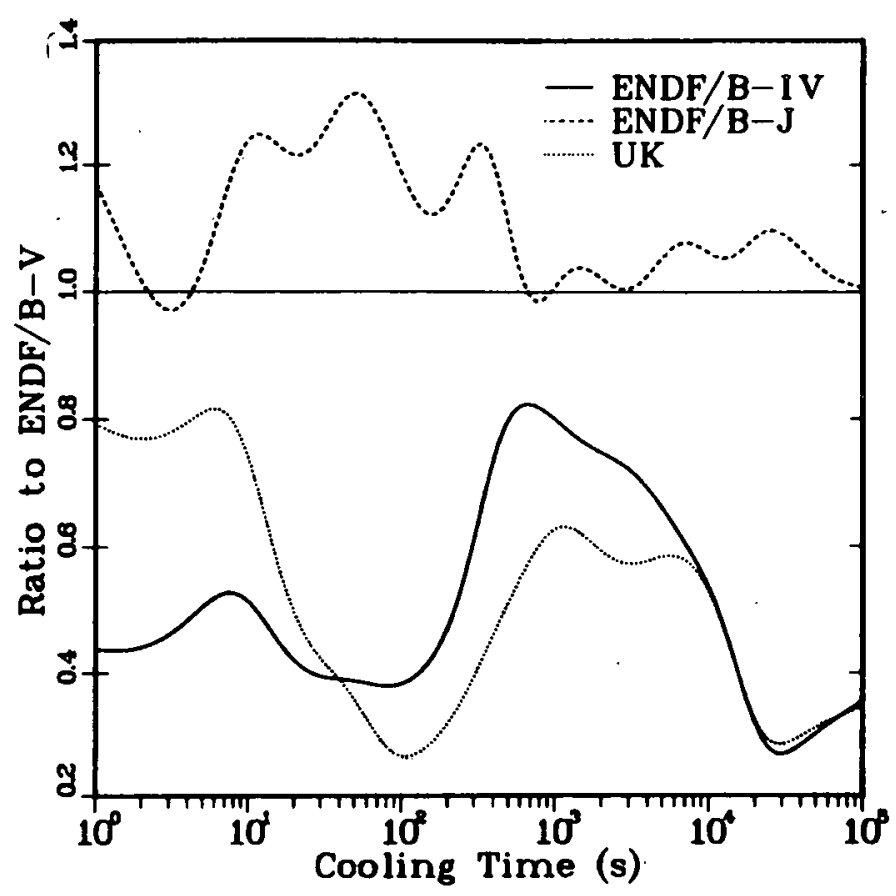

Fig. 29.

${ }^{235} \mathrm{U}$ thermal pulse, gamma fit comparison, Group 1 (0.0 - $0.1 \mathrm{MeV})$.

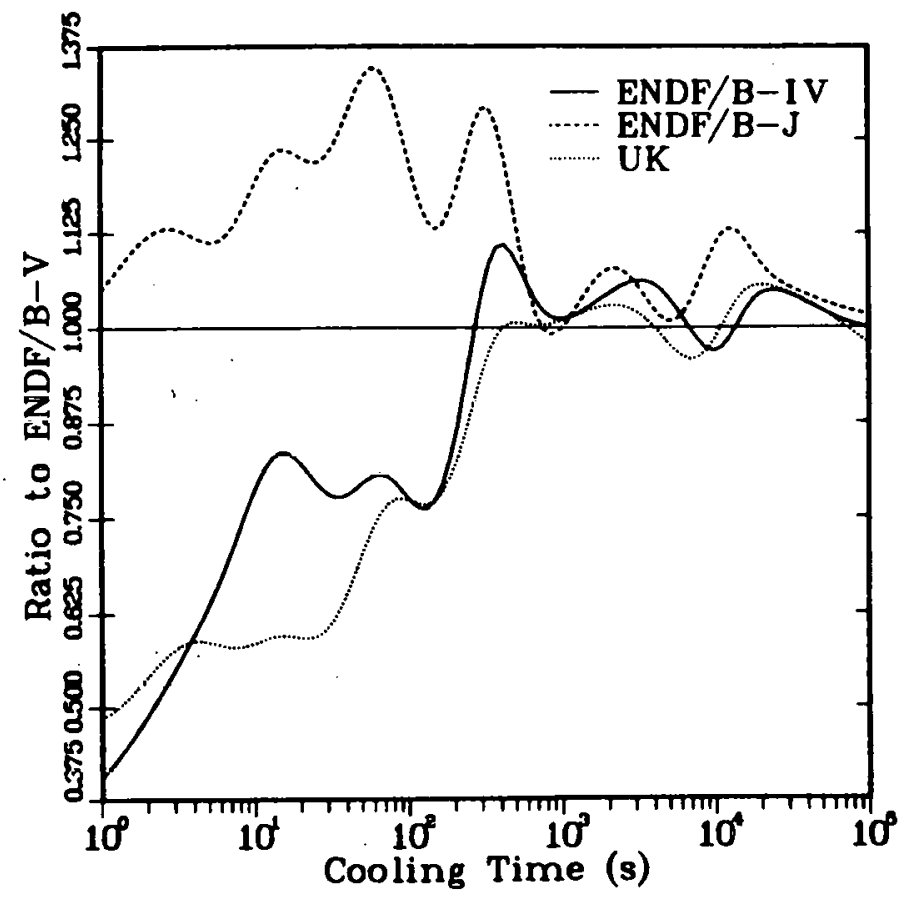

Fig. 31.

${ }^{235} \mathrm{U}$ thermal pulse, gamma fit comparison, Group $3(0.2 \cdots 0.4 \mathrm{MeV})$. 


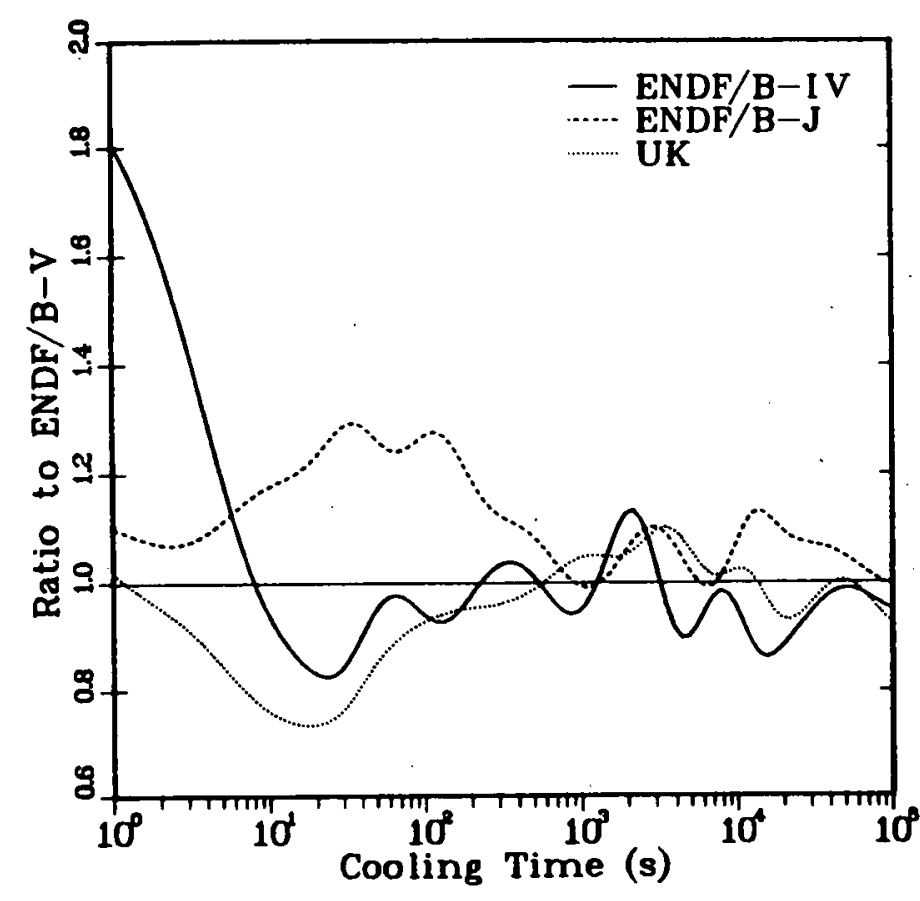

Fig. 32 .

${ }^{235} \mathrm{U}$ thermal pulse, gamma fit comparison, Group $4(0.4-0.6 \mathrm{MeV})$.

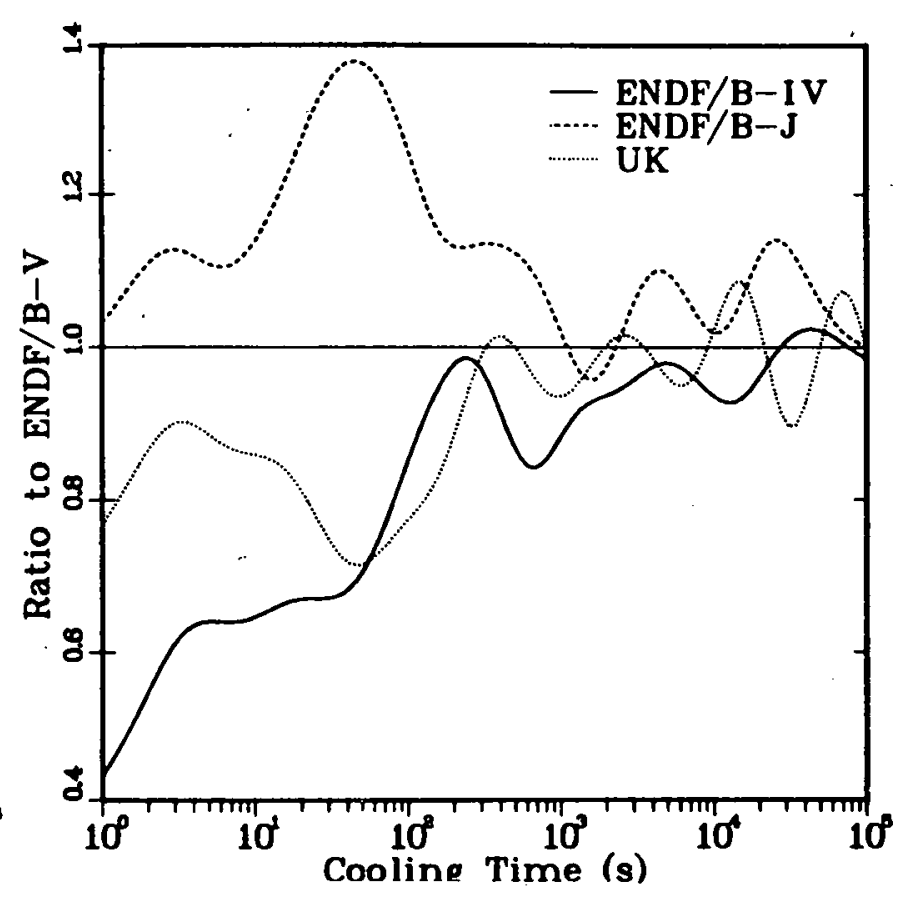

Fig. 33.

${ }^{235} \mathrm{U}$ thermal pulse, gamma fit comparison, Group 5 ( $0.6-0.8 \mathrm{MeV})$.

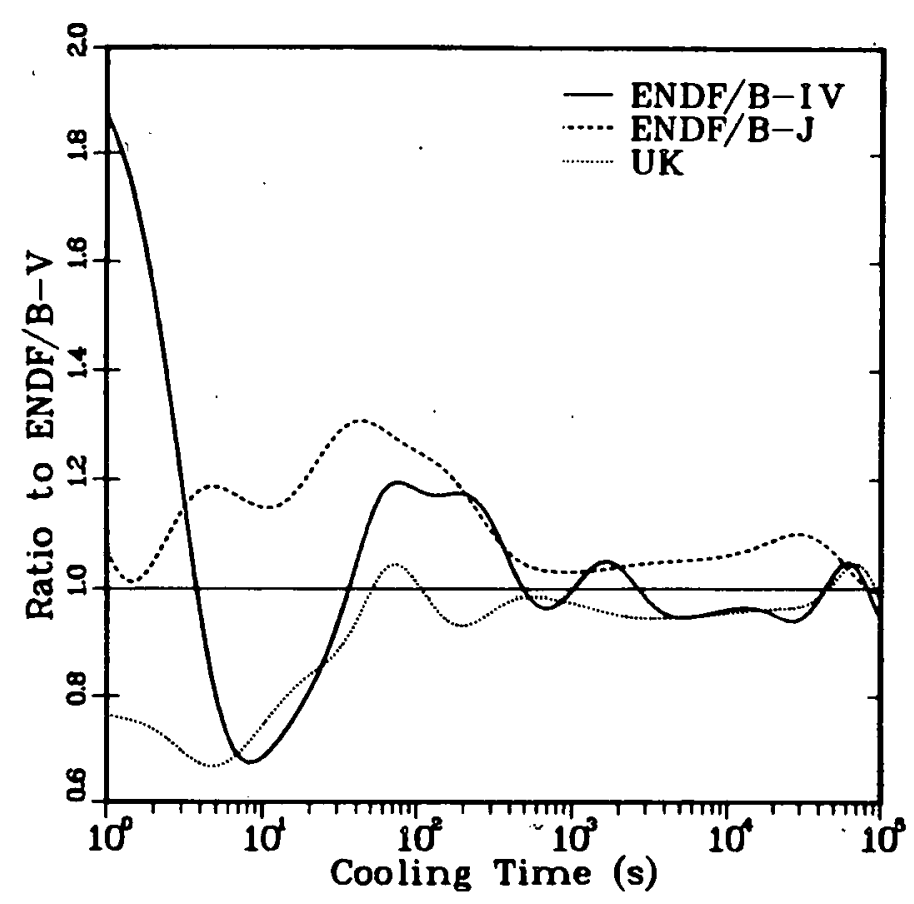

Fig. 34 .

${ }^{235} \mathrm{U}$ thermal pulse, gamma fit comparison, Group $6(0.8-1.0 \mathrm{MeV})$.

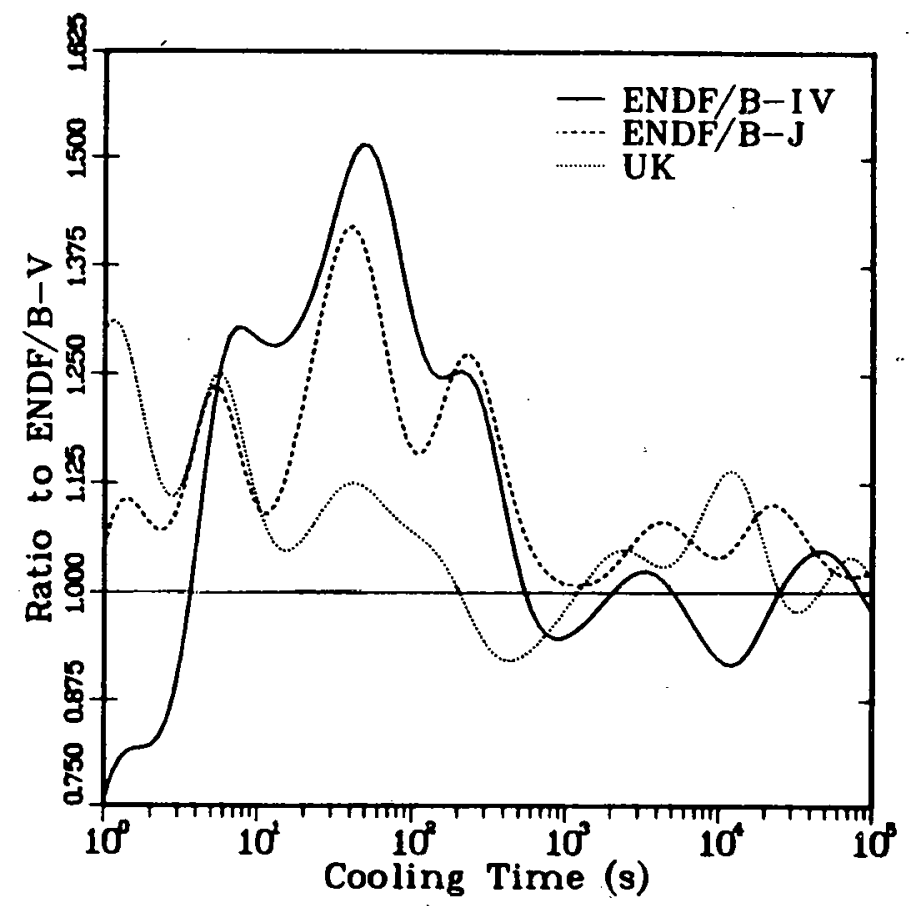

Fig. 35.

${ }^{235} \mathrm{U}$ thermal pulse, gamma fit comparison, Group 7 (1:0 - $1.2 \mathrm{MeV})$. 


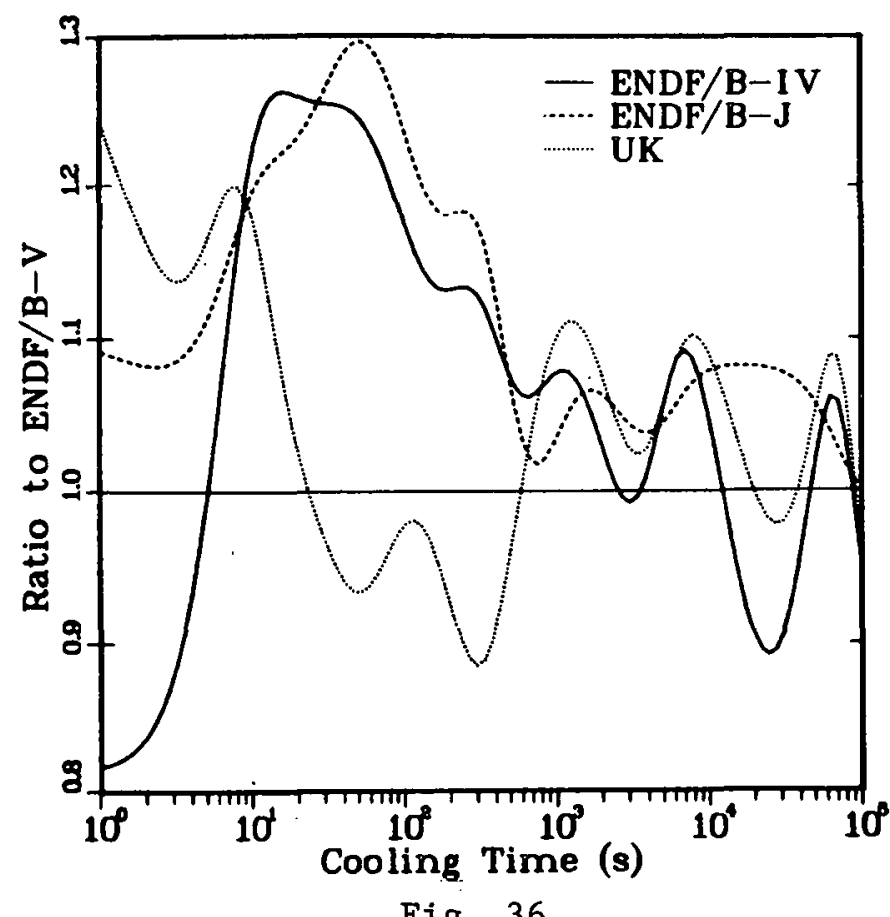

Fig. 36.

${ }^{235} \mathrm{U}$ thermal pulse, gamma fit comparison, Group $8(1.2-1.4 \mathrm{MeV})$.

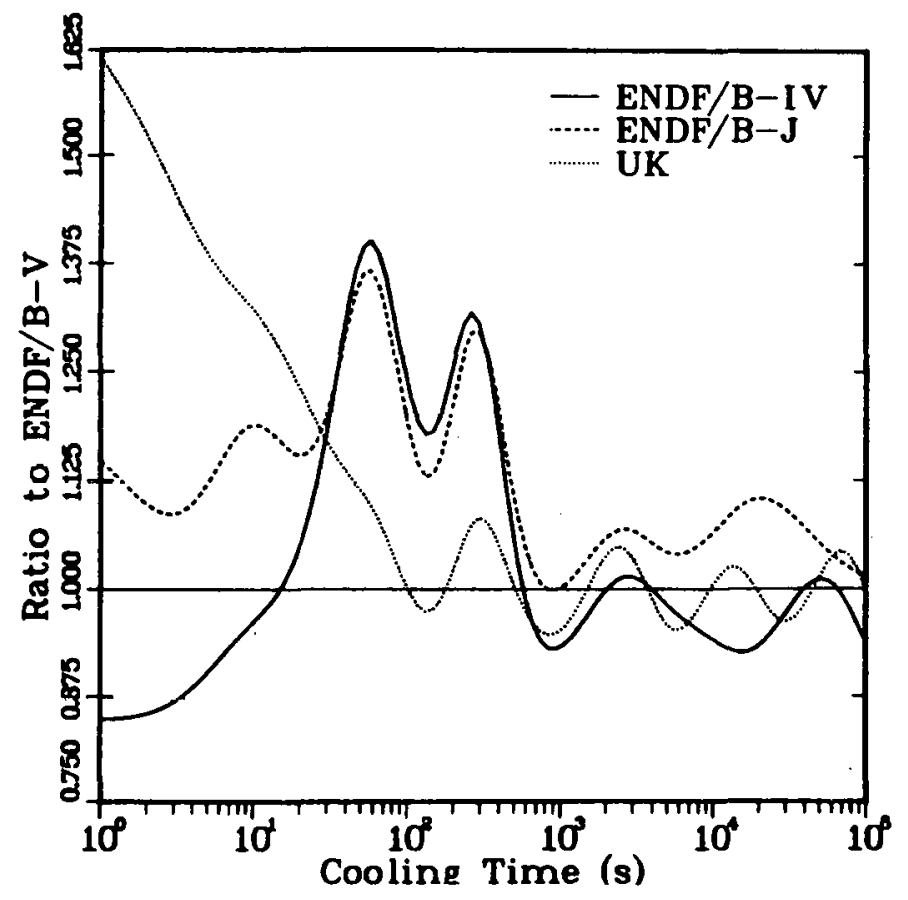

Fig. 38.

${ }^{235} \mathrm{U}$ thermal pulse, gamma fit comparison, Group $10(1.6-1.8 \mathrm{MeV})$.

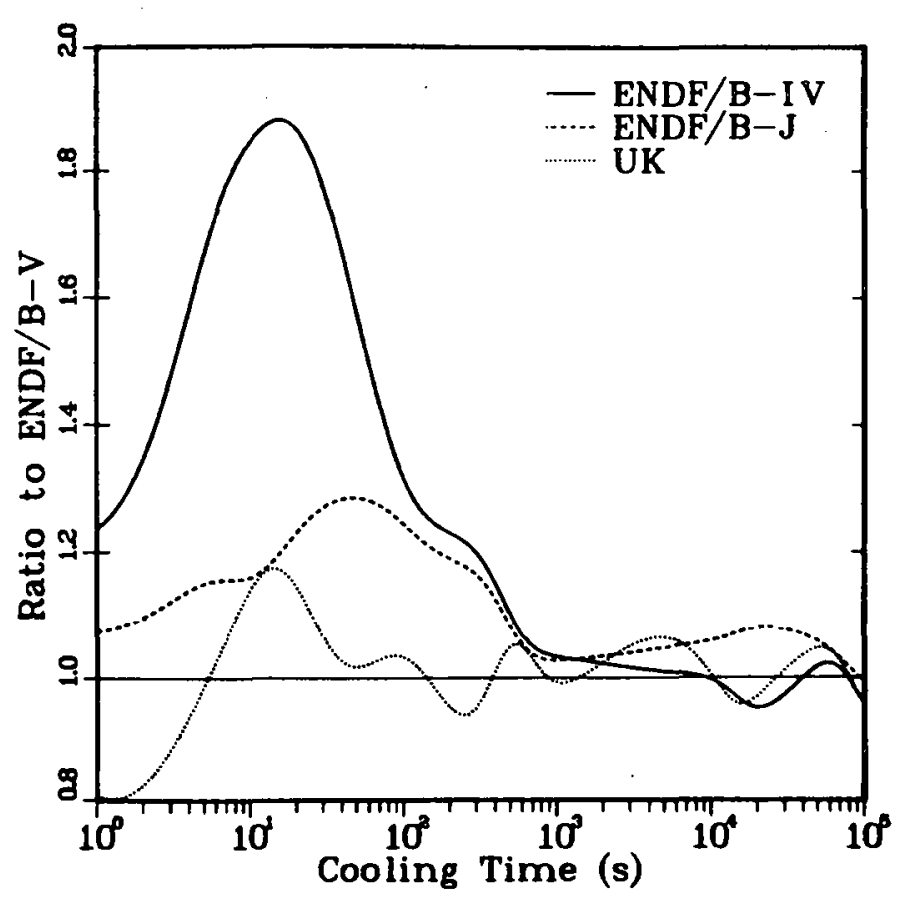

Fig. 37 .

${ }^{235_{U}}$ thermal pulse, gamma fit comparison, Group $9(1.4-1.6 \mathrm{MeV})$.

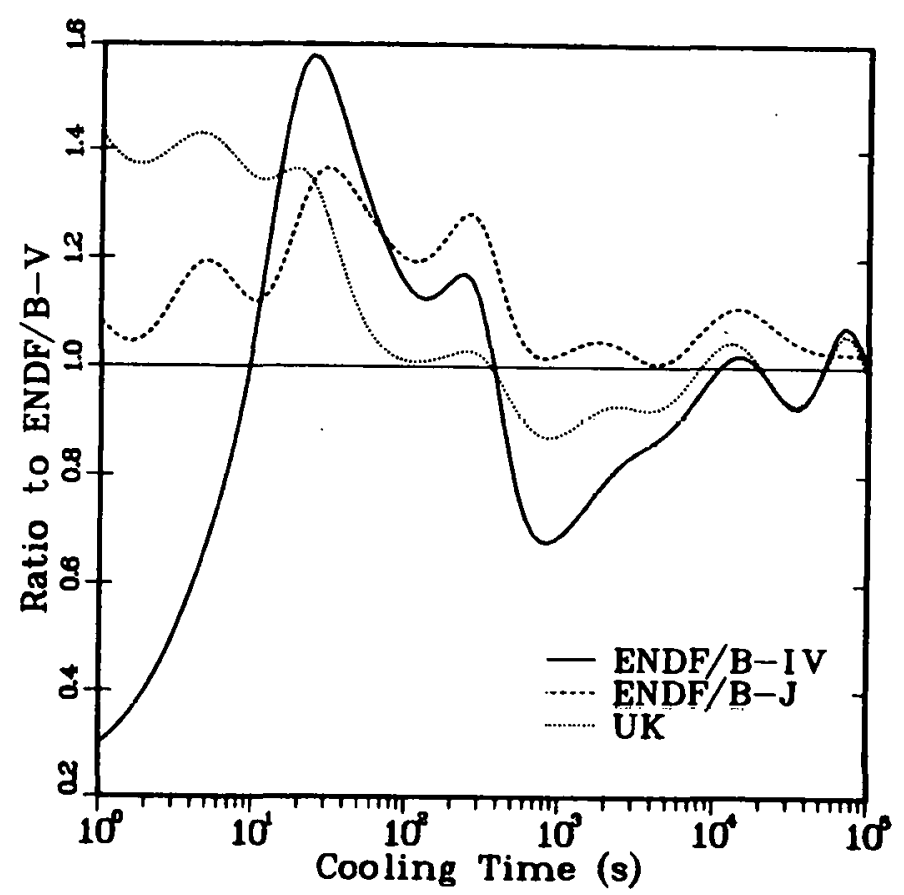

Fig. 39.

${ }^{235_{U}}$ thermal pulse, gamma fit comparison, Group $11(1.8-2.0 \mathrm{MeV})$. 


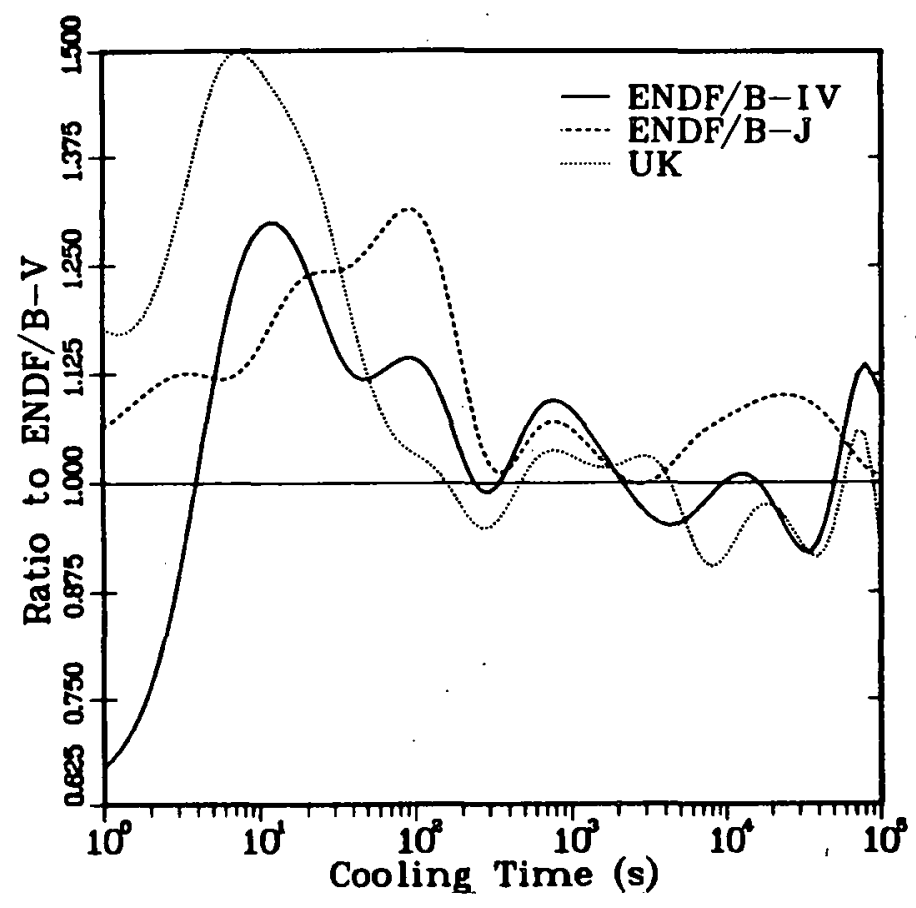

Fig. 40.

235 thermal pulse, Group $12(2.0-2.2 \mathrm{MeV})$.

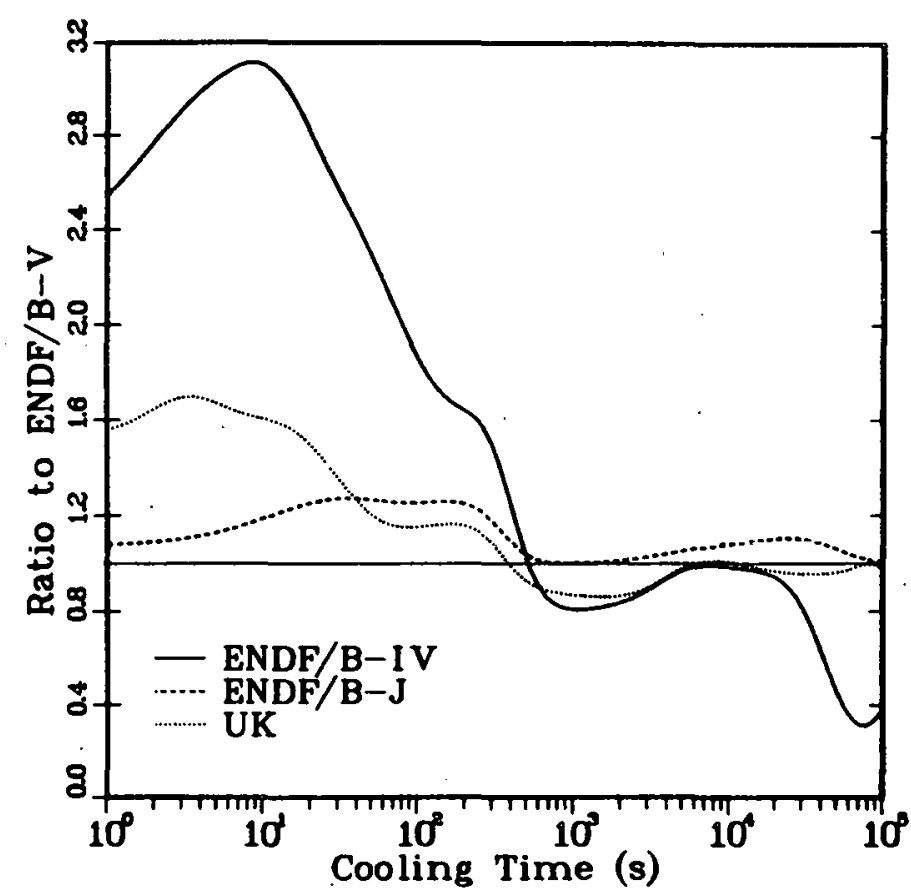

Fig. 42.

${ }^{235} \mathrm{U}$ thermal pulse, gamma fit comparison, Group $14(2.4-2.6 \mathrm{MeV})$.

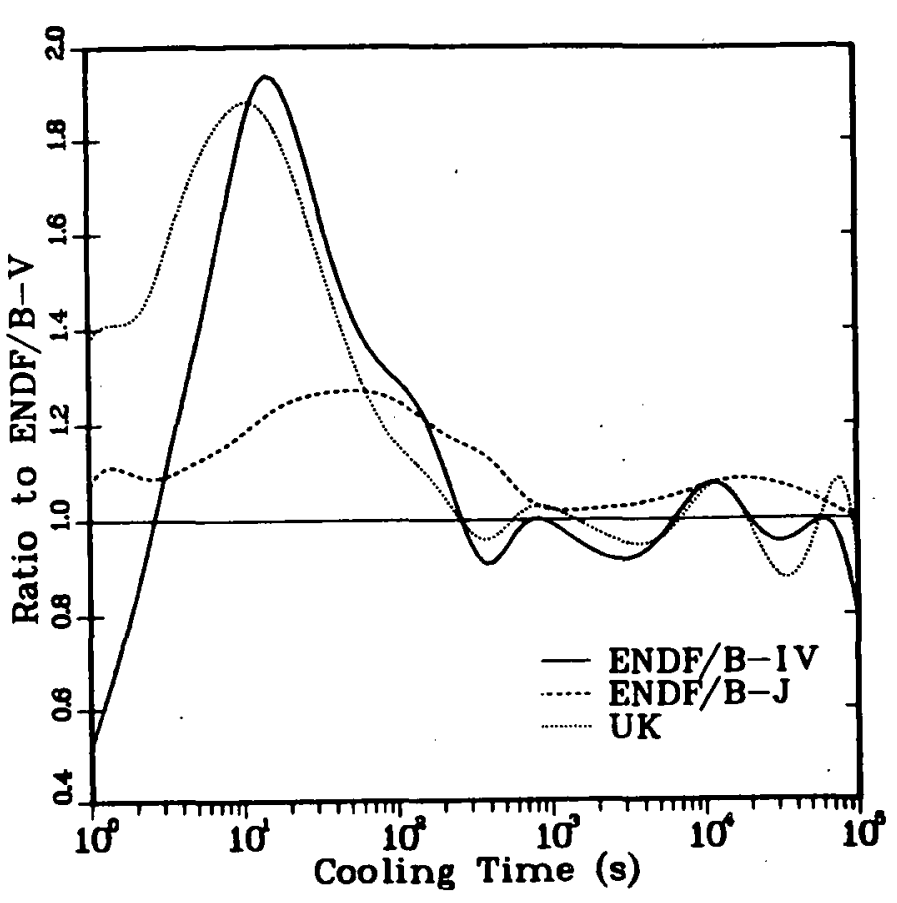

Fig. 41.

${ }^{235} \mathrm{U}$ thermal pulse, gamma fit comparison, Group $13 \cdot(2.2-2.4 \mathrm{MeV})$.

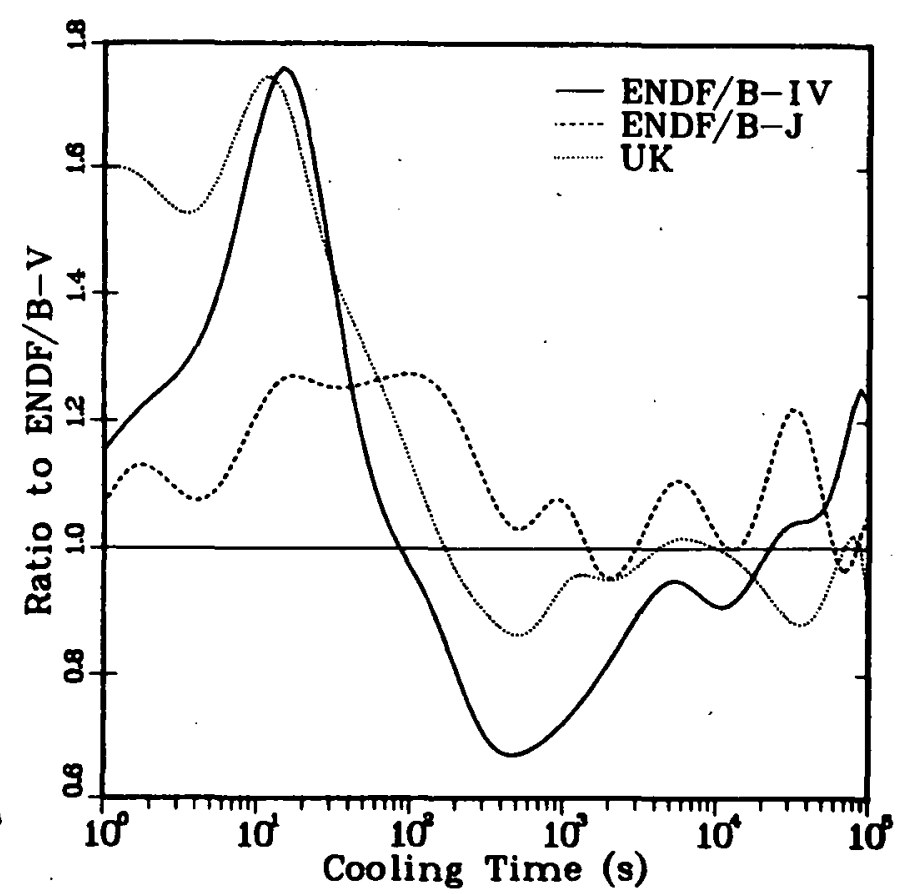

Fig. 43.

235 thermal pulse, gamma fit comparison, Group $15(2.6-3.0 \mathrm{MeV})$. 


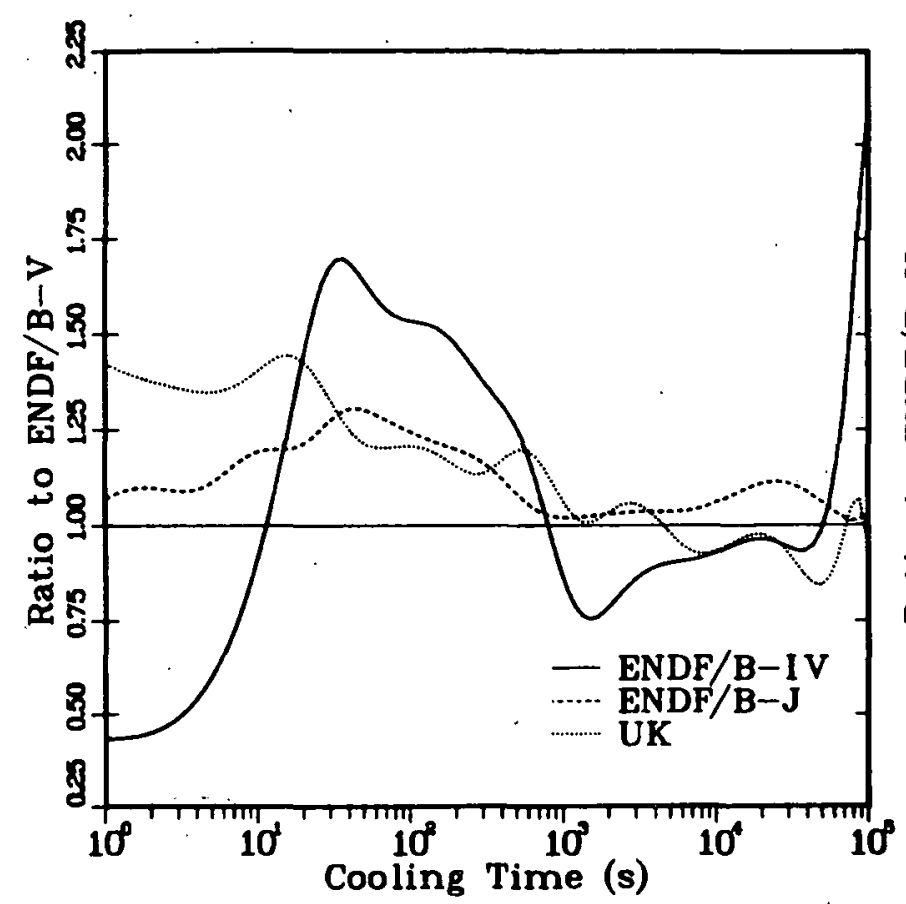

Fig. 44.

${ }^{235} \mathrm{U}$ thermal pulse gamma fit comparison, Group 16 (3.0 - 4.0 MeV).

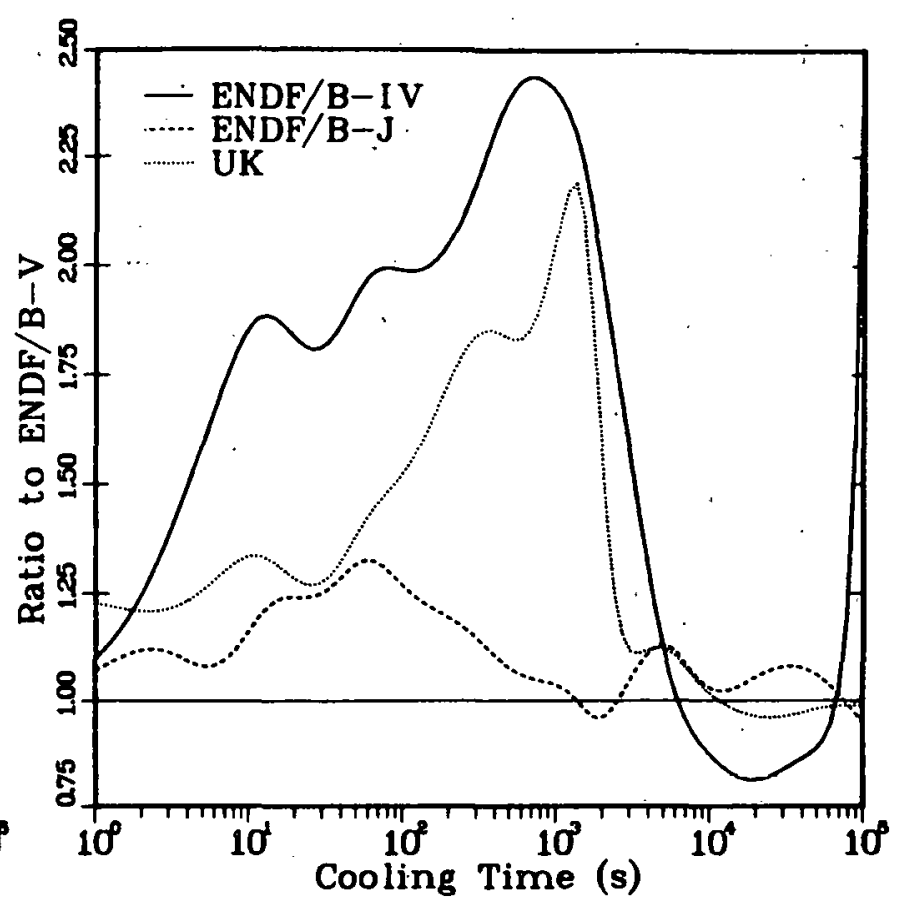

Fig. 45. Group $17(4.0-5.0 \mathrm{MeV})$.

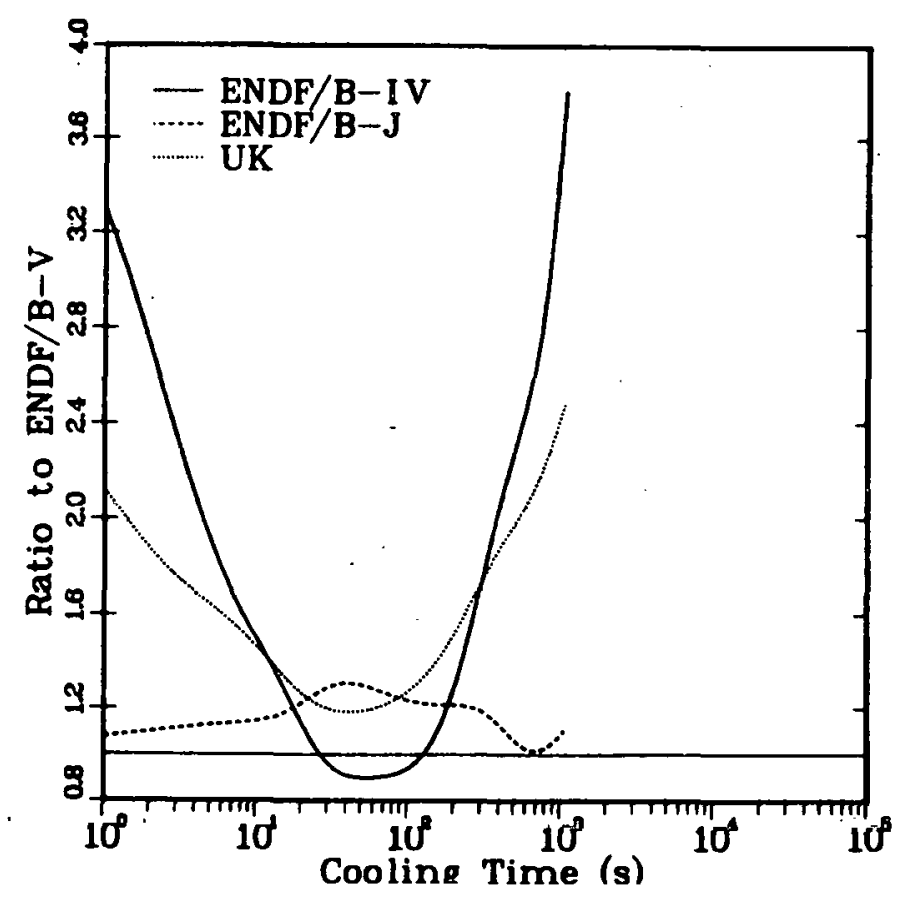

Fig. 46.

${ }^{235} \mathrm{U}$ thermal pulse, gamma fit comparison, Group $18(5.0-6.0 \mathrm{MeV})$. 


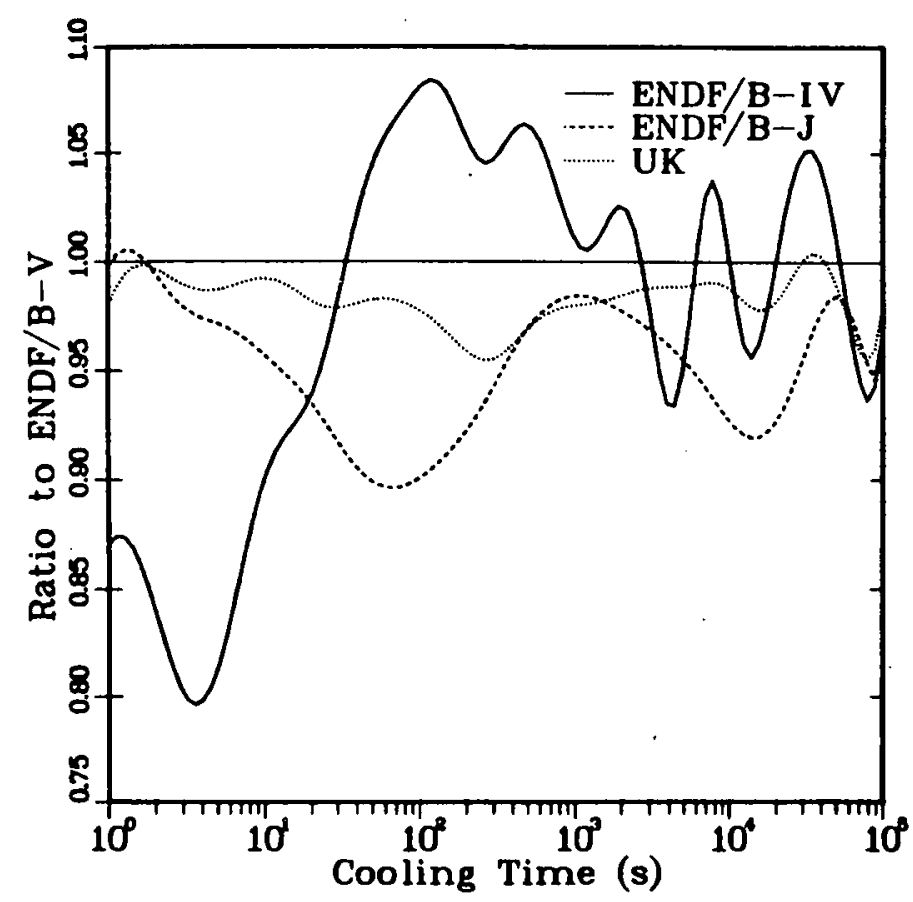

Fig. 47.

${ }^{235} \mathrm{U}$ thermal pulse, beta fit comparison, total over all groups.

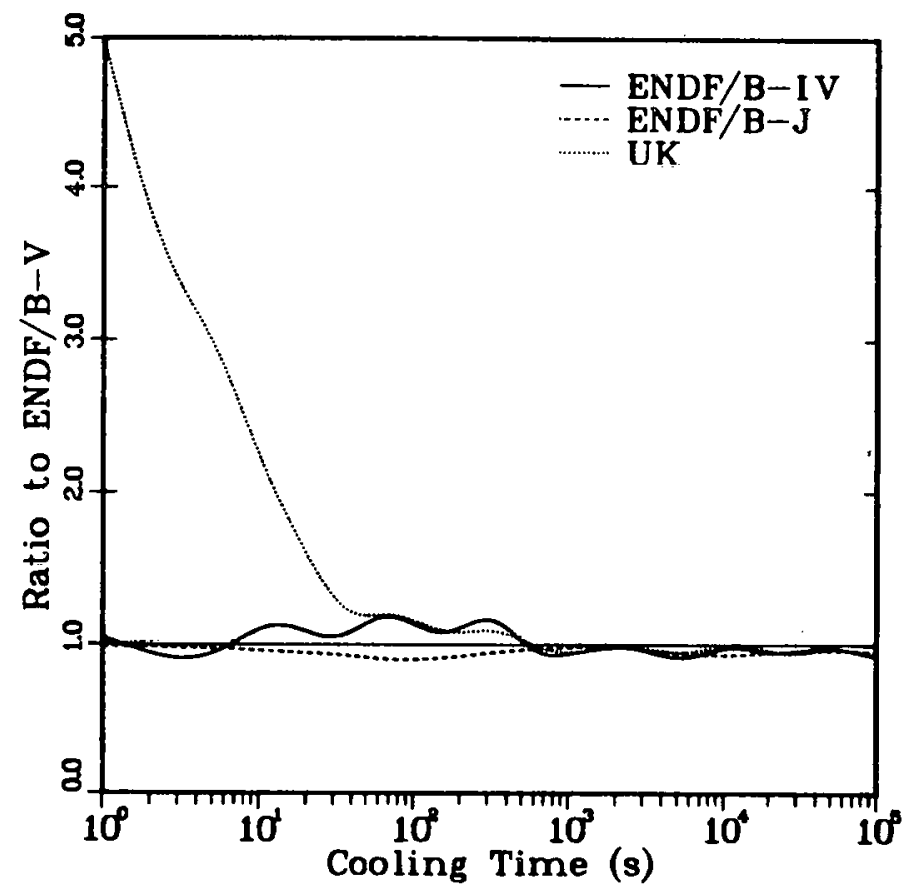

Fig. 49.

${ }^{235} \mathrm{U}$ thermal pulse, beta fit comparison, Group $2(0.2-0.4 \mathrm{MeV})$.

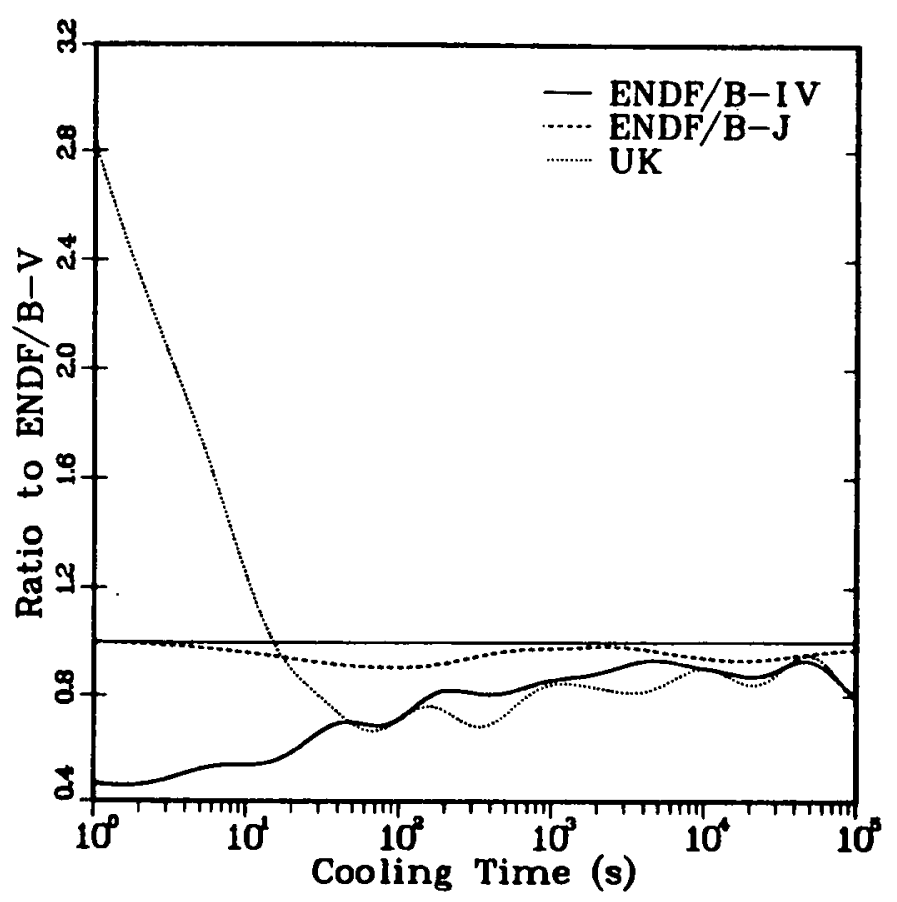

Fig. 48.

${ }^{235} \mathrm{U}$ thermal pulse, beta fit comparison, Group $1(0,0-0,2 \mathrm{MeV})$.

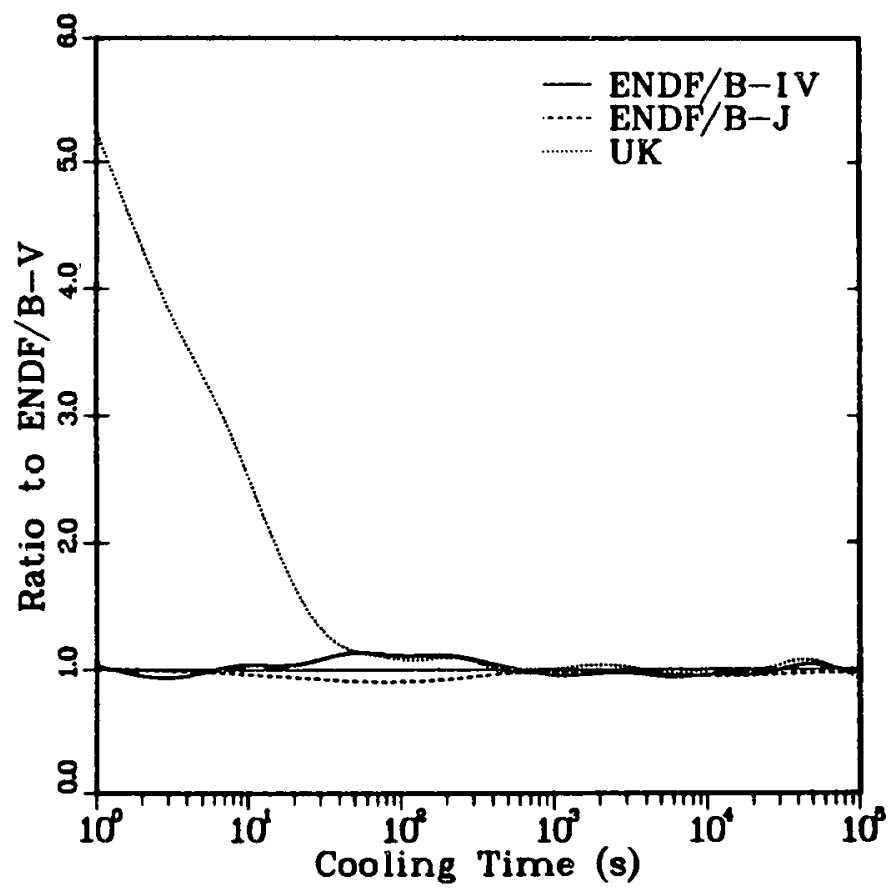

Fig. 50 .

${ }^{235} \mathrm{U}$ thermal pulse, beta fit comparison, Group $3(0.4-0.6 \mathrm{MeV})$. 


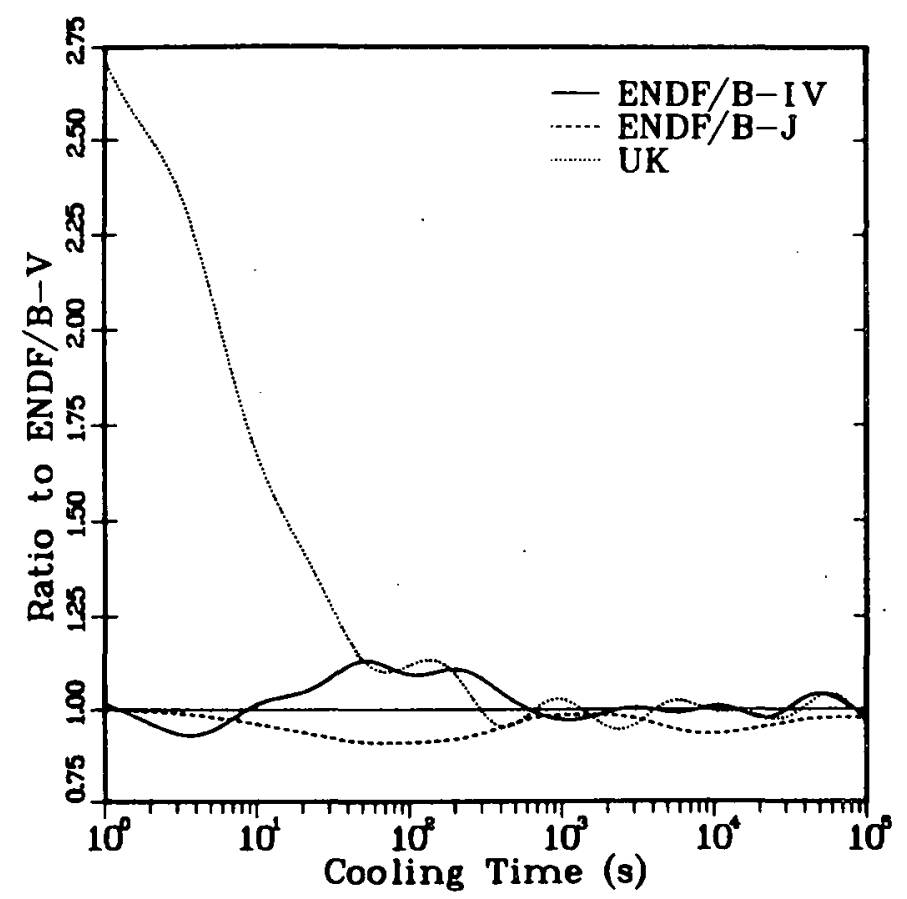

Fig. 51.

${ }^{235} \mathrm{U} \cdot$ thermal pulse, beta fit comparison, Group $4(0.6-0.8 \mathrm{MeV})$.

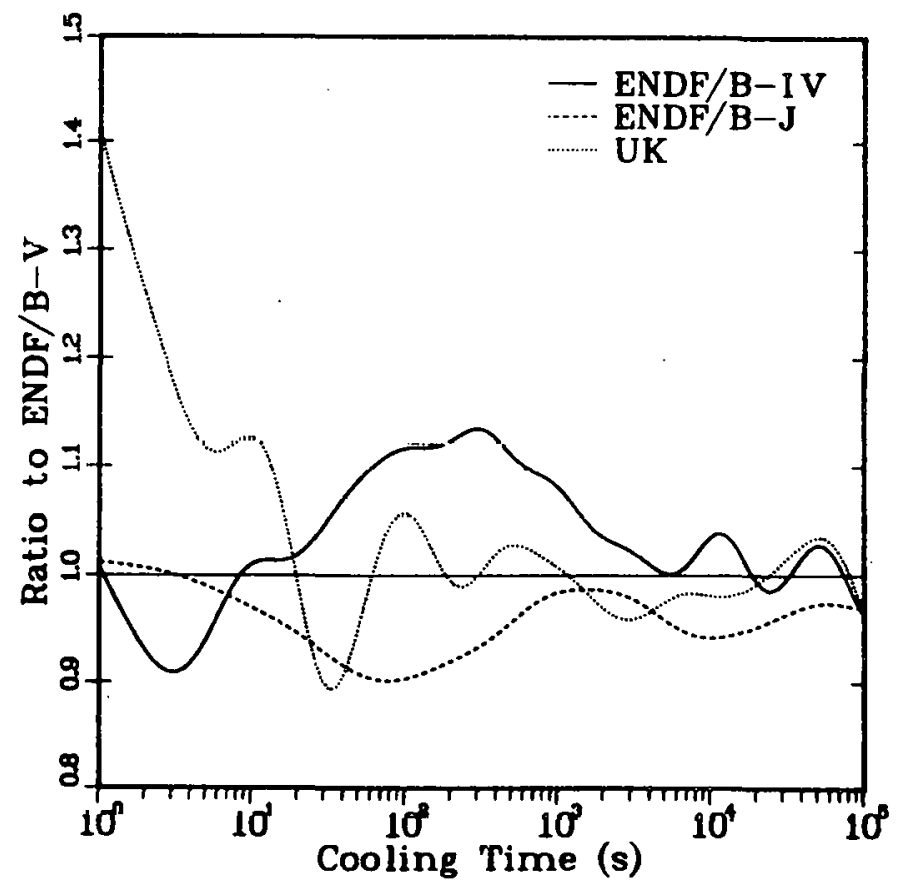

Fig. 53.

${ }^{235} \mathrm{U}$ thermal pulse, beta fit comparison, Group 6 (1.0 - 1.2 MeV).

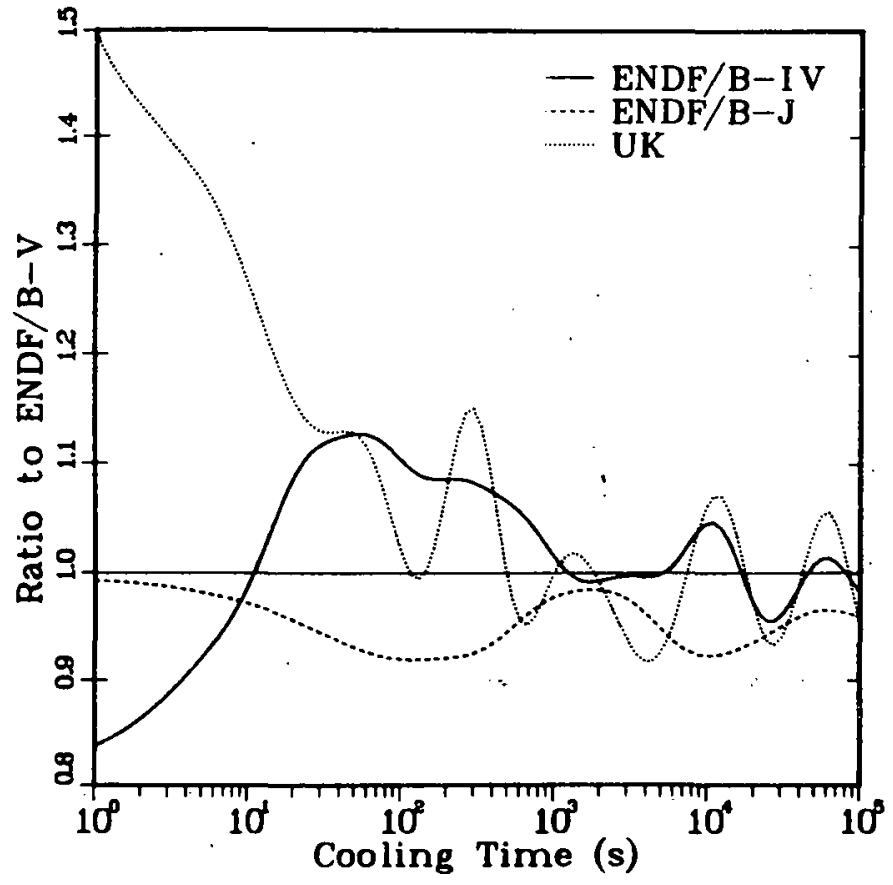

Fig. 52.

${ }^{235} \mathrm{U}$ thermal pulse, beta fit comparison, Group $5(0.8-1.0 \mathrm{MeV})$.

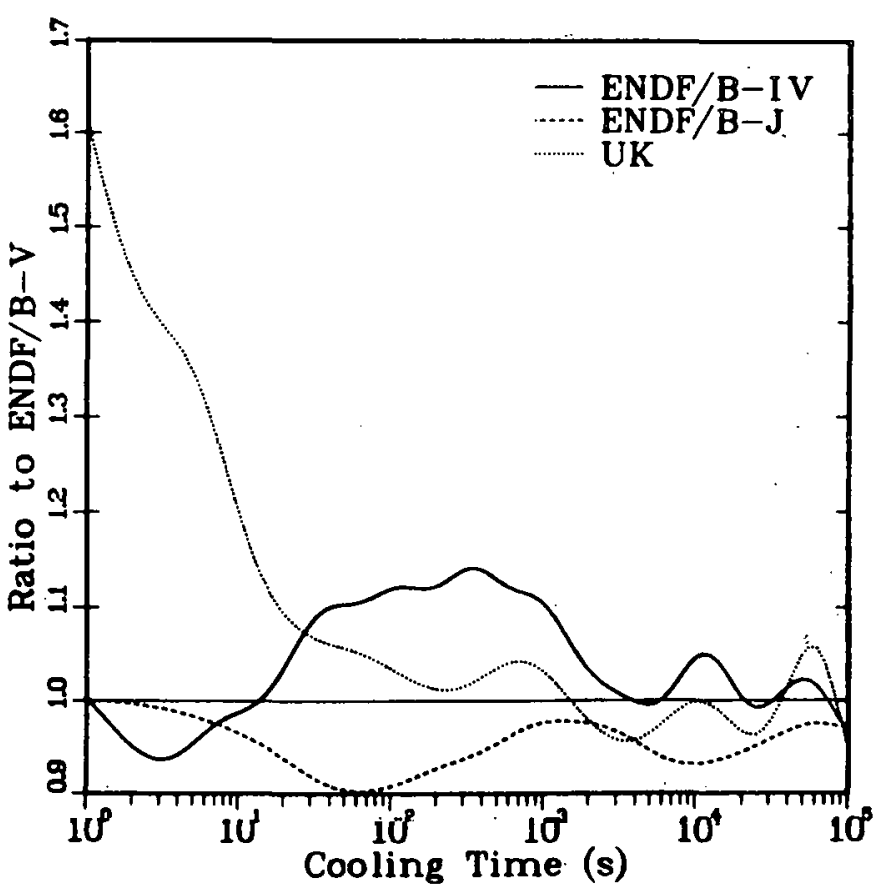

Fig. 54.

${ }^{235_{U}}$ thermal pulse, beta fit comparison, Group 7 (1.2 - $1.4 \mathrm{MeV})$. 


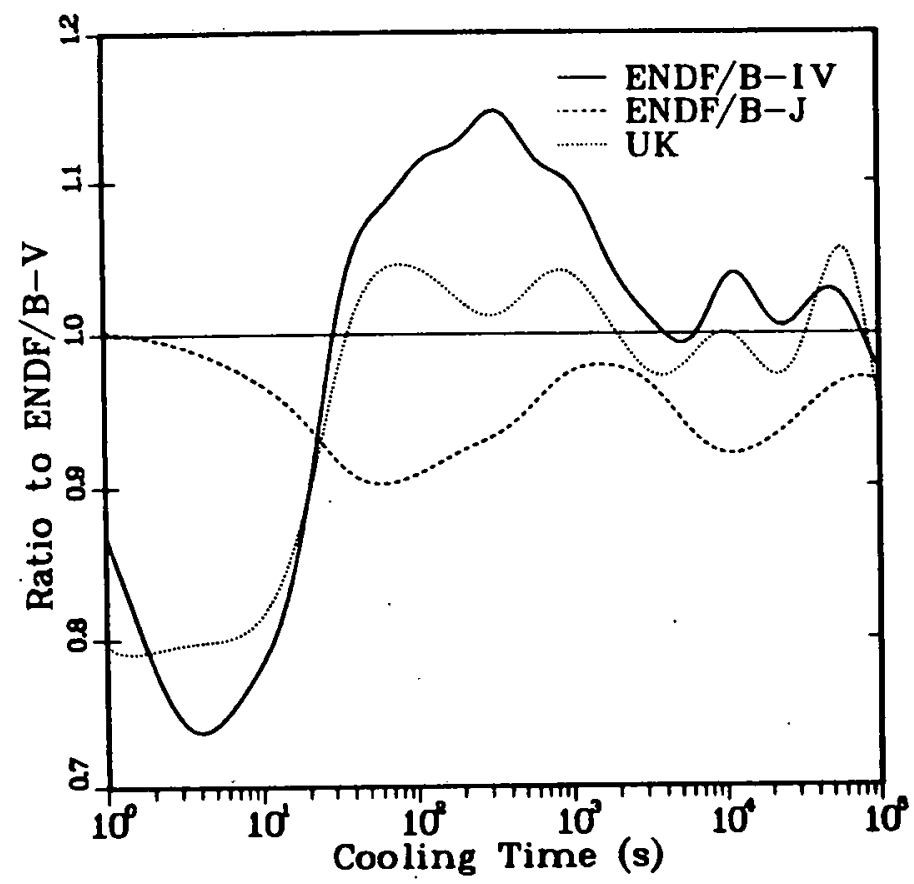

Fig. 55.

${ }^{235} \mathrm{U}$ thermal pulse, beta fit comparison, Group $8(1.4-1.6 \mathrm{MeV})$.

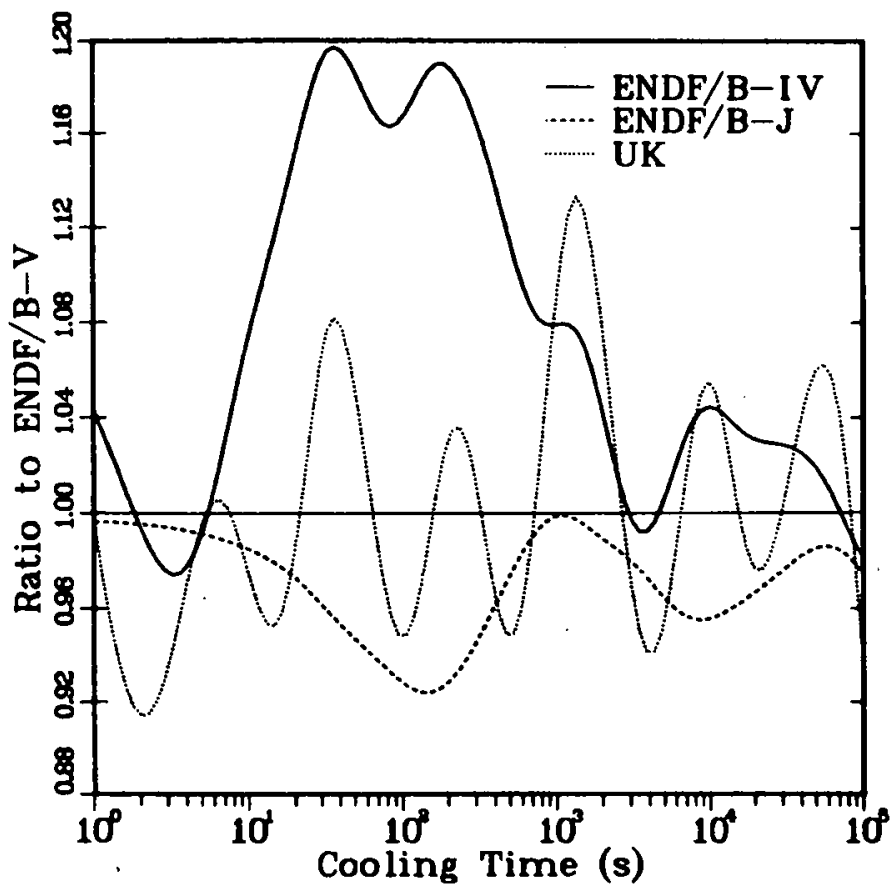

Fig. 57.

${ }^{235} \mathrm{U}$ thermal pulse beta fit comparison, Group $10(1.8-2.0 \mathrm{MeV})$.

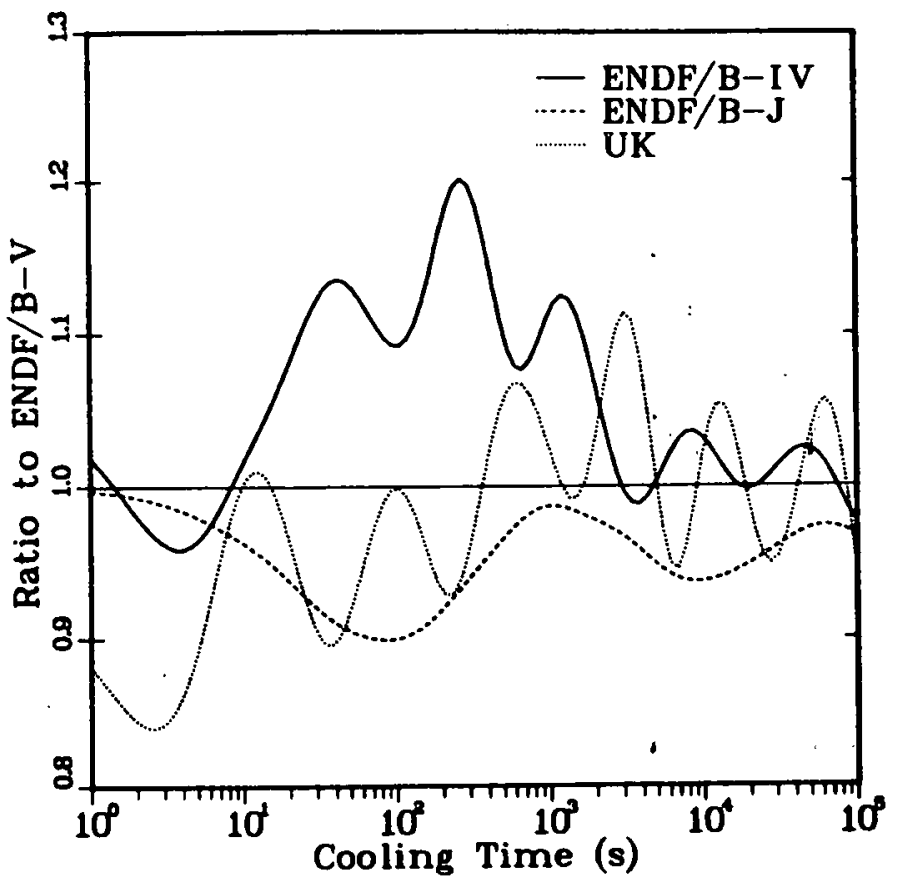

Fig. 56.

${ }^{235} \mathrm{U}$ thermal pulse, beta fit comparison, Group $9(1.6-1.8 \mathrm{MeV})$.

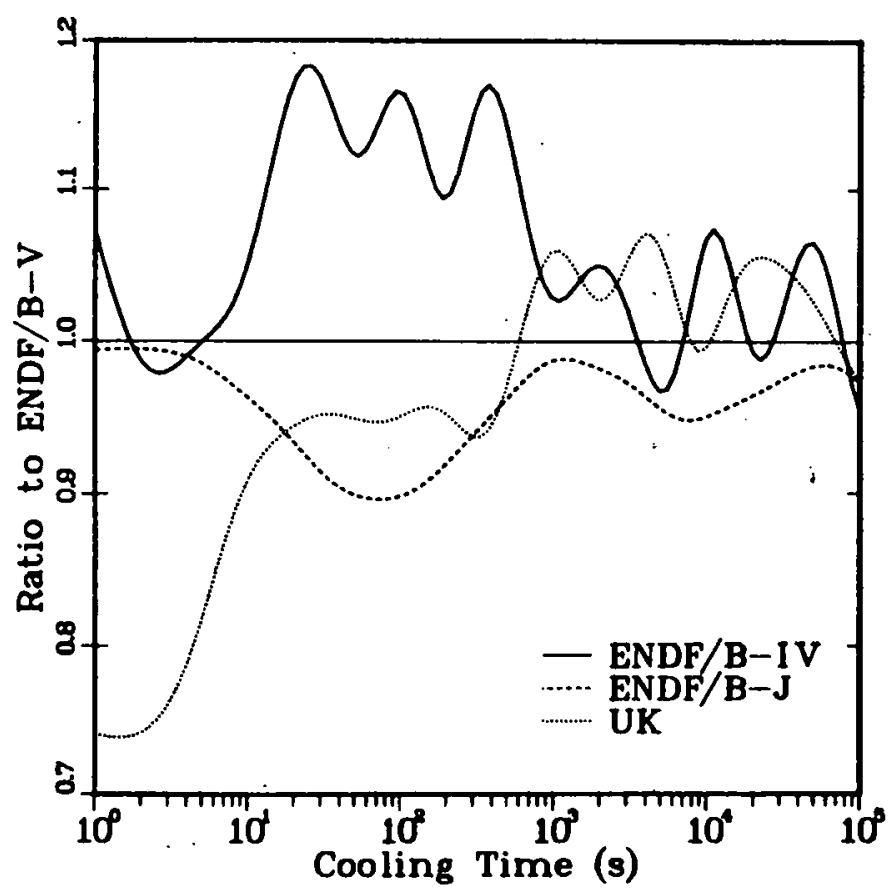

Fig. 58 .

${ }^{235} \mathrm{U}$ thermal pulse, beta fit comparison, Group $11(2.0-2.2 \mathrm{MeV})$. 


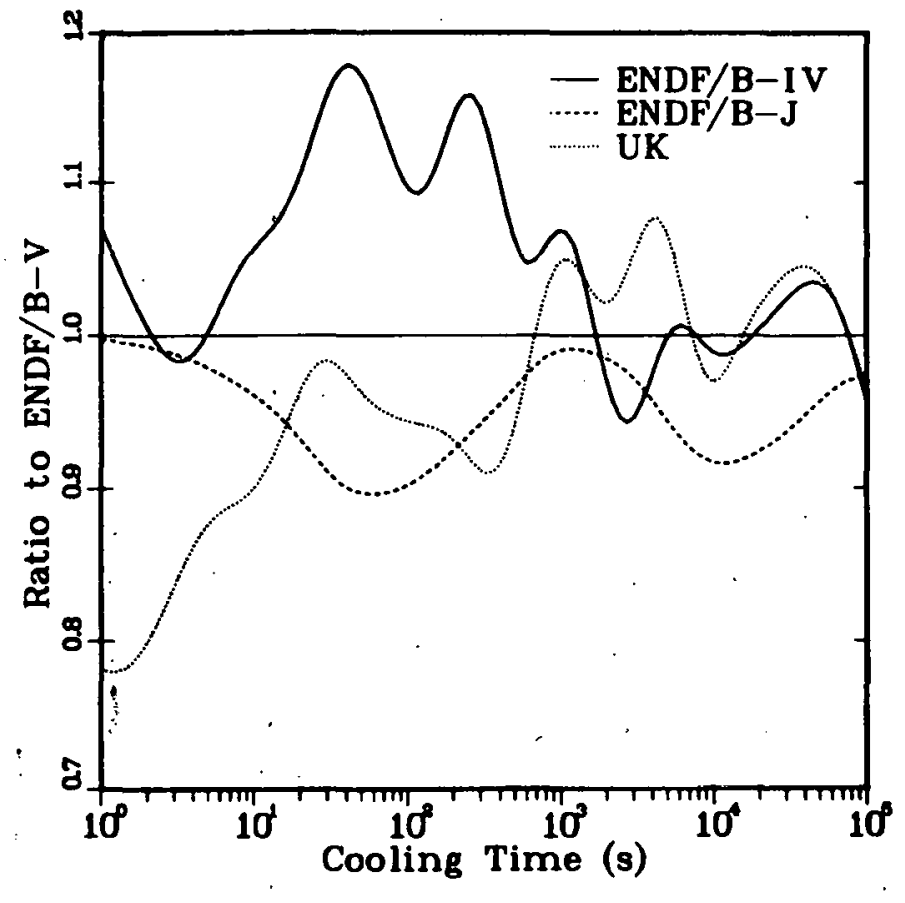

Fig. 59

${ }^{235} \mathrm{U}$ thermal pulse, beta fit comparison, Group $12 \cdot(2.2-2.4 \mathrm{MeV})$.

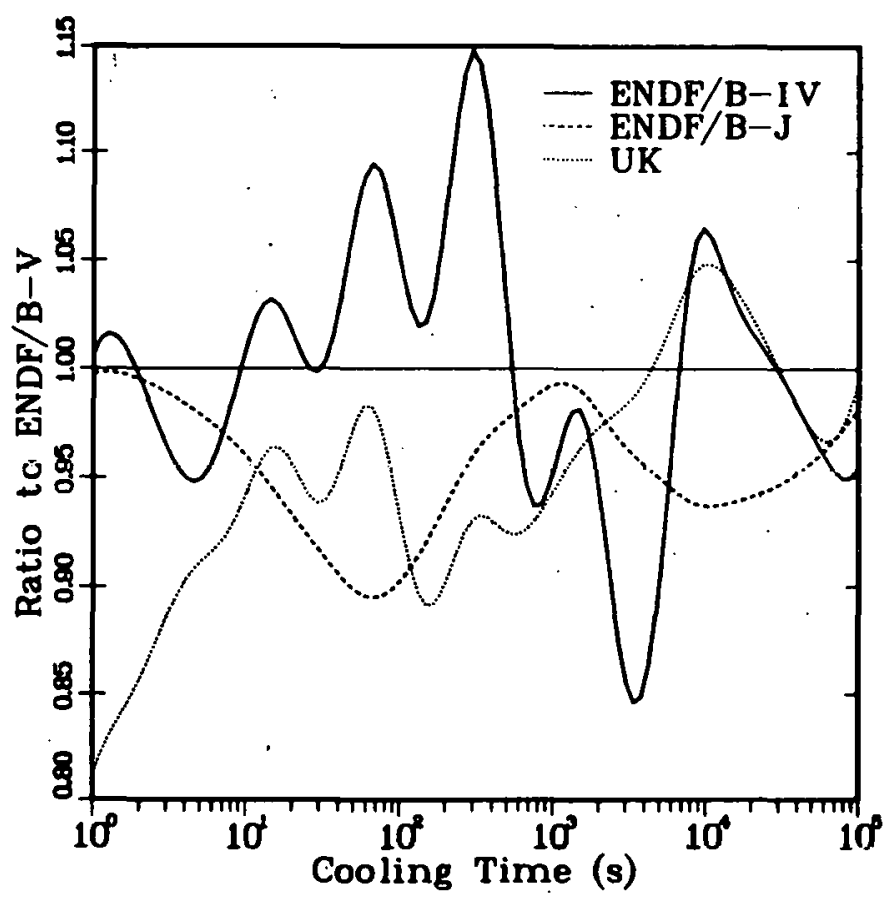

Fig. 61.

${ }^{235} \mathrm{U}$ thermal pulse, beta fit comparison, Group $14(2.0-3.0 \mathrm{MeV})$.

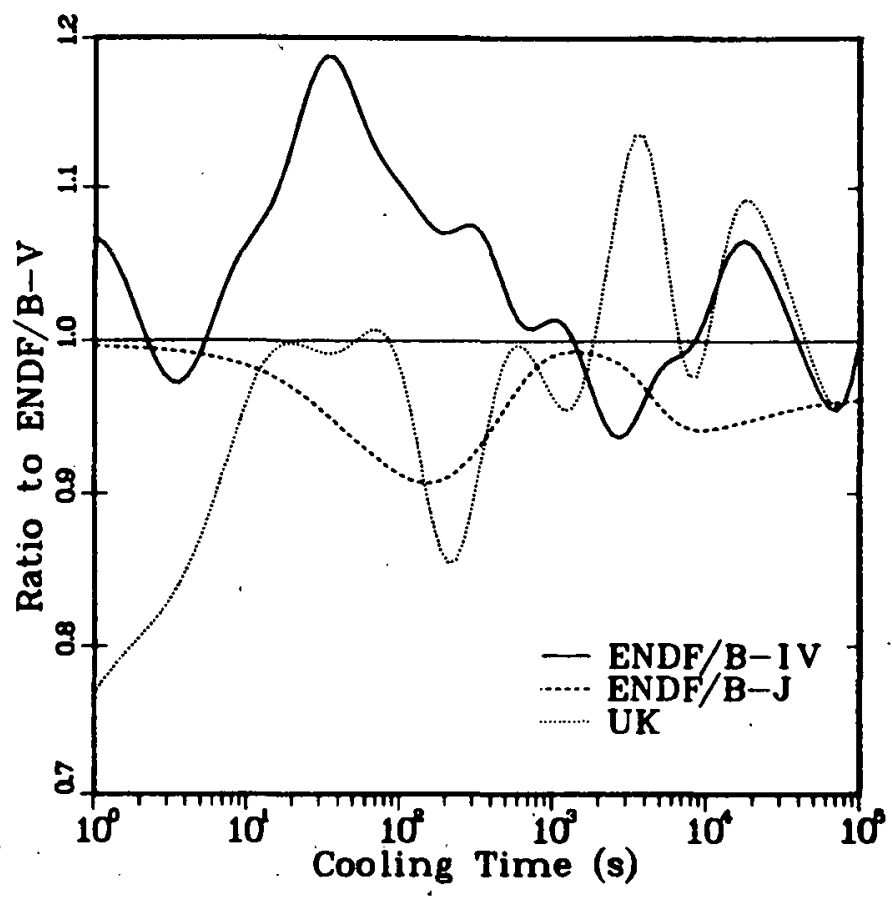

Fi.g. 60 .

${ }^{235} \mathrm{U}$ thermal pulse, beta fit comparison, Group $13(2.4-2.6 \mathrm{MeV})$. .

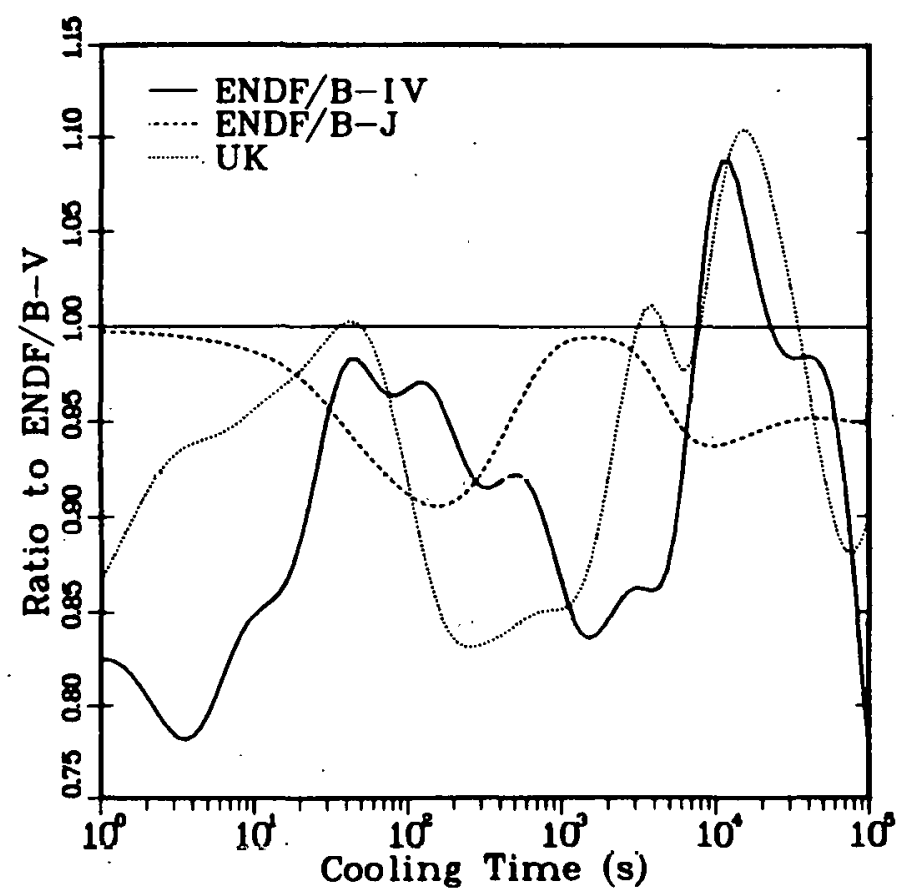

Fig. 62.

${ }^{235} \mathrm{U}$ thermal pulse, beta fit comparison, Group $15(3.0-4.0 \mathrm{MeV})$. 


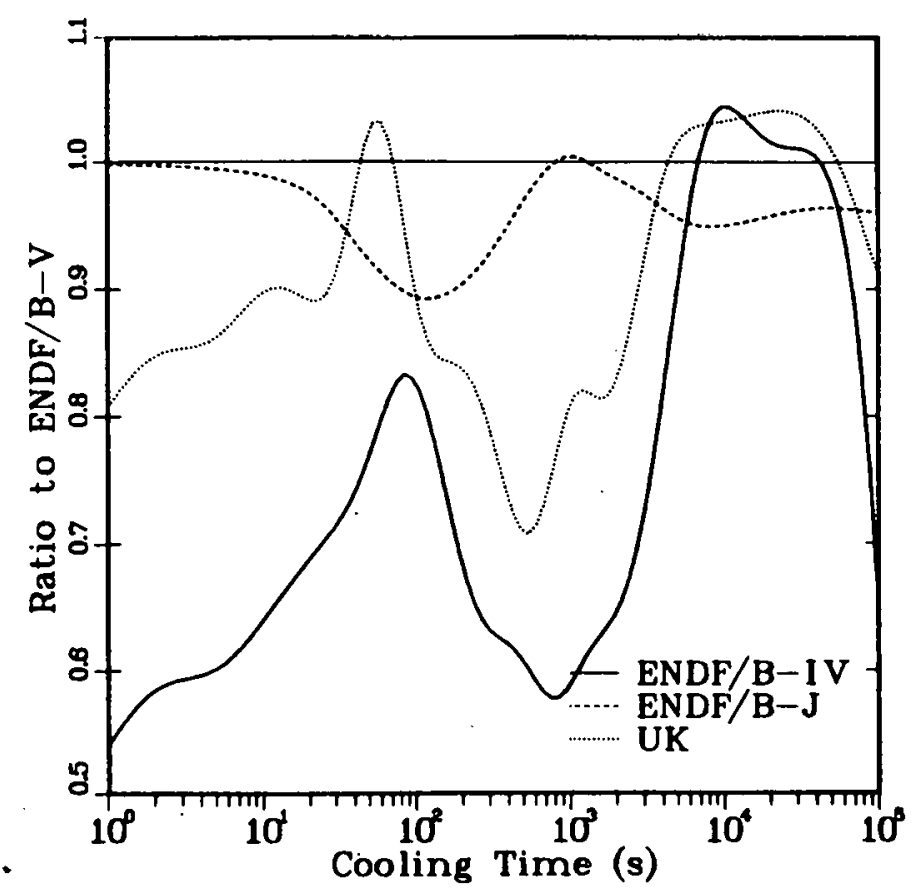

Fig. 63.

${ }^{235} \mathrm{U}$ thermal pulse, beta fit comparison, Group $16(4.0-5.0 \mathrm{MeV})$.

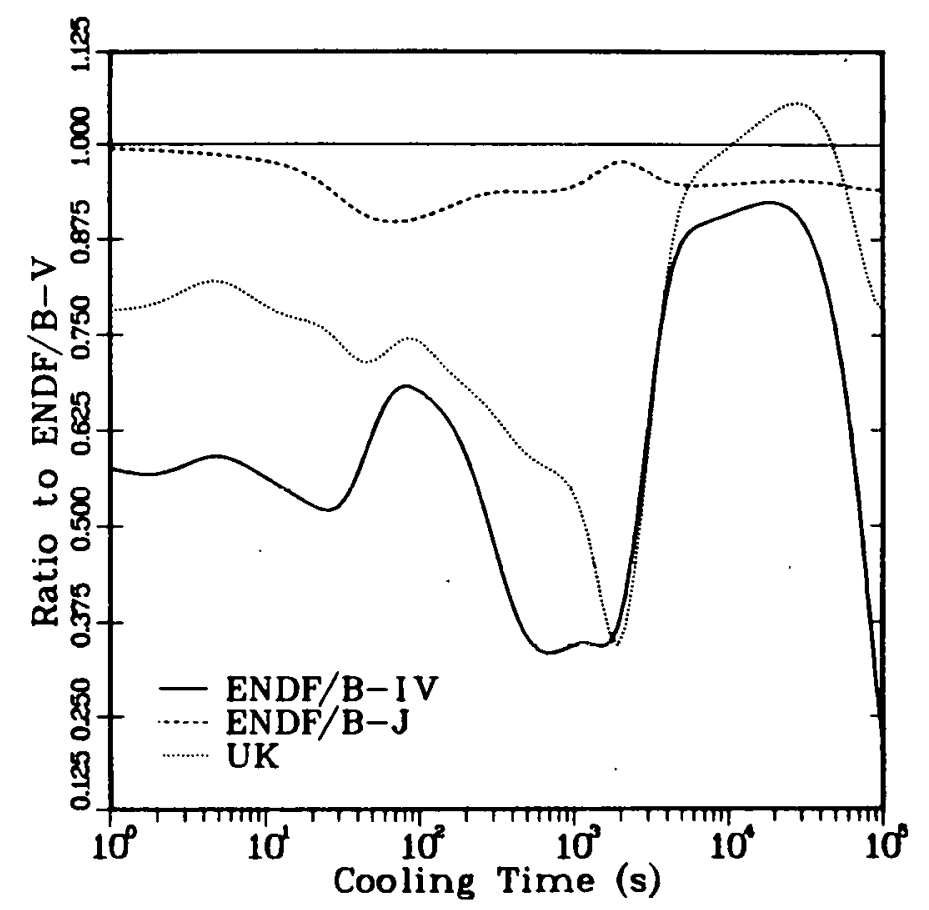

Fig. 64 .

${ }^{235} \mathrm{U}$ thermal pulse, beta fit comparison, Group $17(5.0-6.0 \mathrm{MeV})$. 
for the pulse can also be determined by folding the pulse fits back into the expression above for a certain cooling and finite irradiation time, noting the percentage difference of the result from the experimental point, and applying this percentage difference to the pulse case. This is the manner in which Figs. 65 through 83 were generated, showing the "equivalent" points plotted along with the pulse fits from the data files. Note that neither the "experimental pulse" fits nor the reconstructed "experimental points" are unique. Consequently, some "confidence limits" must be placed on each fit. In general, these limits contain all except one or two of the "experimental points" for each energy group. These "confidence limits" are given in Appendix B.

In Figs. 65 through 83, the "equivalent pulse" experimental data, identified by experiment, for thermal $235_{\mathrm{U}}$ fission-product gamma-ray decay-energies are plotted along with the pulse fits from the four fission-product data libraaries for the sum over all groups (Fig. 65) as well as each of the 18. individual gamma-ray energy groups. In Figs. 84 - 102, the same plots are given for thermal $235 \mathrm{U}$ pulse beta-ray decay-energies (sum and 17 groups); Figs. 103 - 20 are for ${ }^{239} \mathrm{Pu}$ thermal pulse gamma rays; and Figs. $121-138$ are for ${ }^{239} \mathrm{Pu}$ thermal pulse beta rays. Note that the beta-ray comparisons are limited to cooling times of $10^{4} \mathrm{~s}$ (the ORNL experiments) and that UK data are not included in the figures for ${ }^{239} \mathrm{Pu}$, as these comparisons have thus far been limited to ${ }^{235} \mathrm{U}$. . Also note from all the figures that the experimental data are remarkably consistent. Except for cooling times greater than $1000 \mathrm{~s}$ in the two highest energy groups, where the experimental data have large experimental errors, almost a11 the data points are within the confidence limits set in Appendix $B$. The parameters for the fits to the "equivalent pulse" experimental data are also given in Appendix B. Users of these fits should keep in mind that the fits do not apply for cooling times less than 1 or greater than $2 \times 10^{5} \mathrm{~s}$.

\section{CONCLUSIONS FROM SPECTRAL COMPARISONS}

Conclusions drawn from spectral comparisons are essentially the same as those drawn from the direct CINDER-10 calculations. Figures 23, 24, 26, and 27 can be compared to Figs. 65, 84, 103, and 121. Note, however, that the Los Alamos experiments have been included in gamma-ray comparisons, Los Alamos "experimental beta-ray points". were obtained first by fitting the Los Alamos ca1orimetric experiment, in which total $\left(\beta^{-}+\gamma\right)$ decay heat from fission products was measured; second, by using these "total" fits to calculate values for cooling times at which the gamma-ray energies were measured; and finally subtracting 


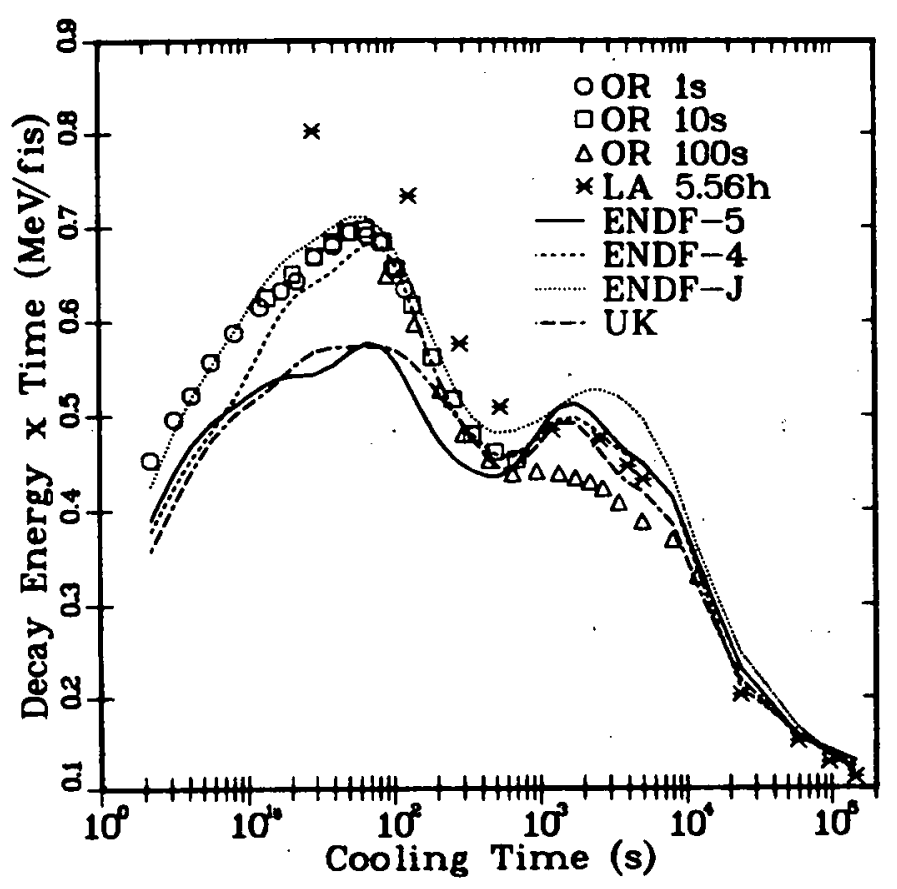

Fig. 65.

Comparison of ${ }^{235} \mathrm{U}$ thermal gamma-fits with experiment, total over all groups.

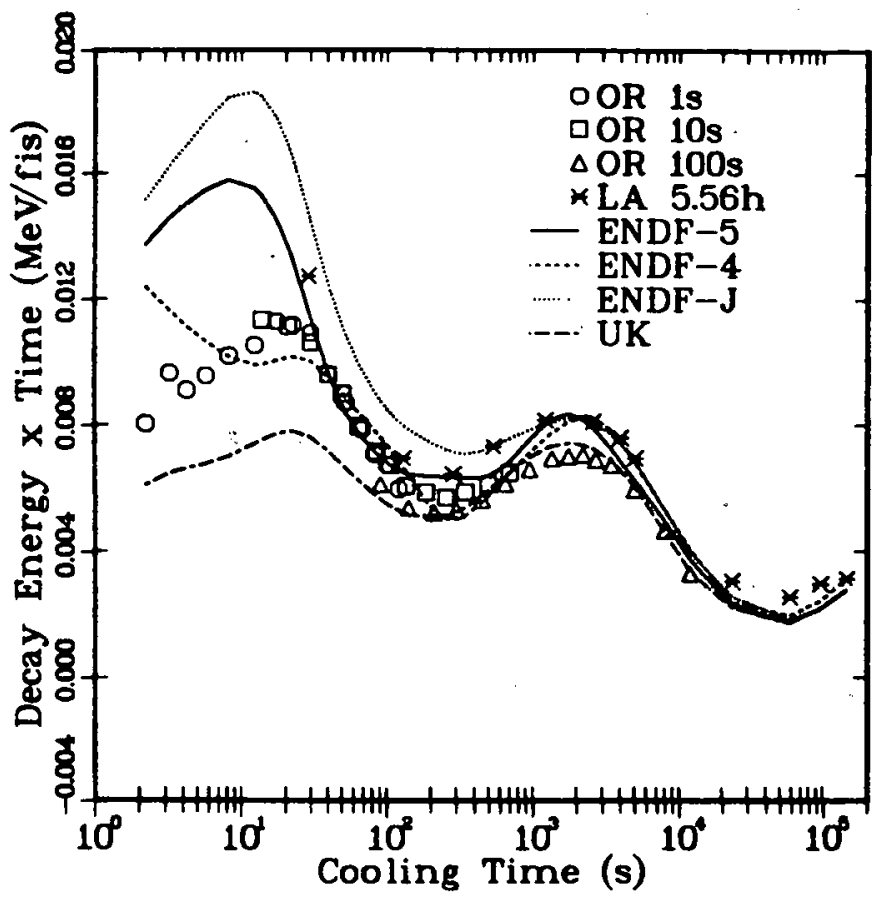

Fig. 67.

Comparison of ${ }^{235} \mathrm{U}$ thermal gamma-fits with experiment, Group 2.

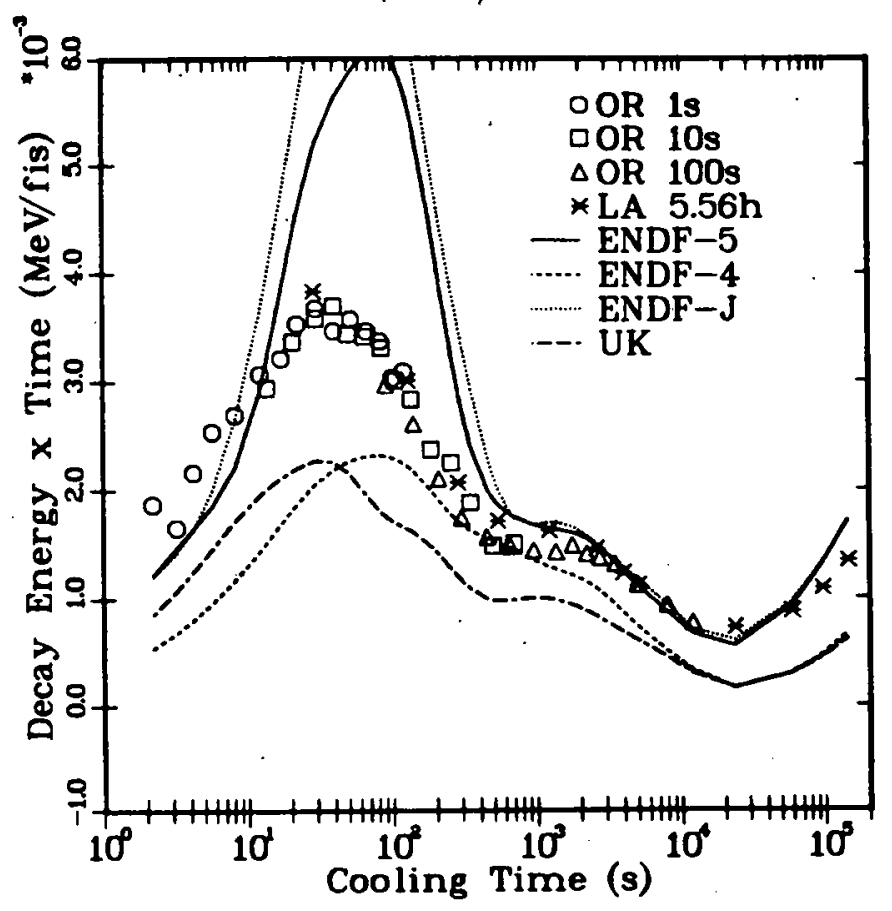

Fig. 66.

Comparison of ${ }^{235} \mathrm{U}$ thermal gamma-fits with experiment, Group 1.

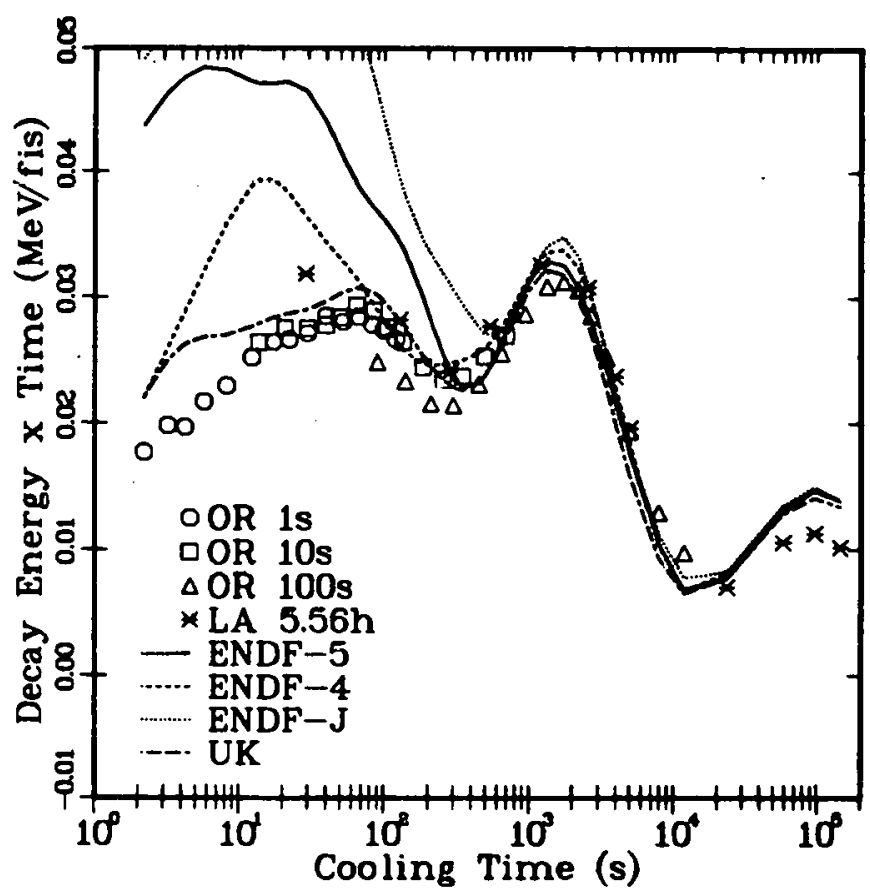

Fig. 68.

Comparison of ${ }^{235} \mathrm{U}$ thermal gamma-fits with experiment, Group 3. 


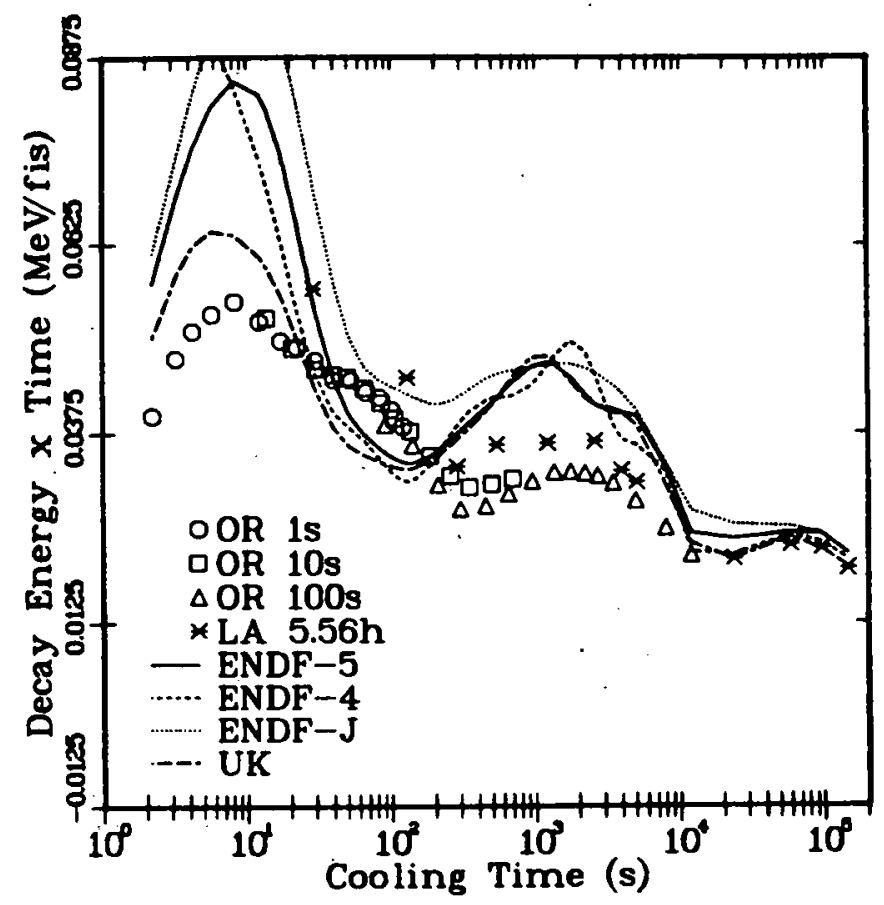

Fig. 69.

Comparison of $235 \mathrm{U}$ thermal gamma-fits with experiment, Group 4.

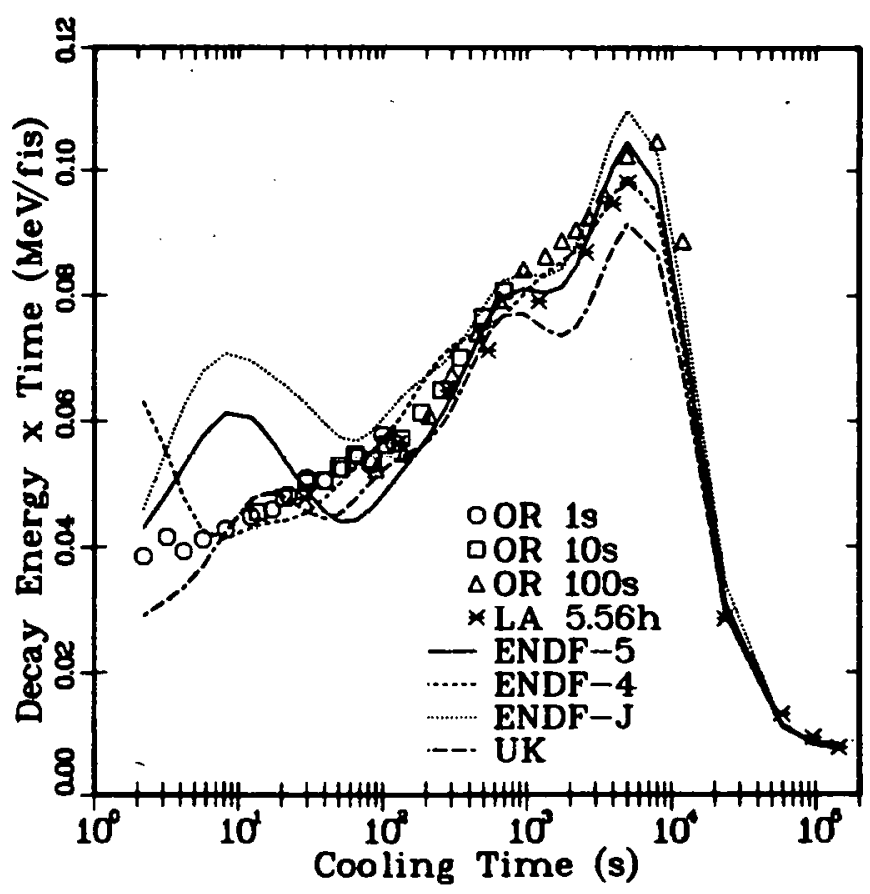

Fig. 71.

Comparison of ${ }^{235} \mathrm{U}$ thermal gamma-fits with experiment, Group 6 .

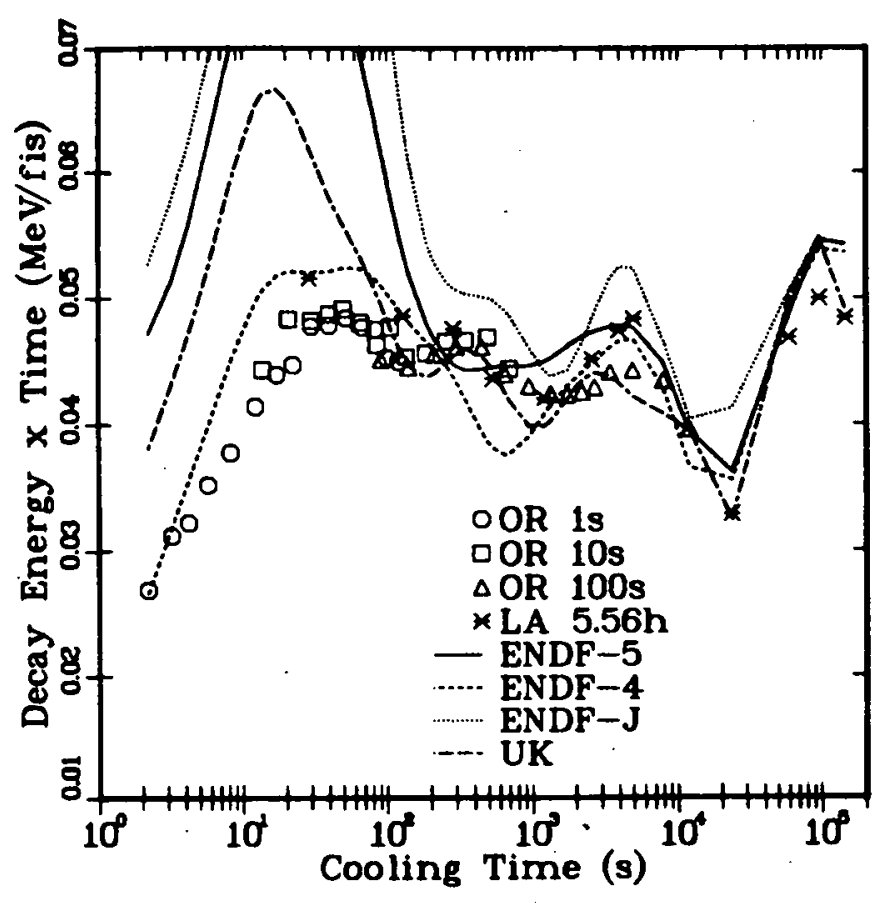

Fig. 70.

Comparison of ${ }^{235} \mathrm{U}$ thermal gamma-fits with experiment, Group 5.

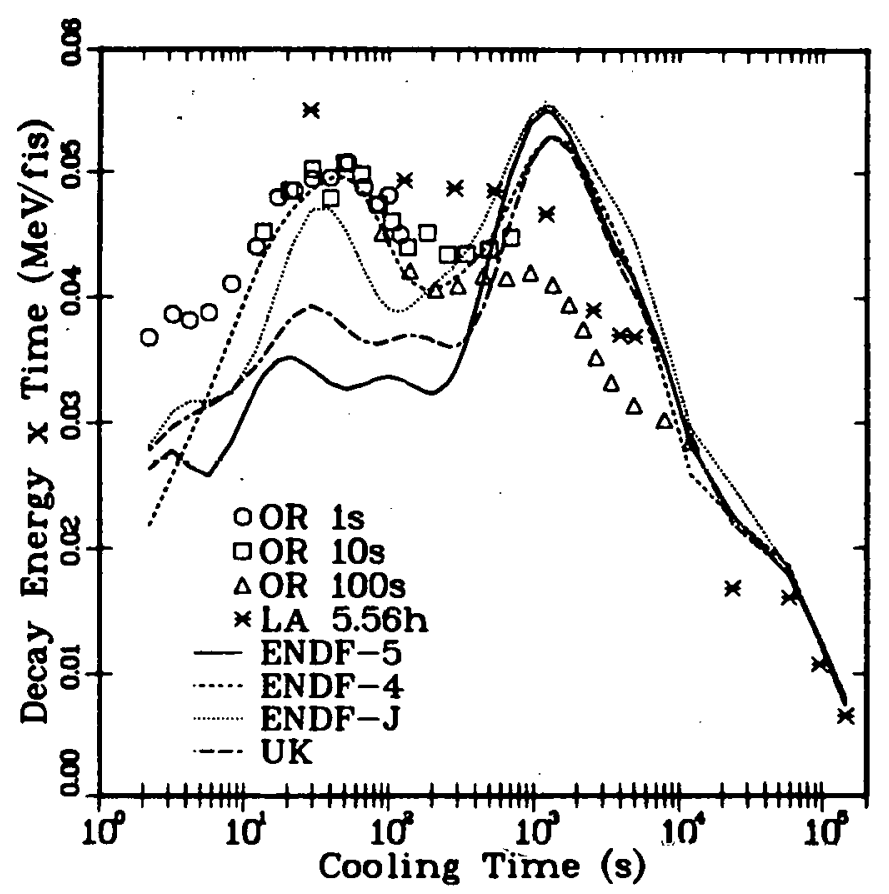

Fig. 72 .

Comparison of ${ }^{235} \mathrm{U}$ thermal gamma-fits with experiment, Group 7. 


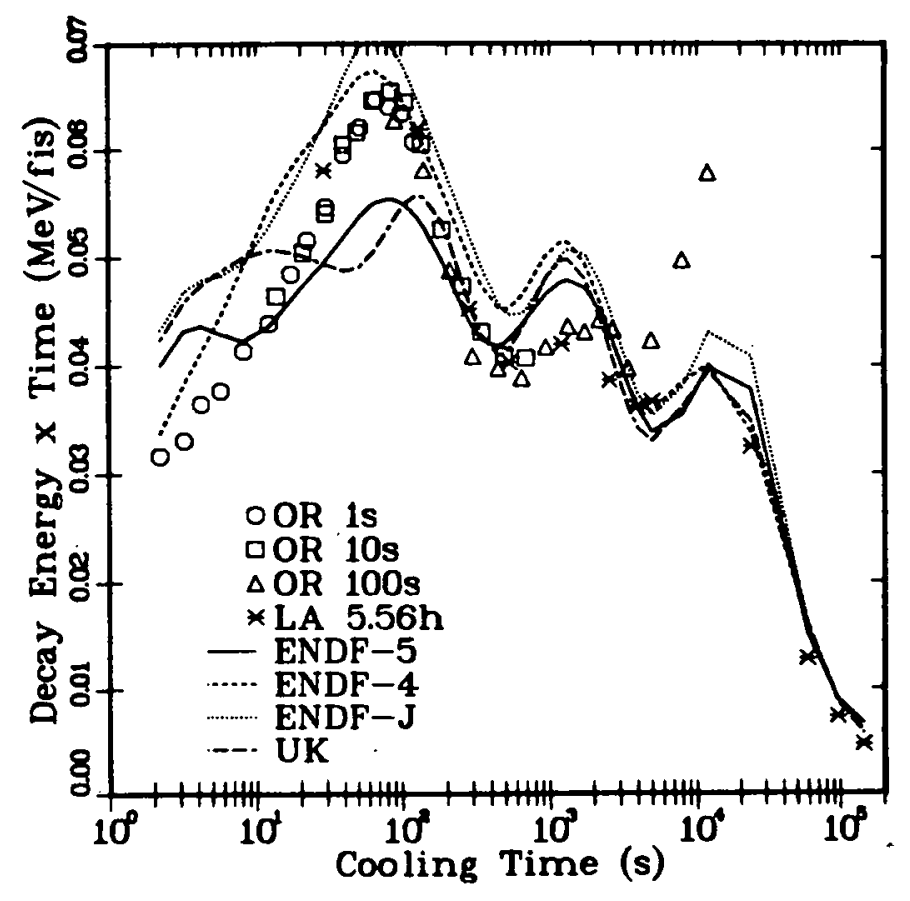

Fig. 73.

Comparison of ${ }^{235} \mathrm{U}$ thermal gamma-fits with experiment, Group 8.

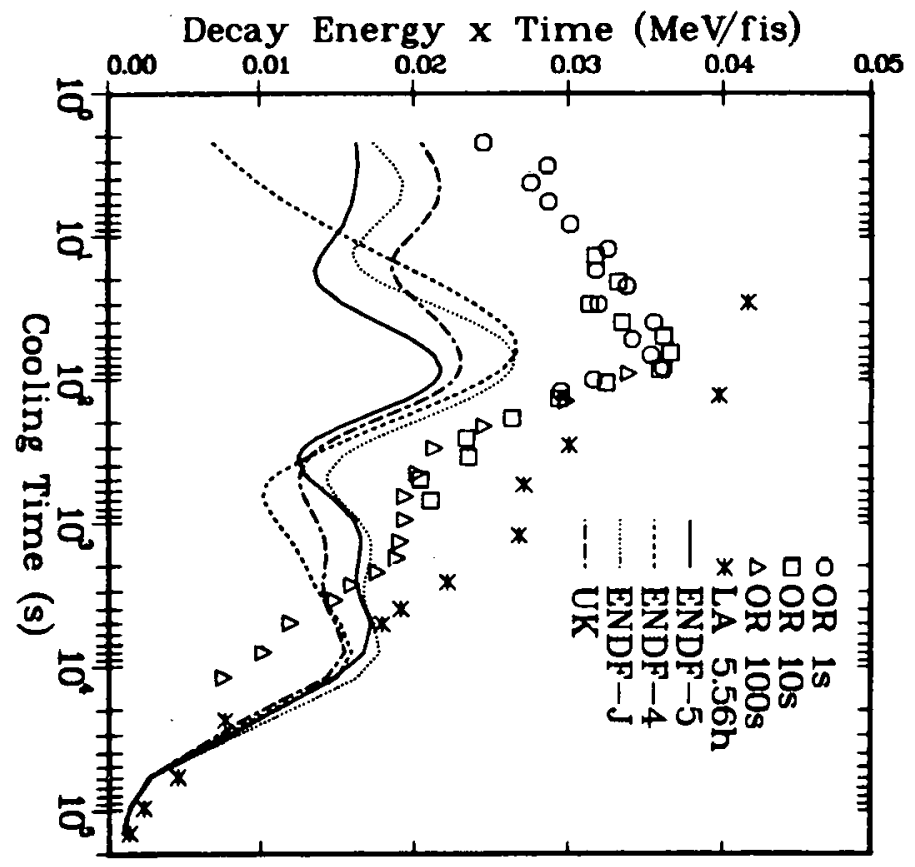

Fig. 75.

Comparison of ${ }^{235} \mathrm{U}$ thermal gamma-fits with experiment, Group 10.

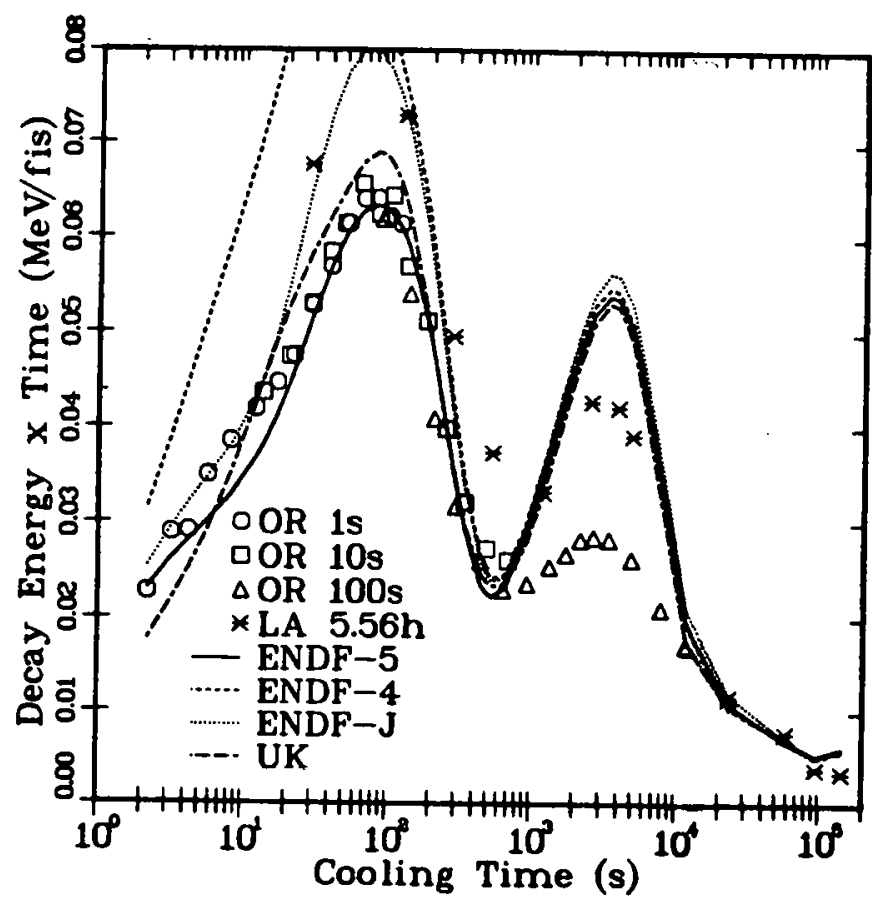

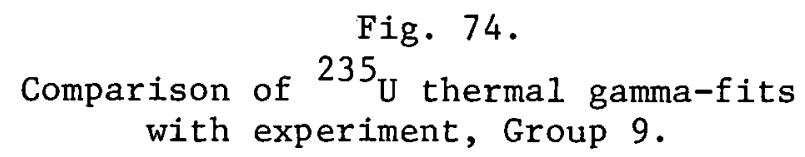

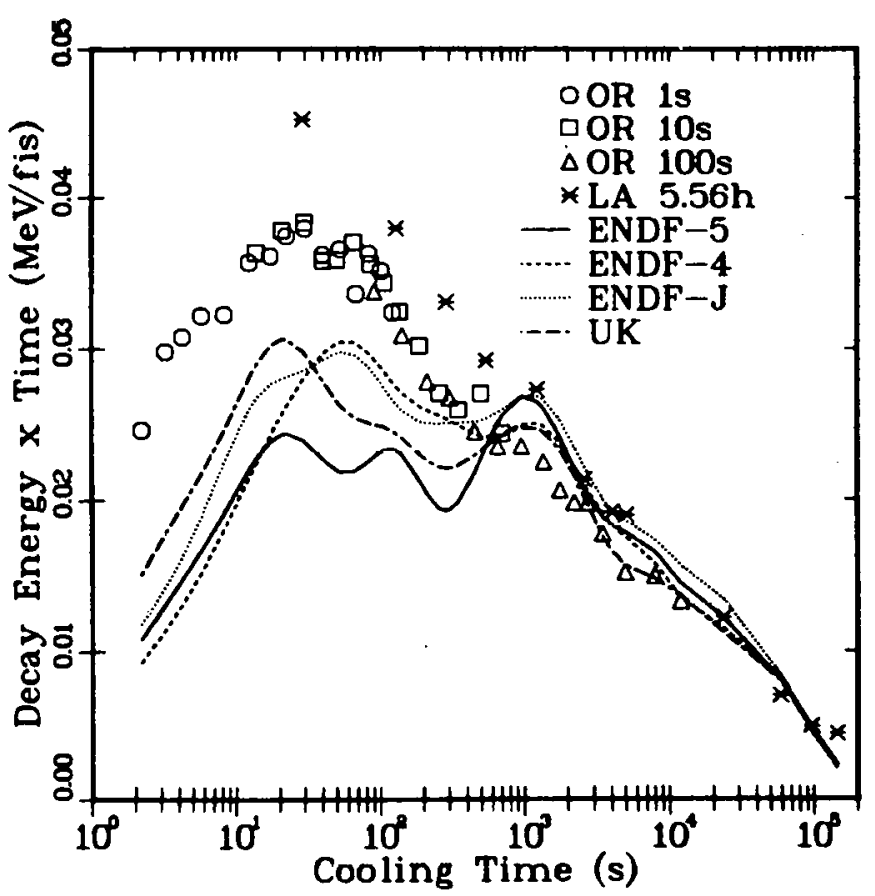

Fig. 76.

Comparison of ${ }^{235} U$ thermal gamma-fits with experiment, Group 11. 


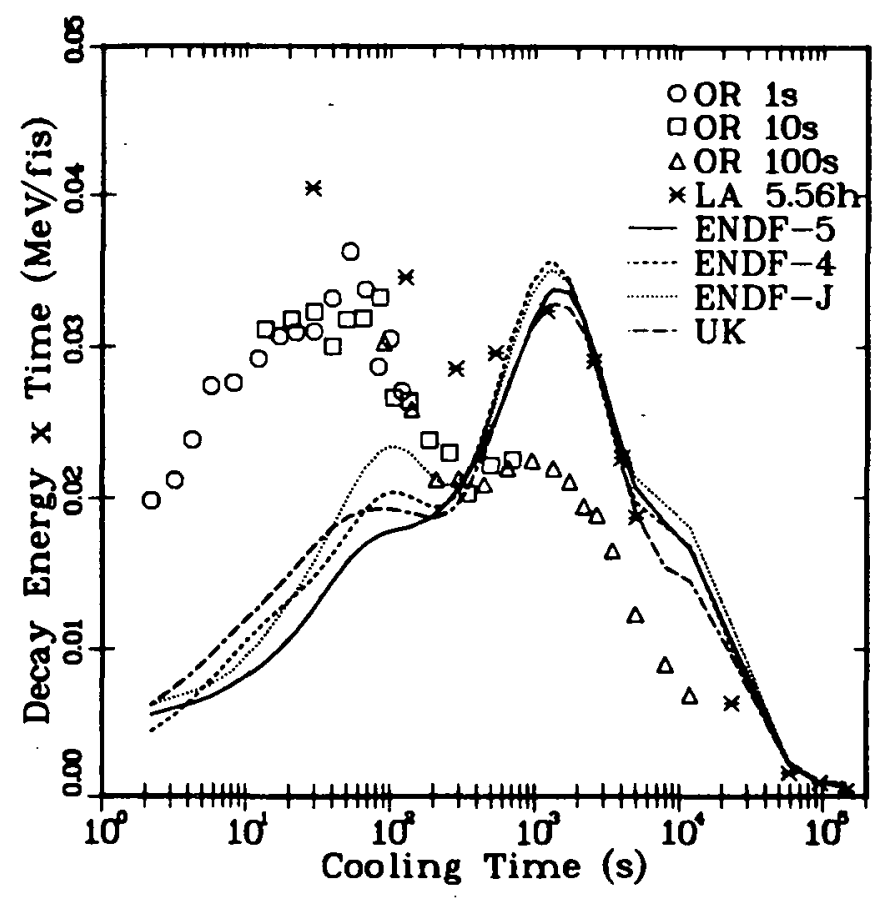

Fig. 77.

Comparison of ${ }^{235} \mathrm{U}$ thermal gamma-fits with experiment, Group 12.

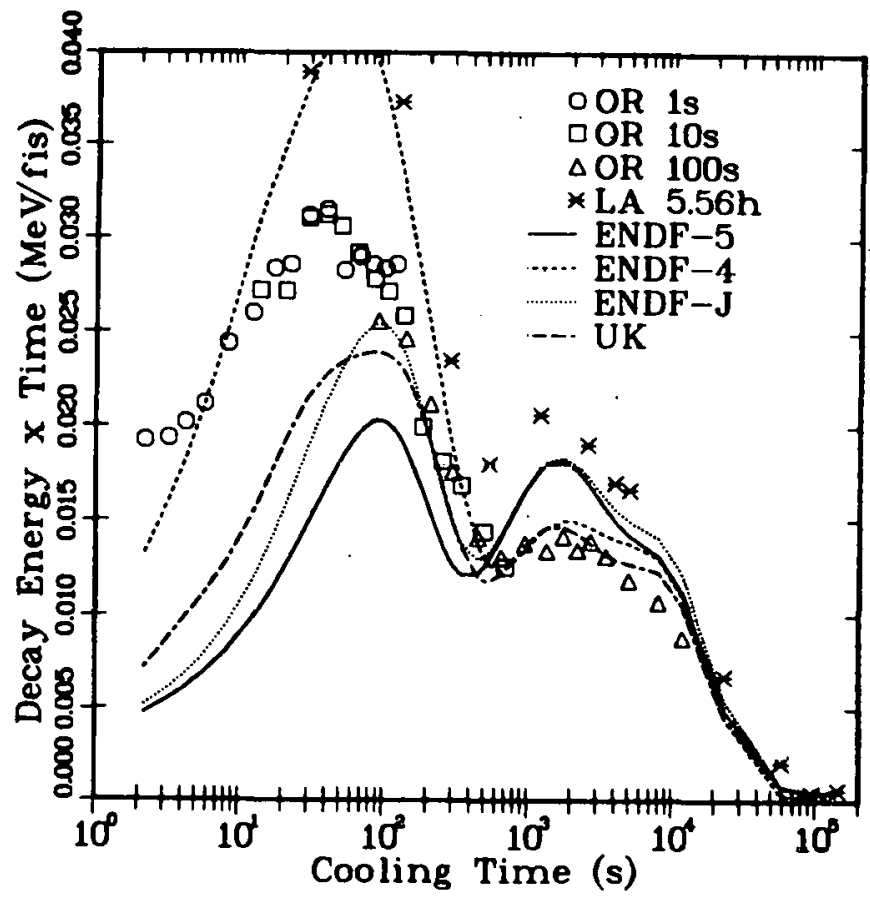

Fig. 79.

Comparison of ${ }^{235} \mathrm{U}$ thermal gamma-fits with experiment, Group 14.

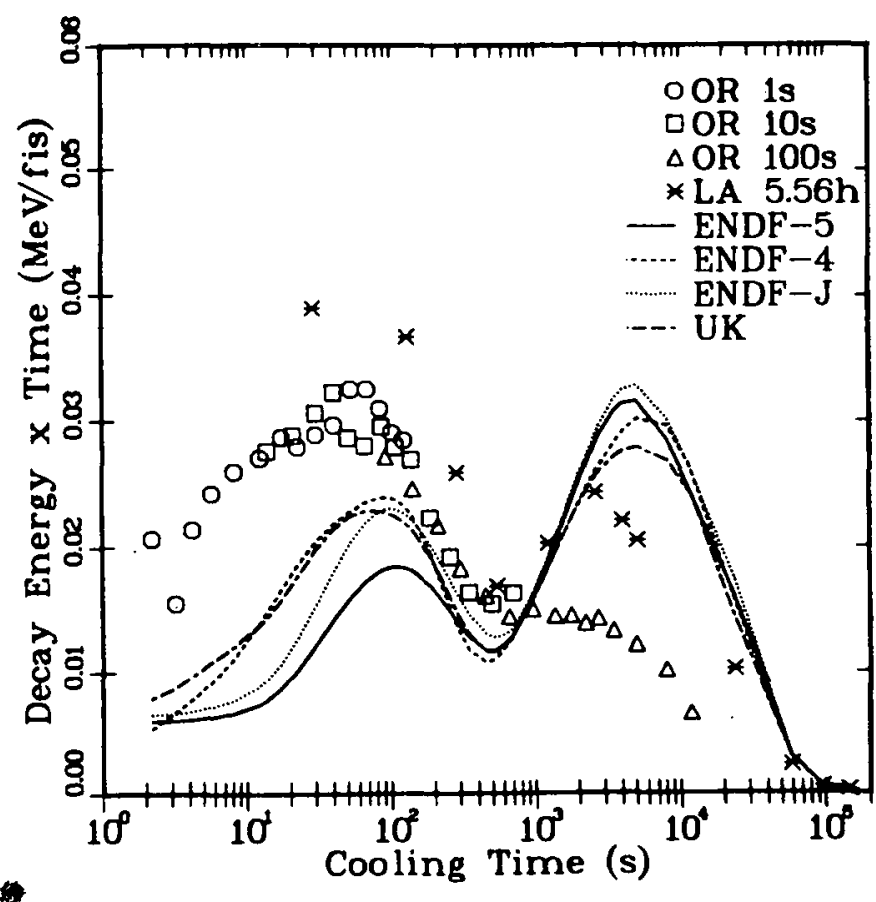

Comparison of $235_{\mathrm{U}}^{\mathrm{Fig} .} 78$. with experiment, Group 13.

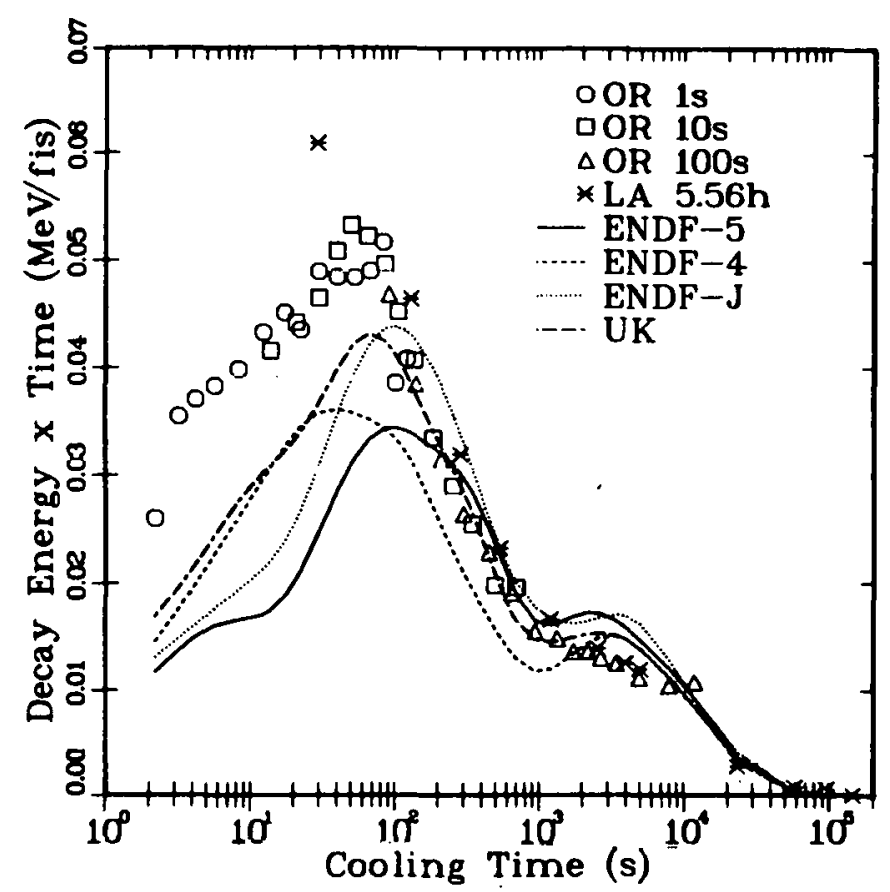

Fig. 80.

Comparison of ${ }^{235_{U}}$ thermal gamma-fits with experiment, Group 15 : 


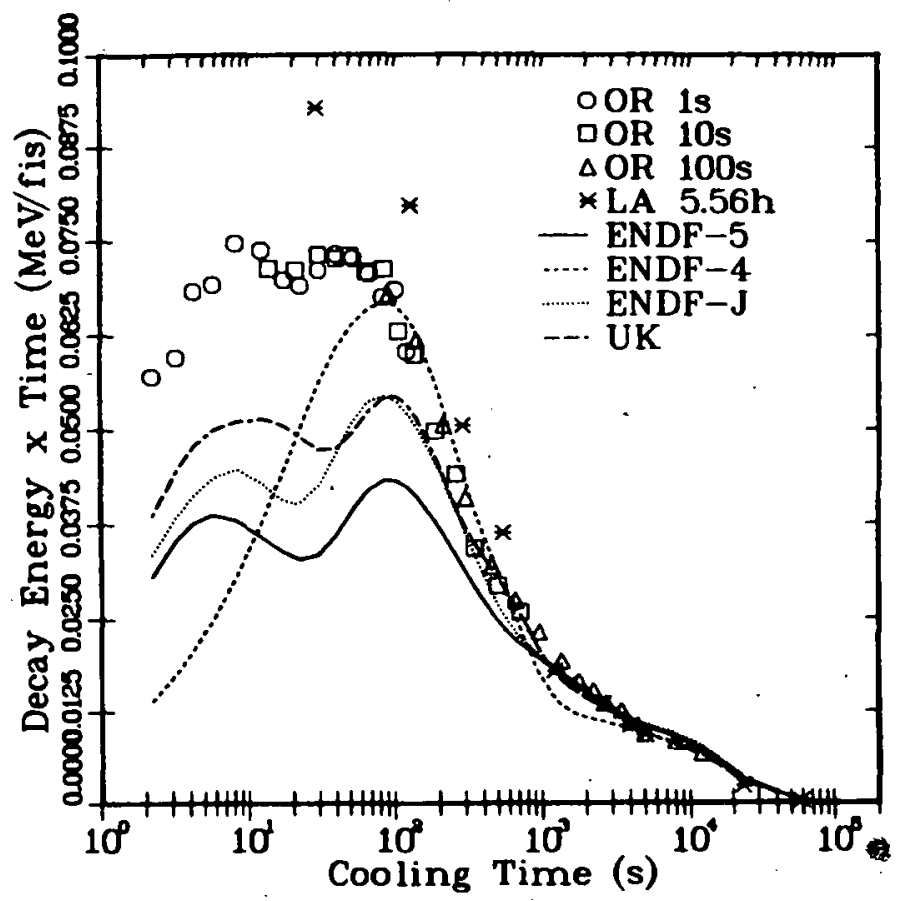

Fig. 81 .

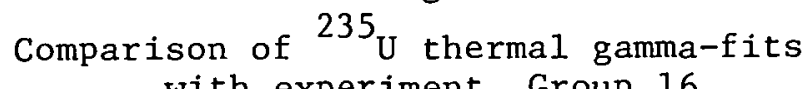
with experiment, Group 16.

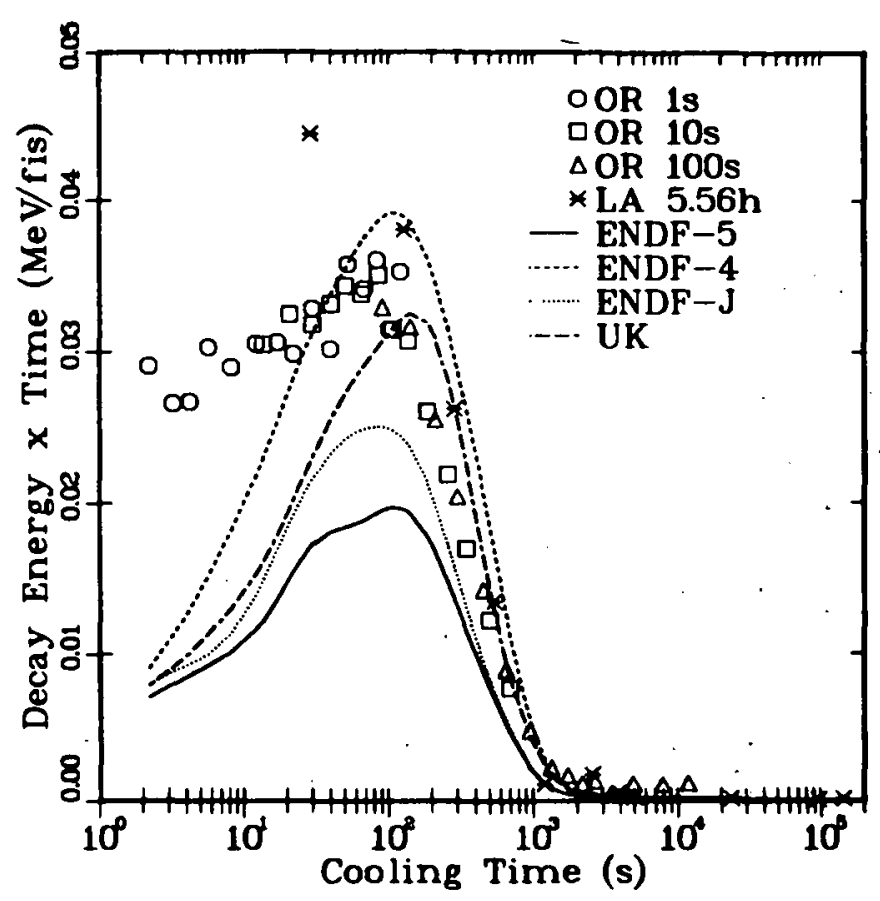

Fig. 82.

Comparison of ${ }^{235} \mathrm{U}$ thermal gamma-fits with experiment, Group 17.

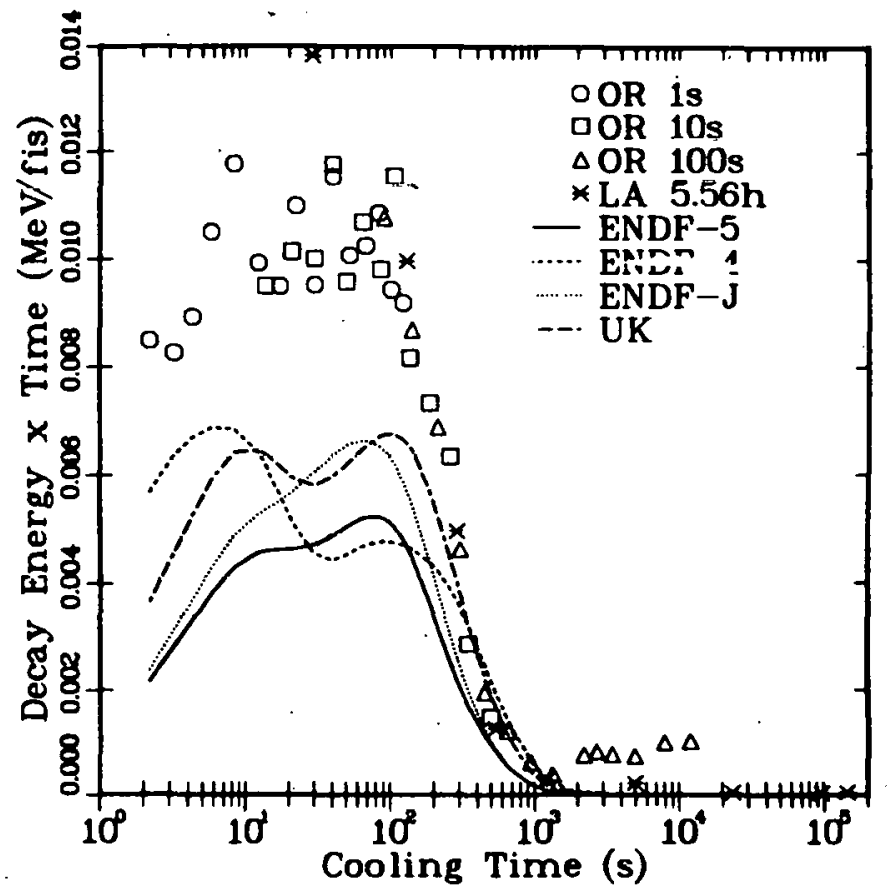

\footnotetext{
Fig. 83.

Comparison of ${ }^{235} \mathrm{U}$ thermal gamma-fits with experiment, Group 18.
} 


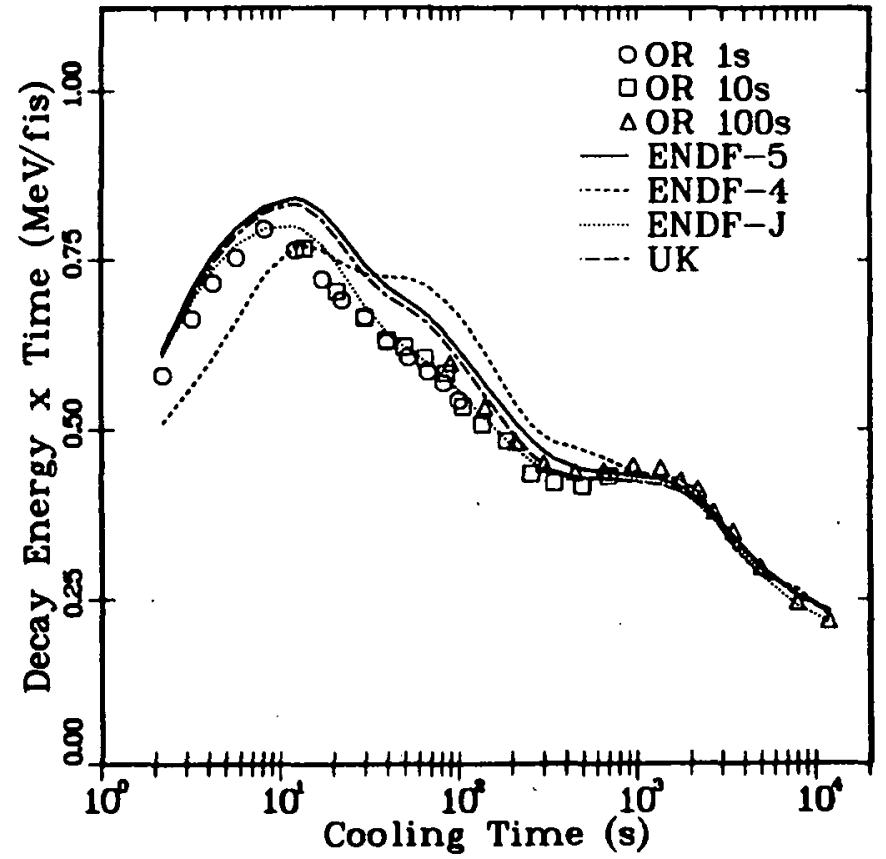

Fig. 84 .

Comparison of ${ }^{235} \mathrm{U}$ thermal beta-fits with experiment, total over all groups.

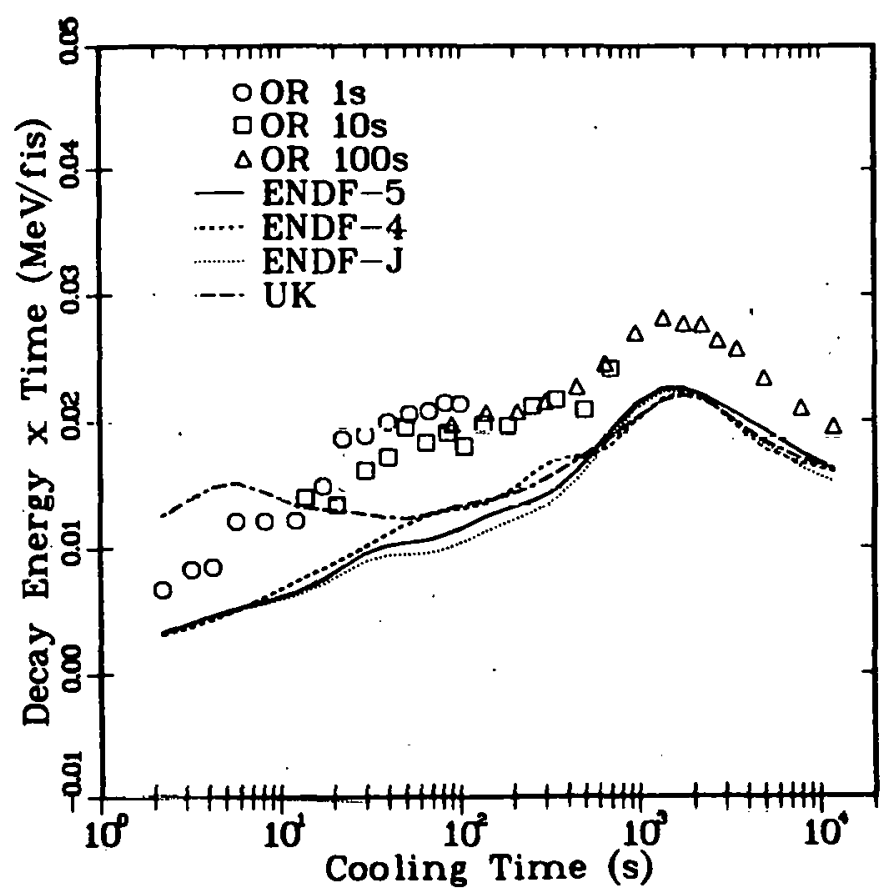

Fig. 86.

Comparison of ${ }^{235} U$ thermal beta-fits witli experiment, Group 2.

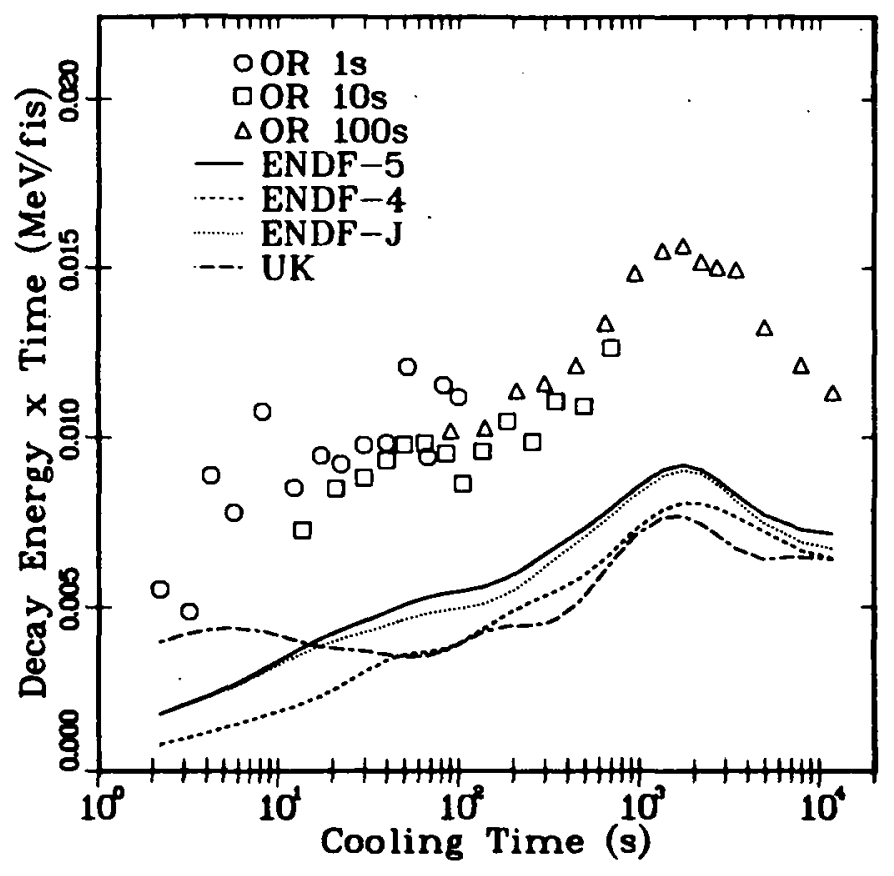

Fig. 85.

Comparison of ${ }^{235} \mathrm{U}$ thermal beta-fits with experiment, Group 1.
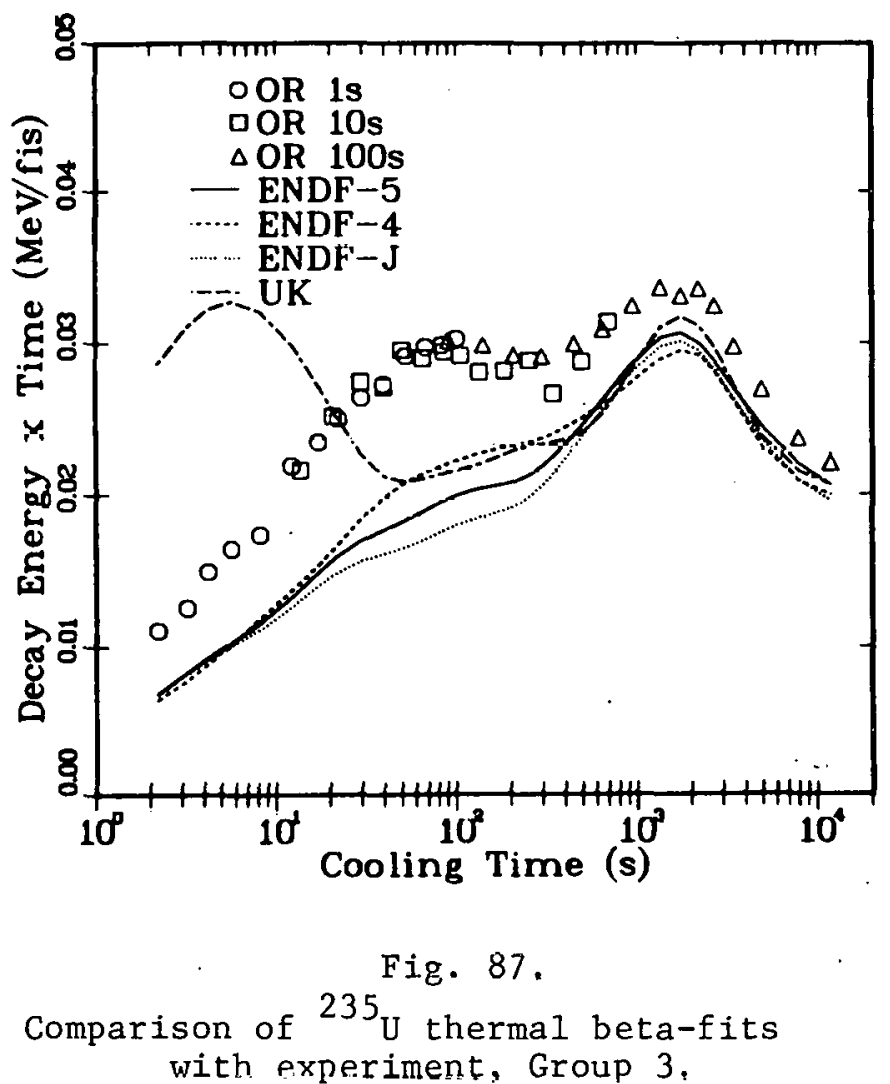


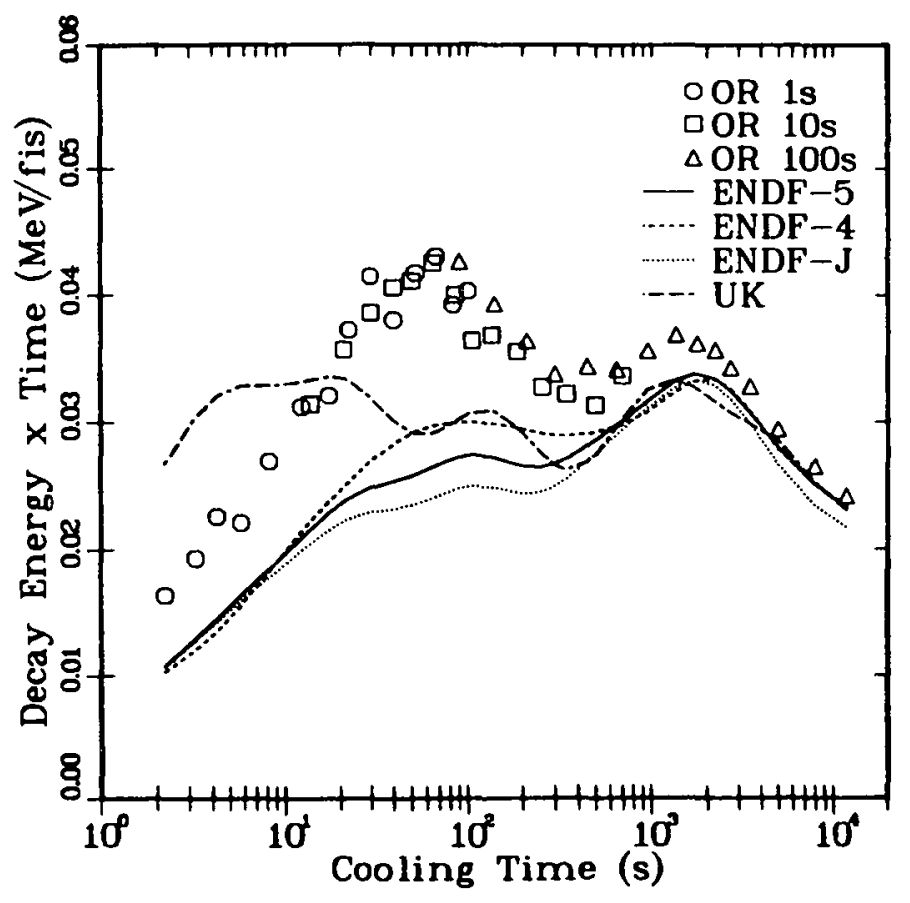

Fig. 88 .

Comparison of ${ }^{235} \mathrm{U}$ thermal beta-fits with experiment, Group 4.

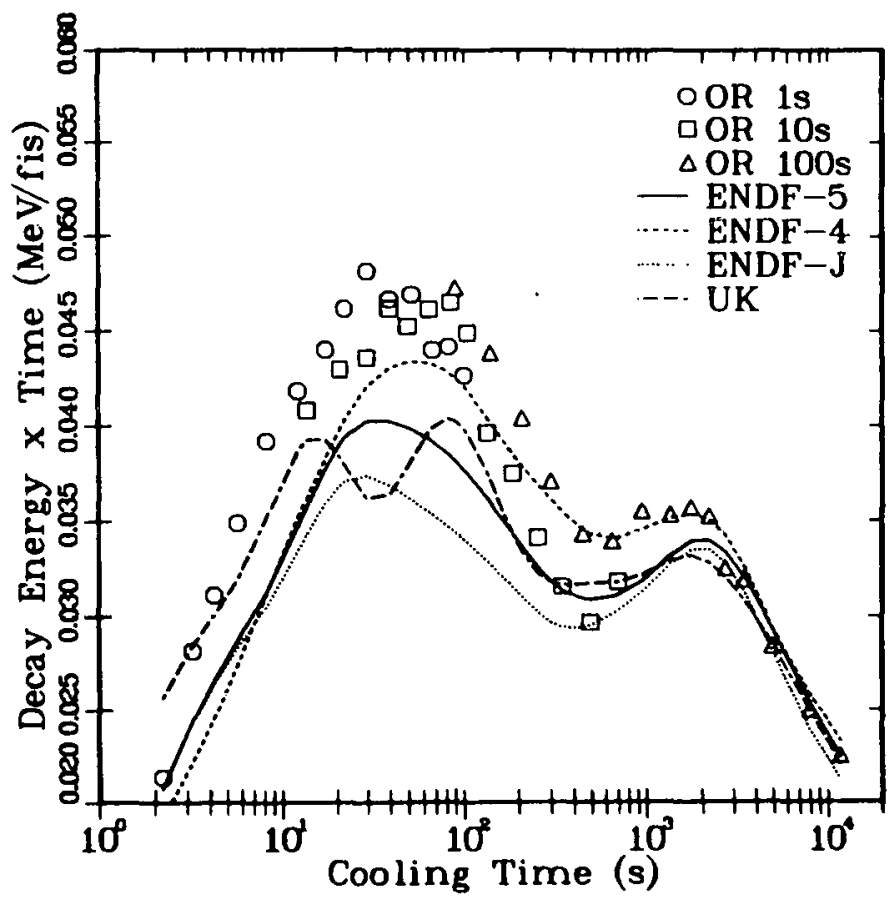

Fig. 90.

Comparison of ${ }^{235} \mathrm{U}$ thermal beta-fits with experiment, Group 6 .

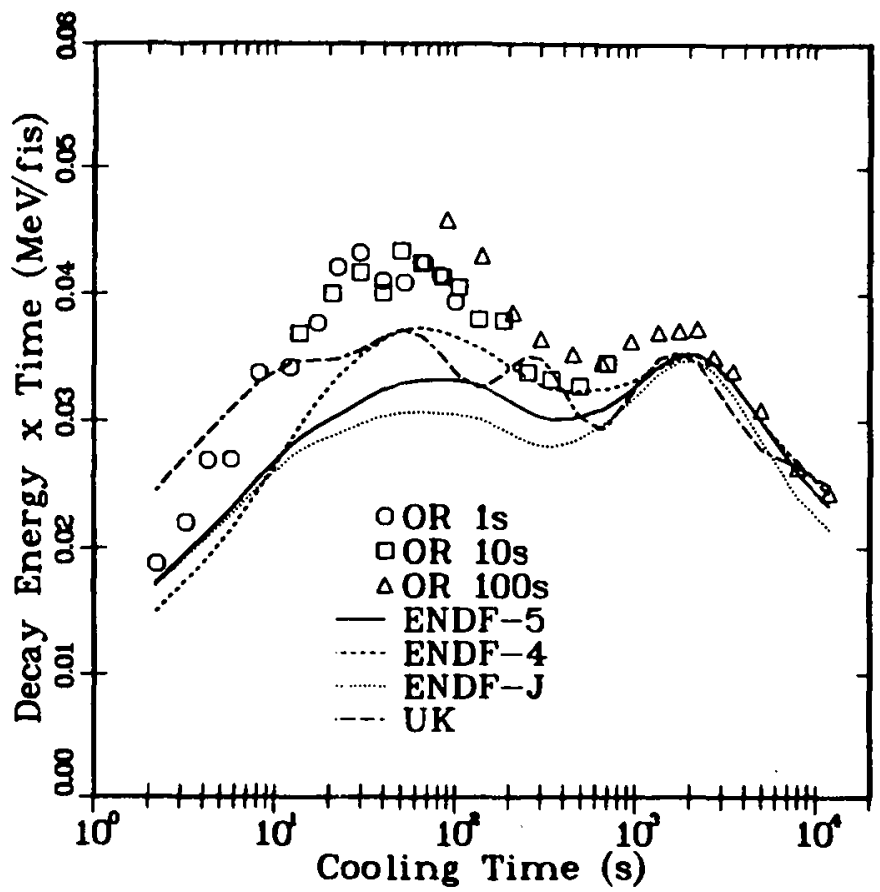

Fig. 89.

Comparison of ${ }^{235} \mathrm{U}$ thermal beta-fits with experiment, Group 5.

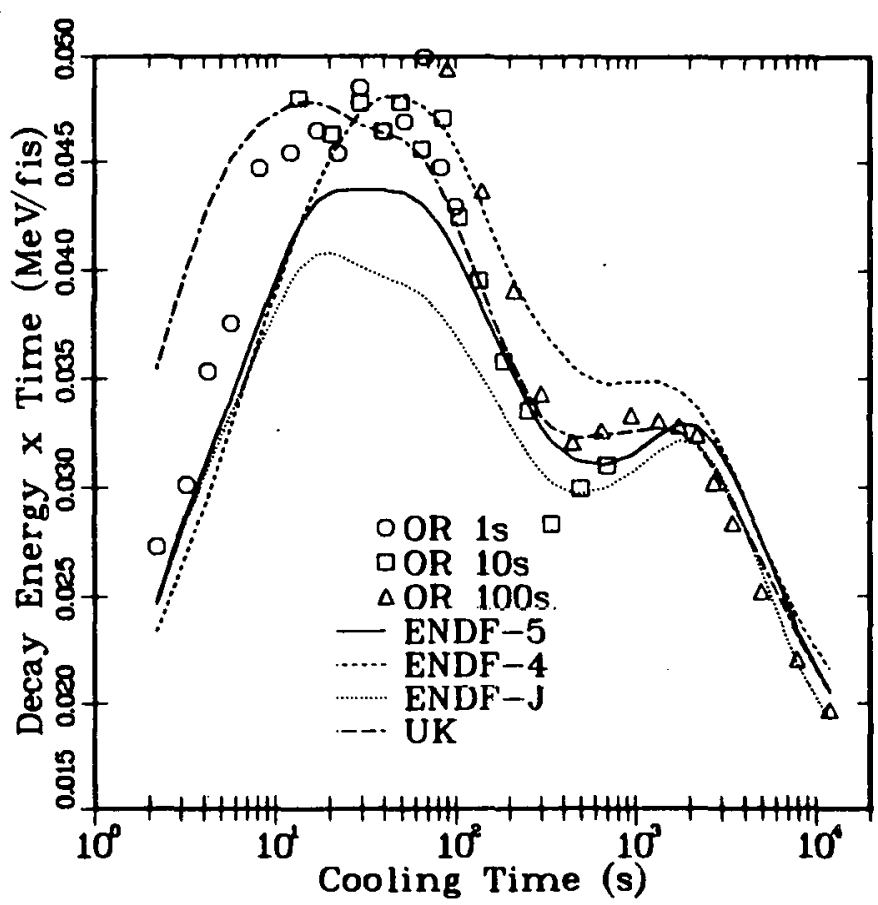

Fig. 91.

Comparison of ${ }^{235} \mathrm{U}$ thermal beta-fits with experiment, Group 7. 


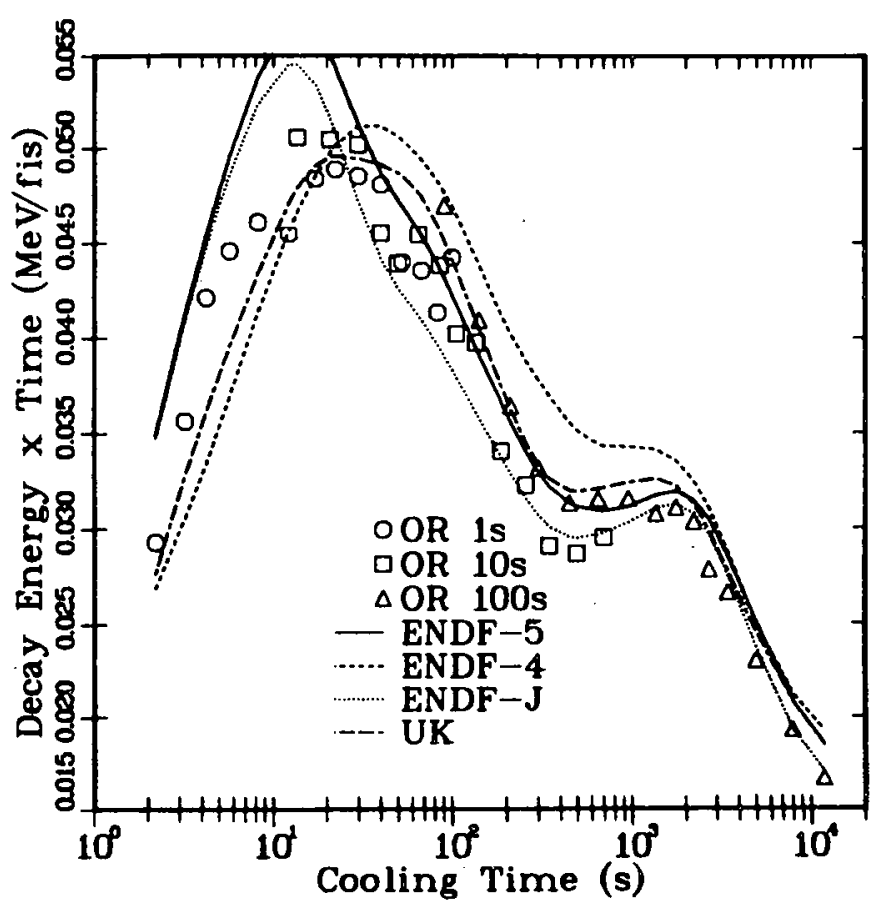

Fig. 92.

Comparison of ${ }^{235} U$ thermal beta-fits with experiment, Group 8.

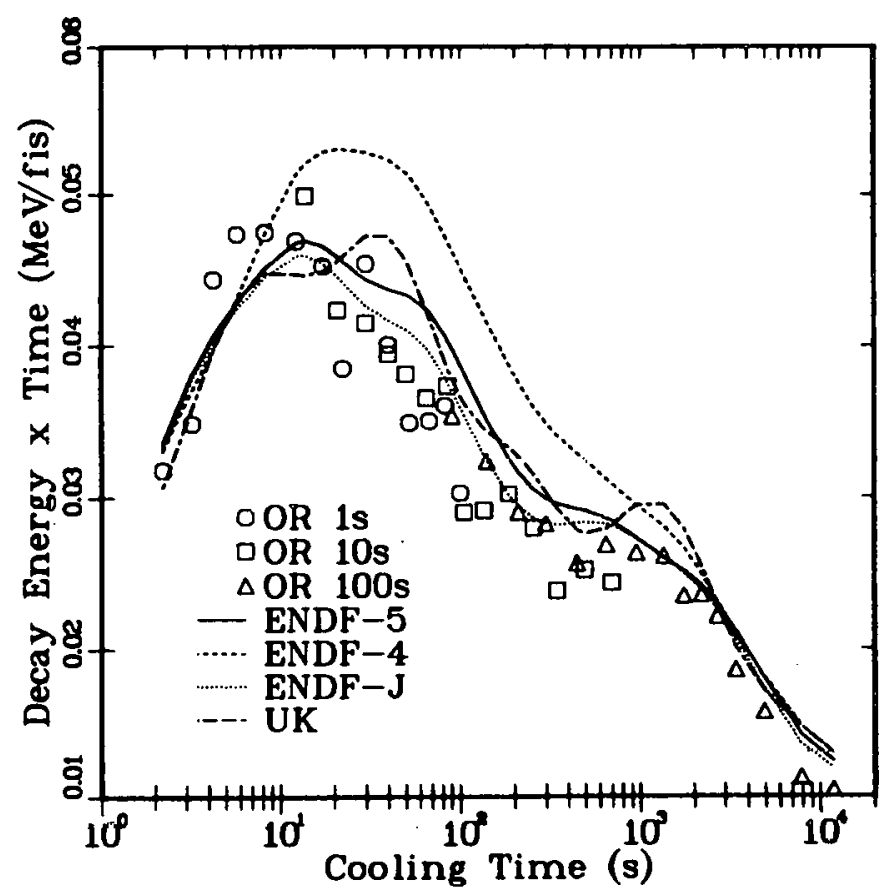

Fig. 94.

Comparison of ${ }^{235} \mathrm{U}$ thermal beta-fits. with experiment, Group 10.

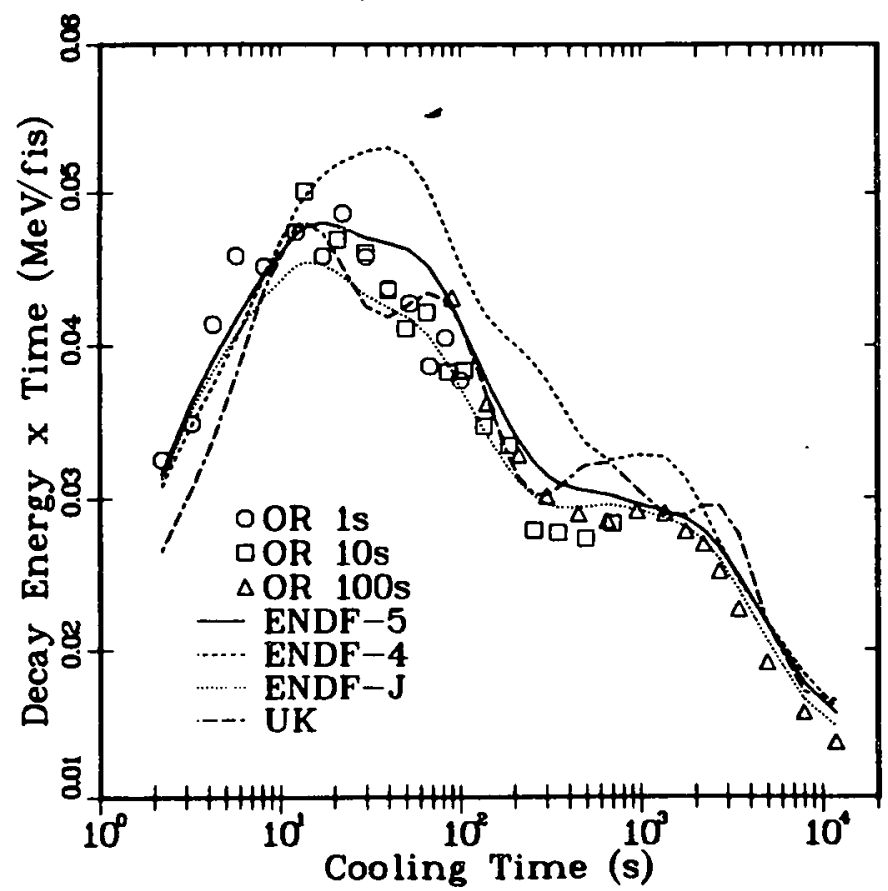

Fig. 93.

Comparison of ${ }^{235} \mathrm{U}$ thermal beta-fits with experiment, Group 9.

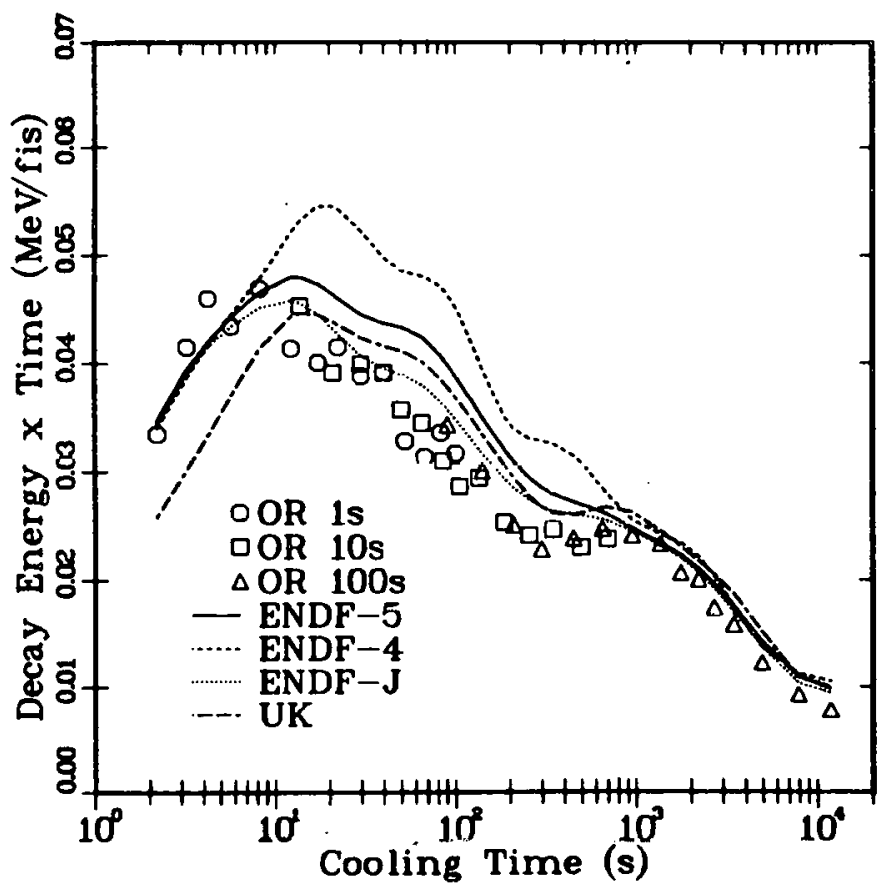

Fig. 95.

Comparison of ${ }^{235} \mathrm{U}$ thermal beta-fits with experiment, Group 11. 


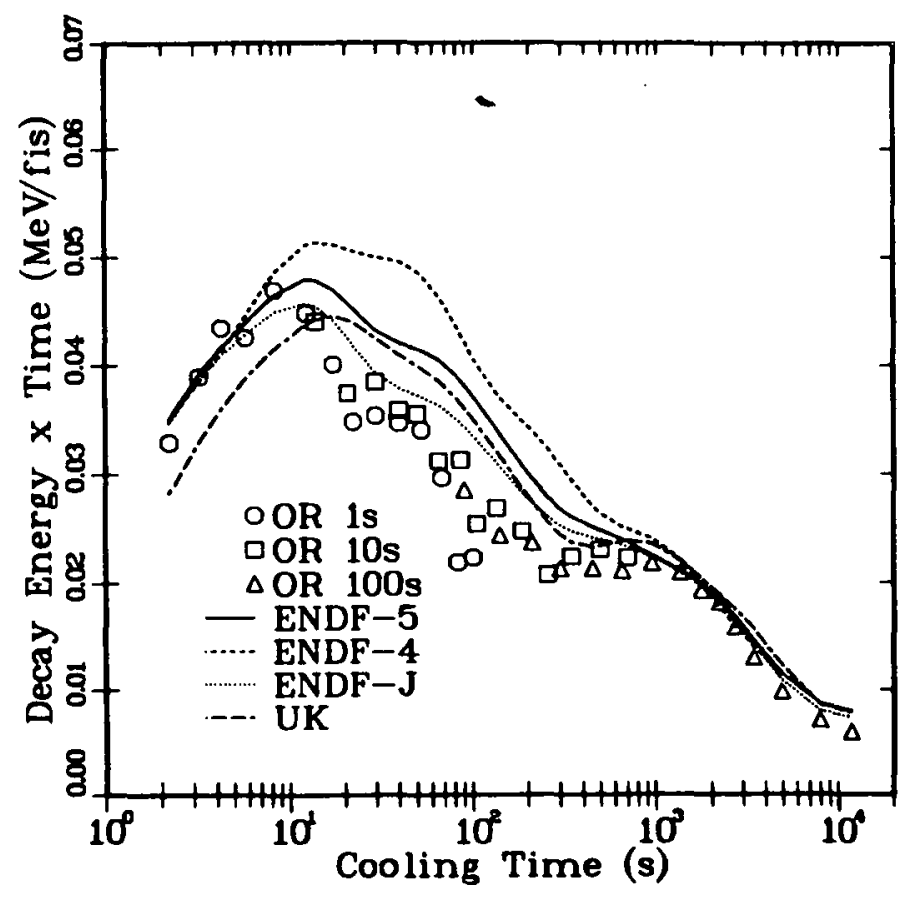

Fig. 96 .

Comparison of ${ }^{235} \mathrm{U}$ thermal beta-fits with experiment, Group 12.

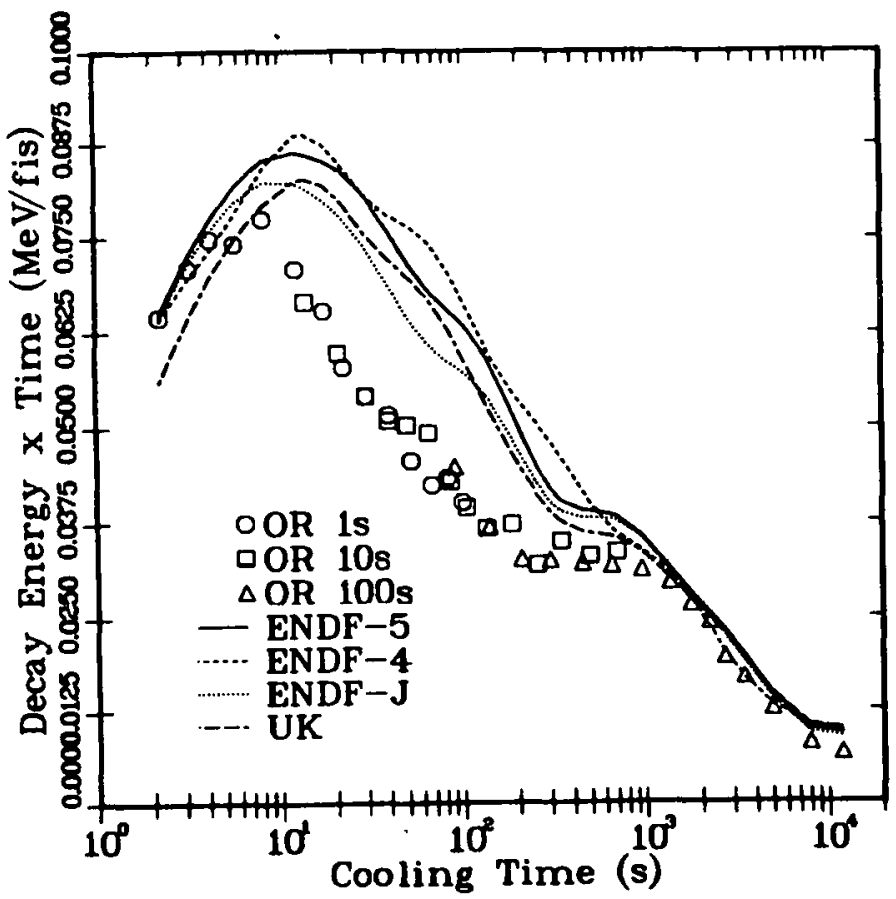

Fig. 98.

Comparison of ${ }^{235} \mathrm{U}$ thermal beta-fits with experiment, Group 14.

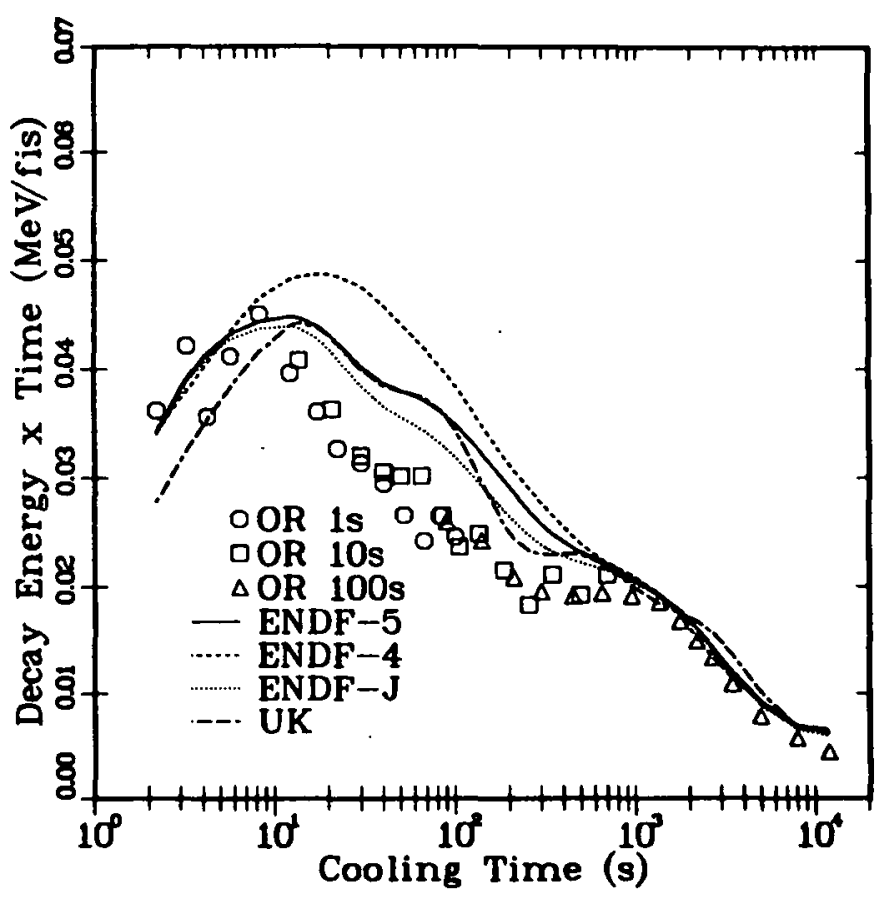

Fig. 97.

Comparison of ${ }^{235} \mathrm{U}$ thermal beta-fits with experiment, Group 13.

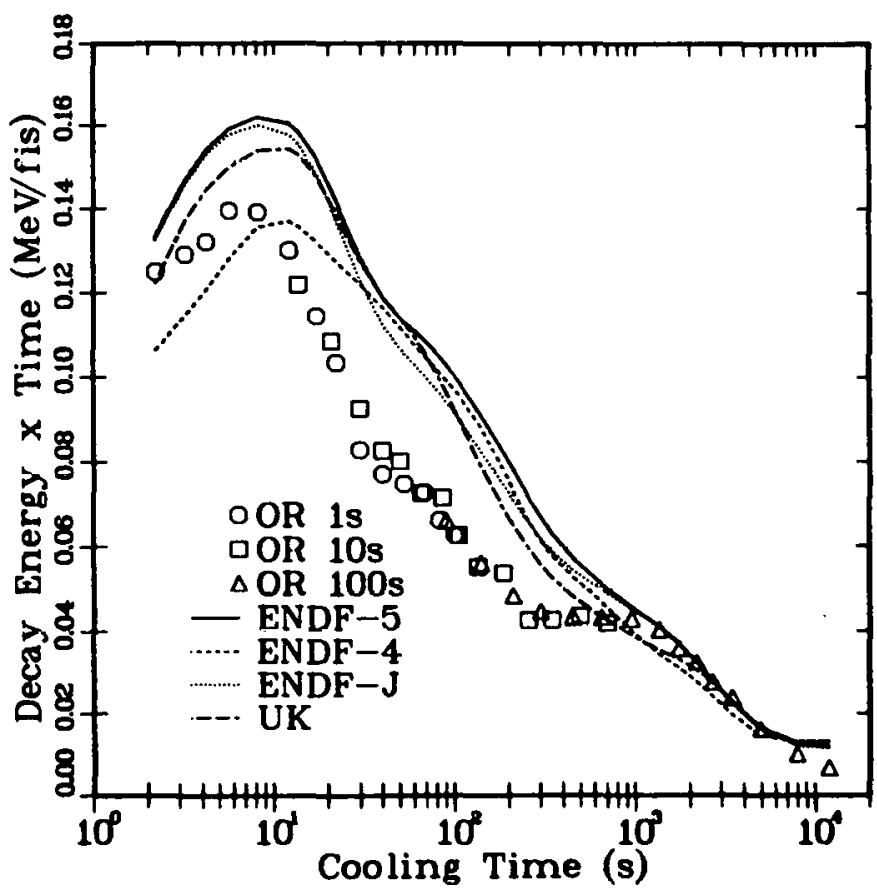

Fig. 99.

Comparison of ${ }^{235} \mathrm{U}$ thermal beta-fits with experiment, Group 15. 

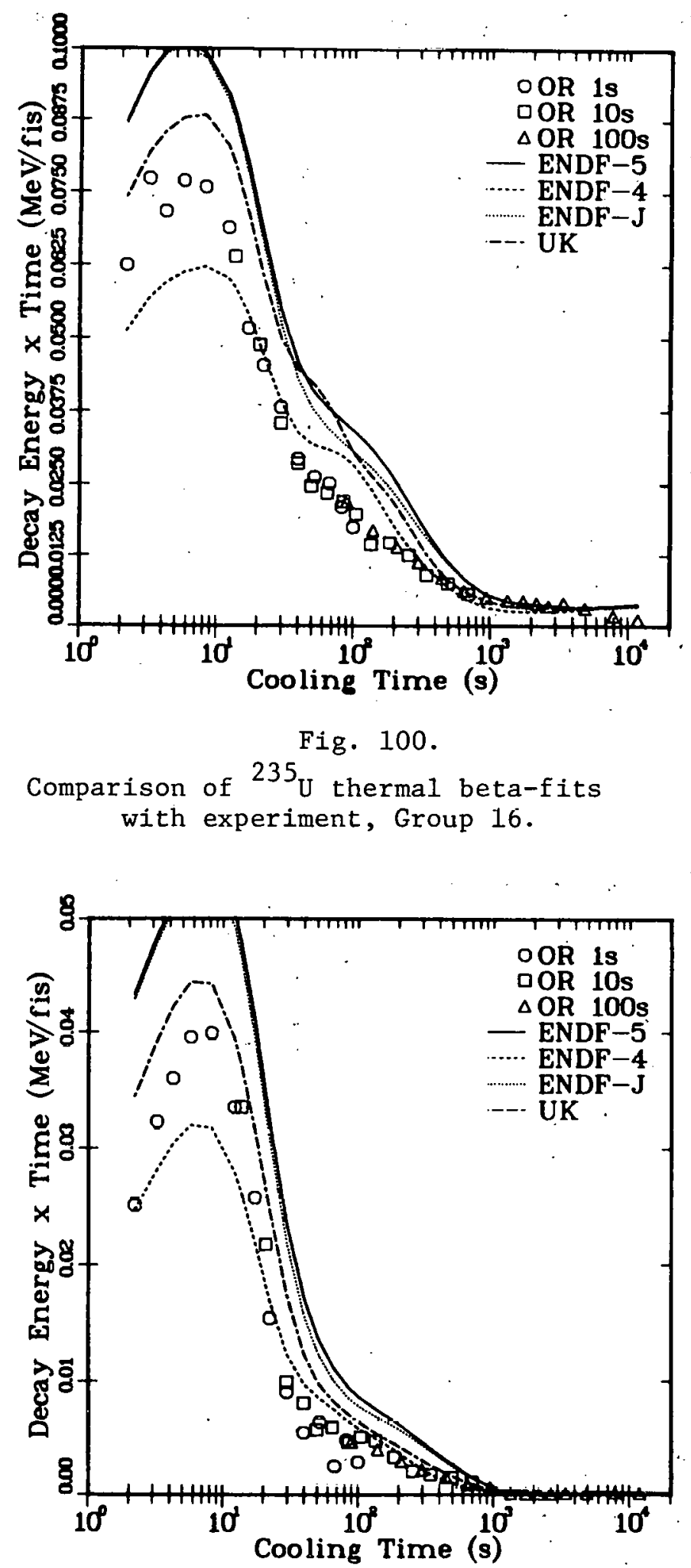

Fig. 101.

Comparison of ${ }^{235} \mathrm{U}$ thermal beta-fits with experiment, Group 17. 


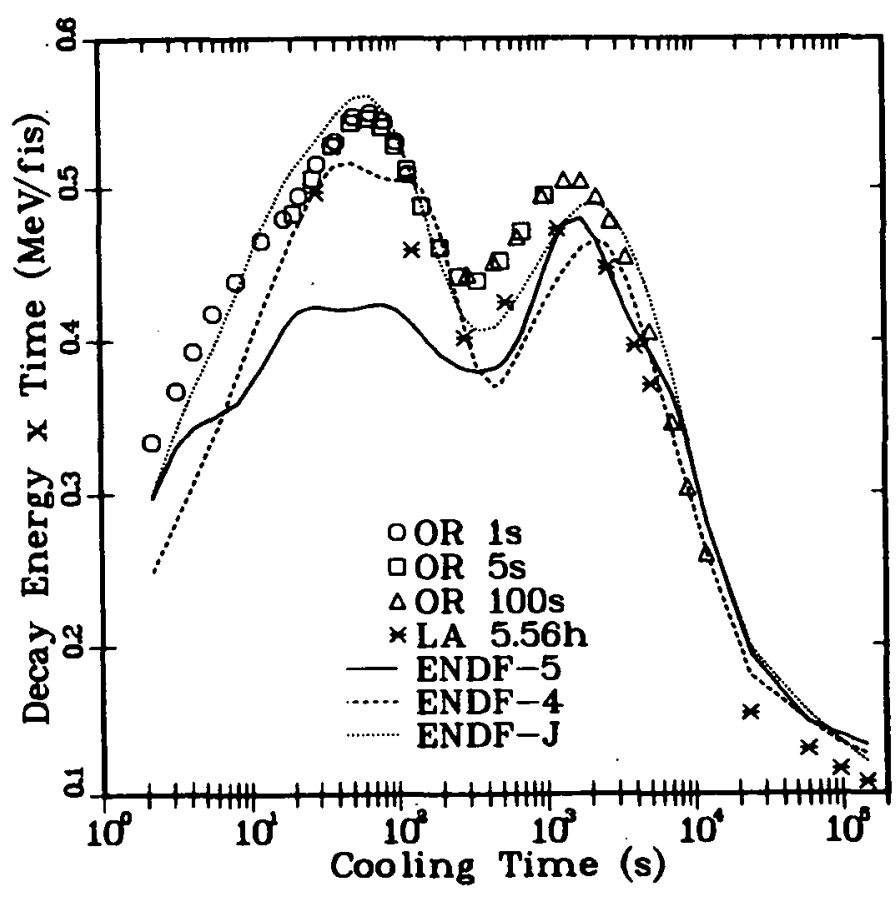

Fig. 102.

Comparison of ${ }^{239} \mathrm{Pu}$ thermal gamma-fits with experiment, total over all groups.

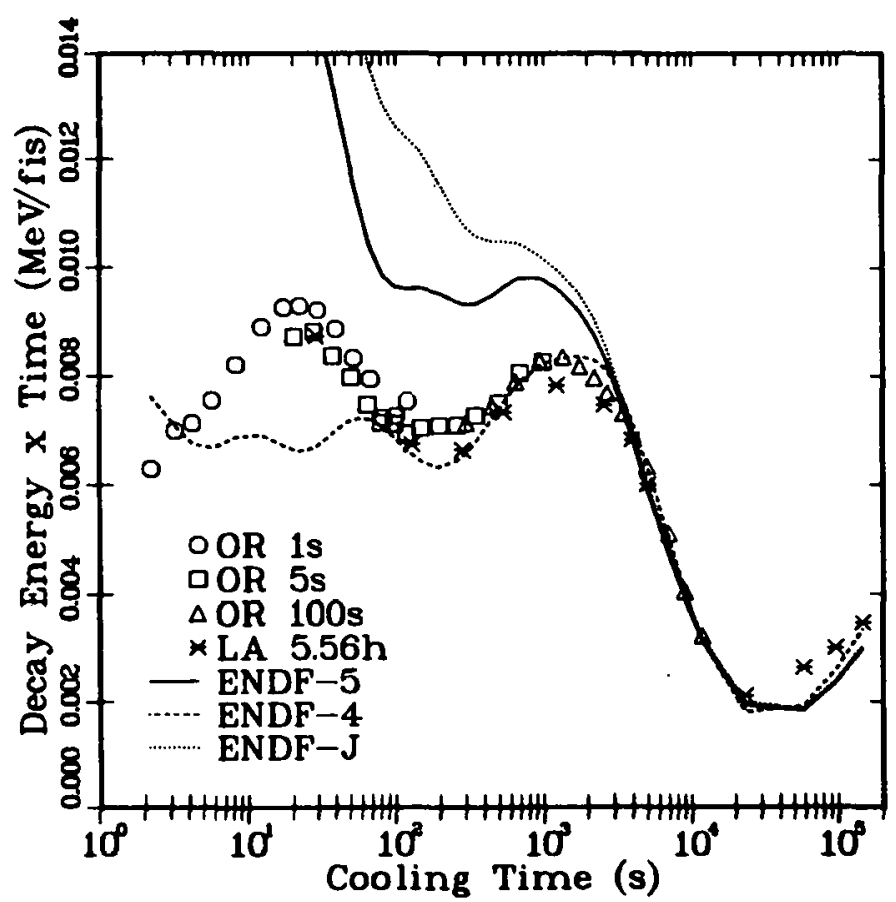

$$
\text { Fig. } 104 .
$$

Comparison of ${ }^{239} \mathrm{Pu}$ thermal gamma-fits with experiment, Group 2.

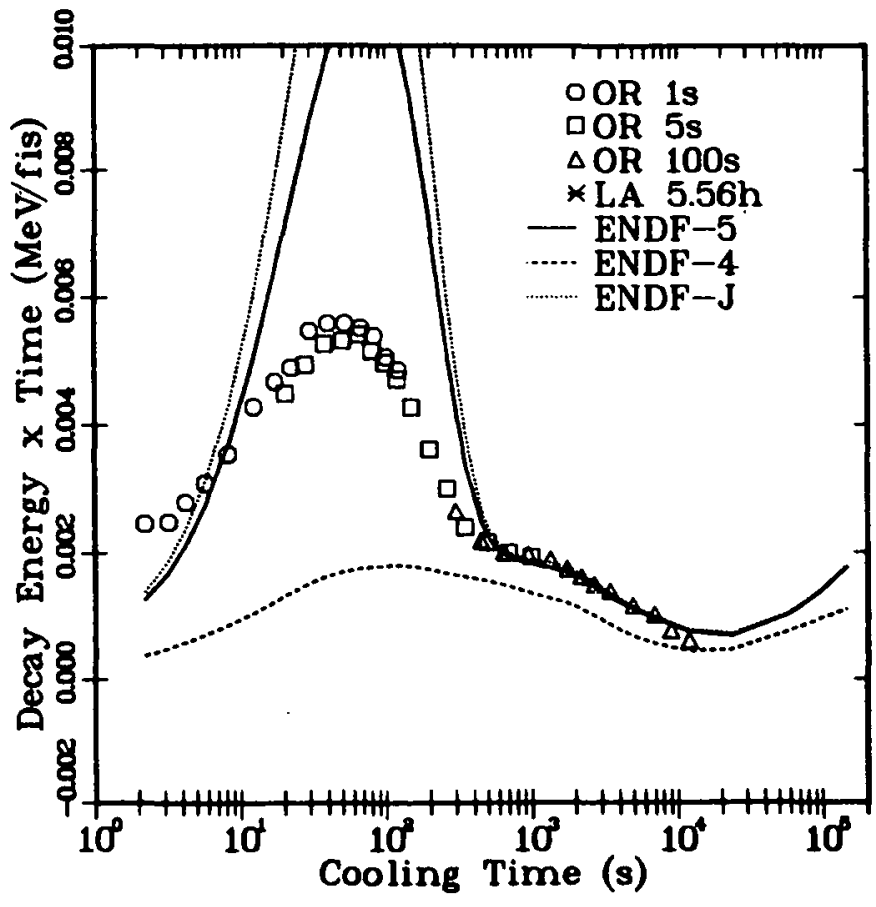

Fig. 103.

Comparison of ${ }^{239} \mathrm{Pu}$ thermal gamma-fits with experiment, Group 1.

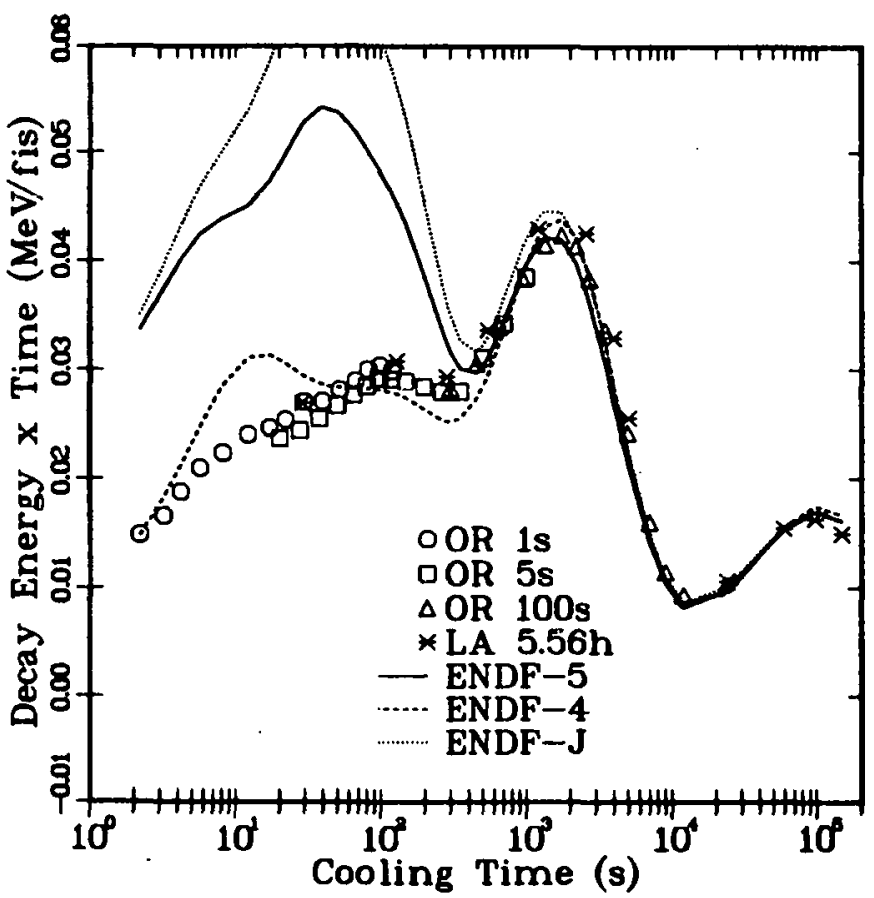

Fig. 105.

Comparison of ${ }^{239} \mathrm{Pu}$ thermal gamma-fits with experiment, Group 3. 


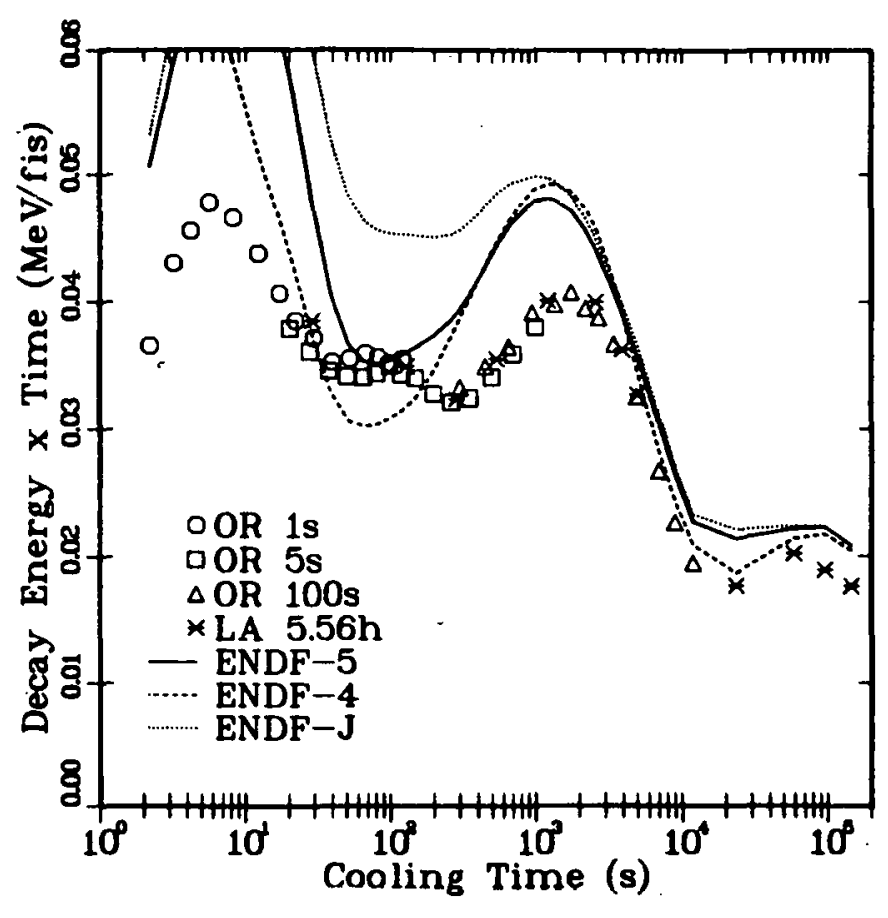

Fig. 106.

Comparison of ${ }^{239} \mathrm{Pu}$ thermal gamma-fits with experiment, Group 4.

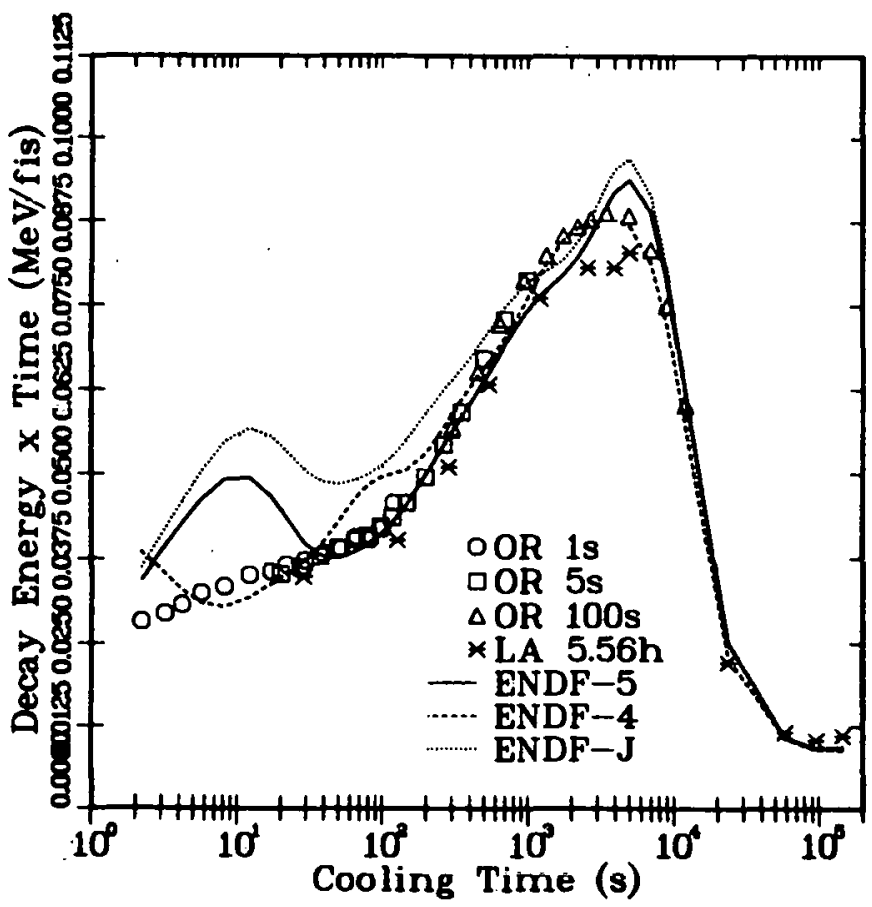

F士g. 108.

Comparison of ${ }^{239} \mathrm{Pu}$ thermal gamma-fit's with experiment, Group 6 .

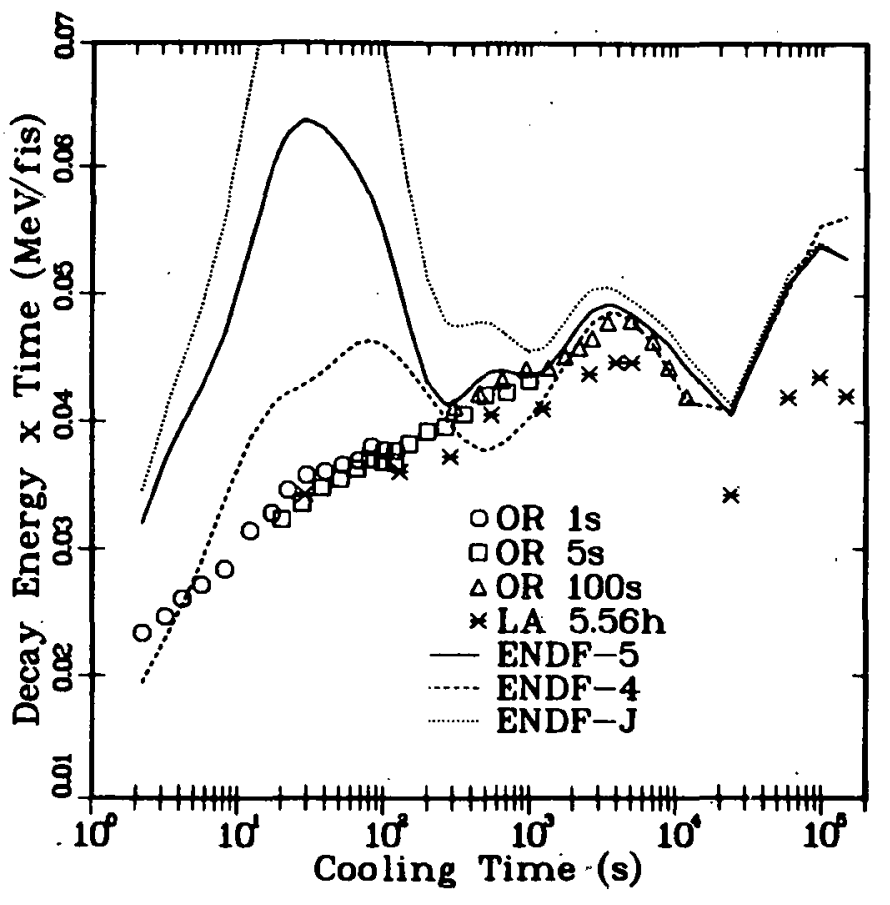

Fig. 107.

Comparison of ${ }^{239} \mathrm{Pu}$ thermal gamma-fits with experiment, Group 5.

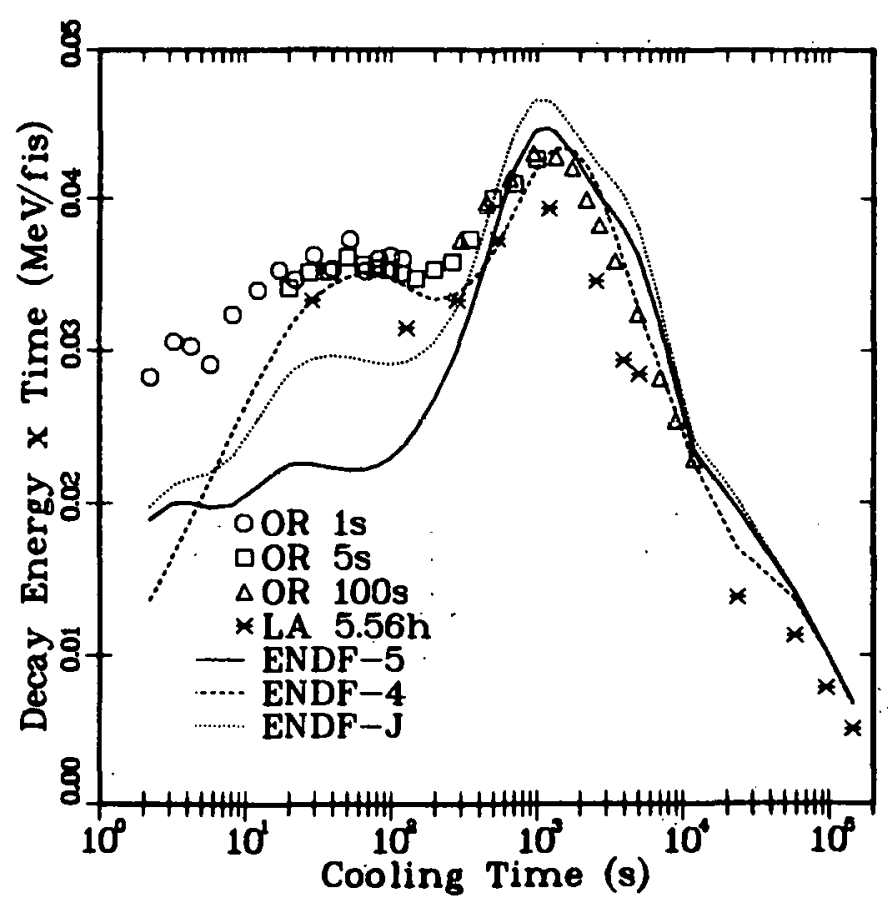

Fig. 109.

Comparison of ${ }^{239} \mathrm{Pu}$ thermal gamma-fits with experiment, Croup 7. 


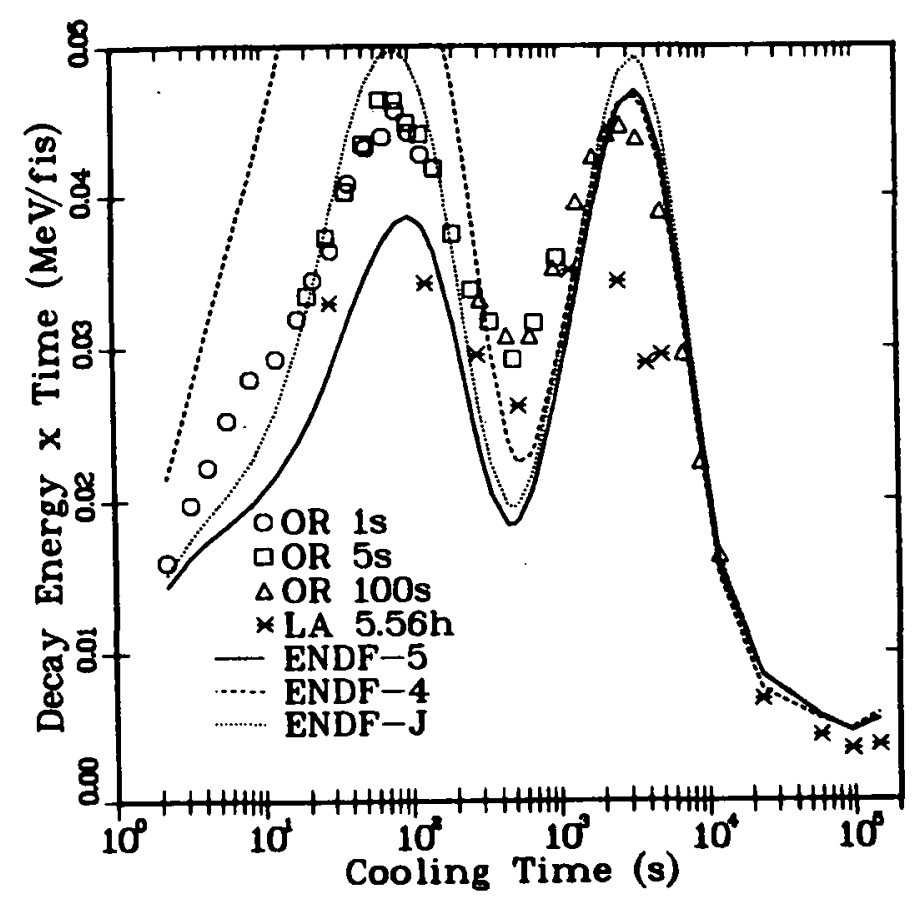

Fig. 110.

Comparison of ${ }^{239} \mathrm{Pu}$ thermal gamma-fits with experiment, Group 8.

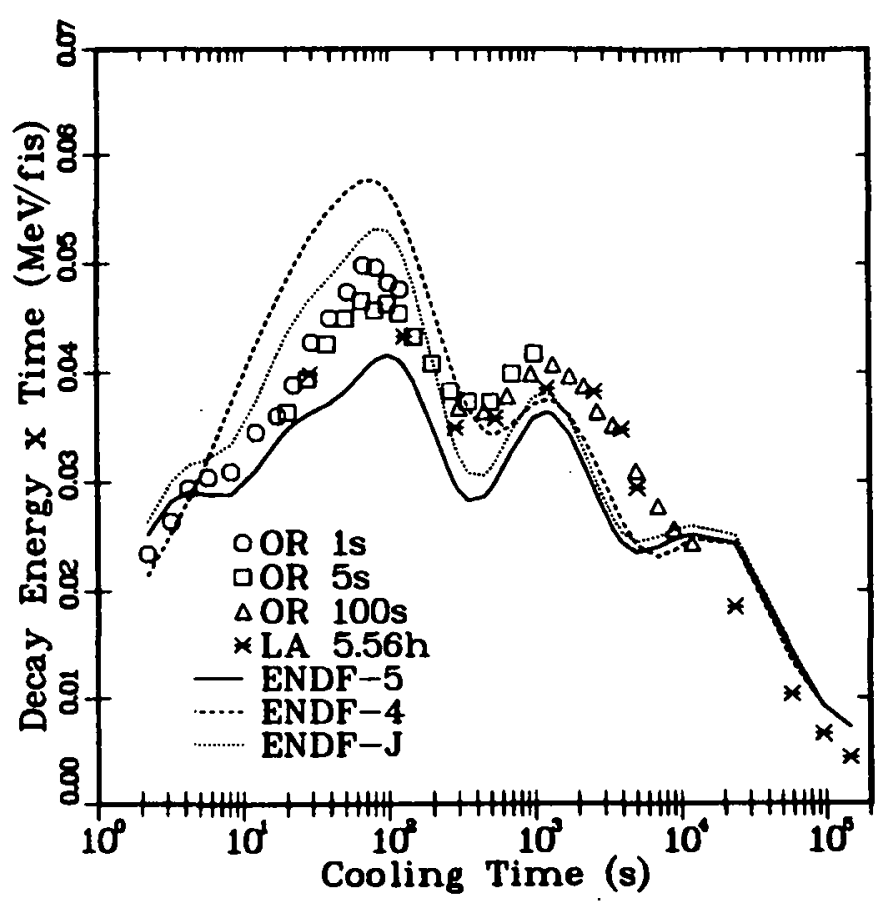

Fig. 111.

Comparison of ${ }^{239} \mathrm{Pu}$ thermal gamma-fits with experiment, Group 9.

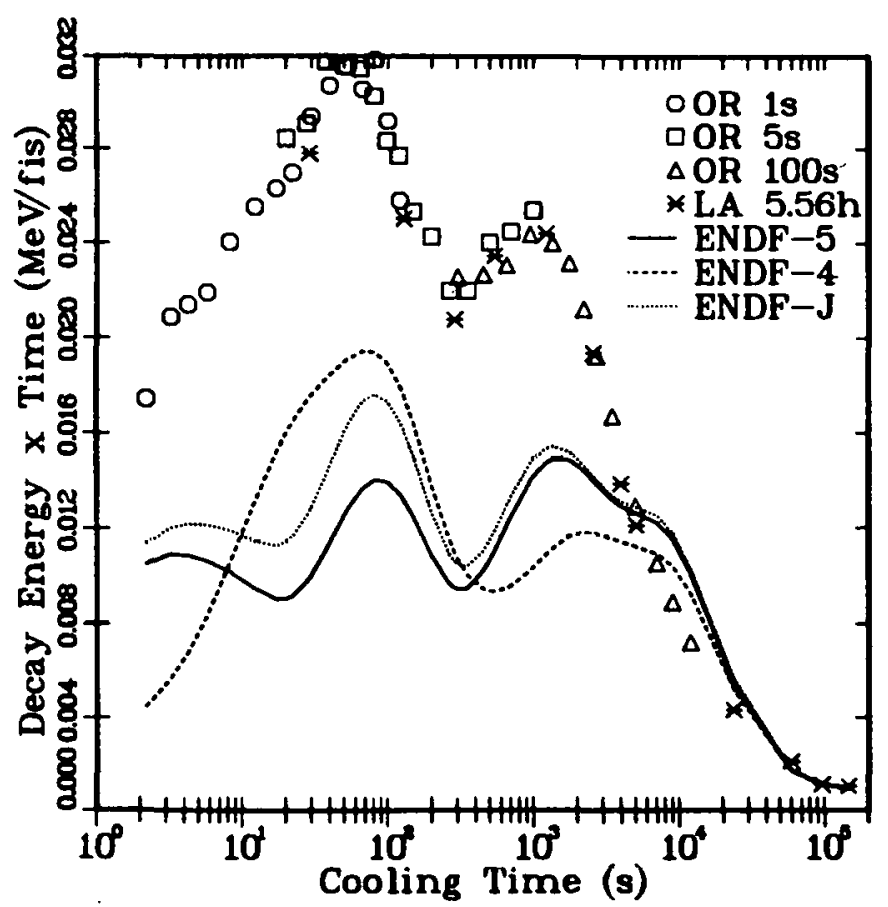

Fig. 113.

Comparison of ${ }^{239} \mathrm{Pu}$ thermal gamma-fits with experiment, Group 11. 


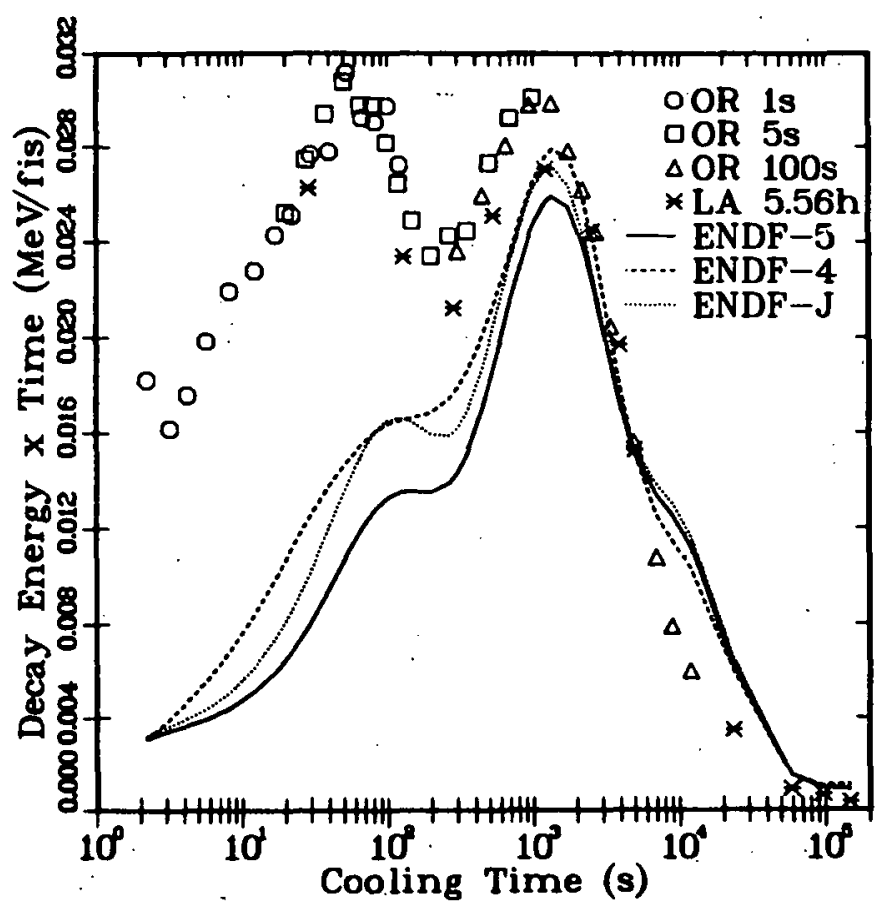

Fig. 114.

Comparison of ${ }^{239} \mathrm{Pu}$ thermal gamma-fits with experiment, Group 12.

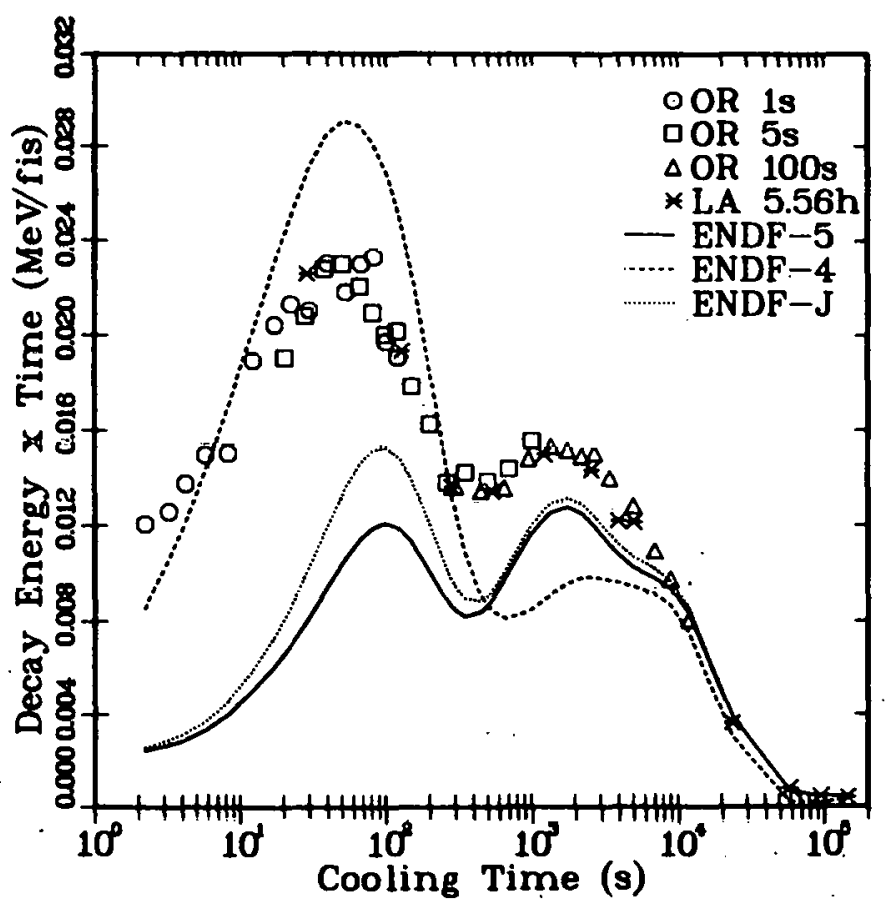

Fig. 116.

Comparison of ${ }^{239} \mathrm{Pu}$ thermal gamma-fits with experiment, Group 14.

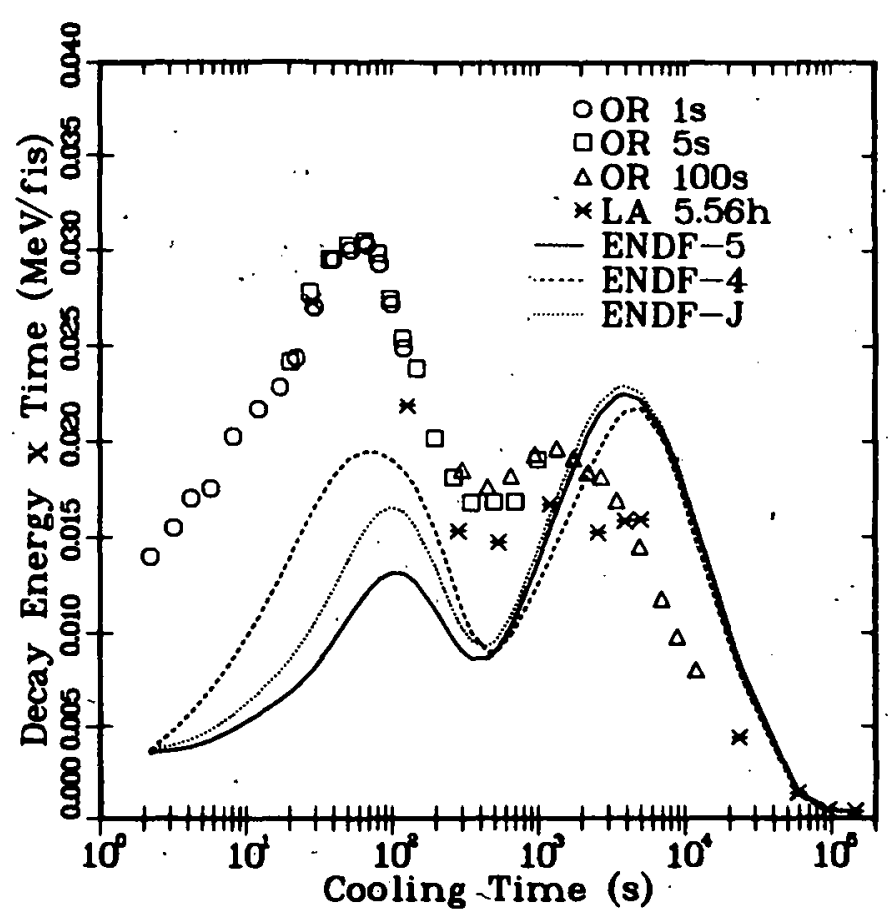

Fig. 115.

Comparison of ${ }^{239} \mathrm{pu}$ thermal gamma-fits with experiment, Group 13.

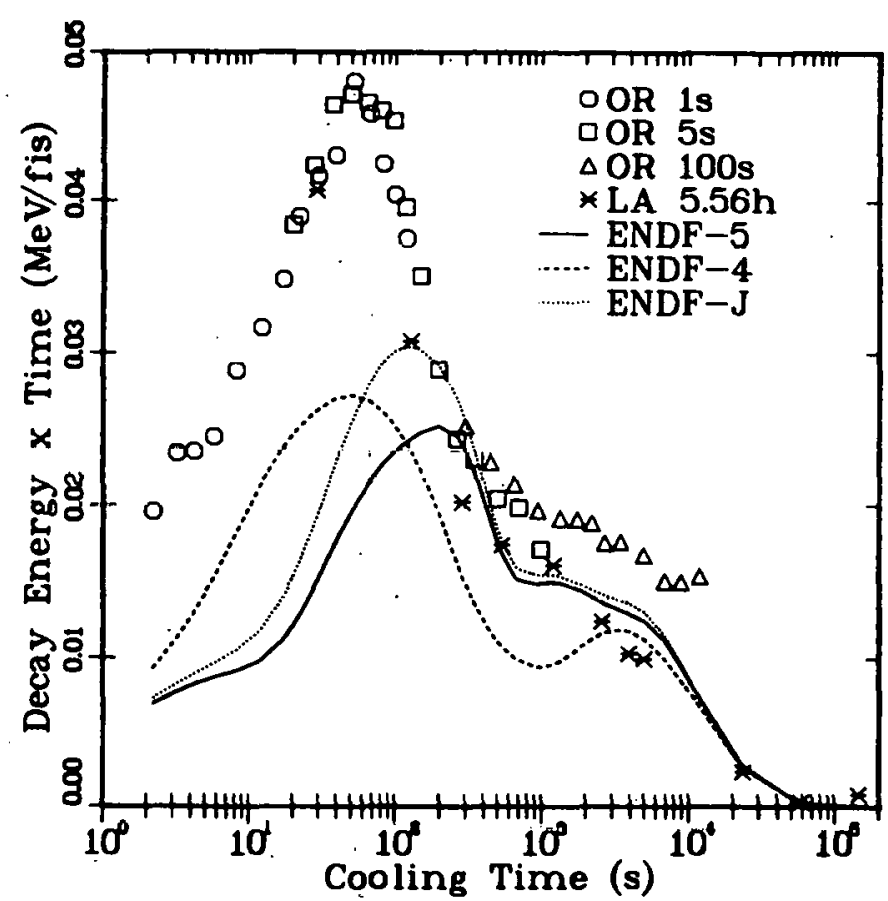

Fig. 117.

Comparison of ${ }^{239} \mathrm{Pu}$ thermal gamma-fits with experiment, Group 15. 


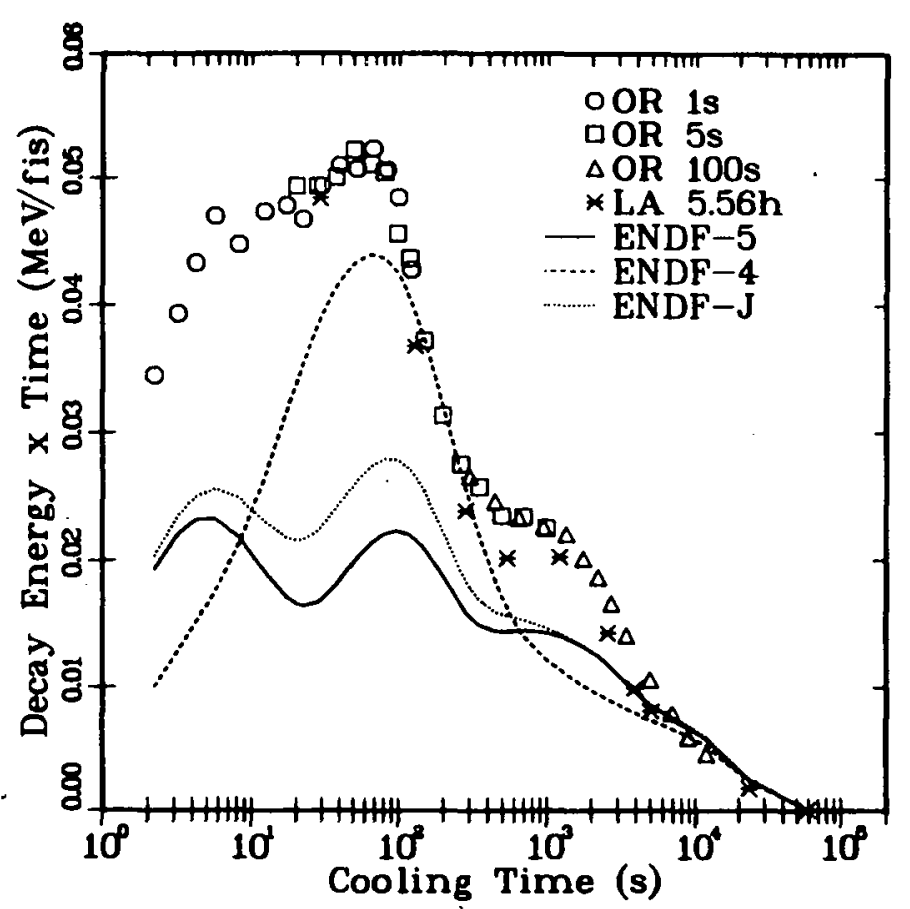

Fig. 118.

Comparison of ${ }^{239} \mathrm{Pu}$ thermal gamma-fits with experiment, Group 16.

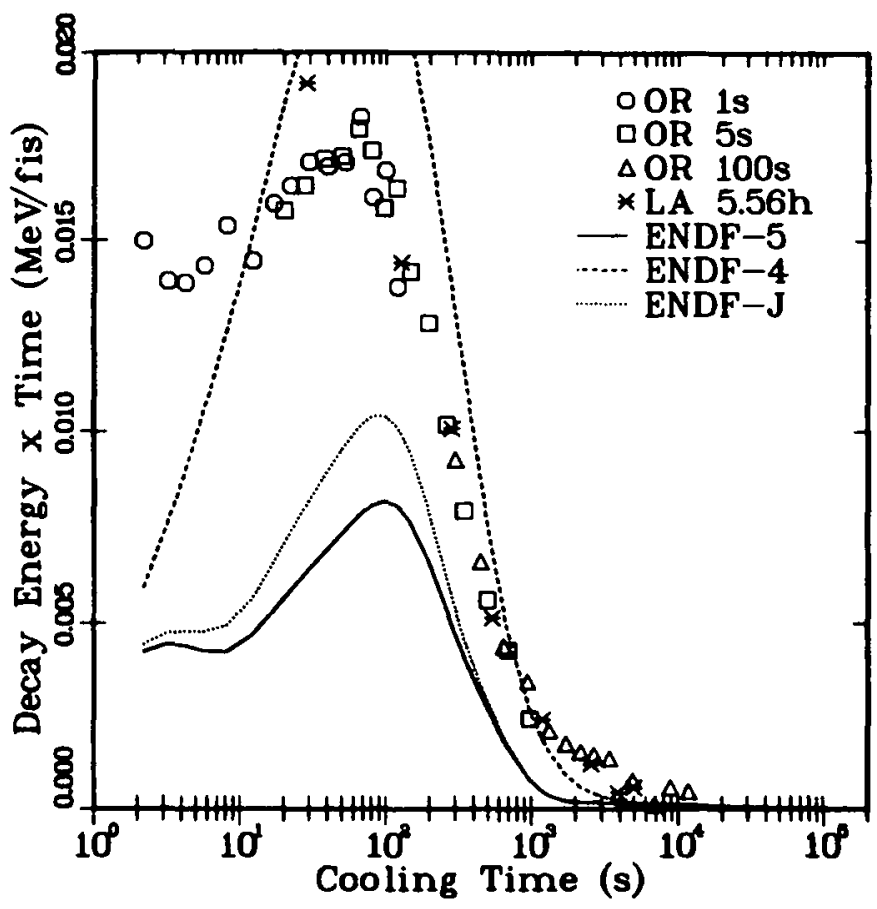

Fig. 119.

Comparison of ${ }^{239} \mathrm{Pu}$ thermal gamma-fits with experiment, Group 17.
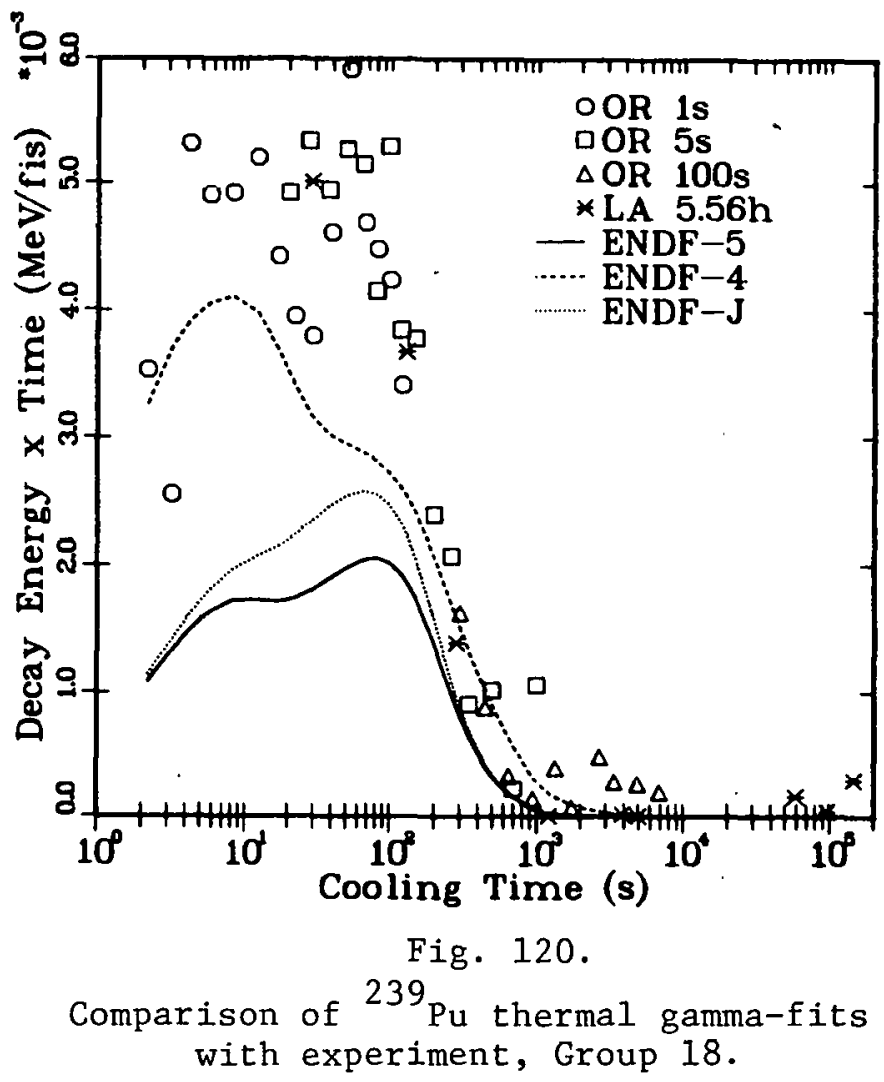


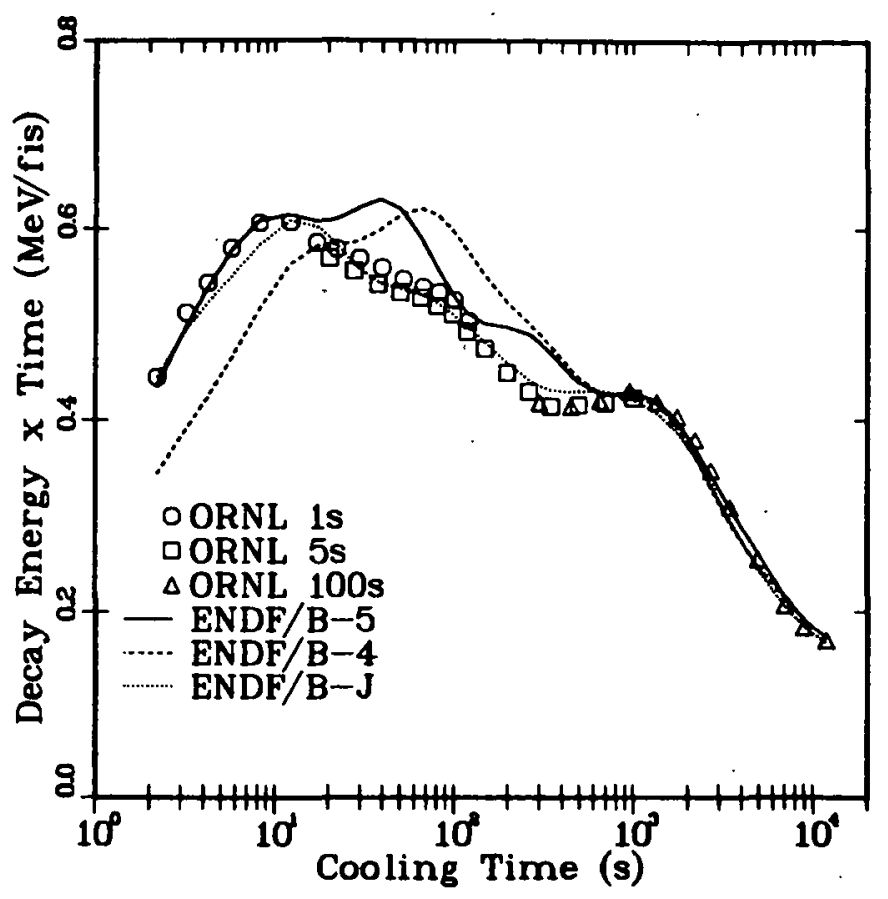

Fig. 121.

Comparison of ${ }^{239} \mathrm{Pu}$ thermal beta-fits with experiment, total over all groups.

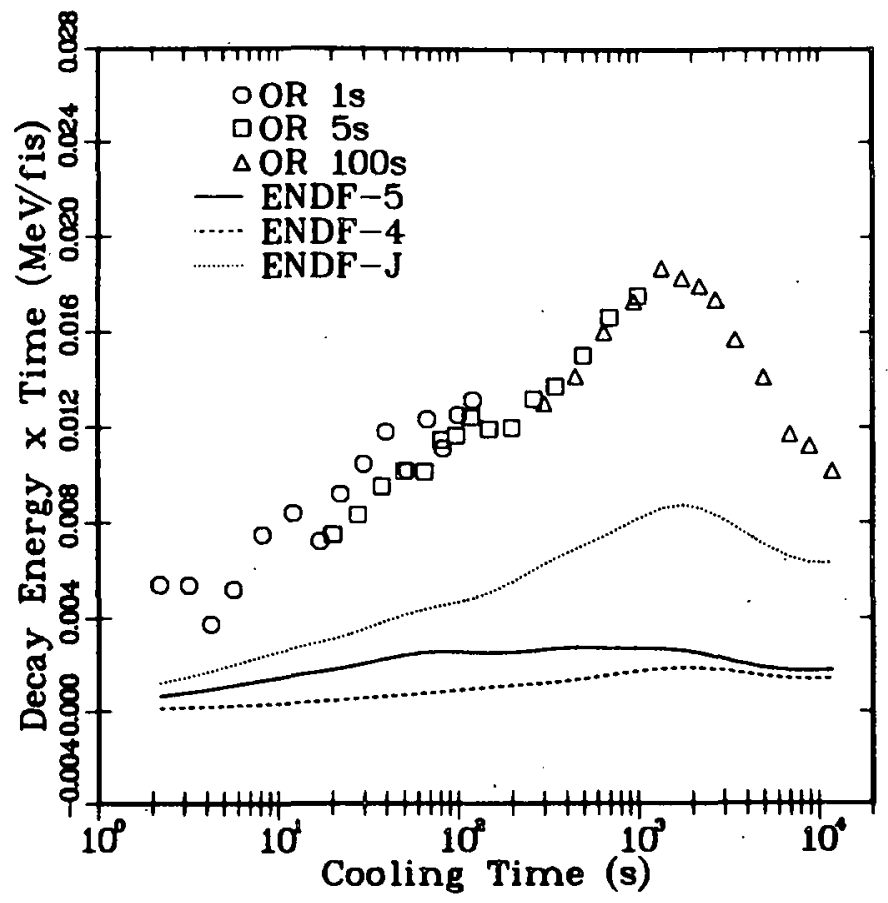

Fig. 122.

Comparison of ${ }^{239} \mathrm{Pu}$ thermal beta-fits with experiment, Group 1.

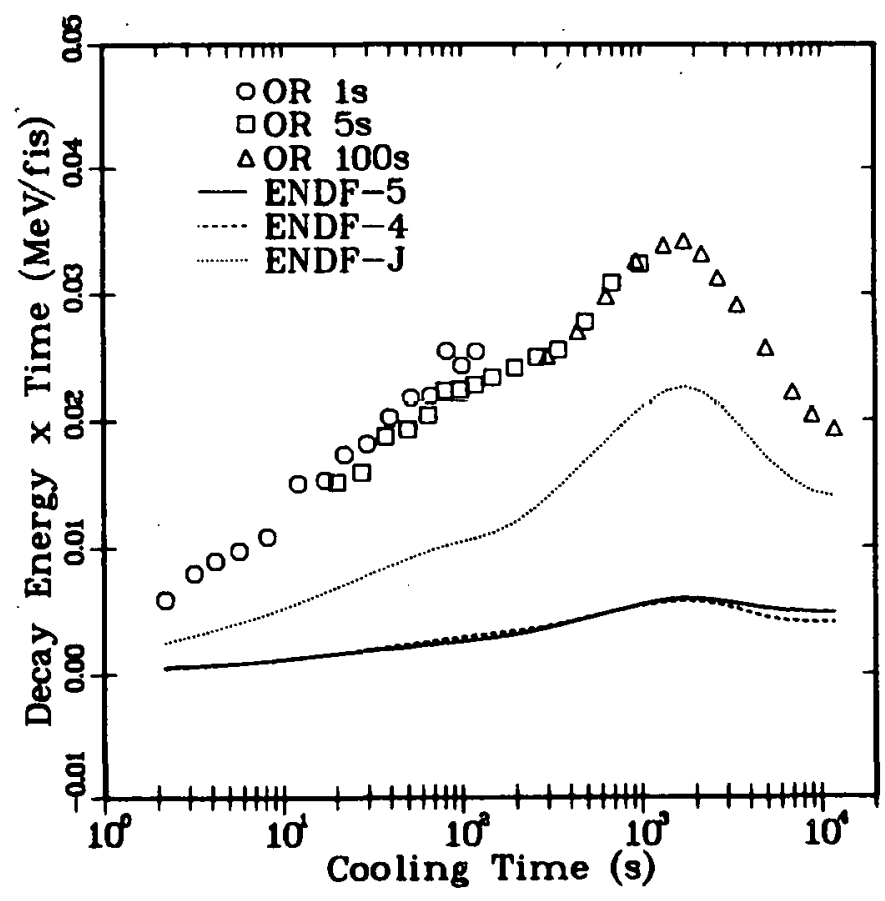

Fig. 123.

Comparison of ${ }^{239} \mathrm{Pu}$ thermal beta-fits with experinuent, Group 2.

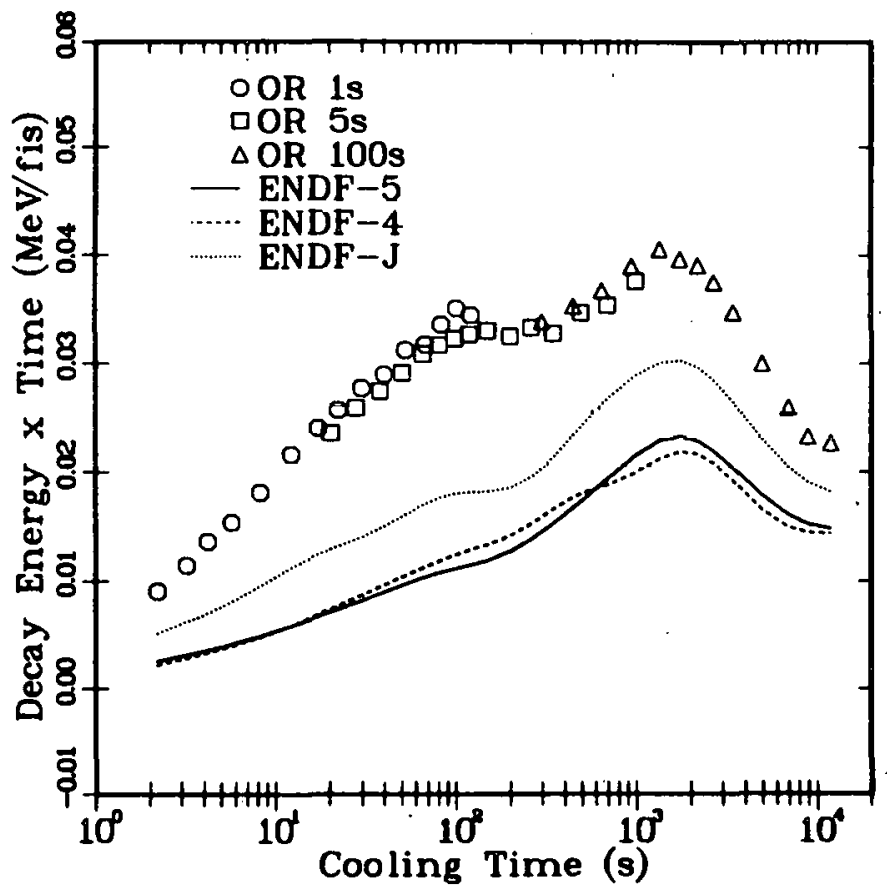

Fig. 124.

Comparison of ${ }^{239} \mathrm{Pu}$ thermal beta-fits with experimenl, Group 3. 


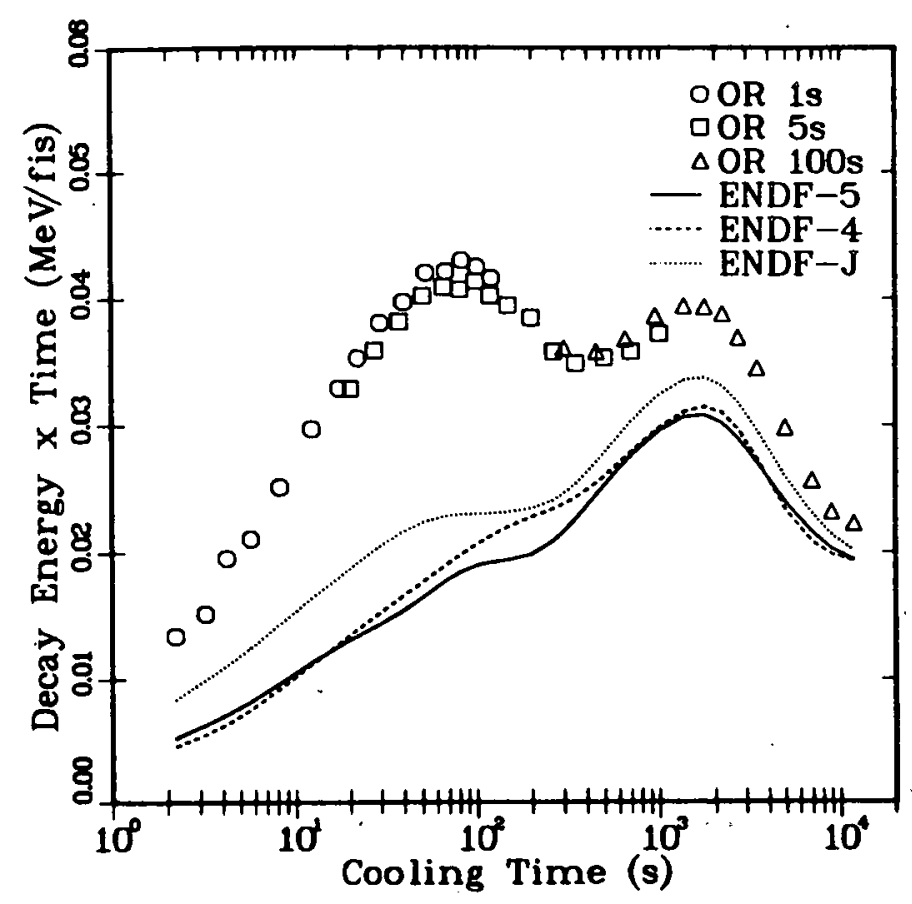

Fig. 125.

Comparison of ${ }^{239} \mathrm{Pu}$ thermal beta-fits with experiment, Group 4.

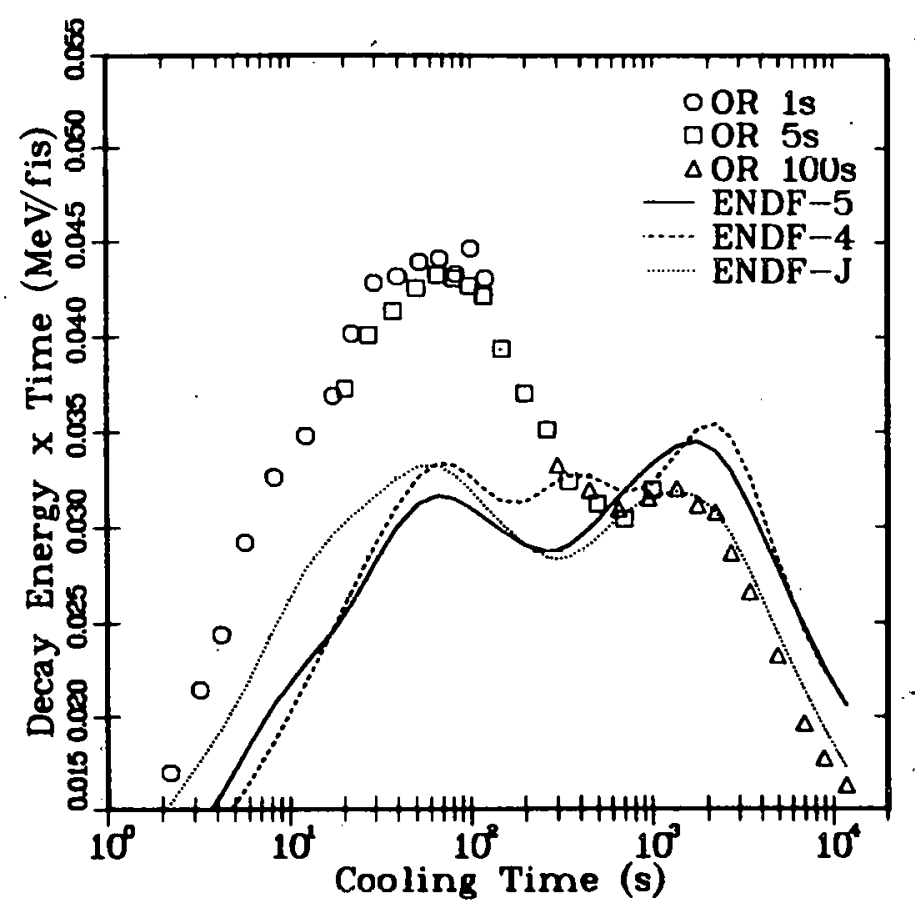

Fig. 127.

Comparison of ${ }^{239} \mathrm{Pu}$ thermal beta-fits with experiment, Group 6 .

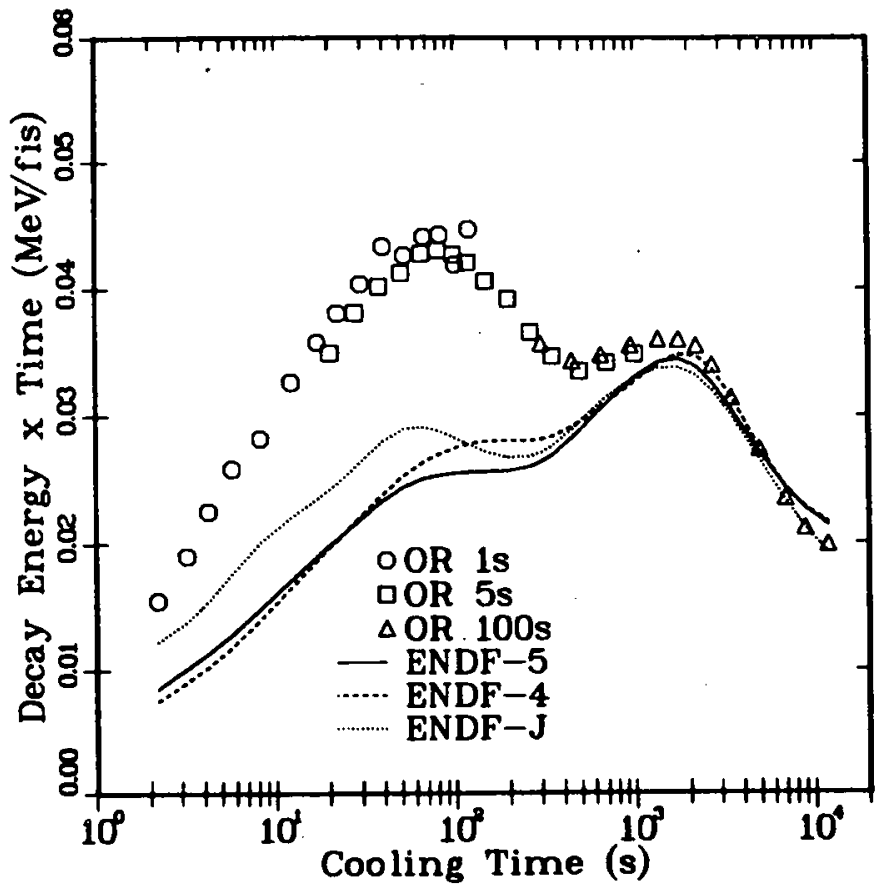

Fig. 126.

Comparison of ${ }^{239} \mathrm{Pu}$ thermal beta-fits with experiment, Group 5.

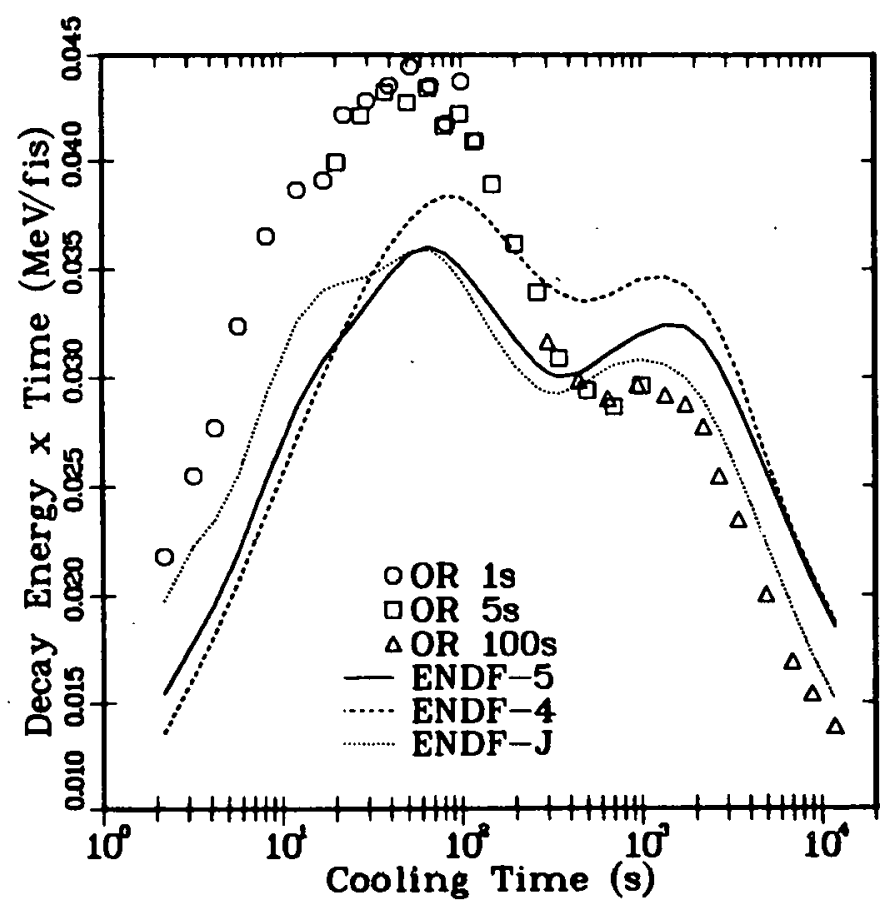

Fig. 128.

Comparison of ${ }^{239} \mathrm{Pu}$ thermal beta-fits with experiment, Group 7. 


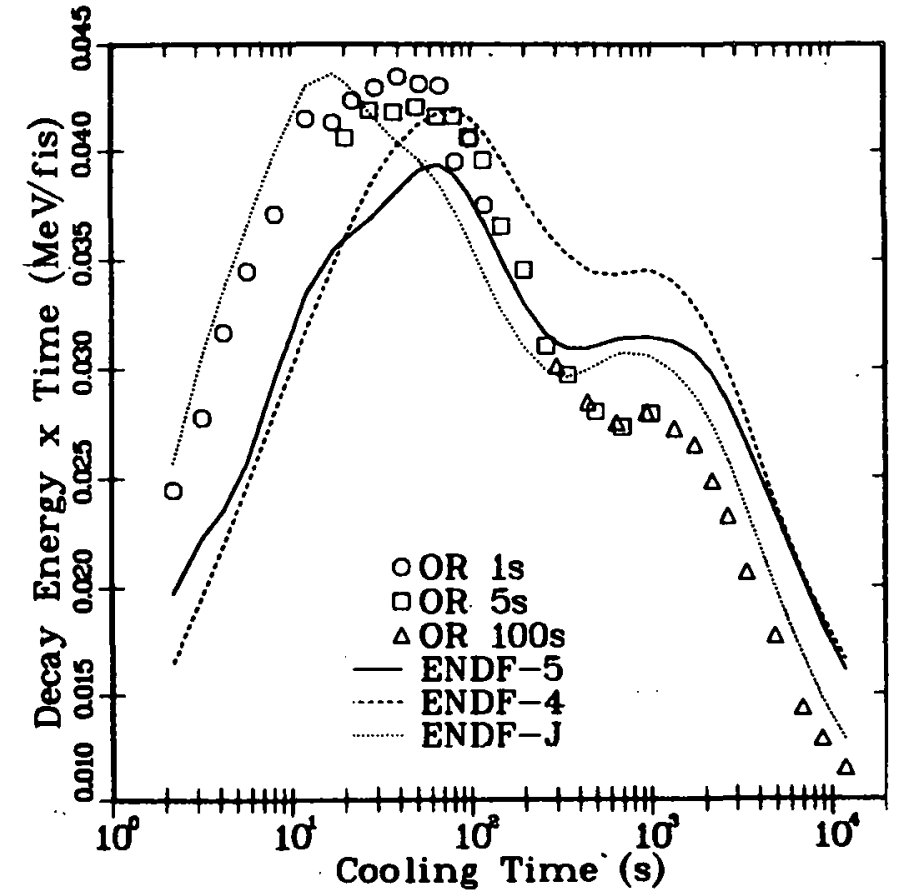

Fig. 129.

Comparison of ${ }^{239} \mathrm{Pu}$ thermal beta-fits with experiment, Group 8.

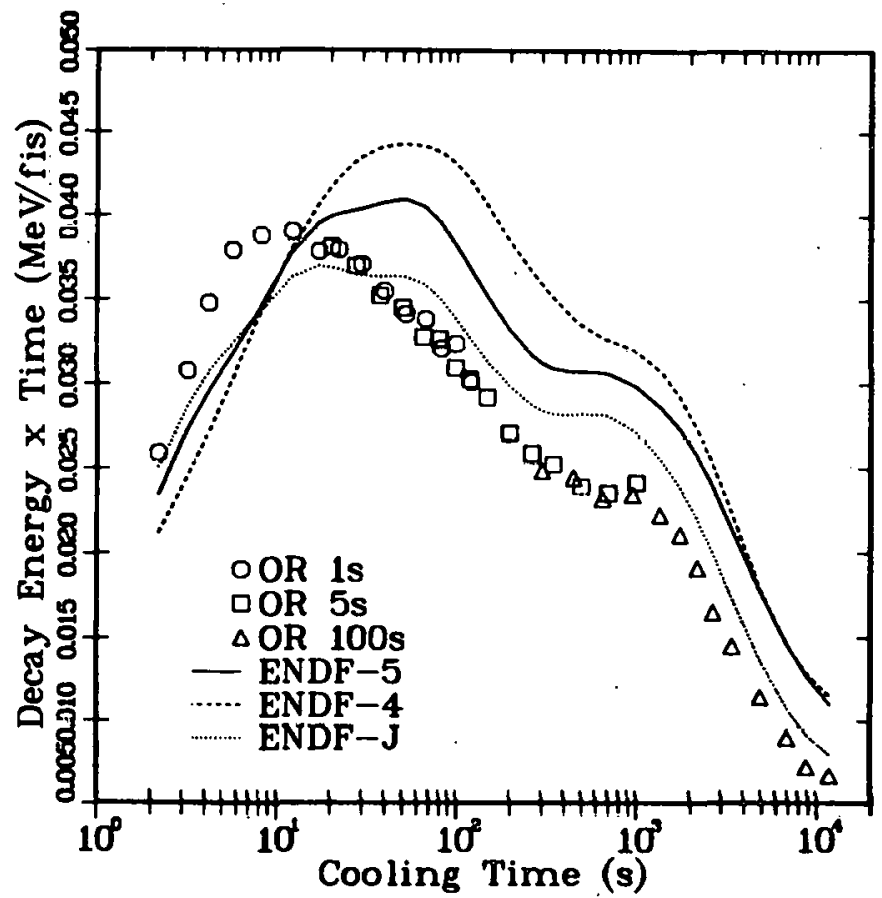

Fig. 131.

Comparison of ${ }^{239} \mathrm{Pu}$ thermal beta-fits with experiment, Group 10.

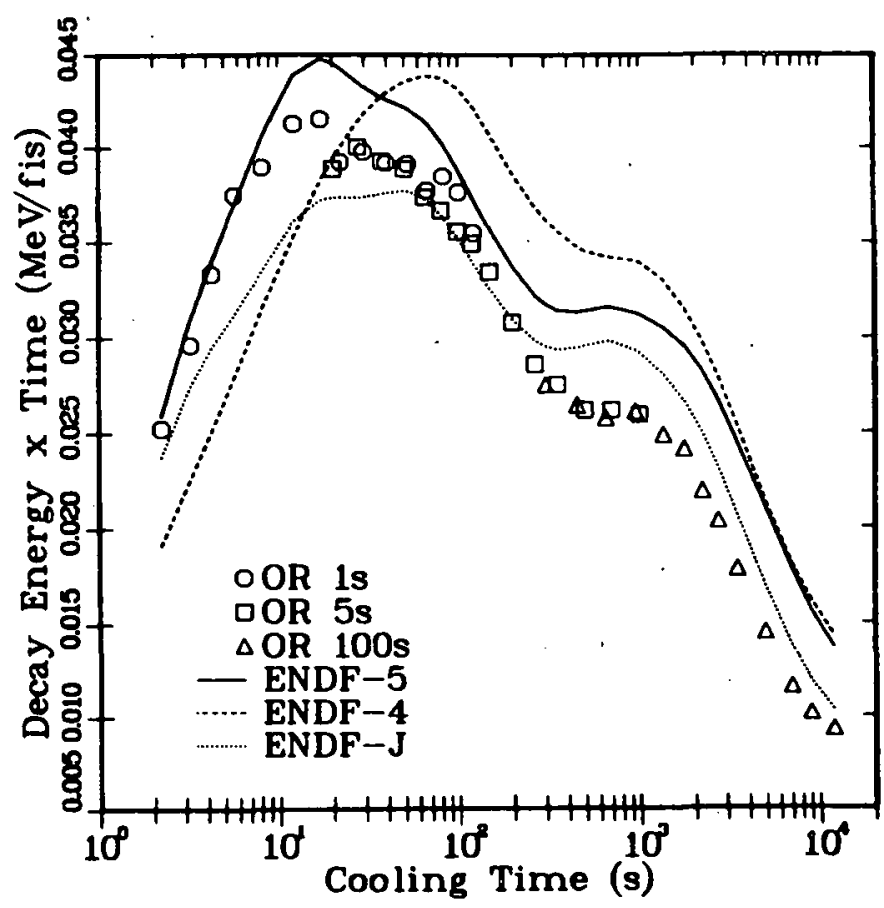

Fig. 130.

Comparison of ${ }^{239} \mathrm{Pu}$ thermal beta-fits with experiment, Group 9.

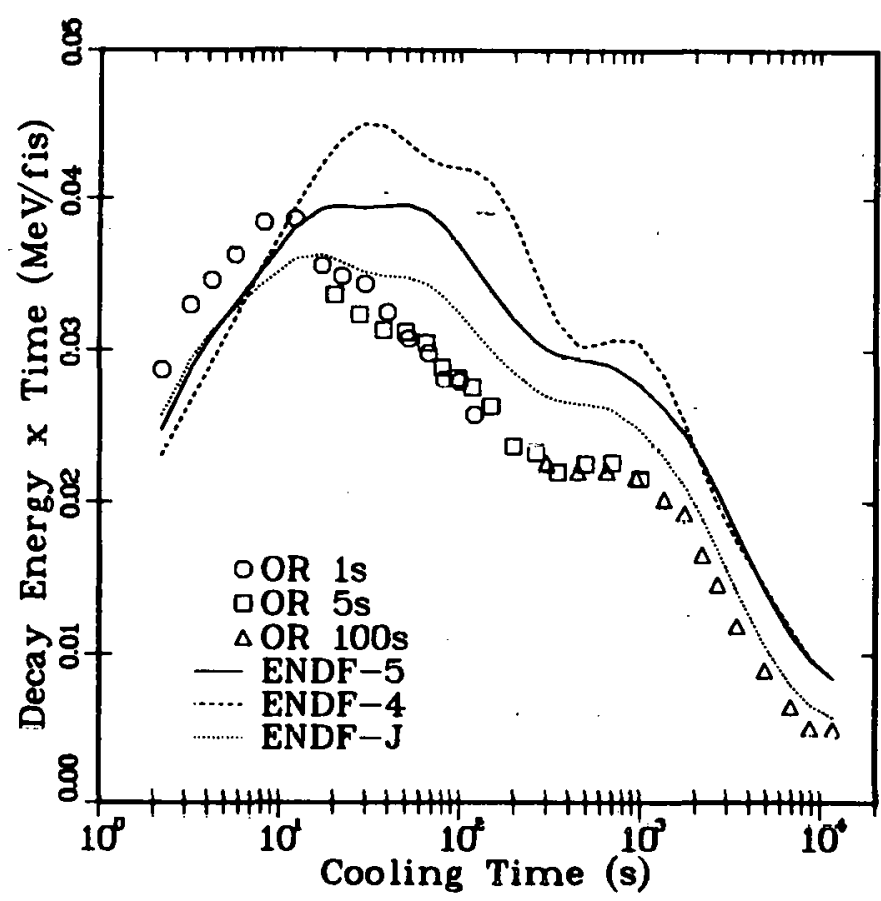

Fig. 132 .

Comparison of ${ }^{239} \mathrm{Pu}$ thermal beta-fits with experiment, Group 11. 


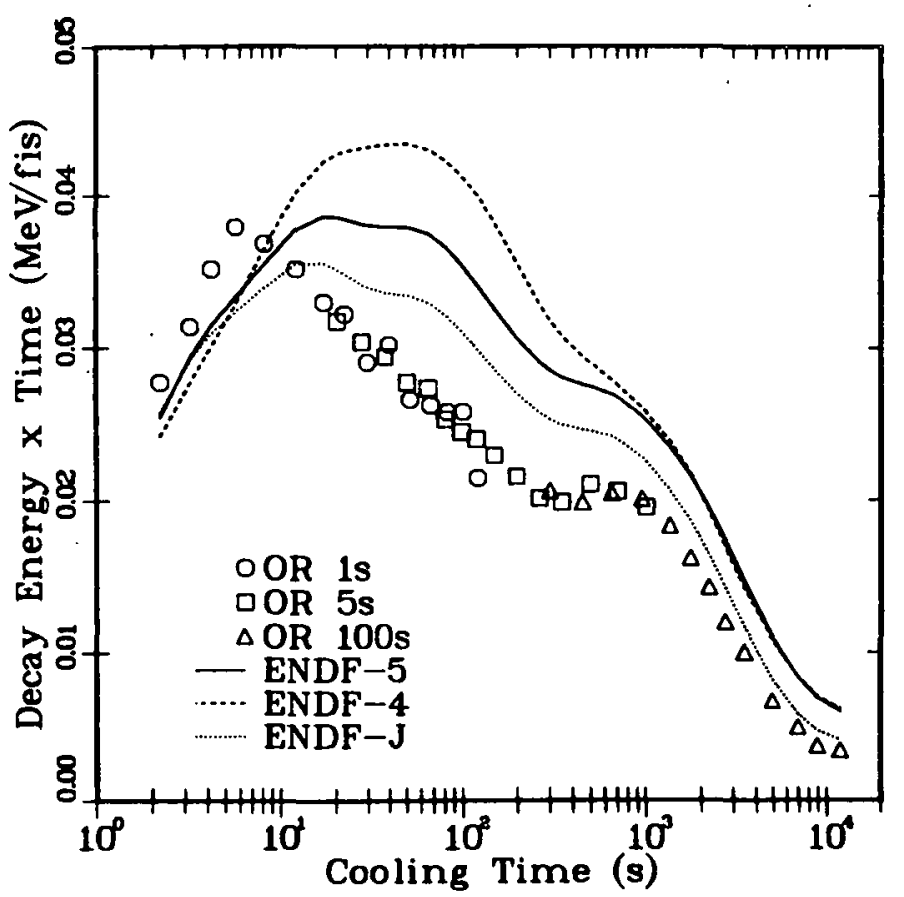

Fig. 133.

Comparison of ${ }^{239} \mathrm{Pu}$ thermal beta-fits with experiment, Group 12.

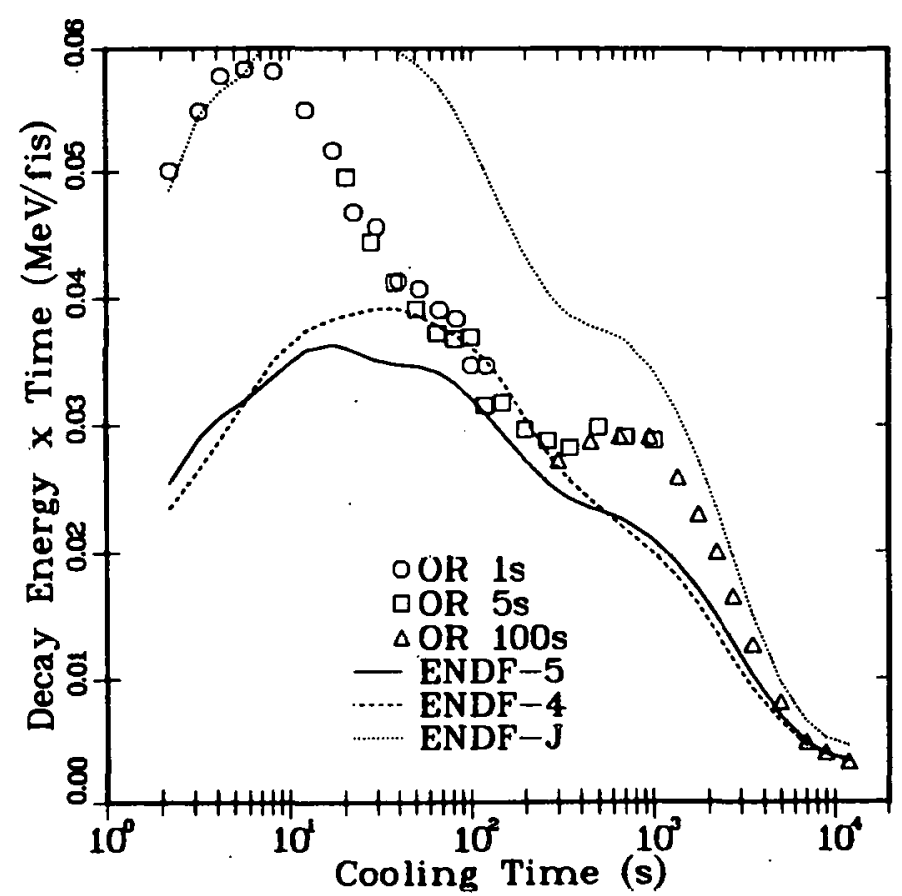

Fig. 135.

Comparison of ${ }^{239} \mathrm{Pu}$ thermal beta-fits with experiment, Group 14.

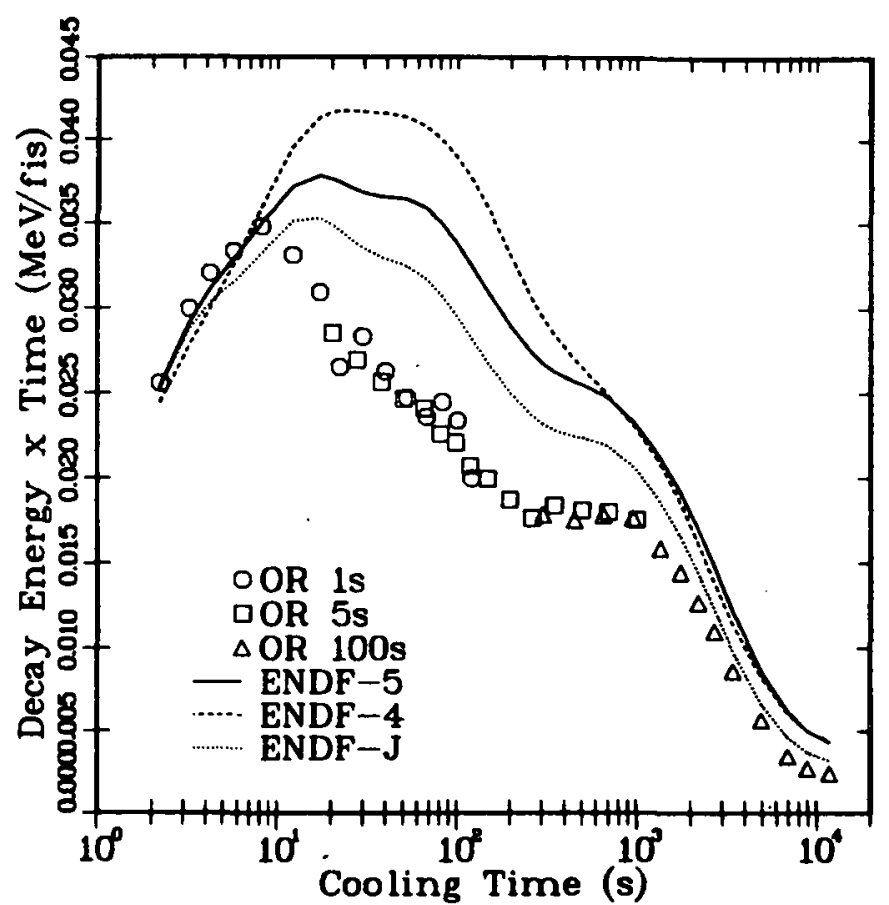

Fig. 134 .

Comparison of ${ }^{239} \mathrm{Pu}$ thermal beta-fits with experiment, Group 13.

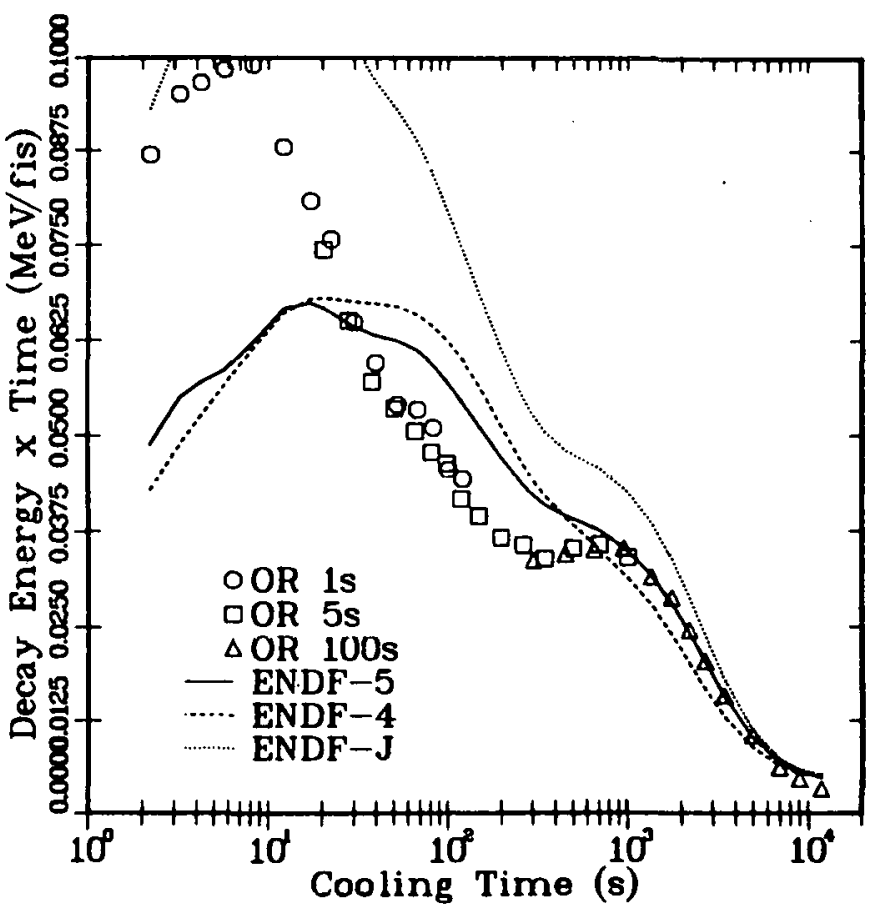

Fig. 136 .

Comparison of ${ }^{239} \mathrm{Pu}$ thermal beta-fits with experiment, Group 15 . 

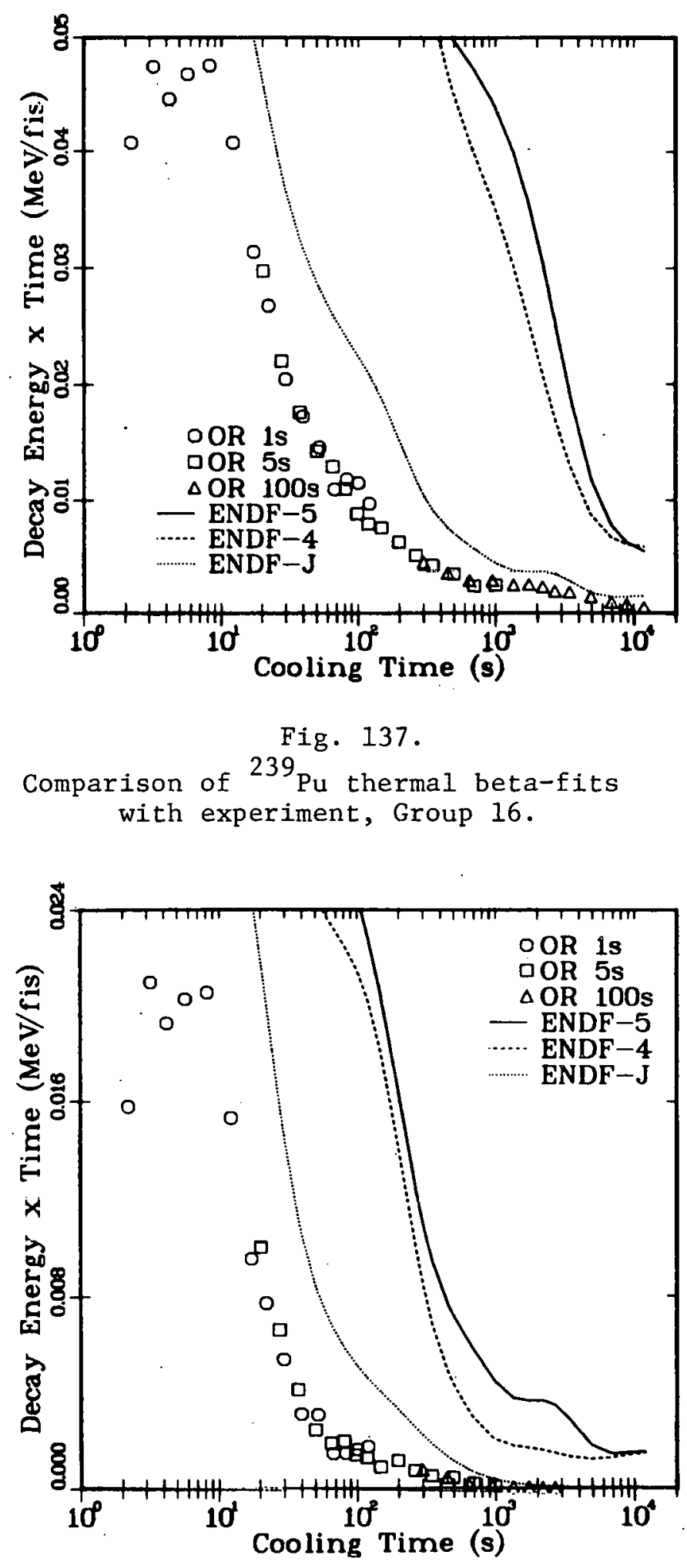

Fig. 138.

Comparison of ${ }^{239} \mathrm{Pu}$ thermal beta-fits with experiment, Group 17. 
the gamma-ray energies from the total energies. Results are displayed in Fig. 139 for ${ }^{235} \mathrm{U}$ betas and Fig. 140 for ${ }^{239} \mathrm{Pu}$ betas. The large discrepancy seen in Fig. 140 for the Los Alamos data has not been resolved.

Specifically, the following conclusions can be drawn from the spectral comparisons. .

(1) The experimental data are consistent except for the ${ }^{239} \mathrm{Pu}$ beta energy inferred from two Los Alamos experiments and compared to the Oak Ridge experiment.

(2) No method of calculating the decay-energy fits the experimental spectral data very well (aggregate results using the combined JNDC/ENDF data agree with the Oak Ridge experiments).

(3) In general, calculated gamma decay-energies at short cooling times $(<100 \mathrm{~s})$ are high at low energies $(<0.8 \mathrm{MeV})$ and low at high energies $(>1.6 \mathrm{MeV})$ in comparison to experiments.

(4) In general, calculated beta decay-energies are low at all cooling times for low energies $(<1.4 \mathrm{MeV})$ and high for high energies $(>1.8 \mathrm{MeV})$.

\section{Summary.}

Three experiments (one from Oak Ridge and two from Los Alamos), in which samples of ${ }^{235} \mathrm{U}$ and ${ }^{239} \mathrm{Pu}$ were irradiated with thermal neutrons and either the total, gamma-ray, or gamma- and beta-ray fission product decay-energies were measured as functions of cooling time, were selected for comparisons with calculations made using four different fission product data flles. The data files used included the ENDF/B-IV, ENDF/B-V, and decay-energies from the JNDC file and spectra from the UK file combined with ENDF/B-V. In the case of the JNDC file, only average total beta-ray and gamma-ray energies for each nuclide were available, so a JNDC-ENDF file was assembled by replacing these energies in the ENDF/B-V fission product data file.

To assess the relative validity of these data files, two types of integral calculations were performed and compared to the experimental results. In the first type, direct summation calculations were performed using the data files as input, and resulting total gamma- and beta-ray decay-energies as a function of cooling time were compared with experiments.

In the second type, integral spectral comparisons were made by rebinning both the experimental data and pulse data from summation calculations, fitting both with sums of exponential functions, and comparing results. 


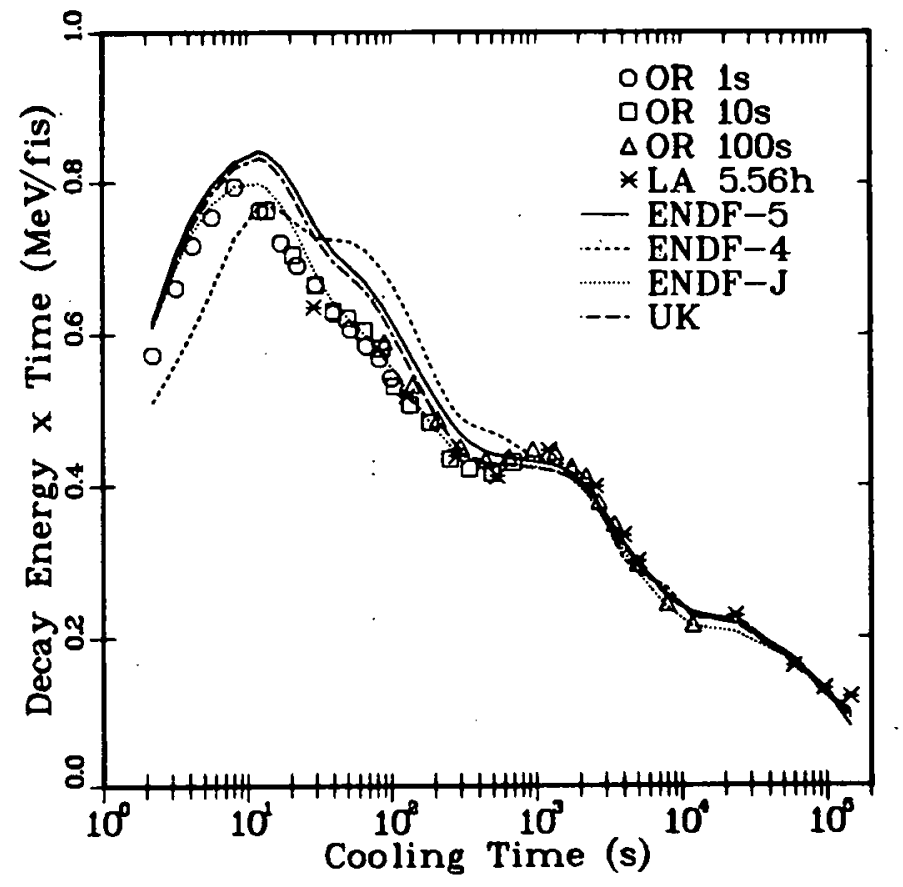

Fig. 139.

Comparison of ${ }^{235} \mathrm{U}$ thermal beta fits

with experiment, total over all groups.

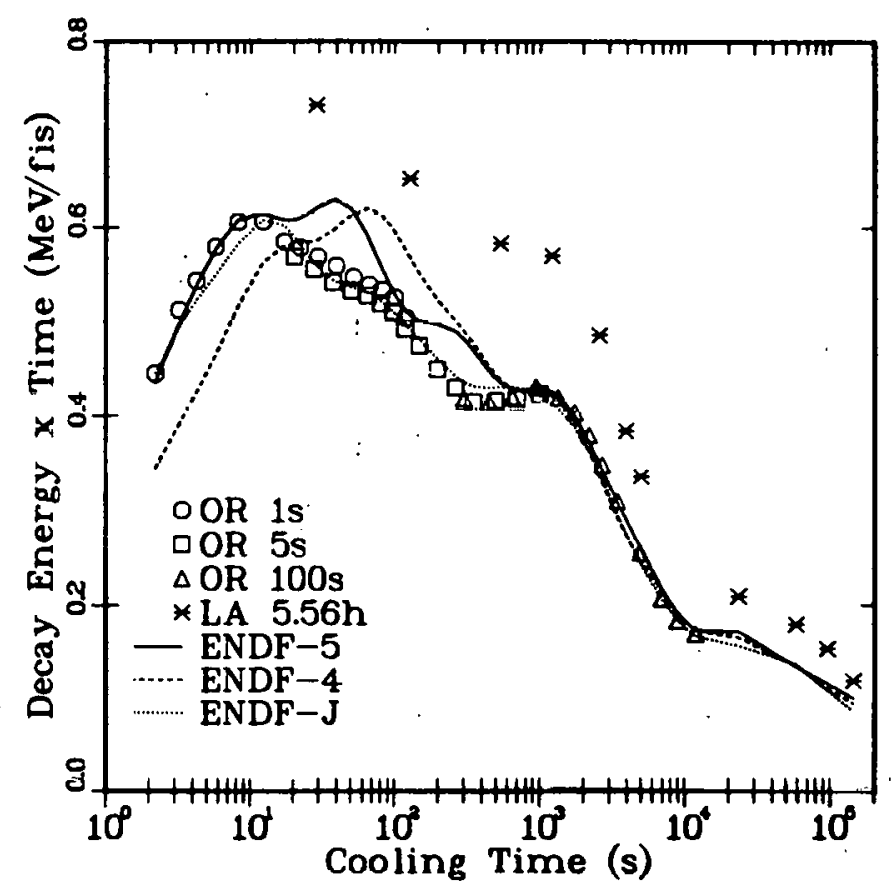

Fig. 140 .

Comparison of ${ }^{239} \mathrm{Pu}$ thermal beta fits with expertmenl, total over all groups. 
Both types of calculational analyses yielded the same results; namely, all data files are deficient, but the JNDC-ENDF results for the gamma- and beta-ray total decay-energy agree best with experiments. In addition, spectral comparisons with experiment generally indicate that calculated gamma-ray decayenergies are relatively high for early cooling times and small gamma-ray energies; they are low for early cooling times and large gamma-ray energies. The opposite is somewhat the case for the beta-ray decay-energies; that is, the calculations tend to be low for small beta-ray energies and high for large energies. Very few errors (none that are significant to the aggregate decay power) have been found in the ENDF/B-V files, and the CINDER-10 code library based on processing these files has been extensively checked for errors. One is forced to conclude that some data in $E N D F / B-V$, probably the experimental decay energies for the individual nuclides, are likely deficient. This has already been assumed in compiling the 1981 Japanese data file in which it is noted "that the complex beta-decay schemes based on gamma-ray peak analysis and intensity balance should be regarded as doubtful from the viewpoint of completeness." For nuclides having Q-values > $5 \mathrm{MeV}$, they used fitted parameters in a model based on the gross theory of beta decay to replace $\beta^{-}$and $\gamma$ experimental energies. When used in our calculation, the improved agreement with sensitive pulse cases for two fuels differing greatly in fission-yield distributions is remarkable; this strongly indicates that yield and decay parameters in ENDF/B-V, other than some decay energies of short-lived nuclides, are very good.

The conclusion regarding deficient gamma energies based on total energy calculations was also suggested in earlier reports. ${ }^{4}, 24,25$. Our comparisons using additional aggregate experiments, and particularly the spectral comparisons, greatly strengthen the conjecture that some short-lived (high-Q) nuclides have a gamma spectrum that is too soft (and an inferred beta spectrum that is too hard). In addition, the deficient spectra are most likely in those nuclides having experimentally measured spectra, not in model estimates, because of their dominance in the aggregate energy calculations. Calculations of total energies using the complete UK and JNDC independently evaluated data files by Tobias and Yoshida (October $1980 \mathrm{file}$ ) are in general agreement with calculations based only on ENDF/B-V. These files generally use the same experimental data in evaluations, but use different models (based on the experimental data) in estimating the unmeasured average decay-energies; and the UK calculations also use an independent fission-yield evaluation. Therefore, evaluations are generally consistent. 


\section{ACKNOWLEDGMENTS}

We greatly appreciate the discussions we have had with R. E. Schenter, F. Mann, and F. Schmittroth (Hanford Engineering Development Laboratory) during the course of this work. We are also grateful to A. Tobias and colleagues (Central Electricity Generating Board), who have not only supplied evaluated data used in this report, but have provided direct assitance in reviewing the ENDF/B-V evaluations. The recent discussions and exchange of U.S. and Japanese data with T. Yoshida and colleagues (Nippon Atomic Industry Group Nuclear Research Laboratory) was clearly important to the work described in this report. Finally, the experimental data provided by J. K. Dickens (Oak Ridge National Laboratory), J. Yarne11, and E. Jurney (Los Alamos) contributed vitally to our timely comparisons.

\section{REFERENCES}

1. Fission-Product Decay Library of the Evaluated Nuclear Data File, Version IV (ENDF/B-IV). [Available from and maintained by the National Nuclear Data Center (NNC) at Brookhaven National Laboratory.] Specral files in these compilations are based on data evaluated at INEL.

2. Fission-Product Decay Library of the Evaluated Nuclear Data File, Version $V$ (ENDF/B-V). [Available from and maintained by the National Nuclear Data Center (NNC) at Brookhaven National Laboratory.] Spectal files in these compilations are based are based on data evaluated at INEL.

3. T. Yamamoto, "JNDC FP Decay Data File," Japanese Atomic Energy Research Institute report JAERI-M-9357 [NEANDC(J)-72N, INDC(JAP)-59/L] (February 1981).

4. A. Tobias and B. S. J. Davies, "UKFPDD-2: A Revised Fission Product Decay Data File in ENDF/B-IV Format," Central Electricity Generating Board report RD/B.N4942 (November 1980). [See also A. Tobias, CEGB reports RD/B/N4949 and $\mathrm{RD} / \mathrm{B} / 5079 \mathrm{~N} 81$.

5. J. K. Dickens, T. A. Love, J. W. McConne11, J. F. Emery, K. J. Northcutt, and R. W. Peelle, "Delayed Beta- and Gamma-Ray Production Due to Thermal-Neutron Fission of ${ }^{23} \mathrm{U}$, Spectral Distributions for Times After Fission Between 2 and $14000 \mathrm{sec}$ : Tabular and Graphical Data," Oak Ridge National Laboratory report NUREG/CR-0162, ORNL/NUREG-39 (August 1978).

6. J. K. Dickens, T. R. England, T. A. Love, J. W. McConne11, J. F. Emery, K. J. Northcutt, and R. W. Peelle, "Delayed Beta- and Gamma-Ray Production Due to Thermal-Neutron Fission of $239^{\mathrm{Pu}}$ : Tabular and Graphical Spectral

Distributions for Times After Fission Between 2 and $14000 \mathrm{sec}$," Oak Ridge Natinna1 Laboratory report NUREG/CR-1172, ORNL/NUREG-66 (January 1980).

7. J. L. Yarnell and P. J. Bendt, "Decay Heat from Products of ${ }^{235} \mathrm{U}$ Thermal Fission by Fast-Response Boil-Off Calorimetry," Los Alamos Scientific Laboratory report LA-NUREG-6713 (September 1977).

8. J. L. Yarne11 and P. J. Bendt, "Calorimetric Fission Product Decay Heat Measurements for ${ }^{239} \mathrm{Pu},{ }^{23} \mathrm{U}$, and ${ }^{235} \mathrm{U}$," Los Alamos Scientific Laboratory report NUREG/CR-0349, LA-7452-MS (September 1978). 
9. E. T. Jurney, P. J. Bendt, and T. R. England, "Fission Product Gamma Spectra," Los Alamos Scientific Laboratory report LA-7620-MS. (January 1979).

10. "American National Standard for Decay Heat Power in Light Water Reactors," prepared by the American Nuclear Society Standards Committee Working Group ANS-5.1, ANSI/ANS-5.1 (1979).

11. T. R. England, R. Wilczynski, and N. L. Whittemore, "CINDER-7: An Interim Report for Users," Los Alamos Scientific Laboratory report LA-5885-MS (April 1976). [CINDER-10, the version used in this report is unpublished; it is described in "Applied Nuclear Data Research and Development January 1 - March 31, 1976," Los Alamos Scientific Laboratory report LA-6472-PR, p. 60 (1976) and in "Applied Nuclear Data Reseach and Development October 1 December 31, 1975," Los Alamos Scientific Laboratory report LA-6266-PR, p. $13(1976)$.

12. M. G. Stamatelatos and T. R. England, "FPDCYS and FPSPEC, Computer Programs for Calculating Fission-Product Beta and Gamma Multigroup Spectra fromENDF/B-IV Data," Los Alamos Scientific Laboratory report LA-NUREG-6818-MS (May 1977).

13. T. R. England, "SPEC5: A Code to Generate Multigroup Spectra per Nuclide in ENDF/B-IV Format," unpublished data (1981). This code was necessary because of the expanded types of decay data and changes in ENDF/B-V format and for improvement in beta-decay spectra.

14. R. J. LaBauve and D. C. George, "PEFPYD - A Library of Aggregate Fission-Product Decay Data Derived from ENDF/B-IV" Los Alamos Scientific Laboratory report LA-8365-MS (May 1980).

15. R. J. LaBauve, D. C. George, and T. R. England, "FITPULS, A Code for Obtaining Analytic Fits to Aggregate Fission-Product. Decay-Energy Spectra," Los Alamos Scientific Laboratory report LA-8277-MS (March 1980).

16. R. J. LaBauve, T. R. England, D. C. George, and M. G. Stamatelatos, "The Application of a Library of Processed ENDF/B-IV Fission-Product Aggregate Decay Data in the Calculation of Decay-Energy Specta," Los Alamos Scientific Laboratory report LA-7483-MS (September 1978).

17. R. J. LaBauve, T. R. England, M. G. Stamatelatos, and D. C. George, "Approximations to Summation Calculations of Delayed Energy and Spectra from Fission Products," Los Alamos Scientific Laboratory report LA-6684-MS (1977).

18. R. J. LaBauve, T. R. England, D. C. George, and C. W. Maynard, "Fission Product Analytic Impulse Source Functions," report to be published in Nuclear Technology (LA-UR 81-908) (March 1981).

19. G. Erdtmann and W. Soyka, The Gamma-Rays of the Radionuclides (Verlag Chemie, Weinheim, New York, 1979).

20. Staff Members of the Nuclear Science Division, Lawrence Berkeley Laboratory, Table of Isotopes - Seventh Edition (Wiley Interscience, New York 1978 ). 
21. R. J. LaBauve and T. R. England, "Integral Data Testing of ENDF/B Fission Product Data," report presented to CSEWG meeting, Brookhaven National Laboratory, May 1981 (LA-UR-81-1417). (This information transmitted in personal communication with R. E. Schenter, Hanford Engineering Development Laboratory, and is accessible through T. R. England, Los Alamos.)

22. T. Yoshida and R. Nakasima, "Decay Heat Calculations Based on Theoretical Estimation of Average Beta- and Gamma-Energies Released from Short-Lived Fission Products, J. Nucl. Sci. and Tech. 18, No. 6, 393-407 (June 1981).' A publication of the Atomic Energy Society of Japan.

23. F. M. Mann, C. Dunn, and R. E. Schenter, "Beta Decay Properties from a Statistical Model," (contributed paper for the Am. Nucl. Soc. Meeting, San Francisco, November 1981).

24. F. Schmittroth, "Theoretica1 Estimates of Decay Information for NonExperimental Nuclides," Proc. of the Conf. on Nuclear Data Evaluation Methods and Procedures, Brookhaven National Laboratory, September 22-25, 1980 [BNL-NCS-51363, March, 1981].

25. R. J. LaBauve, D. C. George, and T. R. England, "Delayed Photon Spectra from ENDF/B-V Fission Product Data," paper presented at Am. Nuc. Soc. meeting, Miam1 Beach, Fla., June, 1981 (LA-UR 81-123). 
APPENDIX A

This appendix contains sets of alpha, lambda parameter pairs derived from the four data libraries, ENDF/B-IV, ENDF/B-V, JNDC, and UK by using the FITPULS code, as described in Section $V$. The sets are given in the 18-group gamma-ray and 17-group beta-ray energy group structure shown in Table III. The appendix contains the following tables:

Table A-I Fits to $235_{U}$ thermal pulse gammas for ENDF/B-IV data

Table A-II Fits to $235 \mathrm{U}$ thermal pulse betas for ENDF/B-IV data

Table A-III Fits to $23{ }^{9} \mathrm{Pu}$ thermal pulse gammas for ENDF/B-IV data

Table A-IV Fits to ${ }^{239} \mathrm{Pu}$ thermal pulse betas for ENDF/B-IV data

Table A-V Fits to 235 thermal pulse gammas for ENDF/B-V data

Table A-VI Fits to ${ }^{235} \mathrm{U}$ thermal pulse betas for ENDF/B-V data

Table A-VII Fits to ${ }^{239} \mathrm{Pu}$ thermal pulse gammas for ENDF/B-V data

Table A-VIII Fits to ${ }^{239} \mathrm{Pu}$ thermal pulse betas for ENDF/B-V data

Table A-IX Fits to $235_{U}$ thermal pulse gammas for JNDC/ENDF data

Table A-X Fits to $235_{U}$ thermal pulse betas for JNDC/ENDF data

Table A-XI Fits to ${ }^{239} \mathrm{Pu}$ thermal pulse gammas for JNDC/ENDF data

Table A-XII Fits to ${ }^{239} \mathrm{Pu}$ thermal pulse betas for JNDC/ENDF data

Table A-XIII Fits to $235 \mathrm{U}$ thermal pulse gammas for UK data

Table A-XIV Fits to ${ }^{235}$ thermal pulse betas for UK data 
TABLE A-I

\section{FITS TO ${ }^{235} \mathrm{U}$ THERMAL PULSE GAMMAS}

FOR ENDF/B-IV DATA

$$
0.0 \text { TO } .1 \text { MEV }
$$

ALPHA

5. $176 \mathrm{E}-09$

3. $436 \mathrm{E}-\mathrm{O} 7$

1. $776 \mathrm{E}-06$

8.570E-O6

5. $873 \mathrm{E}-05$

1. $043 \mathrm{E}-04$

1. $313 \mathrm{E}-\mathrm{O} 4$

1. 1E.2E-04
LAMBDA
9. O8OE- 07
2. $285 \mathrm{E}-\mathrm{O} 4$
$7.981 E-04$
$3.493 \mathrm{E}-\mathrm{O} 3$
1. $399 \mathrm{E}-\mathrm{O} 2$
5. $467 E-02$
$811 E-01$
9. $955 \mathrm{E}-01$

GROUP 5

6 TO . 8 MEV

$\begin{array}{cc}\text { ALPHA } & \text { LAMEDA } \\ 1.044 E-O 6 & 7.273 E-O 6 \\ 1.302 E-O 6 & 3.590 E-05 \\ 2.503 E-O 5 & 2.50^{-} E-O 4 \\ 6.473 E-O 5 & 1.34 \cdot E-03 \\ 5.617 E-O 4 & 6.703 E-03 \\ 2.130 E-O 3 & 2.775 E-O 2 \\ 7.66 O E-O 3 & 1.130 E-01 \\ 1.143 E-O 2 & 5.425 E-01\end{array}$

1. $130 E-O 1$
5. $425 E-O 1$ ,

$$
\underset{1}{\text { GROUP }} 2 \text { ? MEV }
$$

ALPHA

3. $220 \mathrm{E}-08$

$2.332 \mathrm{E}-\mathrm{O}^{\mathrm{T}}$

2. $244 E-O G$

8. $310 E-06$

1. 389E-O5

2. $756 E-0.9$

1. $045 E-03$

$5.5525-03$

1. $959=-02$
LAMBDA
2. $780 E-O 6$
6. $210 \mathrm{E}-05$
2. $053 E-04$
6. $306 \mathrm{E}-04$
2. $966 \mathrm{E}-\mathrm{O} 3$
1. $677 \mathrm{E}-02$
5. $609 \mathrm{E}-02$
3. $312 E-01$
$1.095 E+00$

GRDUP
$8 \mathrm{TJ} 1.0 \mathrm{MEV}$

$\begin{array}{cc}\text { ALFHA } & \text { LAMBDA } \\ 1.029 E-O 7 & 5.022 E-O 6 \\ 2.003 E-03 & 4.778 E-05 \\ 4.646 E-O 5 & 1.900 E-04 \\ 1.613 E-04 & 1.415 E-03 \\ 5.653 E-O 4 & 6.208 E-03 \\ 1.844 E-03 & 3.167 E-02 \\ 8.239 E-03 & 1.378 E-01 \\ 1.073 E-01 & 7.616 E-01\end{array}$

1. $378 \mathrm{E}-01$
$7.616 \mathrm{E}-01$
GROUP 3

.2 TO . 4 MEV

ALPHA

3. $077 \mathrm{E}-07$
1. $547 \mathrm{E}-07$

2. $139 E-05$

4. 199E - O5

2. $537 \mathrm{E}-04$

$.643 \mathrm{E}-03$

$1.017 E-02$
LAMBDA

2. $465 \mathrm{E}-05$

$4.048 E-04$

9. $253 \mathrm{E}-\mathrm{O} 4$

6. $985 \mathrm{E}-03$

2. $850 E-02$

1. $105 \mathrm{E}-01$

5. $671 \mathrm{E}-01$

\begin{tabular}{|c|c|}
\hline ALPHÁ & LAMBDA \\
\hline $504 E-07$ & $9.355 E-06$ \\
\hline $1.393 E-06$ & $4.664 E-05$ \\
\hline 1. $197 E-03$ & $5.616 E-04$ \\
\hline $2.258 \mathrm{E}-\mathrm{O} 2$ & 1. $302 \mathrm{O}-01$ \\
\hline 8. $32 \mathrm{OE}-02$ & 4. $880 E-01$ \\
\hline $1.627 \mathrm{E}-02$ & 4. $503 \mathrm{E}-01$ \\
\hline $1.776 E-03$ & 6. $328 E-04$ \\
\hline $1.601 E-03$ & $1.028 E-03$ \\
\hline $1.316 E-03$ & $1.446 E-0.3$ \\
\hline $5.849 E-04$ & $2.670 E-03$ \\
\hline $.795 E-03$ & 3. $846 E-0 ?$ \\
\hline $.849 E-03$ & $4.684 E-02$ \\
\hline
\end{tabular}

GROUP 4

$$
\begin{gathered}
\text { GROUP } \\
.4 \text { TO } \\
6 \text { MEV }
\end{gathered}
$$

GROUP 7

1.0 TO $1.2 \mathrm{MEV}$

$\begin{array}{cc}\text { ALPHA } & \text { LAMBDA } \\ 4.643 E-O 7 & 1.534 E-O 5 \\ 1.708 E-0.6 & 4.396 E-05 \\ 2.842 E-05 & 3.018 E-04 \\ 9.821 E-O 5 & 1.247 E-03 \\ 3.863 E-O 4 & 7.315 E-03 \\ 2.464 E-03 & 2.863 E-02 \\ 5.290 E-03 & 1.204 E-01 \\ 1.022 E-02 & 5.544 E-01\end{array}$

GROUP 8

$$
\text { 1.2 TO 1.4 MEV }
$$

ALPHA

1. $551 \mathrm{E}-07$

3. $430 \mathrm{O}-\mathrm{OS}$

7. $335 \mathrm{E}-06$

1. $100 E-04$

8. $859 E-04$

2. $478 \mathrm{E}-03$

7. $881 \mathrm{E}-03$

2. $084 \mathrm{E}-\mathrm{O} 2$
LAMBDA

9. $584 E-06$

4. $960 E-O 5$

1. $437 \mathrm{E}-\mathrm{O} 4$

9. $970 E-O A$

8. $400 E-O 3$

2. $780 E-02$

$1.224 \mathrm{E}-01$

5. $672 \mathrm{E}-\mathrm{OI}$ 
GROUP 9 1.4 TO $1.6 \mathrm{MEV}$

ALPHA LAMBDA

5.886E-O8 $1.818 E-06$

6. $44 \mathrm{CE}-\mathrm{O} 8 \quad 2.638 \mathrm{E}-\mathrm{O} 6$

9.827E-07 4.715E-O5

$6.441 \mathrm{E}-05 \quad 3.472 \mathrm{E}-04$

1.837E-O3 $9.744 \mathrm{E}-\mathrm{O} 3$

5. $608 \mathrm{E}-\mathrm{O} 3 \quad 4.107 \mathrm{E}-\mathrm{O} 2$

1. $197 \mathrm{E}-\mathrm{O} 2$ 2.517E-01

7.382E-O3 1. $196 E+O D$

$-2.502 E-05 \quad 4.931 E-01$

$\begin{array}{rr}-1.224 E-07 & 5.717 E-06 \\ 1.771 E-07 & 2.694 E-05\end{array}$

GROUP 13

\subsection{TO 2.4 MEV}

ALPHA

1.811E-O9

3. $211 \mathrm{E}-06$

1. $077 E-05$

$1.086 \mathrm{E}-05$

$1.042 \mathrm{E}-02$

$-9.840 E-03$

1. $146 \mathrm{E}-\mathrm{O}$

$2.031 \mathrm{E}-03$
LAMBDA

1. $195 \mathrm{E}-06$

7. $109 E-05$

2. $191 \mathrm{E}-\mathrm{O} 4$

8. 264E-04

1. $345 \mathrm{E}-02$

1. $345 \mathrm{E}-02$

1. $368 \mathrm{E}-\mathrm{O} 2$

5. $473 E-O 2$
4. $173 E-O 1$
GROUP 10

$$
1.6 \text { TO } 1.8 \text { MEV }
$$

ALPHA

3. $062 \mathrm{E}-07$

8. $791 \mathrm{E}-07$

8. $631 \mathrm{E}-06$

5. $551 E-05$

$1.332 \mathrm{E}-03$

I. $332 \mathrm{E}-03$

3. $419 \mathrm{E}-\mathrm{O} 3$

\begin{abstract}
LAMBDA
2. $139 E-05$

4. $799 E-05$

2. $563 E-O A$

1. $187 \mathrm{E}-03$

6. 892E-O3

2. $735 E-02$

TE- 01

5. 263E-01
\end{abstract}

GROUP 14

2.4 TO $2.6 \mathrm{MEV}$

ALPHA

$5.342 \mathrm{E}-09$

3. 174E-O9

4. $019 E-06$

2. $033 \mathrm{E}-06$

2. $224 \mathrm{E}-05$

2. $2.24 \mathrm{E}-05$

1. $612 E-03$

3. $191 \mathrm{E}-03$

6. $226 \mathrm{E}-\mathrm{O} 3$

2. $930 \mathrm{E}-08$

5. $579 \mathrm{E}-08$

LAMBDA

4. 869E-O6

7. $279 \mathrm{E}-06$

1. $318 E-04$

2. $936 \mathrm{E}-04$

9. $608 \mathrm{E}-04$

8. $958 \mathrm{E}-03$

2. $680 \mathrm{E}-\mathrm{O} 2$

1. $230 E-01$

$6.597 \mathrm{E}-01$

1. 796E-05

3. 519E-O5
GROUP 11

1.8 TO 2.0 MEV

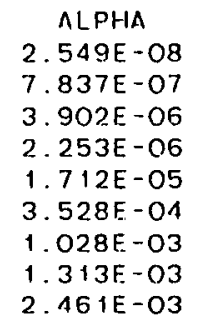

LAMBDA

9.862E-O6

$5.473 \mathrm{E}-05$

1. $337 \mathrm{E}-01$

3. $584 \mathrm{E}-04$

1. $1 \mathrm{GGE}-03$

8. $322 \mathrm{E}-\mathrm{O} 3$

2. $673 \mathrm{E}-\mathrm{O} 2$

1. 146E-01

5. 253E-O 1

GROUP 15

2. 6 TO 3 MEV
GROUP 12

2.0 TO 2.2 MEV

\begin{tabular}{|c|c|}
\hline ALPHA & LAMBDA \\
\hline $.124 E-08$ & $O E-O$ \\
\hline $9.628 E-07$ & $5.943 E-05$ \\
\hline $4.956 E-06$ & 1. $105 E-O$ \\
\hline $1.540 E-04$ & $9.577 \mathrm{E}-0$ \\
\hline $5.568 \mathrm{E}-04$ & $1.443 \mathrm{E}-02$ \\
\hline 1. $432 \mathrm{E}-03$ & $1.074 E-0$ \\
\hline 2. $224 \mathrm{E}-03$ & $1.015 E+0$ \\
\hline $.202 E-05$ & $1.014 \mathrm{E}-\mathrm{C}$ \\
\hline
\end{tabular}

GROUP 16

3.0 TO $4.0 \mathrm{MEV}$

$\begin{array}{cc}\text { ALPHA } & \text { LAMBDA } \\ 9.684 E-11 & 1.031 E-06 \\ 2.288 E-07 & 7.773 E-05 \\ 2.758 E-O 5 & 1.463 E-04 \\ 1.494 E-O 5 & 7.398 E-04 \\ 3.031 E-04 & 3.749 E-03 \\ 1.628 E-O 3 & 1.338 E-02 \\ 2.495 E-O 3 & 5.344 E-02 \\ 3.470 E-03 & 2.834 E-01 \\ 3.427 E-03 & 1.039 E+00\end{array}$




\section{TABLE A-I (Cont)}

GROUP 17 4. 5 TO $5.0 \mathrm{MEV}$

ALPHA

4. $848 \mathrm{E}-1$

2. $184 E-08$

4. 49 1E - 08

1. 39 IE -OG

2. $98 \mathrm{EE}-\mathrm{O} 4$

7. 51 E -01

$1.555 \mathrm{E}-03$

2. $58: E-03$

2. $668 \mathrm{E}-03$

LAMBDA

1. $200 E-06$

7. 1 AOE-O5

2. $185 E-04$

9. $111 \mathrm{E}-04$

4. $280 E-03$

. $374 \mathrm{E}-\mathrm{O}$.

5. $583 E-02$

2. $676 E-01$

1. $046 E+O O$
GROUP 18 5.0 TO $6.0 \mathrm{MEV}$

$\begin{array}{cc}\text { ALPHA } & \text { LAMBDA } \\ 5.413 E-12 & 8.827 E-07 \\ 6.734 E-08 & 8.333 E-04 \\ 1.963 E-05 & 3.672 E-03 \\ 5.447 E-O 5 & 7.807 E-03 \\ 1.418 E-04 & 2.755 E-02 \\ 1.986 E-O 3 & 1.419 E-01 \\ 3.14 O E-O 3 & 5.569 E-01\end{array}$




$$
0.0 \text { TO } .2 \text { MEV }
$$

ALPHA

1. O48E-07

3. $280 \mathrm{E}-\mathrm{O} 7$

1. $258 \mathrm{E}-06$

5. $106 E-06$
9. $437 E-06$

4. $523 \mathrm{E}-05$

4. $604 \mathrm{E}-03$

$-5.369 \mathrm{E}-03$

. 132E-O3

\begin{abstract}
LAMBUA
\end{abstract}
5. $569 E-06$

3. $704 \mathrm{E}-05$

1. $479 E-04$

4. $865 \mathrm{E}-\mathrm{OA}$

$1.254 \mathrm{E}-03$

7. 19OE - O3

$6.779 \mathrm{E}-\mathrm{O} 2$

7. $367 \mathrm{E}-02$

$1.162 \mathrm{~F}-\mathrm{O}$

1. $194 \mathrm{E}+0 \mathrm{O}$

\section{GROUP 5}

$$
.8 \text { TO } 1.0^{5} \mathrm{MEV}
$$

ALPHA
$4.298 E-07$
$1.720 E-O 6$
$9.508 E-O 6$
$4.110 E-05$
$1.541 E-04$
$6.158 E-04$
$1.543 E-03$
$2.803 E-03$
$8.352 E-03$

LAMBDA

$1.066 E-05$

$5.211 E-05$

2. $149 \mathrm{E}-\mathrm{O} 4$

7. $405 E-04$

3. $678 \mathrm{E}-03$

1. $249 \mathrm{E}-\mathrm{O}$ ?

$3.829 E-02$

1. $226 \mathrm{E}-\mathrm{O} 1$

5. $612 \mathrm{E}-01$
GROUP 2

.2 TO .4 MEV

ALPHA

3. $541 \mathrm{E}-07$

$\therefore .096 E-06$

5. $979 E-06$

3. $346 \mathrm{E}-05$

1. 137E-01

1. $213 E-O$

8. $131 \mathrm{E}-03$

1. $523 \mathrm{E}-03$

\begin{abstract}
LAMBDA
8. $407 E-O G$

4. $735 E-05$

$2.274 E-04$

8. $668 \mathrm{E}-01$

1. $129 \mathrm{E}-02$

1. $14 O E-O 2$

1. $335 E-02$

$7.086 E-01$
\end{abstract}

GROUP 6

1.0 TO $1.2 \mathrm{MEV}$

ALPHA

3. $342 E-07$

1. $947 \mathrm{E}-06$

9. $226 \mathrm{E}-06$

4. $005 E-05$

9. $419 E=05$

3. $895 \mathrm{E}-04$

1. $275 \mathrm{E}-03$

2. $734 \mathrm{E}-03$

$4.581 E-03$

1. $048 \mathrm{E}-02$
AMBDA

$1.230 E-05$ $5.437 \mathrm{E}-05$ 2. $234 \mathrm{E}-\mathrm{OA}$ 7. $288 \mathrm{E}-04$ 2. $812 \mathrm{E}-03$ 7. $961 \mathrm{E}-03$ 2. $335 \mathrm{E}-02$ 7. $132 \mathrm{E}-\mathrm{O}$ ?

2. $276 E-O 1$

\section{GROUP 3}

4 TO $6 \mathrm{MEV}$

ALPHA

5. $431 E-07$

1. 127E-06

6. $522 \mathrm{E}-06$

4. O56E-O5

1. $170 E-01$

3. $568 \mathrm{E}-04$

8. 289E-04

5. $214 \mathrm{E}-\mathrm{O} 3$

$-3.546 E-03$

3. $249 \mathrm{E}-03$

\begin{abstract}
LAMBDA
9. 706E-06

4. $846 \mathrm{E}-05$

2. $054 \mathrm{E}-04$

7. $635 \mathrm{E}-\mathrm{O}$

4. $166 \mathrm{E}-03$

1. $386 \mathrm{E}-02$

4. $371 E-02$

2. $262 \mathrm{E}-\mathrm{O}$

2. $584 \mathrm{E}-\mathrm{O}$

8. 707E-0 1
\end{abstract}

\section{GROUP 7 \\ 1.2 TO 1. 4 MEV}

ALPHA

3. O56E-07

1. $978 \mathrm{E}-06$

9. $006 \mathrm{E}-06$

3. $834 E-05$

8. $114 \mathrm{E}-05$

3. $771 \mathrm{E}-04$

1. $431 \mathrm{E}-03$

3. $248 \mathrm{E}-03$

$5.823 E-03$

1. $319 E-02$
LAMBDA

1. $442 \mathrm{E}-05$

5. 592E-O5

2. $367 E-O 4$

7. $394 \mathrm{E}-\mathrm{O} 4$

2. $442 \mathrm{E}-03$

7. $301 \mathrm{E}-03$

2. $179 \mathrm{E}-02$

6. $976 E-O 2$

2. $200 E-O$

7. $786 \mathrm{E}-\mathrm{O} 1$
GROUP 4

6 TO .8 MEV

5. 352E-07

1. $458 \mathrm{E}-06$

8. $406 E-06$

4. $176 \mathrm{E}-05$

1. $506 \mathrm{E}-04$

5. $011 \mathrm{E}-04$

1. $159 E-03$

2. $323 E-O 3$

6. $342 \mathrm{E}-\mathrm{O} 3$

LAMBDA

9. $959 \mathrm{E}-06$

4. $983 \mathrm{E}-05$

2. $110 E-04$

7. $494 \mathrm{E}-04$

$4.071 \mathrm{E}-03$

1. $339 \mathrm{E}-\mathrm{O} 2$

4. $\mathrm{O} 8 \mathrm{OE}-\mathrm{O} 2$

1. $380 E-01$

7. $531 \mathrm{E}-01$

\section{GROUP 8 \\ 1. 4 TO 1.6 MEV}

ALPHA
2. $978 \mathrm{E}-\mathrm{O}$

2. $978 E-07$

1. $937 E-06$

8. $722 \mathrm{E}-\mathrm{O6}$
4. $072 \mathrm{E}-\mathrm{O5}$

4. $072 E-05$
8. O7OE-O5

3. $988 E-04$

1. $521 \mathrm{E}-\mathrm{O} 3$

3. $857 \mathrm{E}-03$

$6.658 E-03$
$1.735 E-02$

LAMBDA

1. 582 E-O5

5. $685 \mathrm{E}-05$

2. $627 \mathrm{E}-04$

$7.628 \mathrm{E}-04$

2. $559 \mathrm{E}-\mathrm{C} . \mathrm{S}$

7. 343E-03

2. $234 \mathrm{E}-\mathrm{O} 2$

6. $990 \mathrm{O}-\mathrm{O} 2$

2. $222 \mathrm{E}-\mathrm{O} 1$

8. $199 E-01$

8. 199E-O

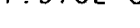


TABLE A-II (Cont)

GROUP 9 1.6 TO $1.8 \mathrm{MEV}$

\section{GROUP 13 \\ 2.4 TO 2.5 MEV}

ALPHA

5. $462 \mathrm{E}-08$

8. $227 E-07$

1. $186 \mathrm{E}-\mathrm{O} 5$

5. $607 \mathrm{E}-05$

3. $391 E-04$

1. $44 E E-03$

4. 835E-O3

1. $086 E-02$

2. $483 E-02$
L.AMBDA

1. 84OE-O5

4. $830 \mathrm{OE}-\mathrm{OS}$

4. $803 E-04$

1. $516 \mathrm{E}-03$

6. $795 \mathrm{E}-03$

2. $267 \mathrm{E}-\mathrm{O} 2$

7. $538 E-02$

2. $442 E-01$

9. $135 E-01$
GROUP 10

1.8 TO

AL PHA

2. $2<2 E-O$ ?

1. 3<6E-O6

1. $359 \mathrm{E}-05$

5. $264 \mathrm{E}-05$

2. $1: 9 E-O 4$

$9.681 \mathrm{E}-0.4$

2. $732 \mathrm{E}-\mathrm{O} 3$

8. $324 \mathrm{E}-\mathrm{O}$

2. $246 \mathrm{E}-02$
GROUP 11

2.0 TO $2.2 \mathrm{MEV}$

1. $804 \mathrm{E}-07$

1. $932 E-06$

3. $992 \mathrm{E}-05$

2. $919 E-04$

$5.015 E-03$

3. $884 \mathrm{E}-\mathrm{O} 2$

$-5.193 E-02$

4. $818 E-02$

$-6.214 \mathrm{E}-\mathrm{O} 3$

. $019 E-02$

$-3.365 E-05$

$-3.004 E-06$

5. $110 E-06$

GROUP 1.1

2.650 3.O MEV

4LPHIA
1.325E-O8
$1.394 E-06$
$1.605 E-05$
8. $907 E-05$
$6.584 E-04$
$3.583 E-03$
$1.773 E-02$
$5.110 E-O 2$
LAMBDA

1. $688 \mathrm{E}-05$

4. $995 \mathrm{E}-05$

$4.831 \mathrm{E}-04$

$1.420 E-03$

$6.799 \mathrm{E}-03$

2. 703E-O2

1. $229 \mathrm{E}-01$

GROUP 17 5.0 TO 6.0 MEV

\begin{tabular}{|c|c|}
\hline ALPHA & LAMBDA \\
\hline $990 E-12$ & $5.137 \mathrm{E}-\mathrm{O}$ \\
\hline $739 E-08$ & 7. $164 E-O$ \\
\hline $209 \mathrm{E}-05$ & 4. $139 E-0$ \\
\hline $.485 E-04$ & $1.217 \mathrm{E}-\mathrm{O}$ \\
\hline $431 E-03$ & $6.044 \mathrm{E}-0$ \\
\hline $646 \mathrm{E}-\mathrm{O} 2$ & $5.579 \mathrm{E}-\mathrm{O}$ \\
\hline $.989 \mathrm{E}-\mathrm{O} 2$ & $7.593 E-0$ \\
\hline $384 E-02$ & 1. $126 E+O$ \\
\hline $850 E-03$ & $8.614 E-0$ \\
\hline $.611 E-02$ & $1.231 \mathrm{E}-\mathrm{O}$ \\
\hline $544 E-09$ & $8.971 E-0$ \\
\hline $22 \mathrm{E}-$ & $9.181 \mathrm{E}$ \\
\hline a & 1.052 \\
\hline
\end{tabular}

GROUP 15

3.O TO $4.0 \mathrm{MEV}$

ALFHA

6. $721 \mathrm{E}-09$

3. $002 \mathrm{E}-06$

2. $474 \mathrm{E}-\mathrm{O} 4$

2. $652 E-03$

1. OO9E-O2

3. $265 \mathrm{E}-\mathrm{O} 2$

9. $322 \mathrm{E}-\mathrm{O} 2$

$-1.977 E-04$

3. $546 \mathrm{E}-04$

$2.650 E-06$

3. $574 \mathrm{E}-\mathrm{O} 6$
LAMEDA

1. $898 \mathrm{BE}-05$

5. $665 \mathrm{E}-05$

7. 864E-O4

4. 149E-O3

2. $642 \mathrm{E}-\mathrm{O} 2$

5. 305E-O 1

8. 179E-O1

1. $136 E+O O$

3. $932 E-O 2$

$7.397 E-02$

$3.415 \mathrm{E}-03$

1. $.008 \mathrm{E}-\mathrm{O}$

$1.728 E-04$

LAMBDA

2. $217 E-05$

$6.473 \mathrm{E}-05$

$.067 E-03$

$.426 \mathrm{E}-02$

. $700 \mathrm{E}-02$

1. $814 \mathrm{E}-01$

8. $447 \mathrm{E}-01$

1. $195 \mathrm{E}-03$

$3.545 E-03$

9. $228 \mathrm{E}-05$

1. $528 \mathrm{E}-\mathrm{O} 4$

GROUP 12

2. 2 TO 2.4 MFV

NLFHA

8. $838 \mathrm{E}-08$

9. $097 E-07$

1. $474 \mathrm{E}-05$

1. $451 E-04$

5. $213 E-04$

2. $875 E-03$

1. $051 \mathrm{E}-02$

2. $723 \mathrm{E}-\mathrm{O} 2$

$-7.479 E-05$
LAMEDA

1. $758 \mathrm{E}-05$

$4.596 E-05$

4. $618 \mathrm{E}-04$

1. $794 \mathrm{E}-0.03$

8. $114 \mathrm{E}-03$

3. 35OE-02

1. $483 \mathrm{E}-01$

7. 69?E-O 1

1. $952 E-O 3$
GROUP 16

4. O TO 5 . O MEV

ALPHA
2. $1212 E-10$
$1.164 E-06$
$7.681 E-06$
$1.753 E-04$
$1.233 E-03$
$1.562 E-02$
$3.276 E-02$
$8.871 E-05$
$1.050 E-06$
$7.708 E-07$
$2.788 E-06$

LAMBDA

1.789E-O5

7. $142 E-05$

2. 348E-O3

$6.003 \mathrm{E}-03$

1. 854E-O?

1. $156 E-01$

5. $457 E-01$

1. $74 A E-O 2$

1. $.035 E-04$

$1.417 \mathrm{E}-\mathrm{OA}$

9. $304 E-O A$ 
FITS TO ${ }^{239}$ PU THERMAL PULSE GAMMAS FOR ENDF/B-IV DATA

$$
0.0 \text { TO . } 1 \text { MEV }
$$

ALPHA

1. LAMBDA

$3.0325-07$

9.115E-OS

3. $385 \mathrm{E}-05$

$7.307 E-05$

3.691E-05

2. $519 E-O A$

8. $909 \mathrm{E}-\mathrm{OA}$

3. $74 A E-03$

1. $351 E-02$

$4.742 E-02$

2. $493 E-01$

GROUP 5

6 TO $.8 \mathrm{MEV}$

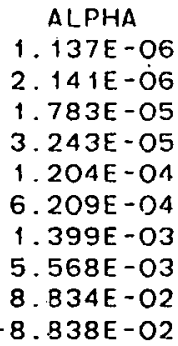

LAMBDA

7. 435E-O6

4. $845 \mathrm{E}-05$

2. $229 E-04$

$7.002 \mathrm{E}-04$

2. $870 E-O 3$

9. $649 \mathrm{E}-03$

$2.833 E-O 2$

$1.095 E-01$

9. $743 E-01$

1. $091 E+00$
GROUP 2

1 TO . 2 MEV

$\begin{array}{cc}\text { ALPHA } & \text { LAMBDA } \\ 3.516 E-O 8 & 3.007 E-O 6 \\ 1.851 E-07 & 7.169 E-05 \\ 2.195 E-O 6 & 2.383 E-04 \\ 8.233 E-O 6 & 6.376 E-O 4 \\ 2.268 E-05 & 2.600 E-03 \\ 9.167 E-05 & 1.248 E-02 \\ 2.846 E-O 4 & 2.977 E-02 \\ 4.791 E-03 & 1.473 E-01 \\ -2.977 E-03 & 1.106 E-01 \\ 1.258 E-02 & 8.837 E-01\end{array}$

GROUP 6

\begin{tabular}{|c|c|}
\hline ALPHA & LAMBDA \\
\hline 1. $586 \mathrm{E}-07$ & $6.644 E-06$ \\
\hline $1.924 \mathrm{E}-06$ & $5.565 E-05$ \\
\hline $.250 E-05$ & $2.057 \mathrm{E}$ \\
\hline $1.067 E-04$ & $1.057 E-03$ \\
\hline $3.317 E-04$ & $4.924 E-03$ \\
\hline 1. $111 \mathrm{E}-02$ & $3.015 E-02$ \\
\hline $5.515 E-02$ & $1.096 \mathrm{E}+\mathrm{OC}$ \\
\hline $1.075 E-02$ & $3.311 E-0$ \\
\hline $.847 E-03$ & $9.366 \varepsilon-0$ \\
\hline $129 E-02$ & $96 E-O$ \\
\hline
\end{tabular}

8 TO $1.0 \mathrm{MEV}$

\section{GROUP 3 \\ .2 TO .4 MEV}

ALPHA

4. O99E-07

1. $152 E-07$

5. $940 E-O 6$

6. $858 \mathrm{E}-05$

5. $670 \mathrm{OE}-\mathrm{OA}$

1. $278 \mathrm{E}-03$

5. $457 \mathrm{E}-03$

$6.643 E-03$

LAMEDA

8. 808E-06

3. $064 \mathrm{E}-\mathrm{O} 5$

2. $629 \mathrm{E}-04$

6. 829E-O4

$1.079 E-02$

4.24OE-O2

$1.229 \mathrm{E}-01$

9. $887 E-O 1$

GROUP 7

1.0 TO $1.2 \mathrm{MEV}$

\section{ALPHA}

4. 249E-O7

1. $192 \mathrm{E}-\mathrm{OG}$

. 257E-O5

5. 309E-05

$5.556 \mathrm{E}-05$

2. $753 E-04$

9. $990 E-O 4$

2. $187 \mathrm{E}-\mathrm{O} 3$

$3.053 E-03$

4 568E-03

\section{LAMBDA}

1. $528 \mathrm{E}-05$

5. $071 \mathrm{E}-05$

2.22OE-O4

$7.758 \mathrm{E}-04$

2. $261 \mathrm{E}-0.3$

7. $601 \mathrm{E}-03$

2. $201 \mathrm{E}-\mathrm{O} 2$

7. $15 O E-O 2$

$2.057 E-01$

6. $700 E-01$
GROUP 4

4 TO . 6 MEV

4.908E-07 8.626E-06

1. $096 \mathrm{E}-0 \mathrm{OG} \quad \mathrm{A} .735 \mathrm{E}-05$

1. $173 \mathrm{E}-05 \quad 2.579 \mathrm{E}-01$

5.506E-O5 7.217E-04

1. $128 \mathrm{E}-\mathrm{OA} 2.52 \mathrm{OE}-\mathrm{O} 3$

$1.923 E-04 \quad 8.245 E-03$

9. $798 E-01 \quad 2.653 E-02$

9. $496 \mathrm{E}-\mathrm{O} 3 \quad 1.009 \mathrm{E}-01$

$4.401 \mathrm{E}-\mathrm{O} 2 \quad 3.833 \mathrm{E}-\mathrm{O} 1$

GROUP 8

1.2 TO 1.4 MEV

ALPHA

2. $470 E-07$

3. $349 E-06$

2. $838 E-06$

5. $173 \mathrm{E}-05$

$4.741 E-05$

$7.604 E-04$

1. $363 E-03$

$3.347 \mathrm{E}-03$

$4.602 \mathrm{~F}-\mathrm{O} 3$

1. $\mathrm{O} 39 \mathrm{E}-\mathrm{O} 2$
LAMBDA

1. $109 E-05$

5. $936 E-05$

2. $226 \mathrm{E}-04$

7. $602 \mathrm{E}-04$

1. $892 E-03$

$8.895 E-03$

2. $151 E-02$

.529E-02

. 201E-01 
TABLE A-III (Cont)

\begin{tabular}{|c|c|}
\hline \multicolumn{2}{|c|}{ GROUP 9} \\
\hline \multicolumn{2}{|c|}{ 1.4 TO $1.6 \mathrm{MEV}$} \\
\hline ALPHA & LAMBDA \\
\hline $4.181 \mathrm{E}-08$ & $6.067 E-07$ \\
\hline $7: 472 E-07$ & $4.532 \mathrm{E}-05$ \\
\hline $3.079 \mathrm{E}-05$ & $3.294 E-04$ \\
\hline $9.102 E-05$ & $3.283 E-04$ \\
\hline $4.770 E-03$ & 1. $106 \mathrm{E}-02$ \\
\hline $2.131 \mathrm{E}-\mathrm{O} 2$ & $2.909 \mathrm{E}-01$ \\
\hline$-1.259 \mathrm{E}-\mathrm{O} 2$ & 3. $16.2 \mathrm{E}-\mathrm{O} 1$ \\
\hline$-3.948 E-03$ & 1. $24^{\prime} 5 \mathrm{E}-02$ \\
\hline $4.254 \mathrm{E}-03$ & $3.577 \mathrm{E}-02$ \\
\hline \multicolumn{2}{|c|}{ GROUP 13} \\
\hline $2.2 \mathrm{TO}$ & 4 MEV \\
\hline ALPHA & LANBDA \\
\hline 3. $\cong 07 E-09$ & $3.577 \mathrm{E}-06$ \\
\hline $2.067 E-05$ & $8.046 E-05$ \\
\hline 1. $160 E-05$ & $2.731 E-04$ \\
\hline 9. $561 \mathrm{E}-05$ & 1. $67 \mathrm{OE}-03$ \\
\hline 3. $163 \mathrm{E}-03$ & 1. $4 C: 3 E-02$ \\
\hline$-3.374 \mathrm{E}-03$ & $1.5 \subseteq 5 E-02$ \\
\hline 1. $266 \mathrm{E}-03$ & $2.811 E-02$ \\
\hline 8. $8: 28 E-04$ & 1. $9 S_{17 E-01}$ \\
\hline 8. $766 \mathrm{E}-04$ & 1. $1<9 E+0 O$ \\
\hline
\end{tabular}

GRDUP 10 1.6 TO 1.8 MEV

ALPHA
$4.212 E-O 7$
$6.347 E-O 7$
$4.846 E-06$
$4.835 E-05$
$1.299 E-03$
$2.645 E-03$
$-1.136 E-03$
$1.095 E-03$

LAMBOA
$2.278 E-05$
$5.473 E-05$
$2.049 E-04$
$8.698 E-04$
$9.805 E-03$
$2.274 E-01$
$1.084 E-02$
$2.755 E-02$

GROUP 14

2.4 TO $2.6 \mathrm{MEV}$

ALPHA
$3.981 E-09$
$3.564 E-07$
$3.19 B E-06$
$1.121 E-05$
$6.583 E-05$
$7.465 E-.04$
$1.271 E-.03$
$1.891 E-03$
$2.707 E-33$
$-1.728 E-38$

LAMBDA

3. $309 E-06$

7. $822 \mathrm{E}-05$

1. $563 \mathrm{E}-04$

8. O67E-O4

5. OOOE-03

1. $307 \mathrm{E}-\mathrm{O} 2$

4. $613 \mathrm{E}-02$

1. $759 \mathrm{E}-01$

6. $639 \mathrm{E}-01$

2. 579E-O5

\begin{tabular}{|c|c|}
\hline \multicolumn{2}{|c|}{ GROUP 11} \\
\hline $1.8 \mathrm{TO}$ & $O$ MEV \\
\hline ALPHA & LAMBDA \\
\hline $910 E-08$ & $1.011 E-05$ \\
\hline $893 E-07$ & $6.972 E-05$ \\
\hline $706 E-06$ & $1.847 E-04$ \\
\hline $474 E-05$ & $8.626 \mathrm{E}-04$ \\
\hline $097 E-05$ & $5.396 \mathrm{E}-03$ \\
\hline $985 E-04$ & $1.535 E-02$ \\
\hline $24 O E-03$ & $7.485 \mathrm{E}-\mathrm{O} 2$ \\
\hline $100 E-03$ & $8.725 \mathrm{E}-01$ \\
\hline
\end{tabular}

GROUP 15

2.6 TO $3.0 \mathrm{MEV}$

ALPHA
$6.437 E-10$
$1.025 E-06$
$3.919 E-06$
$6.523 E-06$
$8.245 E-05$
$5.64 O E-O 4$
$1.238 E-03$
$2.083 E-03$
$4.142 E-03$

LAMBDA

6. 508E-06

1. $02.2 \mathrm{E}-04$

2. 309E-O4

5. $578 \mathrm{E}-\mathrm{O} 4$

3. $932 \mathrm{E}-03$

1. $226 \mathrm{E}-\mathrm{O} 2$

4. $133 \mathrm{E}-\mathrm{O} 2$

b. $281 \mathrm{E}-\mathrm{O}$

7. $182 E-01$
GROUP 12 2.O TO $2.2 \mathrm{MEV}$

\begin{tabular}{|c|c|}
\hline ALPHA & LAMBDA \\
\hline $1.822 E-08$ & $6.150 E-06$ \\
\hline 1. $142 E-06$ & $7.591 E-05$ \\
\hline 3. $154 \mathrm{E}-06$ & $1.766 \mathrm{E}-04$ \\
\hline $5.047 E-05$ & $8.020 E-04$ \\
\hline $9.895 E-05$ & $6.481 E-03$ \\
\hline $3.611 \mathrm{E}-04$ & $1.792 \mathrm{E}-\mathrm{O} 2$ \\
\hline $4.831 E-04$ & $6.226 \mathrm{E}-02$ \\
\hline 8. 580E-04 & $2.84 O E-01$ \\
\hline & \\
\hline
\end{tabular}

GROUP 16

3.0 TO 4.0 MEV

$\begin{array}{cc}\text { ALPHA } & \text { LAMEDA } \\ 3.39 O E-10 & 2.582 E-O 5 \\ 1.250 E-06 & 1.127 E-O A \\ 1.253 E-06 & 2.041 E-04 \\ 1.101 E-05 & 7.247 E-O 4 \\ 4.704 E-05 & 2.348 E-O 3 \\ 4.217 E-04 & 7.587 E-O 3 \\ 1.160 E-03 & 1.908 E-02 \\ 1.696 E-03 & 6.293 E-O 2 \\ 3.025 E-02 & 5.569 E-O 1 \\ -2.858 E-02 & 6.125 E-01\end{array}$


TABLE A-III (Cont)

GROUP 17 4.0 TO 5.0 MEV

ALPHA

1. $507 E-10$

1. $139 E-O 8$

2. $883 \mathrm{E}-08$

1. $155 \mathrm{E}-06$

3. $209 \mathrm{E}-05$

2. $362 \mathrm{E}-\mathrm{O} 4$

$5.933 E-04$

$9.980 \mathrm{O}-04$

1. $729 E-03$

2. $349 E-O 3$
LAMBDA

1. 42.6E - OG

7. 832E-05

2. 179E-04

9. $057 \mathrm{E}-04$

2. $802 \mathrm{E}-\mathrm{O} 3$

7. $200 \mathrm{E}-03$

$.924 \mathrm{E}-\mathrm{O} 2$

$6.31 O E-O 2$

$2.694 \mathrm{E}-01$

2. $036 \mathrm{E}+\infty \mathrm{O}$
GRDUP 18 5.0 TO $6.0 \mathrm{MEV}$

\section{ALPHA LAMBDA} $1.797 E-11 \quad 8.413 E-07$
$1.355 E-08$ 7. $355 \mathrm{E}-08 \quad 8.656 \mathrm{E}-04$

$6.664 \mathrm{E}-07 \quad 1.733 \mathrm{E}-\mathrm{O}$

$1.485 E-05 \quad 4.719 E-03$

1. $4375-05$

1. 50 RE - OA

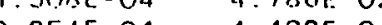

$1.742 \mathrm{E}-03 \quad 5.234 \mathrm{E}-\mathrm{O} 1$ 
TABLE A-IV

FITS TO ${ }^{239}$ PU THERMAL PULSE BETAS FOR ENDF/B-IV DATA

$\begin{array}{cc}\text { GROUP } & 1 \\ 0.0 \text { TO } & .2 \text { MEV } \\ & \\ \text { ALPHA } & \text { LAMBDA } \\ 1.225 E-07 & 5.338 E-O 6 \\ \mathrm{E} .246 E-07 & 3.738 E-O 5 \\ 2.585 E-06 & 2.537 E-04 \\ 1.293 E-05 & 9.908 E-04 \\ 4.438 E-05 & 7.596 E-03 \\ 1.800 E-04 & 4.341 E-02 \\ 7.216 E-05 & 6.051 E-01 \\ -7.887 E-05 & 5.569 E-O 2 \\ -.746 E-04 & 2.639 E-O 1\end{array}$

GROUP 5 . 8 TO $1.0 \mathrm{MEV}$

$\begin{array}{cc}\text { ALPHA. } & \text { LAMBDA } \\ 3.594 E-07 & 1.006 E-05 \\ 1.561 E-06 & 5.273 E-05 \\ 3.550 E-06 & 2.273 E-04 \\ 1.131 E-05 & 6.846 E-04 \\ 2.396 E-04 & 4.432 E-03 \\ 1.299 E-03 & 2.350 E-02 \\ 2.179 E-03 & 1.164 E-O 1 \\ 4.833 E-03 & 5.02 O E-01\end{array}$

\begin{tabular}{|c|c|}
\hline \multicolumn{2}{|c|}{ GROUP 2} \\
\hline .2 TO & $4 \mathrm{MEV}$ \\
\hline ALPHA & LAMBDA \\
\hline $.058 E-07$ & $8.590 E-06$ \\
\hline $9.180 \mathrm{E}-07$ & $4.888 E-05$ \\
\hline 4. $188 E-06$ & 2. $162 \mathrm{E}-04$ \\
\hline $3.048 \equiv-05$ & $7.370 E-04$ \\
\hline $1.039 \equiv-03$ & $6.433 \mathrm{E}-03$ \\
\hline $1.981 \equiv-02$ & $4.351 E+00$ \\
\hline $1.152 \equiv-03$ & 7. $158 \mathrm{E}-03$ \\
\hline 4. $160 E-O 4$ & 1. $360 E-02$ \\
\hline $3.811 E-04$ & $6.737 E-02$ \\
\hline $5.332 E-04$ & $2.974 E-01$ \\
\hline
\end{tabular}

$\begin{array}{cc}\text { GROUP } & 3 \\ .4 \text { TO } & .6 \mathrm{MEV} \\ & \\ \text { ALPHA } & \text { LAMBDA } \\ 5.322 E-O 7 & 9.553 E-O 6 \\ 1.219 E-O 6 & 4.870 E-O 5 \\ 6.340 E-O 6 & 2.204 E-O 4 \\ 4.279 E-O 5 & 7.333 E-O 4 \\ 8.021 E-O 5 & 3.467 E-O 3 \\ 2.954 E-04 & 1.157 E-O 2 \\ 4.937 E-O 4 & 3.917 E-O 2 \\ 9.345 E-O 4 & 1.162 E-O 1 \\ 2.367 E-O 3 & 7.539 E-O 1\end{array}$

$$
\begin{array}{ll}
\text { GROUP } & 4 \\
.6 \text { TO } & .8 \mathrm{MEV}
\end{array}
$$

ALPHA

$\begin{array}{ll}5.05 O E-07 & 9.781 E-06 \\ 1.438 E-06 & 5.041 E-05\end{array}$

LAMBDÁ

8.078E-06 2.224E-04

4.358E-05 $7.173 E-04$

1. $121 \mathrm{E}-\mathrm{O} 4 \quad 3.587 \mathrm{E}-\mathrm{O} 3$

4. $505 \mathrm{E}-04 \quad 1.237 \mathrm{E}-02$

8.28OE-O4 3.971E-O2

$\begin{array}{ll}\text { 1.658E-O3 } & 1.405 E-01 \\ 3.209 E-O 3 & 6.277 E-01\end{array}$

6.332E-O4 2.974E-O1

\section{GROUP 6}

1.O TO 1.2 MEV

\section{GROUP 7 \\ 1.2 TO 1.4 MEV}

ALPHA

2. 676E-07

1. $374 \mathrm{E}-06$

8. 476E-06

3. 88CE- 05

8. $192 \mathrm{E}-05$

.

3. $581 \mathrm{E}-\mathrm{O} 4$

9.62C:E-O4

1. $942 \mathrm{E}-03$

3. $16 \Xi \mathrm{E}-\mathrm{O} 3$

LAMBDA

1. 171E-05

$5.438 \mathrm{E}-05$

2. $200 E-04$

7. $106 \mathrm{E}-\mathrm{O} 4$

2. $464 \mathrm{E}-03$

7. $958 \mathrm{E}-03$

2. $174 \mathrm{E}-02$

7. $048 \mathrm{E}-02$

2. 179E-OI

6. $999 E-01$

ALPHA
$2.233 E-07$
$1.297 E-O 6$
$7.811 E-06$
$3.699 E-O 5$
$7.752 E-05$
$3.580 E-04$
$1.091 E-03$
$2.348 E-O 3$
$3.871 E-03$
$6.801 E-03$

LAMBDA

1. $349 E-05$

$5.654 E-05$

2. $244 \mathrm{E}-\mathrm{O} 4$

7. $202 E-04$

2. $196 \mathrm{E}-\mathrm{O} 3$

7. $441 \mathrm{E}-\mathrm{O} 3$

2. $076 \mathrm{E}-\mathrm{O} 2$

6. $892 \mathrm{E}-\mathrm{O} 2$

2. $100 E-O$

6.799E-O1

\section{GROUP 8 \\ 1. 4 TO 1.6 MEV}

LAMBDA

1. $450 \mathrm{E}-05$ 5. 7 1OE-O5 2. $367 \mathrm{E}-\mathrm{O} 4$ 7. $336 \mathrm{E}-04$ 2. $172 \mathrm{E}-03$ 7. $427 \mathrm{E}-\mathrm{O} 3$ $2.079 E-02$ $6.944 \mathrm{E}-02$ $2.071 E-01$ $6.721 E-01$ 


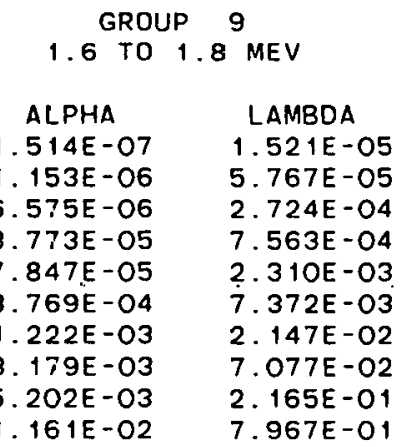

GROUP 13 2. 4 TO 2.6 MEV

LAMBDA
$1.792 E-O 5$
$5.204 E-O 5$
$4.983 E-04$
$1.387 E-03$
$5.146 E-03$
$1.555 E-O 2$
$5.681 E-02$
$2.142 E-01$
$2.436 E-01$
$7.802 E-01$

GROUP 10 1.8 TO 2.0 MEV

\begin{tabular}{|c|c|}
\hline ALPHA & LAMBDA \\
\hline $.192 \mathrm{E}-07$ & $1.665 \mathrm{E}-05$ \\
\hline $8.760 E-07$ & $5.371 E-05$ \\
\hline $1.419 E-05$ & $3.863 E-04$ \\
\hline 1. 159E-04 & $1.491 E-03$ \\
\hline 8. $583 E-04$ & $1.023 E-02$ \\
\hline $3.725 \mathrm{E}-03$ & $5.309 E-02$ \\
\hline $6.110 E-03$ & $2.206 \mathrm{E}-01$ \\
\hline $1.114 E-02$ & $6.863 E-01$ \\
\hline$-2.423 E-05$ & $1.354 \mathrm{E}-03$ \\
\hline
\end{tabular}

GROUP 14 2.6 TO $3.0 \mathrm{MEV}$

ALPHA

1. $761 E-O B$

6. $793 E-07$

1. $483 \mathrm{E}-05$

7.849E-O5

$2.806 \mathrm{E}-04$

$2.806 \mathrm{E}-04$

1. $460 \mathrm{O}-03$

$3.007 E-03$
$1.041 E-02$

$2.474 \mathrm{E}-02$

$1.074 \mathrm{E}-01$

LAMBDA

1. 552E-O5

5. $188 E-05$

5. $144 \mathrm{E}-04$

1. $376 \mathrm{E}-\mathrm{O} 3$

4. $901 \mathrm{E}-03$

1. $476 \mathrm{E}-\mathrm{O} 2$

4. 48OE-O2

1. $319 \mathrm{E}-01$

3. $935 \mathrm{E}+\mathrm{OO}$
GROUP 11 2.0 TO $2.2 \mathrm{MEV}$

ALPHA
$1.221 E-07$
$6.604 E-07$
$1.092 E-05$
$5.340 E-05$
$1.618 E-04$
$8.242 E-04$
$1.836 E-03$
$5.666 E-03$
$1.416 E-02$

LAMEDA

1. 875E-05

$5.606 \mathrm{E}-05$

4. $081 \mathrm{E}-04$

1. $225 \mathrm{E}-03$

1. $225 \mathrm{E}-03$

4. $343 \mathrm{E}-03$

1. $34 \mathrm{OE}-\mathrm{O} 2$

$4.045 \mathrm{E}-02$

1. $24 O E-01$
$5.779 E-01$
GROUP 12 2.2 TO $2.4 \mathrm{MEV}$

$\begin{array}{cc}\text { ALPHA } & \text { LAMBDA } \\ 8.367 E-O 8 & 1.882 E-O 5 \\ 4.829 E-07 & 5.322 E-05 \\ 1.118 E-O 5 & 4.596 E-04 \\ 5.228 E-05 & 1.337 E-03 \\ 1.713 E-04 & 4.724 E-03 \\ 8.355 E-O 4 & 1.431 E-02 \\ 1.799 E-O 3 & 4.277 E-02 \\ 5.635 E-O 3 & 1.241 E-01 \\ 1.509 E-O 2 & 5.878 E-O 1\end{array}$

GROUP 15

3.0 TO $4.0 \mathrm{MEV}$

ALPHA
$9.521 E-09$
$9.441 E-07$
$2.627 E-06$
$4.382 E-05$
$1.238 E-04$
$7.781 E-04$
$2.735 E-03$
$9.073 E-03$
$1.701 E-02$
$5.287 E-02$

LAMBDA
1. $601 \mathrm{E}-05$

6. $503 \mathrm{E}-05$

3. $369 \mathrm{E}-04$

8. $771 \mathrm{E}-04$

2. $215 \mathrm{E}-\mathrm{O} 3$

7.616E-03

2. $028 \mathrm{E}-\mathrm{O} 2$

$7.828 \mathrm{E}-\mathrm{O} 2$

2. O5OE - 01
$8.200 E-01$
$5.878 \mathrm{E}-01$

GROUP $\$ 7$

5.0 TO $6.0 \mathrm{MEV}$

$\begin{array}{cc}\text { ALPHA } & \text { LAMBDA } \\ 3.697 E-1.2 & 2.558 E-06 \\ 5.837 E-09 & 7.098 E-05 \\ 5.337 E-07 & 1.837 E-03 \\ 1.720 E-05 & 6.123 E-03 \\ 4.525 E-04 & 1.706 E-02 \\ 6.711 E-03 & 1.762 E-01 \\ 9.685 E-03 & 1.098 E+00 \\ -3.681 E-04 & 1.985 E-02 \\ 6.387 E-04 & 5.006 E-02 \\ -8.654 E-10 & 8.732 E-05 \\ 1.634 E-09 & 3.916 E-04\end{array}$




$\begin{array}{cc}\text { GROUP } & 1 \\ 0.0 \text { TO } & 1 \\ & 1 \text { MEV } \\ \text { ALPHA } & \text { LAMBDA } \\ 1.227 E-13 & 8.580 E-10 \\ 4.570 E-13 & 1.279 E-08 \\ 9.482 E-12 & 3.190 E-08 \\ 3.366 E-10 & 3.526 E-07 \\ 7.511 E-09 & 1.396 E-06 \\ 3.985 E-08 & 5.524 E-06 \\ 8.720 E-07 & 3.050 E-04 \\ 9.978 E-06 & 1.557 E-03 \\ 1.547 E-04 & 1.101 E-02 \\ 3.732 E-04 & 4.348 E-02 \\ 8.551 E-04 & 7.141 E-01 \\ -1.872 E-04 & 4.440 E-02 \\ -5.286 E-06 & 1.617 E-03 \\ -3.060 E-08 & 6.037 E-06 \\ 2.663 E-08 & 5.393 E-05\end{array}$

GRDUP 5

$$
.6 \text { TO .8 MEV }
$$

$\begin{array}{cc}\text { ALPHA } & \text { LAMBDA } \\ 2.575 E-11 & 7.376 E-10 \\ 7.008 E-12 & 1.595 E-08 \\ 2.036 E-11 & 4.282 E-08 \\ 1.971 E-08 & 1.226 E-07 \\ 2.500 E-07 & 2.335 E-06 \\ 1.502 E-06 & 1.459 E-05 \\ 2.000 E-05 & 1.999 E-04 \\ 5.654 E-05 & 9.623 E-04 \\ 3.118 E-04 & 4.233 E-03 \\ 4.135 E-03 & 2.533 E-02 \\ 1.368 E-02 & 1.285 E-O 1 \\ 1.918 E+0 O & 1.382 E+O O \\ -1.908 E \div 00 & 1.416 E+00 \\ 1.556 E-01 & 4.319 E+00 \\ -1.008 E-01 & 5.466 E+0 O \\ -1.158 E-08 & 2.006 E-07\end{array}$

\section{GROUP 2}

.1 TO .2 MEV

\begin{tabular}{|c|c|}
\hline ALPHA & LAMBDA \\
\hline $4.083 E-14$ & $4.802 E-0$ \\
\hline $2.563 \mathrm{E}-12$ & $2.080 E-C$ \\
\hline $294 E-11$ & $3.117 E$ \\
\hline $1.212 E-09$ & 2.65 \\
\hline $2.047 E-08$ & $2.585 E$ \\
\hline $1.656 \mathrm{E}-08$ & 7. $305 E-C$ \\
\hline $6.303 E-07$ & $9.277 E-$ \\
\hline $5.682 E-06$ & 3. $729 \mathrm{E}-$ \\
\hline $9.09 E E-06$ & 1. $242 \mathrm{E}-$ \\
\hline $1.819 \mathrm{E}-05$ & $3.558 E-$ \\
\hline $1.272 E-04$ & 1. $289 E-$ \\
\hline $1.017 E-03$ & $5.216 E-C$ \\
\hline $3.577 \mathrm{E}-03$ & $1.448 E-C$ \\
\hline $1.318 E-02$ & $7.359 E-$ \\
\hline $2.279 E-03$ & $5.227 E+C$ \\
\hline$E-O$ & $940 \mathrm{OE}$ \\
\hline
\end{tabular}

GROUP 3

2 TO 4 MEV

ALPHA

3. $198 \mathrm{E}-15 \quad 9.184 \mathrm{E}-08$

$6.447 \mathrm{E}-12,1.262 \mathrm{E}-07$

1.631E-09 6.403E-O7

1. $069 \mathrm{E}-08$ 1.105E-05

3. $756 \mathrm{E}-08$ 3.105E-OG

2. $367 E-07 \quad 1.331 E-O 5$

1. $455 E-07$ 1.

1.358E-05 3.505E-O4

$4.509 E-05 \quad 8.140 E-04$

3.601E-04 7.544E-O3

1. $692 \mathrm{E}-03 \quad 2.531 \mathrm{E}-\mathrm{O} 2$

$8.236 \mathrm{E}-03 \quad 1.060 \mathrm{E}-\mathrm{O}$

3.624E-O2 4. 375E-O

$2.059 E-03 \quad 7.317 E+O 0$

$-6.655 \mathrm{E}-03 \quad 3.489 \mathrm{E}-\mathrm{O} 1$

$3.325 \mathrm{E}-\mathrm{O} 2$

$489 \mathrm{E}-\mathrm{O} 1$
$822 \mathrm{E}+\mathrm{OO}$

\section{GROUP ?}

1.0 TO 1.2 MEV

\section{TO 1.0 MEV}

$\begin{array}{cc}\text { ALPFA } & \text { LAMBDA } \\ 1.259 E-17 & 5.694 E-10 \\ 2.932 E-13 & 2.121 E-08 \\ 9.270 E-14 & 3.286 E-08 \\ 7.481 E-09 & 5.608 E-07 \\ 1.233 E-08 & 8.369 E-07 \\ 4.629 E-08 & 4.181 E-06 \\ 1.328 E-06 & 3.809 E-05 \\ 2.465 E-O 5 & 1.608 E-04 \\ 2.512 E-O 5 & 2.192 E-04 \\ 2.151 E-O 4 & 1.685 E-03 \\ 7.097 E-O 4 & 1.068 E-02 \\ 6.00 O E-O 3 & 6.690 E-02 \\ 1.46 B E-O 2 & 1.893 E-01 \\ 4.028 E-O 2 & 1.115 E+O 0 \\ 2.531 E-O 2 & 4.539 E+O O\end{array}$

ALPHA

9. $552 \mathrm{E}-18$

1. $801 \mathrm{E}-12$

$277 \mathrm{E}-14$

1. $903 \mathrm{E}-11$

3. $538 \mathrm{E}-10$

1. $132 E-08$

4. 452E-07

1. 105E-06

1. $376 \mathrm{E}-05$

9. $332 \mathrm{E}-\mathrm{OS}$

.

2. $629 \mathrm{E}-\mathrm{OA}$

$1.554 \mathrm{E}-03$

3. $418 \mathrm{E}-03$

1. $773 \mathrm{E}-02$

1. $905 E-02$

$-1.828 \mathrm{E}-02$

$4.983 \mathrm{E}-\mathrm{O} 3$
LAMBDA

7. $045 E-.10$

2. $167 \mathrm{E}-08$

2. $187 \mathrm{E}-\mathrm{OB}$

3. $598 \mathrm{E}-07$

$8.421 \mathrm{E}-07$

2. $860 E-O 6$

1. $713 E-05$

3. $568 \mathrm{E}-\mathrm{O} 5$

1. $948 E-04$

8. $559 \mathrm{E}-04$

6. 598E-03

2. $932 \mathrm{E}-0$ ?

9. 655E-O2

4. $815 E-01$

1. $590 \mathrm{E}+\mathrm{OO}$

2. $272 E+O O$

$5.454 \mathrm{E}+00$
GROUP 4

4 TO 6 MEV

\begin{tabular}{|c|c|}
\hline ALPHA & I. AMBDA \\
\hline 2. $0 A 7 E-14$ & $2.113 E$ \\
\hline $8.479 E-13$ & $9.883 \mathrm{E}$ \\
\hline $9.555 F-12$ & $2.355 \mathrm{E}$ \\
\hline 3. $104 E-09$ & 2 \\
\hline $3.927 E-08$ & $7.154 \mathrm{~F}$ \\
\hline $4.579 E-07$ & $1.001 \mathrm{E}$ \\
\hline 1. $173 E-06$ & 3. $403 \mathrm{E}$ \\
\hline $2.831 E-05$ & $2.930 E$ \\
\hline $1.287 E-04$ & $1.698 \mathrm{E}$ \\
\hline $8.597 E-04$ & 1. $.374 E-$ \\
\hline $1.793 E-02$ & $9.274 E-$ \\
\hline $7.646 E-02$ & $5.051 \mathrm{E}-$ \\
\hline $.944 E-02$ & $6.330 E-$ \\
\hline 3. $266 \mathrm{E}-02$ & $2.422 E$ \\
\hline $1.505 E-02$ & $3.494 \mathrm{E}$ \\
\hline $1409-08$ & $7.280 \mathrm{E}-$ \\
\hline
\end{tabular}

$-1.429 E-O B \quad 7.280 E-D 7$

\subsection{TO 1.4 MEV}

ALPHA

2. $436 E-17$ $3.417 \mathrm{E}-14$

1. $713 \mathrm{E}-13$

3. $218 E-11$

2. $901 E-09$

2. $217 \mathrm{E}-08$

1. $651 \mathrm{E}-07$

2. $800 \mathrm{E}-06$

6. $387 \mathrm{E}-06$

$1.085 \mathrm{E}-04$

1. $754 \mathrm{E}-03$

5. 15.3E-03

5. $753 \mathrm{E}-02$

$-3.160 \mathrm{O}-\mathrm{O} 2$

2. $566 \mathrm{E}-02$

$-1.121 E-02$

$-3.126 E-04$
LAMBOA

1. 825E-O9

2. O26E-OS

3. $391 \mathrm{E}-08$

1. $420 E-07$

1. $765 \mathrm{E}-06$

2. $864 E-06$

1. $472 E-05$

4. $671 E-05$

1. $158 \mathrm{E}-04$

9. $830 \mathrm{OE}-04$

1. 162E-02

$7.643 E-O 2$

4. $645 \mathrm{E}-01$

5. $683 \mathrm{E}-01$

$2.427 E+0 O$

$3.488 E+O O$

$1.186 E-02$ 
GROUP 9 1. 4 TO $1.5 \mathrm{MEV}$
LAMEDA

4. $328 E-10$

2. $620 E-08$

3. $776 \mathrm{G}-\mathrm{OS}$

$7.018 \mathrm{E}-07$

$1.977 E-O A$

$6.256 \mathrm{E}-\mathrm{O}$

1. $593 \mathrm{E}-\mathrm{O} 2$

4. $010 E-01$

2. $329 \mathrm{E}+\mathrm{OO}$

3. $420 \mathrm{E}-\mathrm{O} 2$

$5.039 E-02$

8. $085 \mathrm{E}-01$

2. $618 \mathrm{E}-\mathrm{O} 3$

9. $062 \mathrm{E}-07$

1. $248 \mathrm{E}-06$

4. $221 E-06$

2. $986 \mathrm{E}-05$
GROUP 10 1.6 TO 1.8 MEV

$\begin{array}{cc}\text { ALFHA } & \text { LAMBDA } \\ 2.67 O E-19 & 6.139 E-11 \\ 1.056 E-13 & 2.175 E-08 \\ 3.048 E-14 & 1.813 E-07 \\ 1.319 E-12 & 8.071 E-07 \\ 1.345 E-09 & 2.493 E-06 \\ 1.798 E-08 & 1.111 E-O 5 \\ 7.201 E-07 & 2.933 E-O 5 \\ 1.123 E-06 & 1.093 E-O 4 \\ 5.261 E-06 & 2.004 E-04 \\ 4.995 E-04 & 1.410 E-03 \\ 2.813 E-03 & 8.605 E-O 2 \\ 8.723 E-03 & 6.141 E-01 \\ -3.620 E-03 & 8.414 E-01 \\ 1.567 E-03 & 5.082 E+00 \\ -7.724 E-04 & 6.977 E+00 \\ -4.593 E-04 & 1.503 E-03 \\ 1.921 E-04 & 5.87 O E-03 \\ 7.701 E-04 & 2.420 E-02\end{array}$

GROUP 14 2.4 TO 2.6 MEV 2. 2 TO 2.4 MEV
LAMBDA

2. 17AE-OS

1. $796 \mathrm{E}-08$

1. $118 E-07$

4. $051 \mathrm{E}-07$

6. $331 E-07$

2. $195 E-06$

$6.023 E-05$

1. $151 E-04$

3. $842 \mathrm{E}-04$

9. $403 E-03$

2. $405 E-02$

1.84 IE-O

7. $527 \mathrm{E}-01$

3. $206 E+00$

4. $773 E+00$
GROUP 11 .

1.8 TO 2.0 MEV

ALPHA

1. $916 \mathrm{E}-19$

$6.384 \mathrm{E}-11$

. B39E-11

1. $033 \mathrm{E}-09$

1. $033 E-09$
2. $728 E-08$

2. $728 \mathrm{E}-08$
4. $774 \mathrm{E}-\mathrm{O} 7$

3. $320 E-06$

3. $691 \mathrm{E}-06$

2. $579 \mathrm{E}-05$

3. $357 \mathrm{E}-05$

3. $.357 \mathrm{E}-05$

. $356 E-O A$

3. $356 \mathrm{E}-01$

6. 109E-03

$1.601 E-02$

1. O99E-02

LAMBDA
$4.999 E-11$
$2.175 E-08$
$5.986 E-07$
$2.310 E-06$
$3.551 E-06$
$1.509 E-O 5$
$4.826 E-05$
$1.129 E-O 4$
$2.823 E-04$
$1.029 E-03$
$4.223 E-03$
$1.345 E-O 2$
$4.143 E-O 2$
$2.265 E-01$
$7.579 E-01$
$3.850 E+00$

GROUP 15 2. 6 TO 3.0 MEV

\section{ALFHA}

4. $554 \mathrm{E}-14$

2. $863 E-17$

3. $783 E-12$

4. $397 \mathrm{E}-09$

1. $432 \mathrm{E}-\mathrm{O} 7$

$.266 E-06$

. 559E-O5

$5.436 E-04$

5. $314 \mathrm{E}-04$

1. $214 E-03$

$2.776 \mathrm{E}-03$

. $502 E-03$

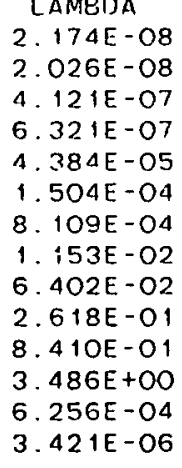

$.384 \mathrm{E}-05$

1. $453 \mathrm{E}-02$

2. $618 \mathrm{E}-01$

8. $410 E-01$

6. $256 E-04$

3. $421 \mathrm{E}-06$
GROUP 12 2.O TO 2.2 MEV

\begin{tabular}{|c|c|}
\hline$A L P H A$ & LAMBOA \\
\hline $2.550 E-13$ & $2.271 E-08$ \\
\hline 3. $446 E-11$ & $2.874 \mathrm{E}-08$ \\
\hline $2.706 E-09$ & 2. $205 E-06$ \\
\hline $2.927 E-09$ & $5.712 \mathrm{E}-06$ \\
\hline $1.922 E-07$ & 3. $854 E-05$ \\
\hline $3.301 \mathrm{E}-06$ & $9.393 E-05$ \\
\hline $6.44 O E-06$ & $3.038 E-04$ \\
\hline $6.223 E-05$ & $9.315 E-O 4$ \\
\hline 4. $327 E-04$ & 1. $313 E-02$ \\
\hline $7.528 \mathrm{E}-04$ & $8.315 E-02$ \\
\hline $4.365 E-03$ & $5.088 \mathrm{E}-01$ \\
\hline 2. $112 \mathrm{E}-\mathrm{O} 2$ & $3.566 E+00$ \\
\hline $1.745 \mathrm{E}-02$ & $3.954 E+O O$ \\
\hline $1.043 E-11$ & $2.966 E-08$ \\
\hline
\end{tabular}

GROUP 16 3.0 TO 4.O MEV

\begin{tabular}{|c|c|}
\hline ALPHA & LAMEDA \\
\hline $2.496 E-14$ & $2.173 \mathrm{~F}-08$ \\
\hline 7. $442 E-15$ & $2.818 E-08$ \\
\hline 8. $944 \mathrm{E}-11$ & 6. $365 E-07$ \\
\hline $3.613 E-07$ & $7.552 E-05$ \\
\hline $3.173 E-O 6$ & $1.487 E-04$ \\
\hline 1. $309 \mathrm{E}-05$ & 4. $550 E-04$ \\
\hline $1.573 E-04$ & $3.363 E-03$ \\
\hline $7.503 E-04$ & $1.197 E-02$ \\
\hline $9.51+E-04$ & $6.938 E-02$ \\
\hline $4.436 \mathrm{E}-03$ & $2.368 E-01$ \\
\hline $3.085 E-02$ & $1.044 E+0 O$ \\
\hline $2.74 O E-02$ & 1. $182 E+O O$ \\
\hline $5.016 E-03$ & $3.255 E+00$ \\
\hline 3. $263 E-03$ & $3.534 E+00$ \\
\hline $2.000 E-07$ & 1. $700 E-06$ \\
\hline 2. OOOE - O7 & 1.7OOE -OG \\
\hline
\end{tabular}

\begin{tabular}{|c|c|}
\hline AL.PHA & LAMBDA \\
\hline $6.509 E-15$ & 2. $174 \mathrm{E}-08$ \\
\hline $8.050 E-18$ & $2.097 E-08$ \\
\hline $5.955 E-13$ & $4.470 E-07$ \\
\hline $4.018 E-11$ & $6.394 E-07$ \\
\hline $3.537 E-07$ & $8.690 E-05$ \\
\hline $2.832 \mathrm{E}-06$ & 1. $467 \mathrm{E}-04$ \\
\hline $2.574 E-05$ & 8. $189 \mathrm{E}-0 \mathrm{~A}$ \\
\hline 1. $517 E-04$ & $3.422 E-03$ \\
\hline $9.728 \mathrm{E}-04$ & 1. $23 \mathrm{OE}-\mathrm{O} 2$ \\
\hline $8.263 E-04$ & 4. $154 \mathrm{E}-02$ \\
\hline 1. $236 \mathrm{E}-02$ & $1.767 \mathrm{E}-01$ \\
\hline 2. $168 \mathrm{E}-\mathrm{O} 2$ & $6.341 E-01$ \\
\hline $1.269 E-02$ & $9.152 \mathrm{E}-01$ \\
\hline $7.220 E-04$ & $2.868 E+00$ \\
\hline$-2.941 E-12$ & $6.447 E-07$ \\
\hline$-6.490 E-11$ & $5.286 E-06$ \\
\hline 1. OOOE - O6 & 1. $100 E-05$ \\
\hline-1. OOOE - O6 & 1. 1 OOE -O5 \\
\hline
\end{tabular}


TABLE A-V (Cont)

GROUP 17 4.O TO 5.O MEV
GROUP 18 5.0 TO $6.0 \mathrm{MFV}$
AI $\mathrm{CHA}$

8. $81 \in \mathrm{E}-20$

2. $175 E-15$

2. $497 E-13$

1. 77 IE- -07

1. $493 E-05$

1. $258 E-04$

2. $010 E-01$

$-2.012 \mathrm{E}-01$

4. $349 E-O 3$

-3. $240 E-O 3$

2. $865 \mathrm{E}-04$

$-5.322 E-O 5$

$-6.367 \mathrm{E}-20$

2. 126E-03

1. $991 E-03$

1. OOOE-2.1
LAMBBOA

5.758E-OS $2.011 E-01$ 6. 372E-O4 2. $754 E-03$

$4.604 E-03$

1. $212 \mathrm{E}-\mathrm{O} 2$ .014E-OI . $022 E-01$ 3. $740 E-O 1$ 4. $116 \mathrm{E}-01$ 1. $818 E+00$ 1. $799 E+O O$ $.043 E-06$

4. $025 E-02$

4.044E-O2

1. OOOE - O6 


$\begin{array}{cc}\text { GROUP } & 1 \\ 0.0 \text { TO } & .2 \text { MEV } \\ \text { ALPHA } & \text { LAMBDA } \\ 6.433 E-12 & 7.896 E-10 \\ 1.913 E-11 & 9.474 E-09 \\ 1.582 E-10 & 3.256 E-08 \\ 2.549 E-09 & 1.501 E-07 \\ 1.678 E-08 & 9.199 E-07 \\ 3.644 E-08 & 3.012 E-06 \\ 1.295 E-07 & 1.395 E-05 \\ 2.234 E-07 & 1.082 E-05 \\ 9.170 E-07 & 1.107 E-04 \\ 3.544 E-O 6 & 3.518 E-04 \\ 1.243 E-05 & 9.974 E-04 \\ 3.725 E-05 & 5.024 E-03 \\ 2.293 E-04 & 2.638 E-02 \\ 4.069 E-04 & 1.375 E-01 \\ 1.468 E-03 & 7.177 E-01 \\ -6.506 E-04 & 8.648 E-01 \\ 5.738 E-04 & 5.108 E+00 \\ -3.108 E-04 & 7.283 E+00\end{array}$

GROUP 5

8 TO 1.0 M̂EV

\begin{tabular}{|c|c|c|}
\hline LAMBDA & ALPHA & LAMBDA \\
\hline $7.685 E-10$ & 7. $109 E-12$ & $7.703 E-10$ \\
\hline $2.614 E-08$ & $1.538 E-10$ & 2. $6.40 E-08$ \\
\hline $3.807 E-08$ & $6.969 E-11$ & $4.575 E-08$ \\
\hline $1.591 \mathrm{E}-07$ & 2. $153 E-09$ & $1.623 E-C 7$ \\
\hline 1. $02.0 E-06$ & $5.450 E-09$ & 9. $555 E-C 7$ \\
\hline $8.633 E-06$ & $6.111 E-08$ & $7.050 E-06$ \\
\hline $1.670 E-04$ & $4.833 E-07$ & $2.021 \mathrm{E}-05$ \\
\hline $8.297 E-04$ & $2.012 \mathrm{E}-06$ & 6. $188 E-05$ \\
\hline $1.067 \mathrm{E}-02$ & $1.777 E-05$ & $3.075 E-04$ \\
\hline $4.821 E+\infty 0$ & $5.473 E-05$ & 1. $234 E-03$ \\
\hline $3.761 E+00$ & 1. $698 E-04$ & $5.013 E-O$ \\
\hline 1. $117 \mathrm{E}-02$ & $1.379 E-03$ & 1. $840 E-02$ \\
\hline $2.008 E-02$ & $3.576 E-01$ & $1.664 E-01$ \\
\hline 1. $359 E-01$ & $-3.685 E-01$ & $1.706 E-O$ \\
\hline $9.784 \mathrm{E}-01$ & $2.551 E-02$ & $3.114 E-01$ \\
\hline $9.252 E-06$ & $7.886 E-03$ & $2.876 E+O O$ \\
\hline \multirow[t]{2}{*}{$2.925 E-05$} & $-2.430 E-03$ & $5.114 E+O O$ \\
\hline & $-4.059 E-10$ & $1.779 E-O$ \\
\hline
\end{tabular}

GROUP 2

ALPHA

1. $062 \mathrm{E}-1$

1. $890 \mathrm{E}-12$

6. $351 \mathrm{E}-11$

2. $014 E-09$

5. $122 \mathrm{E}-08$

4 . $11 E-07$

5. $915 E-07$

2. $782 \mathrm{E}-06$

1. $034 \mathrm{E}-05$

3. $319 \mathrm{E}-05$

1. $024 \mathrm{E}-04$

$3.31+\mathrm{E}-\mathrm{O}$

5. $944 \mathrm{E}-\mathrm{O} 3$

$-2.499 E-02$

2. $153 E-02$

1. $11 O E-O 2$
$-1.126 E-02$
LAMBDA

1. $148 E-08$

6. $529 E-07$

3. $311 E-06$

1. $481 E-05$

4. $804 \mathrm{E}-05$

4. $120 E-01$

$1.072 E-03$

7. $37 \mathrm{OE}-03$

2. $877 E-O 2$

$4.593 E-01$

7. $693 \mathrm{E}-01$

8. $770 E-01$

9. $788 E+O O$
9.

GROUP 6

1.0 TO 1.2 MEV

ALPHA

. $042 E-10$

$.662 E-11$

$.504 E-09$
$150 E-08$

6. $932 \mathrm{E}-\mathrm{O} 7$

8. 377E-06

$5.688 E-05$

. $738 E-02$

ITOE-O2

$-2.289 \mathrm{E}-02$

$-1.879 \mathrm{E}-\mathrm{O} 2$

.830E-03

$5.412 \mathrm{E}-07$

1. $123 \mathrm{E}-\mathrm{O} 6$

\begin{tabular}{|c|c|}
\hline GROUP & 3 \\
\hline $4 \mathrm{TO}$ & $.6 \mathrm{MEV}$ \\
\hline ALPHA & LAMBDA \\
\hline $4.749 E-12$ & $7.805 E-10$ \\
\hline 2. $348 E-12$ & 1. $191 E-08$ \\
\hline $7.886 E-11$ & 3. $140 E-08$ \\
\hline 2. $393 E-09$ & $1.698 E-07$ \\
\hline 1. $844 E-08$ & $7.808 E-07$ \\
\hline $7.477 E-08$ & $4.323 E-06$ \\
\hline $6.173 E-07$ & $1.522 \mathrm{E}-05$ \\
\hline 1. $138 E-06$ & 5. $337 E-05$ \\
\hline $8.664 E-06$ & $1.855 E-04$ \\
\hline $4.551 E-05$ & $8.001 E-04$ \\
\hline $1.917 E-04$ & $6.076 E-03$ \\
\hline $6.038 \mathrm{E}-04$ & $2.67 \mathrm{OE}-02$ \\
\hline $1.677 E-03$ & $1.095 E-01$ \\
\hline $2.093 E-03$ & $5.290 E-01$ \\
\hline $5.858 E-03$ & $1: 87 O E+O O$ \\
\hline $5.279 E-0.3$ & $5.604 \mathrm{E}+0 \mathrm{O}$ \\
\hline$-9.027 E-03$ & $3.458 E+00$ \\
\hline$-1.671 E-06$ & 1. $186 E-04$ \\
\hline
\end{tabular}

GROUP 7

1.2 TO 1.4 MFV

ALPHA
$7.264 E-12$
$1.605 E-10$
$8.736 E-11$
$8.812 E-10$
$3.709 E-09$
$1.781 E-07$
$1.347 E-06$
$2.821 E-06$
$1.412 E-O 5$
$4.066 E-05$
$1.189 E-04$
$6.901 E-04$
$1.944 E-03$
$4.653 E-03$
$3.292 E-03$
$2.351 E-02$
$-1.457 E-02$
$7.860 E-03$
$-1.119 E-11$
LAMBDA

7. $709 \mathrm{E}-10$

2. $619 \mathrm{E}-08$

3. $81 \mathrm{IE}-08$

$1.81 \mathrm{IE}-07$

1. $336 E-06$

1. $290 E-05$

$4.029 E-05$

1. $406 \mathrm{E}-04$

3. $443 \mathrm{E}-04$

1. $005 E-03$

3. $625 \mathrm{E}-03$

1. $211 \mathrm{E}-\mathrm{O} 2$

3. $361 E-02$

1. 109E-O 1

2. $212 \mathrm{E}-\mathrm{O} 1$

$1.007 E+O O$

$1.917 \mathrm{E}+00$

1. $917 E+O 0$

4. $235 E+00$
1. $489 E-06$
GROUP 4

6 TO .8 MEV

$\begin{array}{rc}\text { ALPHA } & \text { LAMBDA } \\ 4.882 E-12 & 7.495 E-10 \\ 1.895 E-11 & 2.139 E-08 \\ 9.873 E-11 & 3.127 E-08 \\ 4.302 E-09 & 1.626 E-07 \\ 1.435 E-08 & 7.583 E-07 \\ 1.318 E-07 & 5.416 E-06 \\ 8.950 E-07 & 2.036 E-05 \\ 3.846 E-06 & 1.175 E-04 \\ 6.792 E-05 & 5.156 E-04 \\ 9.362 E-04 & 9.120 E-03 \\ 1.562 E-03 & 4.021 E-02 \\ 7.476 E-03 & 2.929 E-01 \\ 7.551 E-05 & 2.183 E+01 \\ -7.676 E-03 & 7.213 E-01 \\ 9.321 E-03 & 1.217 E+0 O \\ -5.527 E-04 & 9.269 E-03 \\ -7.346 E-05 & 6.718 E-04 \\ 8.493 E-05 & 1.236 E-03 \\ -1.823 E-09 & 1.742 E-07\end{array}$

GROUP 8

1.4 TO 1.6 MEV 
TABLE A-VI (Cont)

GRDUP 9 1.6 TO 1.8 MEV
GROUP 10 1.8 TO 2 MEV

\begin{tabular}{|c|c|}
\hline ALPHA & L_AMBDA \\
\hline $95 \mathrm{OF}-12$ & $7.718 E-10$ \\
\hline $977 E-10$ & $2.751 E-08$ \\
\hline $591 E-11$ & 3. $726 E-08$ \\
\hline $307 E-10$ & $1.317 E-06$ \\
\hline $755 E-08$ & $1.411 E-05$ \\
\hline $144 E-C 6$ & $3.954 E-05$ \\
\hline $626 E-C 6$ & $2.798 E-04$ \\
\hline $427 E-C .5$ & $1.130 E-03$ \\
\hline $6.79 E-04$ & E. $222 E-03$ \\
\hline $016 \mathrm{E}-\mathrm{C} 2$ & 4. $309 E-02$ \\
\hline $459 E-C 2$ & $2:-118 E-01$ \\
\hline $994 E-02$ & 1. $204 E+O O$ \\
\hline $7.25 E-03$ & $4.583 \mathrm{E} \cdot 02$ \\
\hline $159 E-07$ & $1.178 E-03$ \\
\hline
\end{tabular}

GROUP 11 2. O TO 2.2 MEV

\begin{tabular}{|c|c|}
\hline ALPHA & LAMBDA \\
\hline $1.020 E-12$ & $7.529 E-10$ \\
\hline $1.452 \mathrm{E}-10$ & $2.621 E-08$ \\
\hline 7. $992 \mathrm{E}-11$ & 3. $554 E-08$ \\
\hline $2.066 E-10$ & 2. $178 E-06$ \\
\hline $2.250 E-07$ & $2.054 \mathrm{E}-05$ \\
\hline 1. $962 \mathrm{E}-06$ & $5.725 \mathrm{E}-05$ \\
\hline 2. $299 \mathrm{E}-05$ & $5.016 E-04$ \\
\hline $9.626 E-05$ & $2.274 \mathrm{E}-\mathrm{O} 3$ \\
\hline $8.843 E-04$ & $1.289 E-02$ \\
\hline $2.628 \mathrm{E}-03$ & $4.427 \mathrm{E}-02$ \\
\hline 1. $168 \mathrm{E}-02$ & $1.633 E-01$ \\
\hline 2. $205 E-02$ & $7.768 E-01$ \\
\hline 4. $229 E-03$ & $7.775 E+\infty 0$ \\
\hline $1.67 \mathrm{IE}-04$ & $5.778 E-02$ \\
\hline $8.804 E-07$ & $6.407 E-05$ \\
\hline $963 \mathrm{~F}$ & 45 \\
\hline
\end{tabular}

GROUP 12 2. 2 TO 2.4 MEV
GROUP 13 2.4 TO 2.6 MEV

\begin{tabular}{|c|c|c|}
\hline ALLPHA & LAMBDA & ALPHA \\
\hline $.537 E-13$ & T. $278 E-10$ & $2.727 E-13$ \\
\hline $8.367 E-11$ & $2.623 E-08$ & 4. $1,10 E-11$ \\
\hline $2.371 E-11$ & 1. $436 E-08$ & $1.707 E-11$ \\
\hline 5. $243 \mathrm{E}-08$ & 1. $844=-05$ & $1.012 E-11$ \\
\hline $8.250 E-07$ & $4.876 \bar{r}-05$ & 1. $454 E-10$ \\
\hline $2.276 \mathrm{E}-05$ & $5.820 E-04$ & 1. $281 E-08$ \\
\hline $1.415 E-03$ & $3.356 E-03$ & 1. $663 E-06$ \\
\hline 1. OE9E-O3 & $1.422 \mathrm{E}-02$ & $3.970 E-05$ \\
\hline $5.417 E-03$ & $7.034 E-02$ & $1.491 \mathrm{E}-04$ \\
\hline 3. $14.5 \mathrm{E}-02$ & $3.508 E-01$ & $8.592 E-04$ \\
\hline$-1.7: 5 E-02$ & $4.658 E-01$ & 1. $364 E-02$ \\
\hline $2.328 \mathrm{E}-\mathrm{O} 2$ & $1.37 \mathrm{GE}+00$ & $4.362 E-O 2$ \\
\hline 1. $326 E-03$ & $3.445 \mathrm{E}-03$ & $4.606 E-02$ \\
\hline $6.592 E-12$ & 4. $397 E-08$ & $-2.469 E-02$ \\
\hline $8.756 E-11$ & $2.68 \mathrm{iE}-06$ & $-2.176 \mathrm{E}-\mathrm{O} 2$ \\
\hline & & $3.023 E-02$ \\
\hline
\end{tabular}

GROUF 14 2.6 TO $3.0 \mathrm{MEV}$

LAMBDA
$-.243 E-10$
$2.441 E-08$
$3.570 E-08$
$2.328 E-07$
$3.553 E-06$
$1.636 E-05$
$5.024 E-05$
$5.158 E-04$
$2.504 E-03$
$7.734 E-03$
$4.362 E-02$
$6.259 E-01$
$3.300 E+O O$
$4.033 E+O O$
$6.306 E-O 2$
$1.055 E-01$
$5.693 E-05$

GROUP 15 3.0 TO 4.O MEV

ALPHA 4. $158 \mathrm{E}-13$ $3.557 E-12$

1. $286 \mathrm{E}-12$

$418 \mathrm{E}-1$ 1. $418 E-1$ . 179E- 10 .

2. $556 \mathrm{E}-06$

4. $138 \mathrm{E}-05$ 1. $229 E-04$ $1.016 \mathrm{E}-03$

$5.507 \mathrm{E}-03$

3. $562 \mathrm{E}-02$

1. $110 \mathrm{E}-01$

$4.835 E-03$

$-3.220 E-02$

$6.881 \mathrm{E}-\mathrm{O} 2$ $-1.43 O E-O 6$
GROUP 16 4. TO 5.0 MEV

ALPHA 1. $360 \mathrm{O}-13$ $2.947 \mathrm{E}-12$

5. $275 E-10$

6. $879 E-O 7$

4. $340 E-O 6$

4. $340 E-06$

$6.982 \mathrm{E}-\mathrm{O}$

$6.117 \mathrm{E}-04$

$2.022 \mathrm{E}-\mathrm{O}$

$-4.819 \mathrm{E}-\mathrm{O} 1$

6. $891 \mathrm{E}-\mathrm{O} 2$

3. $867 \mathrm{E}-\mathrm{O} 2$

$-1.126 \mathrm{E}-02$

$-6.426 E-13$

$6.094 \mathrm{E}-12$
LAMBDA

7. $002 \mathrm{E}-10$ 2. $113 E-O 7$ $.036 E-05$
$6.763 E-05$

6. $535 E-04$

$3.349 E-03$

9. $518 \mathrm{E}-\mathrm{O} 3$

7. $016 \mathrm{E}-\mathrm{O}$ ?

7.834E-02

8. $722 \mathrm{E}-\mathrm{O} 2$

$6.108 E-01$

1. $492 \mathrm{E}+00$

3. $680 \mathrm{OE}-07$

1. $638 \mathrm{E}-\mathrm{OG}$
LAMBOA

7. $394 \mathrm{E}-10$

2. $525 \mathrm{E}-08$

3. $441 \mathrm{E}-08$

3. $010 \mathrm{E}-06$

5. $563 \mathrm{E}-05$

5. $134 E-04$

2. $183 \mathrm{E}-\mathrm{O} 3$

1. $215 \mathrm{E}-02$

4. 348E-O2

. 255E-O1

4. $955 \mathrm{E}-\mathrm{O}$

2. $264 E+00$

6. $598 \mathrm{E}-05$

5.667E-01

1. $826 \mathrm{E}+00$

4. $401 E-05$

GROUP 17 5.0 TO 6.0 MEV

$\begin{array}{cc}\text { ALPHA } & \text { LAMBDA } \\ 3.393 E-14 & 6.960 E-10 \\ 5.069 E-14 & 2.328 E-07 \\ 2.022 E-13 & 1.952 F-06 \\ 1.293 E-10 & 1.129 E-05 \\ 9.027 E-10 & 4.095 E-05 \\ 2.923 E-O 8 & 7.999 E-O 5 \\ 1.011 E-O 5 & 2.898 E-03 \\ 1.129 E-O 4 & 7.502 E-03 \\ 1.484 E-O 3 & 4.192 E-02 \\ 1.699 E-02 & 1.378 E-01 \\ 4.167 E-02 & 7.733 E-01 \\ -1.329 E-O 2 & 8.698 E-01 \\ 1.913 E-O 2 & 4.829 E+O O \\ -1.031 E-02 & 6.826 E+O 0 \\ -1.564 E-O 8 & 9.097 E-05\end{array}$




\section{GROUP 1 \\ 0.0 TO $.1 \mathrm{MEV}$}

\begin{tabular}{|c|c|}
\hline ALPHA & LAMBDA \\
\hline $670 E-13$ & 1. $050 E-09$ \\
\hline $5.839 E-13$ & $7.458 E-09$ \\
\hline $6.518 E-12$ & 3. $186 \mathrm{E}-0 \mathrm{O}$ \\
\hline $1.542 \mathrm{E}-10$ & $2.521 E-07$ \\
\hline $2.799 E-09$ & $9.366 E-07$ \\
\hline ४. O09E-08 & $2.267 E-O 6$ \\
\hline $7.020 E-09$ & $8.699 E-06$ \\
\hline 3. $301 E-08$ & 5. $131 E-05$ \\
\hline $6.052 E-07$ & $2.655 E-04$ \\
\hline $3.496 E-06$ & $1.067 E-03$ \\
\hline 1.694E-05 & $4.908 E-03$ \\
\hline 3. $700 E-04$ & 1. $332 E-02$ \\
\hline $1.401 \mathrm{E}-04$ & $5.828 \mathrm{E}-\mathrm{O} 2$ \\
\hline $6.886 E-02$ & $1.653 E+O O$ \\
\hline $6.983 E-02$ & $1.685 E+00$ \\
\hline $3.490 E-03$ & $5.119 E+0 O$ \\
\hline 2. $089 \mathrm{E}-03$ & $7.391 E+00$ \\
\hline
\end{tabular}

GROUP 5 6 TO .8 MEV

\begin{tabular}{|c|c|}
\hline ALPHA & LAMBDA \\
\hline $2.743 E-11$ & 7. $280 E-10$ \\
\hline 1. $239 E-11$ & $1.071 \mathrm{E}-08$ \\
\hline $7.56 \wedge \mathrm{E}-11$ & 2. $945 E-08$ \\
\hline 1. $.480 E-08$ & 1. $238 E-07$ \\
\hline $2.851 E-07$ & $2.739 E-06$ \\
\hline $1.477 \mathrm{E}-06$ & $1.511 \mathrm{E}-05$ \\
\hline 3. $220 E-O 6$ & $8.748 E-05$ \\
\hline $2.373 E-05$ & $2.726 E-04$ \\
\hline $5.598 E-05$ & $1.219 E-0.3$ \\
\hline $1.878 E-04$ & $3.671 E-03$ \\
\hline 1. $202 E-03$ & $1.524 E-02$ \\
\hline $3.933 E-03$ & 4. $138 E-02$ \\
\hline $1.641 E-02$ & $2.611 E-01$ \\
\hline $6.941 E-02$ & $2.589 E+00$ \\
\hline$-1.238 E-01$ & $4.786 E+00$ \\
\hline $7.486 E-02$ & $6.330 E+O O$ \\
\hline$-8.173 E-04$ & $1.815 E-01$ \\
\hline$-7.639 E-09$ & $1.949 E-07$ \\
\hline
\end{tabular}

GROUP . 2

1 TO 2 MEV

ALPHA

1. $896 \mathrm{E}-13$

$1.611 E-13$

1. $096 \mathrm{E}-09$

2. $534 E-08$

2. $477 \mathrm{E}-08$

1. $082 E-06$

8. $421 \mathrm{E}-06$

3. $055 \mathrm{E}-05$

2. $267 \mathrm{E}-04$

1. $828 \mathrm{E}-03$

6. $561 \mathrm{E}-\mathrm{O} 3$

1. $924 \mathrm{E}-02$

$-1.016 E-02$

$-7.216 E-09$
GROUP 6 8 TO $1.0 \mathrm{MEV}$

ALPH

6. $117 E-16$

3. $416 \mathrm{E}-12$

3. $362 E-12$

1. $485 \mathrm{E}-08$

$5.403 E-08$

5. $403 \mathrm{E}-08$

$9.079 \mathrm{E}-07$

1. $890 E-05$
2. $774 \mathrm{E}-05$

2. $774 \mathrm{E}-05$
1. $436 \mathrm{E}-\mathrm{O4}$

3. $430 \mathrm{OE}-04$

$9.460 E-03$

2. $034 \mathrm{E}-02$

1. $831 \mathrm{E}-\mathrm{O} 2$

$-1.649 E-02$

2. $032 \mathrm{E}-\mathrm{O} 2$
LAMBDA

4. 578E-09

2. $997 E-O 8$

2. $627 \mathrm{E}-07$

2. $783 E-06$

1. 255E-O5

1. $380 E-O 4$

2. $048 \mathrm{E}-03$

1. $269 \mathrm{E}-02$

6. $259 E-O 2$

2. $680 E-01$

1. $183 E+00$

1. $657 E+00$
1. $044 E-05$
GROUP 3 2 TO . 4 MEV

ALPHA

1. $903 \mathrm{E}-14$

8. $135 E-14$

7. $393 E-14$

5. $409 E-O 9$

1. $739 E-08$

5. $477 \mathrm{E}-08$

2. $790 E-O 7$

2. $130 \mathrm{O}-07$

2. $495 \mathrm{E}-05$

6. 306E-05

1. $382 \mathrm{E}-\mathrm{O} 3$

2. $573 \mathrm{E}-\mathrm{O} 2$

1. $178 \mathrm{E}-01$

$-1.127 \mathrm{E}-\mathrm{O}$

$-2.403 E-02$

2. $065 \mathrm{E}-\mathrm{O} 2$
GROUP 4 TO . 6 MEV

ALPHA

1. $580 E-13$

1. $982 \mathrm{E}-11$

1. 7 TE- 10

7. $923 \mathrm{E}-09$

3. $234 \mathrm{E}-08$

5. $247 E-07$

1. $632 E-06$

2. $450 E-05$

$6.970 E-05$

1. $167 \mathrm{E}-04$

5. 742E-O4

5. $542 E-04$

1. $571 E-02$

$3.813 E-02$

$-1.669 \mathrm{E}-02$

4. $628 \mathrm{E}-03$

$-2.427 \mathrm{E}-03$

2. $523 \mathrm{E}-01$

8. 512E-01

GROUP 7

1. O TO 1.2 MEV

LAMBDA

2. 209E-O9

2. $162 \mathrm{E}-08$

1. $917 E-07$

6. $318 \mathrm{E}-07$

3. $097 \mathrm{E}-06$

3. 290E-O5

1. $553 \mathrm{E}-04$

2. $362 E-O 4$

1. $386 E-.03$

6. $531 \mathrm{E}-03$

4. $801 \mathrm{E}-\mathrm{D} 2$

6. $756 \mathrm{E}-\mathrm{O} 1$

2. $81 O E+D O$

$6.493 E-02$

1. $029 \varepsilon-01$
ALPHA
3. 386E-16
$1.890 E-11$
$1.025 E-12$
$5.911 E-10$
$1.484 E-09$
$1.534 E-08$
$1.426 E-O 7$
$1.155 E-06$
$1.196 E-05$
$6.409 E-05$
$1.142 E-04$
$6.309 E-04$
$3.842 E-03$
$2.294 E-02$
$8.489 E-03$
$2.067 E-03$
$-3.884 E-04$
LAMBDA

1. $872 \mathrm{E}-09$

2. $159 \mathrm{E}-\mathrm{O} 8$

3. $516 E-08$

$5.600 E-07$

1. $391 \mathrm{E}-06$

3. $243 \mathrm{E}-06$

1. $332 \mathrm{E}-05$

3. $267 E-05$

1. $930 E-04$

7. $898 \mathrm{E}-04$

3. $677 \mathrm{E}-03$

2. $021 E-02$

8. $491 \mathrm{E}-\mathrm{O} 2$

$6.773 \mathrm{E}-01$

1. $522 \mathrm{E}+00$

1. $522 E+O O$

4. $049 E+O O$
$5.491 E-02$
GROUP 8 1.2 TO 1.4 MEV

ALPHA

1. O36E-15

1. $073 E-13$

3. $379 E-13$

1. $553 E-11$

3. $637 E-10$

2. $568 \mathrm{E}-08$

8. $736 \mathrm{E}-03$

1. $729 \mathrm{E}-\mathrm{O6}$

3. $669 \mathrm{E}-06$

5. $368 \mathrm{E}-05$

8. $563 E-05$

1. 106E-03

2. $631 E-03$

1. $417 E-02$

$8.020 E-O 3$

3. $146 \mathrm{E}-04$
LAMBDA

4.501E-09

2. $817 E-08$

2. $249 E-07$

8. $605 \mathrm{E}-07$

1. $073 \mathrm{E}-05$

5. $358 \mathrm{E}-05$

3. $160 E-04$

3. $288 \mathrm{E}-03$

1. $281 E-02$

4. $071 \mathrm{E}-02$

1. 183E-01

4. $711 E-01$

5. $685 \mathrm{E}-01$

2. $426 \mathrm{E}+0 \mathrm{O}$

3. $388 \mathrm{E}+00$

8. 149E-07
LAMBDA

2. $421 \mathrm{E}-09$

1. $667 \mathrm{E}-08$

3. $110 E-08$

6. $206 \mathrm{E}-07$

2. 534E-06

1. $025 \mathrm{E}-05$

3. $900 E-05$

1. 145E-O4

7. 606E-04

3. $009 E-03$

1. $355 \mathrm{E}-\mathrm{O2}$

3. $351 \mathrm{E}-\mathrm{O} 1$

9. $121 E-01$

7. $574 \mathrm{E}+0 \mathrm{O}$ 
GRoup 9

1.4 TO $1.6 \mathrm{MEV}$

ALPHA
$6.011 E-17$
$3.490 E-12$
$3.887 E-12$
$6.366 E-07$
$6.966 E-05$
$9.237 E-04$
$1.062 E-03$
$4.314 E-03$
$1.449 E-02$
$-7.729 E-03$
$3.395 E-03$
$-1.896 E-03$
$-3.698 E-05$
$2.521 E-04$
$-1.615 E-06$
$9.959 E-07$
$8.358 E-07$
$2.107 E-07$
$-1.997 E-07$

GROUP 10

1.6 TO $1.8 \mathrm{MEV}$

ALPHE.

1. $420 \equiv-18 \quad 1.548 E-10$

$\begin{array}{ll}\text { 1. } 126 \bar{E}-12 & 2.180 E-08\end{array}$

3. $113 \mathrm{E}-13 \quad 2.102 \mathrm{E}-07$

7.98OE-12 7.468E-O7

1.701E-09 2.531E-06

$\begin{array}{ll}1.767 E-O B & 1.044 E-05 \\ 7.775 E-07 & 2.995 E-O 5\end{array}$

$3.716 E-06 \quad 1.589 E-04$

9. $373 E-O 6 \quad 4.781 E-04$

9. $157 \mathrm{E}-05$ Q.

4. $157 E-05 \quad 9.785 E-04$

9. $154 \mathrm{E}-05 \quad 5.255 \mathrm{E}-03$

4.222E-04 2.027E-02

1. $138 \mathrm{E}-\mathrm{O} 2$ 1.066E-01

$-8.813 E-03 \quad 1.236 E-01$

$6.044 \mathrm{E}-03 \quad 5.659 \mathrm{E}-01$

$-2.806 E-03 \quad 7.952 E-01$

5.546E-O4 4. $441 E+O O$

$-3.250 E-04 \quad 6.614 \mathrm{E}+\mathrm{OO}$
GROUP 13

2.2 TO $2.4 \mathrm{MEV}$

ALPHA

9. $394 \mathrm{E}-13$

$5.163 E-17$

1. $838 \mathrm{E}-13$

7. $984 \mathrm{E}-10$

4. $681 \mathrm{E}-11$

9. $505 \mathrm{E}-10$

6. $957 \mathrm{E}-\mathrm{O} 7$

1. $192 \mathrm{E}-05$

1. $322 \mathrm{E}-\mathrm{O} 5$

1. $727 \mathrm{E}-04$

2. $205 E-04$

8. $254 E-04$

3. $706 \mathrm{E}-03$

$8.477 \mathrm{E}-03$

$-6.024 \mathrm{E}=03$

LAMBDA

2. $179 \mathrm{E}-08$

6. $141 \mathrm{E}-08$

1. $983 E-07$

6. $244 \mathrm{E}-07$

6. $297 \mathrm{E}-07$

$2.706 \mathrm{E}-06$

$5.774 \mathrm{E}-05$

1. $727 \mathrm{E}-04$

$8.401 \mathrm{E}-03$

1. $852 E-D 2$

1. $672 E-01$

8. $109 E-01$

3. $461 \mathrm{E}+\mathrm{DO}$

$4.097 E+00$

2. $048 E-04$
GROUP 11

1.8 TO 2.0 MEV

ALPHA
$9.703 E-19$
$6.838 E-13$
$1.764 E-10$
$4.299 E-09$
$6.138 E-08$
$1.352 E-06$
$4.201 E-06$
$2.228 E-O 5$
$2.066 E-05$
$3.102 E-04$
$2.559 E-01$
$3.677 E-O 3$
$1.095 E-O 2$.
$3.473 E-03$
$4.161 E-03$

LAMEDA

3. $628 \mathrm{E}-11$

2. $180 E-08$

5. $694 E-07$

2. $792 \mathrm{E}-0 \mathrm{G}$

2. $122 \mathrm{E}-05$

8. $784 \mathrm{E}-05$

2. $167 E-04$

9. $266 \mathrm{E}-\mathrm{O} 4$

9. $266 \mathrm{E}-04$

4. $180 E-O 3$

1. $350 E-O 2$

3. $930 E-O 2$

2. $138 E-01$

6. $441 \mathrm{E}-\mathrm{O}$

6. $998 \mathrm{E}-\mathrm{O}$

2. $733 E+00$

\section{SROUP 14 \\ 2.4 TO $2.6 \mathrm{MEV}$}

Al_FHA

4. $849 \mathrm{E}-13$

1. $274 \mathrm{E}-15$

3. $614 \mathrm{E}-16$

3. $351 \mathrm{E}-\mathrm{O}$

1. $133 \mathrm{E}-07$

3. $652 \mathrm{E}-06$

3. $260 \mathrm{OE}-\mathrm{O5}$

2. 562E-OA

1. $500 E-04$

6. $456 \mathrm{E}-\mathrm{O} 4$

2. 567E-03

$-1.017 E-03$

8. $6.43 E-04$

$-5.213 E-01$

$-1.369 E-05$

1. $990 \mathrm{E}-07$

$-2.004 E-07$
LAMBDA

2. $178 E-08$

2. $263 \mathrm{E}-08$

2. $264 \mathrm{E}-08$

6. $159 \mathrm{E}-07$

4. $128 \mathrm{E}-05$

1. $477 E-04$

8. $180 \mathrm{OE}-04$

3. $264 \mathrm{E}-\mathrm{O} 2$

2. $243 E-01$

7. $295 \mathrm{E}-01$

.7. $514 \mathrm{E}-01$

3. $250 E+00$

$3.643 E+O O$

$7.735 E-04$

1. $692 \mathrm{E}-\mathrm{O} 6$
GROUP 12

2.0 TO $2.2 \mathrm{MEV}$

ALPHA

2. $750 E-10 \quad 5.999 E-07$

5. $343 \mathrm{E}-09 \quad 2.795 \mathrm{E}-06$

3. $214 \mathrm{E}-08 \quad 1.937 \mathrm{E}-05$

2. $172 \mathrm{E}-06 \quad 9.154 \mathrm{E}-05$

6. $465 \mathrm{E}-06 \quad 3.141 \mathrm{E}-\mathrm{OA}$

4. $567 E-05 \quad 9.525 E-04$

$1.578 E-04 \quad 9.497 \mathrm{E}-03$

2. $130 \mathrm{E}-04 \quad 2.481 \mathrm{E}-\mathrm{O} 2$

5.85OE-O4 $1.718 \mathrm{E}-01$

1. $798 \mathrm{E}-03 \quad 5.363 \mathrm{E}-01$

1.217E-O3 2.065E+OO

\section{GROUP 15 \\ 2. 6 TO 3.0 MEV}

ALPHA
$2.686 E-13$
$4.817 E-15$
$7.459 E-11$
$2.684 E-12$
$7.742 E-10$
$1.241 E-06$
$6.752 E-06$
$3.101 E-05$
$1.027 E-O 2$
$1.131 E-02$
$1.770 E-03$
$2.934 E-03$
$4.135 E-03$
$8.825 E-04$
$1.904 E-05$

LAMBDA

2. $179 E-08$

2. $837 \mathrm{E}-08$

6. $281 E-07$

3. $417 \mathrm{E}-05$

1. $523 \mathrm{E}-05$

1. $057 \mathrm{E}-04$

2. $743 E-04$

1. $308 E-03$

$1.014 E-02$

$1.073 E-02$

1. $647 \mathrm{E}-02$

2. $347 \mathrm{E}-\mathrm{O}$

8. $442 \mathrm{E}-\mathrm{O}$

1. $591 \mathrm{E}+00$
GROUP 16

3.0 TO 4.O MEV

ALPHA

6. $975 E-1 A$

2. $154 \mathrm{E}-16$

3. $329 E-1$

1. $566 \mathrm{E}-07$

2. $274 E-O G$

2. $399 E-05$

1. $110 E-04$

$5.741 E-04$

$6.399 \mathrm{E}-03$

9. $267 \mathrm{E}-03$

$-1.695 \mathrm{E}-11$
I $\triangle M B D A$

2. $179 E-O B$ 6. $113 E-08$ $612 \mathrm{E}-07$ 8. $601 \mathrm{E}-05$ 1. $378 \mathrm{E}-\mathrm{OA}$ 8. $247 E-04$ $4.547 E-0.3$ . $518 E-02$ 4. $513 \mathrm{E}-\mathrm{O} 1$ 3. $17 \mathrm{OE}-\mathrm{O} 6$ 
TABLE A-VII (Cont)

\begin{tabular}{|c|c|}
\hline \multicolumn{2}{|c|}{ GROUP 1.7} \\
\hline 4.0 & MEV \\
\hline ALPHA & LAMBDA \\
\hline $7.781 E-19$ & $4.142 E-06$ \\
\hline $8.000 E-09$ & $6.785 E-05$ \\
\hline $1.593 E-08$ & $1.281 E-04$ \\
\hline 8. $143 E-08$ & $4.281 E-04$ \\
\hline $1.668 E-05$ & $3.204 E-03$ \\
\hline 1. $362 E-04$ & $8.617 E-03$ \\
\hline $1.823 E-04$ & $2.727 E-02$ \\
\hline $7.263 E-04$ & $1.492 \mathrm{E}-01$ \\
\hline $3.578 E-0.3$ & $5.724 E-01$ \\
\hline $4.702 E-04$ & 1. $.989 E+00$ \\
\hline $2.463 E-04$ & $8.098 E+00$ \\
\hline
\end{tabular}

GROUP 18 5.0 TO 6.0 MFV 
TABLE A-VIII

FITS TO ${ }^{239}$ PU THERMAL PULSE BETAS

FOR ENDF/B-V DATA

\begin{tabular}{|c|c|}
\hline \multicolumn{2}{|c|}{ GROUP 1} \\
\hline 0.0 TO & 2 MEV \\
\hline ALPHA & LAMBDA \\
\hline$-123 E-12$ & 8. $892 \mathrm{E}-10$ \\
\hline $5.889 E-11$ & $1.582 E-08$ \\
\hline $7.567 E-10$ & 8. $555 E-08$ \\
\hline $3.899 E-09$ & $2.915 E-07$ \\
\hline 3. $160 \mathrm{E}-\mathrm{O} 8$ & 1. $\angle 39 E-06$ \\
\hline $9.646 \mathrm{E}-03$ & $6.122 \mathrm{E}-06$ \\
\hline $3.444 \mathrm{E}-07$ & 3. $422 \mathrm{E}-05$ \\
\hline 1. $565 \mathrm{E}-\mathrm{O}$ & 1. $655 \mathrm{E}-04$ \\
\hline 1. $113 E-05$ & $6.813 E-04$ \\
\hline $2.082 E-05$ & $3.007 E-03$ \\
\hline $9.493 E-05$ & 1. $388 E-02$ \\
\hline $2.127 E-O 4$ & $5.649 E-02$ \\
\hline $4.021 E-04$ & 2. $866 \mathrm{E}-01$ \\
\hline 3. $211 \mathrm{E}-04$ & $8.994 \mathrm{E}-01$ \\
\hline $3.215 E-05$ & $4.354 E+O O$ \\
\hline
\end{tabular}

GROUP 5
8 TO 1 ME

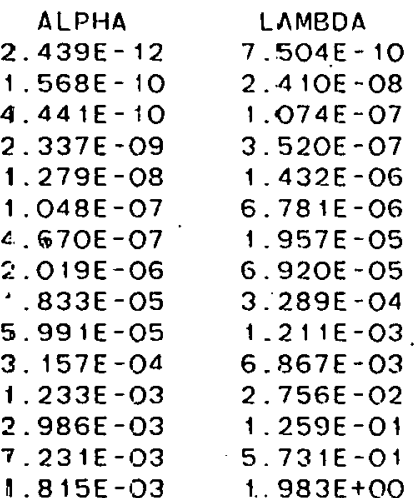

GROUP 2

$$
2 \text { TO }^{2} .4 \mathrm{MEV}
$$

ALPHA

$\begin{array}{ll}6.815 E-12 & 7.591 E-10 \\ 5.07 A E-11 & 2.618 E-08\end{array}$

LAMBDA

8.636E-10 1.4C5E-O7

6. $726 \mathrm{E}-09$

2. 525E-09

$4.525 \mathrm{E}-07$

$4.525 \mathrm{E}-07$
$1.392 \mathrm{E}-06$

1. $392 \mathrm{E}-06$

$6.766 \mathrm{E}-06$

$2.453 \mathrm{E}-05$

$1.800 E-04$

$7.031 \mathrm{E}-04$

2. $980 \mathrm{E}-03$

1. $401 \mathrm{E}-\mathrm{O} 2$

5. $746 \mathrm{E}-\mathrm{O} 2$

2. $753 \mathrm{E}-01$

9. 173E-O1

. $253 E-C$

5. $389 E-04$

4. $499 E+00$

GROUP 6

1.0 TO $1.2 \mathrm{MEV}$

ALPHA
$2.630 E-12$
$2.006 E-10$
$2.810 E-10$
$1.345 E-09$
$6.258 E-09$
$4.733 E-08$
$3.599 \equiv-07$
$1.919 \equiv-06$
$1.715 \equiv-05$
$6.172 \equiv-05$
$3.671 E-04$
$1.503 E-03$
$3.960 E-03$
$6.902 E-03$
$1.507 E-03$

LAMBDA

7. $524 E-10$

2. $402 E-08$

9. $519 E-08$
3. $138 E-07$

3. $138 E-O 7$
1. $343 E-O G$

$6.853 \mathrm{E}-06$

1. $915 E-05$

6. $855 \mathrm{E}-05$

3. $254 \mathrm{E}-04$

1. $265 E-03$

$6.986 \mathrm{E}-03$

$2.771 \mathrm{E}-02$

1. $267 E-O 1$

5. $191 \mathrm{E}-\mathrm{O}$

2. $453 E+00$
GROUP 3

4 TO . 6 MEV

ALPHA

$6.773 E-11, \quad 2.413 E-08$

$4.447 \mathrm{E}-10 \quad 1.174 \mathrm{E}-07$

$6.464 E-09 \quad 4.460 E-07$

2. $256 \mathrm{E}-08 \quad 1.391 \mathrm{E}-06$

1.688E-07 $6.698 \mathrm{E}-06$

$7.552 \mathrm{E}-07$

1. $743 E-06$

1. $669 \mathrm{gE}-05$

$4.880 E-0.5$

1. $695 E-04$

5. $973 \mathrm{E}-\mathrm{O} 4$

2. $016 E-03$

$4.068 E-04$

$6.698 E-06$
$2.064 E-05$

8. $792 \mathrm{E}-05$

$3.579 E-01$

1. $149 \mathrm{E}-03$

6. $704 \mathrm{E}-\mathrm{O} 3$

1. $242 \mathrm{E}-01$

1. $242 \mathrm{E}-01$

2. $517 E+O O$

\section{GROUP 7 \\ 1.2 TO $1.4 \mathrm{MEV}$}

$\begin{array}{cc}\text { ALPHA } & \text { LAMBDA } \\ 2.669 E-12 & 7.529 E-10 \\ 2.367 E-10 & 2.395 E-08 \\ 1.115 E-10 & 7.533 E-08 \\ 6.495 E-10 & 3.016 E-07 \\ 3.249 E-09 & 1.357 E-06 \\ 2.175 E-08 & 6.902 E-O 6 \\ 3.068 E-07 & 1.939 E-05 \\ 1.730 E-06 & 6.761 E-05 \\ 1.637 E-O 5 & 3.314 E-04 \\ 6.594 E-05 & 1.306 E-03 \\ 3.989 E-04 & 7.054 E-03 \\ 1.705 E-03 & 2.785 E-02 \\ 4.889 E-O 3 & 1.274 E-01 \\ 8.676 E-03 & 5.205 E-01 \\ 1.958 E-03 & .2 .432 E+00\end{array}$

GROUP 4

6 TO 8 MEV

\begin{tabular}{|c|c|}
\hline ALPHA & LAMBDA \\
\hline $.048 E-12$ & $7.503 E-10$ \\
\hline $1.107 E-10$ & $2.418 E-08$ \\
\hline $5.223 E-10$ & $1.153 E-07$ \\
\hline $4.596 E-09$ & A. $194 \mathrm{E}-07$ \\
\hline $1.937 E-08$ & $1.434 E-06$ \\
\hline $1.516 E-07$ & $6.712 E-06$ \\
\hline $6.573 E-07$ & $1.992 \mathrm{E}-05$ \\
\hline $1.893 E-06$ & $7.350 E-05$ \\
\hline $1.820 E-05$ & 3. 39OE -O4 \\
\hline $5.661 E-05$ & $1.173 \mathrm{E}-\mathrm{O} 3$ \\
\hline $2.47 \mathrm{OE}-04$ & $6.756 \mathrm{E}-03$ \\
\hline $9.173 E-04$ & $2.743 \mathrm{E}-\mathrm{O} 2$ \\
\hline $2.044 E-03$ & 1.250E-01 \\
\hline 3. $448 E-03$ & $5.179 E-01$ \\
\hline $7.133 E-04$ & $2.498 E+00$ \\
\hline
\end{tabular}

GROUP 8

1.4 TO $1.6 \mathrm{MEV}$

\begin{tabular}{|c|c|}
\hline ALPHA & LAMBDA \\
\hline $2.42 \mathrm{OE}-12$ & $7.532 \mathrm{E}-10$ \\
\hline $2.603 E-10$ & $2.386 E-08$ \\
\hline $3.708 E-11$ & $5.222 E-08$ \\
\hline $3.376 E-10$ & $3.842 E-07$ \\
\hline $1.971 E-09$ & $1.474 E \cdot 06$ \\
\hline $1.412 E-08$ & $7.076 E-06$ \\
\hline $2.724 E-07$ & $1.977 E-05$ \\
\hline $1.458 E-06$ & $5.581 E-05$ \\
\hline $1.607 E-05$ & $3.463 E-04$ \\
\hline $6.881 E-05$ & $1.328 \mathrm{E}-03$ \\
\hline $4.097 E-04$ & 7. $061 E-03$ \\
\hline $1.966 \mathrm{E}-03$ & $2.859 E-02$ \\
\hline $7.996 \mathrm{E}-03$ & $1.262 \mathrm{E}-01$ \\
\hline $1.062 E-02$ & $5.173 E-01$ \\
\hline $2.454 E-03$ & $2.489 E+O O$ \\
\hline
\end{tabular}




\begin{tabular}{|c|c|}
\hline \multicolumn{2}{|c|}{ GROUP 9} \\
\hline TO & $8 \mathrm{MEV}$. \\
\hline ALPHA & LAMPDA \\
\hline $878 E-12$ & $7.538 E-10$ \\
\hline $671 E-10$ & $2.375 E-08$ \\
\hline $288 E-11$ & $4.842 E-08$ \\
\hline $818 E-10$ & $3.927 \mathrm{E}-07$ \\
\hline $189 E-09$ & $1.570 E-O G$ \\
\hline $701 E-09$ & $6.966 E-06$ \\
\hline $399 E-07$ & $2.083 E-05$ \\
\hline $133 E-06$ & $6.346 E-05$ \\
\hline $525 \mathrm{E}-05$ & $3.637 E-04$ \\
\hline $958 E-05$ & $1.354 \mathrm{E}-03$ \\
\hline $001 E-04$ & $7.029 E-03$ \\
\hline $839 E-03$ & $2.808 E-02$ \\
\hline $353 E-03$ & $1.237 E-01$ \\
\hline & $5.251 E-O 1$ \\
\hline & \\
\hline
\end{tabular}

GROUP 13 2. 4 TO 2.6 MEV

$\begin{array}{cc}\text { ALPHA } & \text { L.AMBDA } \\ 1.7 O 4 E-13 & 7.606 E-10 \\ 1.172 E-10 & 2.287 E-08 \\ 1.516 E-11 & 4.760 E-08 \\ 1.576 E-11 & 2.449 E-07 \\ 1.984 E-10 & 4.173 E-06 \\ 2.140 E-08 & 1.506 E-05 \\ 3.893 E-07 & 1.520 E-05 \\ 1.223 E-05 & 4.906 E-04 \\ 5.795 E-05 & 1.490 E-03 \\ 3.444 E-O 4 & 7.239 E-03 \\ 1.596 E-O 3 & 2.84 O E-02 \\ 6.936 E-03 & 1.293 E-01 \\ 1.398 E-02 & 5.479 E-01 \\ 4.109 E-03 & 2.305 E+00\end{array}$

GROUP 10 1.8 TO 2.0 MEV

ALPHA
1. $158 E-12$
$2.57 G E-10$
$3.195 E-11$
$8.927 E-11$
$5.160 E-10$
$2.911 E-09$
$2.030 E-07$
$8.045 E-07$
$1.407 E-05$
$6.87 O E-05$
$3.84 O E-04$
$1.791 E-03$
$6.802 E-03$
$1.283 E-O 2$
$3.263 E-03$

GROUP 14 2. 6 TO $3.0 \mathrm{MEV}$

AL.PHA
3. OOGE-13
$1.549 E-10$
$1.026 E-11$
$2.436 E-11$
$2.623 E-10$
$9.980 E-09$
$6.395 E-07$
$2.22 .4 E-O 5$
$9.687 E-O 5$
$6.210 E-04$
$2.961 E-03$
$1.287 E-D 2$
$2.703 E-02$
$8.516 E-03$

LAMBDA 7. $511 E-10$ 2. $222 \mathrm{E}-\mathrm{O} 8$ 4. $843 \mathrm{E}-08$ 2. $350 \mathrm{E}-07$ 4. $229 \mathrm{E}-\mathrm{OS}$ 1. $286 \mathrm{E}-05$ 1. $236 \mathrm{E}-05$ 4. $849 E-05$ 5. $373 E-04$ 1. $.509 \mathrm{E}-03$ 7. $401 \mathrm{E}-03$ 2. $866 \mathrm{E}-\mathrm{O} 2$ 1. $280 F-O$ $5.629 E-01$ 2. $286 \mathrm{E}+0 \mathrm{O}$
GROUP 11 2.0 TO 2.2 MEV

$\begin{array}{cc}\text { ALPHA } & \text { LAMBOA } \\ 4.89 O E-13 & 7.583 E-10 \\ 2.320 E-10 & 2.342 E-08 \\ 2.864 E-11 & 4.762 E-08 \\ 3.332 E-11 & 2.789 E-07 \\ 1.057 E-10 & 1.600 E-06 \\ 2.415 E-09 & 8.034 E-06 \\ 1.644 E-07 & 2.202 E-05 \\ 5.426 E-07 & 5.658 E-05 \\ 1.310 E-05 & 4.160 E-04 \\ 6.613 E-05 & 1.420 E-03 \\ 3.718 E-04 & 7.039 E-03 \\ 1.719 E-03 & 2.826 E-02 \\ 7.044 E-03 & 1.295 E-01 \\ 1.358 E-02 & 5.337 E-01 \\ 3.617 E-03 & 2.340 E+00\end{array}$

GROUP 12 2. 2 TO 2.4 MEV

$\begin{array}{cc}\text { ALPHA } & \text { LAMBDA } \\ 1.913 E-13 & 7.645 E-10 \\ 1.939 E-10 & 2.319 E-08 \\ 2.273 E-11 & 4.744 \mathrm{E}-08 \\ 2.019 \mathrm{E}-11 & 2.544 \mathrm{E}-07 \\ 2.158 \mathrm{E}-10 & 3.741 \mathrm{E}-06 \\ 4.088 \mathrm{E}-08 & 1.554 \mathrm{E}-05 \\ 4.47 \mathrm{OE}-07 & 4.328 \mathrm{E}-05 \\ 1.238 \mathrm{E}-05 & 4.471 \mathrm{E}-04 \\ 6.260 \mathrm{E}-05 & 1.449 \mathrm{E}-03 \\ 3.599 \mathrm{E}-04 & 7.119 \mathrm{E}-03 \\ 1.658 \mathrm{E}-03 & 2.831 \mathrm{E}-02 \\ 7.084 \mathrm{E}-03 & 1.296 \mathrm{E}-01 \\ 1.396 \mathrm{E}-\mathrm{O} 2 & 5.400 \mathrm{E}-\mathrm{O} 1 \\ 3.904 \mathrm{E}-03 & 2.322 \mathrm{E}+00\end{array}$

GROUP 17 GROUP 16

GROUP 15 3.0 TO $4.0 \mathrm{MEV}$

- ALPHA

4. $564 E-13$

4. $211 E-11$

$3.043 E-11$

5. $368 \mathrm{E}-11$

3. $422 E-09$

6. $663 \mathrm{E}-08$

8. $362 E-07$

2. $394 \mathrm{E}-05$

1. $182 E-04$

9.789E-OA

$5.043 E-03$

2. $487 \mathrm{E}-02$

$5.887 E-02$

1. $954 \mathrm{E}-02$

\section{LAMBOA}

7. $311 E-10$

2. $179 E-08$

2. $459 E-06$

9. $667 \mathrm{E}-06$

3. $152 E-05$

. $774 \mathrm{E}-05$

$5.373 E-04$

1. $426 \mathrm{E}-03$

7. $688 \mathrm{E}-03$

$2.938 \mathrm{E}-\mathrm{O} 2$

1. $281 E-O$ !

$5.880 E-01$

2. $14 O E+O O$
4.O TO $5.0 \mathrm{MEV}$

$\begin{array}{cc}\text { ALPHA } & \text { LAMBDA } \\ 1.453 E-13 & 6.892 E-10 \\ 6.188 E-12 & 2.079 E-07 \\ 6.925 E-12 & 1.675 E-06 \\ 3.310 E-10 & 8.784 E-O 6 \\ 3.80 O F-09 & 2.069 E-05 \\ 2.84 O E-07 & 7.170 E-05 \\ 4.849 E-O 6 & 6.655 E-04 \\ 1.357 E-05 & 1.977 E-03 \\ 3.566 E-O 4 & 8.369 E-03 \\ 1.821 E-03 & 3.245 E-02 \\ 1.725 E-O 2 & 1.325 E-01 \\ 3.912 E-O 2 & 5.935 E-O 1 \\ 1.244 E-O 2 & 2.019 E+O 0\end{array}$

5.0 TO 6.0 MEV

\begin{tabular}{|c|c|}
\hline ALPHA & LAMBDA \\
\hline $3.72 .1 E-14$ & $7.203 E-10$ \\
\hline 8. $359 E-13$ & $3.793 E-07$ \\
\hline 4. $442 E-10$ & $1.313 E-05$ \\
\hline 2. $150 E-O 8$ & $6.238 E-05$ \\
\hline $6.992 \mathrm{E}-07$ & $1.325 E-03$ \\
\hline $2.523 E-05$ & $5.022 \mathrm{E}-0.3$ \\
\hline $1.951 E-04$ & $1.572 E-02$ \\
\hline $4.585 E-03$ & 8. 239E-02 \\
\hline $9.162 \mathrm{E}-\mathrm{O} 3$ & $2.242 E-01$ \\
\hline $3.320 \mathrm{E}-\mathrm{O} 2$ & $8.158 E-01$ \\
\hline $1.686 E-02$ & $8.597 E-01$ \\
\hline $6.880 E-03$ & $3.363 E+O O$ \\
\hline 4. $319 E-03$ & $3.590 E+O O$ \\
\hline $1.544 E-08$ & $6.362 E-05$ \\
\hline 1. $568 E-12$ & $5.147 E-07$ \\
\hline 1. $452 E-10$ & $6.878 E-07$ \\
\hline
\end{tabular}


FITS TO 235 THERMAL PULSE GAMMAS FOR JNDC/ENDF DATA

$\begin{array}{cc}\text { GROUP } & 1 \\ 0.0 \text { TO } & 1 \\ & 1 \text { MEV } \\ \text { ALPHA } & \text { LAMMEDA } \\ 1.802 E-C 8 & 2.957 E-O 6 \\ 3.161 E-08 & 5.309 E-O 5 \\ 7.303 E-C 7 & 2.781 E-04 \\ 3.183 E-06 & 1.115 E-03 \\ 7.811 E-05 & 7.630 E-03 \\ 3.583 E-04 & 2.166 E-O 2 \\ 9.655 E-04 & 7.422 E-01 \\ -6.459 E-05 & 1.895 E-02\end{array}$

GPOUP 5 "

$$
6 \text {.TO . } 8 \text { NEV }
$$

ALPHA

. $213 E-06$

2. $595 E-O 6$

3. $237 E-05$

$2.451 E-04$

$8.542 E-04$
$6.623 E-03$

1. $210 E-02$

4. $563 \mathrm{E}-\mathrm{O} 2$

LAMBDA
$8.128 E-O 6$
$5.453 E-O 5$
$2.972 E-O 4$
$2.615 E-03$
$1.201 E-02$
$3.226 E-02$
$1.565 E-01$
$7.863 E-01$

GROUP
1 TO .2
MEV

\begin{tabular}{|c|c|}
\hline$-1 A$ & LAMBDA \\
\hline $773 E-08$ & $2.695 E-06$ \\
\hline $.520 E-08$ & 4. $570 E-O$ \\
\hline $48 B E-07$ & $1.086 E-04$ \\
\hline $.976 E-06$ & $3.539 E-0$ \\
\hline $46 B E-06$ & $1.059 \mathrm{E}-0$ \\
\hline $367 E-05$ & 3. 4 COE -O \\
\hline $.420 E-04$ & 1. $202 \mathrm{E}-\mathrm{O}$ \\
\hline $.773 E-04$ & 4. $151 E-O$ \\
\hline $143 E-03$ & $1.076 \mathrm{E}-\mathrm{O}$ \\
\hline-03 & 7 \\
\hline & \\
\hline
\end{tabular}

GROUP

$$
3 \text { TO } 1.0 \mathrm{MEV}
$$

$\triangle \mathrm{L} P H A$

$1.530 \equiv-07$

4. $039 \equiv-06$

$5.175 \equiv-05$

$2.846=-04$

1. $005 \mathrm{E}-03$

7. $297 \mathrm{E}-03$

2. $173 \mathrm{E}-02$

1. $249 \mathrm{E}-01$
6. $980 E-06$

6. $376 \mathrm{E}-05$

2. $020 E-04$

2. C32E-O3

1. $193 \mathrm{E}-\mathrm{O} 2$

$6.483 \mathrm{E}-\mathrm{O} 2$

2. $374 E-O$

2. $E 36 E+O O$
GROUP 7

$$
\text { 1.O TO } 1.2 \mathrm{MEV}
$$

ALPHA

6. $796 \mathrm{E}-\mathrm{O} 7$

$3.019 E-05$

.019E-05

. 205E-04

. $874 E-04$

2. $198 \mathrm{E}-\mathrm{O} 2$

$721 \mathrm{E}-\mathrm{O}$

6. $253 \mathrm{E}-05$

3. $136 \mathrm{E}-\mathrm{O} 4$

1. $400 \mathrm{E}-03$

8. $968 \mathrm{E}-03$

4. 195E-O2

4. $158 \mathrm{E}-01$

GROUP

4 TO . $6 \mathrm{MEV}$

ALPHA

6. $364 \mathrm{E}-07$

2. $157 E-06$

2. $829 E-05$

7. $086 E-05$

2. $174 \mathrm{E}-04$

1. $320 \mathrm{E}-03$

1. 493E-O2

1. $609 E-02$

2. $007 E-02$
$1.007 E-05$

$5.717 E-05$

3. $188 \mathrm{E}-04$

1. $262 \mathrm{E}-03$

$.285 \mathrm{E}-03$

$.891 \mathrm{E}-\mathrm{O} 2$

7. $798 \mathrm{E}-01$
GROUP 8 1.2 TO 1.4 MEV

ALPHA

2. $684 \mathrm{E}-\mathrm{O} 7$

9. $374 \mathrm{E}-05$

$7.879 E-04$

7.879E-04

2.584E-03

7. $474 \mathrm{E}-03$

3. $278 \mathrm{E}-02$

$-1.442 E-06$
LAMPDA

.221E-05

$8.34 O E-O 4$

7.274E-O3

2. $528 E-02$

1. $293 E-01$

$.082 E-0.1$

7. $474 \mathrm{E}-05$ 
TABLE A-IX (Cont)

GROUP 9 1.4 TO 1.6 MEV

$\begin{array}{cc}\text { ALPHA } & \text { LAMEDA } \\ 4.885 E-O 3 & 1.411 E-O 6 \\ 1.429 E-O 6 & 4.990 E-O 5 \\ 6.988 E-O 5 & 3.549 E-O 4 \\ 1.728 E-O 3 & 9.646 E-03 \\ 2.299 E-03 & 3.310 E-O 2 \\ 1.173 E-O 2 & 2.743 E-01 \\ 7.996 E-O 3 & 8.433 E-01 \\ -3.218 E-O 5 & 5.131 E-O 4\end{array}$

GROUP 13

2.2 TO 2.4 MEV

$\begin{array}{cc}\text { ALPHA } & \text { LAMBDA } \\ 9.670 E-O 9 & 1.092 \mathrm{E}-05 \\ 4.432 \mathrm{E}-\mathrm{O} & 7.704 \mathrm{E}-\mathrm{O5} \\ 1.732 \mathrm{E}-05 & 3.177 \mathrm{E}-\mathrm{O} \\ 3.242 \mathrm{E}-04 & 7.784 \mathrm{E}-03 \\ 4.202 \mathrm{E}-04 & 1.943 \mathrm{E}-02 \\ 3.043 \mathrm{E}-03 & 3.033 \mathrm{O}-01 \\ 1.266 \mathrm{O}-02 & 1.354 \mathrm{E}+\mathrm{O}\end{array}$

GROUP 10

1.6 TO $1.8 \mathrm{MEV}$

\begin{abstract}
ALPHA
4. $194 \mathrm{E}-07$

1. $4 \mathrm{i3E-06}$

8. $226 \mathrm{E}-06$

6. $118 \mathrm{E}-05$

$.452 E-04$

. $358 E-03$

$9.267 \varepsilon-03$

$-7.101 E-O 3$
$6.602 E-03$
\end{abstract}

LAMBOA
2.241 E-O5
$6.462 E-05$
$2.568 E-04$
$1.191 E-03$
$6.887 E-03$
$2.718 E-02$
$1.500 E-01$
$1.989 E-01$
$6.196 E-01$

GROUP 14

2. 4 TO $2.6 \mathrm{MEV}$

ALPHA
$6.686 E-09$
$5.325 E-07$
$4.875 E-06$
$3.440 E-05$
$6.950 E-04$
$5.274 E-04$
$1.326 E-03$
$3.036 E-03$
$4.816 E-06$

LAMBDA

5. $177 \mathrm{E}-\mathrm{OG}$

7. $208 \mathrm{E}-05$

1. $533 \mathrm{E}-04$

8. $739 \mathrm{E}-04$

1. $154 E-02$

5. $378 \mathrm{E}-02$

2. $747 \mathrm{E}-\mathrm{O}$

$8.776 E-0.1$

8.099E-O4
GROUP 11

1.8 TO 2.0 MEV

$\begin{array}{cc}\text { ALPHA } & \text { LAMBDA } \\ 4.679 E-O 8 & 1.363 E-05 \\ 2.392 E-06 & 7.729 E-05 \\ 5.239 E-06 & 2.207 E-04 \\ 3.319 E-05 & 1.183 E-03 \\ 4.325 E-04 & 9.737 E-03 \\ 7.474 E-04 & 2.581 E-02 \\ 1.144 E-02 & 2.848 E-01 \\ 2.438 E-02 & 1.642 E+00\end{array}$

GROUP 15

2.6 TO $3.0 \mathrm{ME}$

ALPHA

3. $620 \mathrm{OE}-10$

2. $678 \mathrm{E}-08$

2. $194 \mathrm{E}-06$

1. $155 \mathrm{E}-05$

?.041E-05

5. $249 E-O 4$

1. $004 \mathrm{E}-03$

$5.087 \mathrm{E}-03$

1.020E-O2

- $9.026 \mathrm{E}-03$

$-4.068 \mathrm{E}-10$

LAMBDA

3. 594E-06

$.874 \mathrm{E}-05$

1. $103 \mathrm{E}-04$

3. $534 \mathrm{E}-\mathrm{O} 4$

2. $302 \mathrm{E}-\mathrm{O} 3$

7. $185 \mathrm{E}-03$

2. $183 \mathrm{E}-\mathrm{O} 2$

$2.062 \mathrm{E}-01$

9. $497 \mathrm{E}-01$

$2.042 E+.00$

6. $012 E-06$
GROUP 12

2.O TO 2.2 MEV

$\begin{array}{cc}\text { ALPHA } & \text { LAMBDA } \\ 2.047 E-O 8 & 9.890 E-06 \\ 2.905 E-06 & 7.954 E-05 \\ 4.529 E-06 & 2.097 E-04 \\ 8.796 E-05 & 9.121 E-04 \\ 6.305 E-O 4 & 1.348 E-02 \\ 8.705 E-04 & 1.071 E-01 \\ 8.014 E-O 3 & 5.510 E-01 \\ -2.937 E-03 & 5.174 E-01 \\ -1.937 E-05 & 9.074 E-04\end{array}$

GROUP 16

3.0 TO $4.0 \mathrm{MEV}$

1 LAMBA

1. 259E-OG $1.018 E-0 A$

2. $378 \mathrm{E}-\mathrm{OG} \quad 1.756 \mathrm{E}-\mathrm{OA}$

2.088E-O5 7.94OE-O4

7.047E-05 2.313E-03

$6.371 \mathrm{E}-\mathrm{O} 4 \quad 7.685 \mathrm{E}-03$

1. $469 E-03 \quad 2.192 E-02$

$1.522 \mathrm{E}-02 \quad 1.781 \mathrm{E}-\mathrm{O} 1$

$1.079 E+00$

$-6.555 \mathrm{E}-01$ 1. $1.099 \mathrm{E}+\mathrm{OO}$ 
TABLE A-IX (Cont)

GROUP 17

4.J TO $5.0 \mathrm{MEV}$

ALPHA
$8.302 E-11$
$2.631 E-08$
$1.964 E-08$
$2.905 E-07$
$1.181 E-04$
$5.099 E-04$
$1.011 E-03$
$8.146 E-03$
$2.189 E-03$

LAMBDA

4. $608 \mathrm{E}-05$

4. $608 E-05$
7. $071 E-05$

1. $415 \mathrm{E}-01$

5. $660 \mathrm{OE}-04$

4. $151 \mathrm{E}-03$

1. $154 \mathrm{E}-02$

4. $578 \mathrm{E}-02$

4. $.03 \mathrm{E}-01$

4. $101 E-01$
GROUP 18

5.0 TO 6.0 MEV
ALPHA

2. $925 E-20$

1. $104 \mathrm{~F}-15$

2. O9OE - 14

2. $790 E-09$

1. $234 E-05$

$9.681 \mathrm{E}-05$

1. $395 \mathrm{E}-04$

2. $999 E-04$

$1.330 \mathrm{E}-03$

$-5.383 E-04$
LAMBDA

4. 187E-OG

1. $869 \mathrm{E}-04$

3. $566 \mathrm{E}-04$

. $905 \mathrm{E}-03$

4. $316 \mathrm{E}-03$

1. $032 \mathrm{E}-02$

1. $942 \mathrm{E}-\mathrm{O} 2$

6. 7 IOE-O2

2. $107 E-01$

3. 34 IE-O1 
FITS TO ${ }^{235}$ U THERMAL PULSE BETAS FOR JNDC/ENDF DATA

$\begin{array}{cc}\text { GROUP } & 1 \\ 0.0 \text { TO } & 2 \text { MEV } \\ \text { ALPHA } & \text { LAMBDA } \\ 1.589 E-07 & 6.629 E-O 6 \\ 8.468 E-07 & 7.392 E-05 \\ 3.235 E-06 & 3.259 E-04 \\ 1.246 E-05 & 9.343 E-04 \\ 3.231 E-05 & 5.024 E-03 \\ 1.671 E-04 & 2.456 E-02 \\ 4.007 E-O 4 & 1.058 E-01 \\ 8.547 E-O 4 & 5.505 E-01\end{array}$

GROUP 5

8 TO $1.0 \mathrm{MEV}$

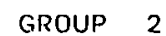

ALPHA

4. $157 \mathrm{E}-\mathrm{O} 7$

1. $414 E-06$

1. $071 \mathrm{E}-05$

$3.629 E-05$

1. $628 \mathrm{E}-\mathrm{OA}$

$7.315 \mathrm{E}-03$

$-7.676 \mathrm{E}-03$

$2: 373 E-0.3$

LAMBOA
$9.348 E-O 6$
$6.074 E-O 5$
$3.276 E-O 4$
$1.124 E-03$
$1.041 E-02$
$7.698 E-02$
$8.513 E-02$
$2.112 E-01$

GROUP 6

1.0 TO 1.2 MEV

NLPHA

3.718E-07

2. $402 \mathrm{E}-06$

1. $543 \mathrm{E}-05$

3. $715 \mathrm{E}-05$

1. $317 \mathrm{E}-04$

$5.845 E-04$

1. $345 \mathrm{E}-03$

$1.345 E-03$

$3.328 \mathrm{E}-03$

1. $144 \mathrm{E}-\mathrm{O} 2$
LAMBDA

1. $286 E-05$

$6.411 E-05$

3. $206 E-04$

8. $993 E-O 4$

3. $922 \mathrm{E}-\mathrm{O} 3$

3. $676 E-02$

8. $935 E-02$

$4.023 E-O 1$
GROUP 3

4 TO 6 MEV

\section{ALPHA}

5. $928 \mathrm{E}-\mathrm{O} 7$

2. $036 \mathrm{E}-06$

4. 295E-05

7. $907 E-05$

. $921 E-04$

. $259 \mathrm{E}-\mathrm{O}$

3. $249 \mathrm{E}-03$

\section{. LAMBDA}

1. $031 \mathrm{E}-05$

7. $409 \mathrm{E}-05$

3. $086 \mathrm{E}-04$

9. $281 \mathrm{E}-04$

4. $412 \mathrm{E}-\mathrm{O} 3$

1. $647 \mathrm{E}-02$

$6.906 \mathrm{E}-\mathrm{O} 2$

3. $594 \mathrm{E}-\mathrm{O}$

1. 059

1. $172 \mathrm{E}-02$

$5.750 E-01$

GROUP 7

1. 2 TO $1.4 \mathrm{MEV}$

$\begin{array}{cc}\text { ALPHA } & \text { LAMBOA } \\ 3.393 E-O 7 & 1.5 O 2 E-O 5 \\ 2.193 E-O G & 6.260 E-O 5 \\ 1.569 E-O 5 & 3.357 E-04 \\ 3.575 E-O 5 & 9.153 E-04 \\ 1.333 E-O 4 & 3.828 E-03 \\ 6.087 E-O 4 & 1.207 E-O 2 \\ 1.610 E-O 3 & 3.537 E-02 \\ 5.991 E-O 3 & 1.158 E-01 \\ 1.333 E-O 2 & 5.169 E-01\end{array}$

GROUP 4 6 TO .8 MEV

\begin{tabular}{|c|c|}
\hline ALPHA & LAMBDA \\
\hline $5.866 \mathrm{E}-07$ & 1. O6OE - O5 \\
\hline $2.244 E-06$ & $6.881 E-05$ \\
\hline 1. $245 \mathrm{E}-05$ & $3.084 E-01$ \\
\hline $4.310 E-05$ & $8.868 E-04$ \\
\hline $1.029 E-04$ & $4.007 E-03$ \\
\hline $6.157 E-04$ & 1. $595 E-02$ \\
\hline $2.272 \mathrm{E}-\mathrm{O} 3$ & $.7 .573 E-02$ \\
\hline $3.959 E-03$ & $3.337 E-01$ \\
\hline $2.837 E-03$ & 1. $04 O E+O O$ \\
\hline
\end{tabular}

GROUP 8

1. 4 TO $1.6 \mathrm{MEV}$

ALPHA

3. $321 E-07$

1. $958 \mathrm{E}-06$

1. $530 E-05$

3. $645 \mathrm{E}-05$

1. $312 \mathrm{E}-04$

$6.341 E-04$

$6.341 \mathrm{E}-04$

$1.810 \mathrm{E}-03$

$1.027 \mathrm{E}-02$

1. $605 \mathrm{E}-\mathrm{O} 2$
LAMBDA

1. 656E-O5

6. 224E-05

3. 54OE-O4

$.094 E-04$

3.822E-O3

1. 1 1GE -02

. $149 E-O 2$

4. $998 E-01$ 
TABLE A-X (Cont)

$\begin{array}{ll}\text { GROUP } & 9 \\ 1.6 \text { TO } & 1.8 \text { MEV } \\ & \\ \text { ALPHA } & \text { LAMBDA } \\ .012 E-O 7 & 1.806 E-05 \\ .638 E-O 6 & 5.955 E-05 \\ .428 E-O 5 & 3.634 E-O 4 \\ .426 E-05 & 9.579 E-O 4 \\ .219 E-04 & 3.349 E-03 \\ .359 E-04 & 1.279 E-02 \\ .821 E-03 & 3.377 E-02 \\ .080 E-03 & 1.248 E-01 \\ .755 E-02 & 5.178 E-01\end{array}$

GROUP 13 2.4 TO $2.6 \mathrm{MEV}$

\begin{tabular}{|c|c|}
\hline ALPHA & LAMEDA \\
\hline 6. $960 \mathrm{E}-09$ & $8.336 E-06$ \\
\hline $6.458 E-07$ & 4.037E-05 \\
\hline $5.359 E-08$ & $.5 .527 E-05$ \\
\hline $7.535 E-06$ & $4.036 E-04$ \\
\hline $3.565 E-05$ & $1.059 E-03$ \\
\hline $1.055 E-01$ & $3.823 \mathrm{E}-03$ \\
\hline $5.829 E-04$ & 1. $276 E-02$ \\
\hline $1.442 \mathrm{E}-03$ & $3.492 E-02$ \\
\hline $8.065 E-03$ & $1.170 E-01$ \\
\hline $4.887 E-02$ & 4. $447 E-01$ \\
\hline 3. $122 \mathrm{E}-\mathrm{O} 2$ & $2.676 E+O O$ \\
\hline
\end{tabular}

GROUP 17 5.0 TO 6.0 MEV

\begin{tabular}{|c|c|}
\hline ALPHA & LAMBDA \\
\hline $1.092 E-10$ & $1.054 E-05$ \\
\hline 7. $488 \mathrm{E}-09$ & $5.796 \mathrm{E} \cdot 05$ \\
\hline 6. $509 E-09$ & $9.119 E-05$ \\
\hline $4.949 E-07$ & $1.433 E-03$ \\
\hline 4. 596E-05 & $4.619 F-03$ \\
\hline $1.524 E-04$ & $1.358 E-02$ \\
\hline $1.555 E-03$ & $5.085 \mathrm{E}-02$ \\
\hline $1.726 \mathrm{E}-02$ & $1.426 E-01$ \\
\hline $2.788 E-02$ & $7.548 E-01$ \\
\hline 2. $4 G .5 E-02$ & $4.675 E+00$ \\
\hline
\end{tabular}

$2.4 C 5 E-02 \quad 4.675 E+00$
GROUP 10

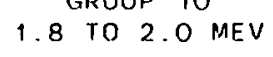

$\begin{array}{cc}\text { ALPHA } & \text { LAMBDA } \\ 2.507 E-O 7 & 1.933 E-05 \\ 1.2 \cdot 1 E-O 6 & 5.281 E-O 5 \\ 1.369 E-O 5 & 3.782 E-04 \\ 3.0-0 E-05 & 9.791 E-O 4 \\ 1.2 .9 E-04 . & 3.191 E-03 \\ 6.088 E-O 4 & 1.329 E-02 \\ 1.761 E-O 3 & 3.259 E-O 2 \\ 8.800 E-03 & 1.27 O E-O 1 \\ 1.936 E-O 2 & 5.221 E-O 1\end{array}$

GROUP 14 2. 6 TO 3.O MEV

\begin{tabular}{|c|c|}
\hline ALPHA & LAMEDA \\
\hline $2.400 E-O \exists$ & $7.152 \mathrm{E}-\mathrm{O}$ \\
\hline 1. $2.40 E-06$ & $4.721 \mathrm{E}$ \\
\hline 3. $424 \mathrm{E}-05$ & 5 \\
\hline $1.519 E-04$ & 206 \\
\hline $1.537 \mathrm{E}-03$ & 1. $330 E$ \\
\hline $.675 E-03$ & $6.528 E-C$ \\
\hline $2.210 E-02$ & $2.302 E-C$ \\
\hline 7. $4 \cong 5 E-02$ & 8. $430 E-$ \\
\hline $.155 E-02$ & \\
\hline $.110 E-02$ & $3.937 \mathrm{E}$ \\
\hline
\end{tabular}

GROUP 11 2.0 TO 2.2 MEV

$\begin{array}{cc}\text { ALPHA } & \text { LAMBOA } \\ 2.141 E-07 & 2.013 E-O 5 \\ 9.708 E-07 & 5.143 E-O 5 \\ 1.244 E-O 5 & 4.144 E-O 4 \\ 2.941 E-O 5 & 9.992 E-O A \\ 1.167 E-O 4 & 3.349 E-O 3 \\ 6.281 E-O 4 & 1.309 E-02 \\ 1.600 E-03 & 3.363 E-O 2 \\ 9.413 E-O 3 & 1.283 E-O 1 \\ 1.966 E-O 2 & 5.175 E-O 1\end{array}$

GROUP 15 3.0 TO 4 .O MEV

$\begin{array}{cc}\text { ALPHA } & \text { LAMBDA } \\ 1.025 E-09 & 6.835 E-06 \\ 1.403 E-06 & 5.504 E-05 \\ 5.675 E-07 & 1.058 E-04 \\ 1.481 E-05 & 4.782 E-04 \\ 8.425 E-05 & 1.086 E-03 \\ 3.267 E-04 & 4.157 E-03 \\ 1.790 E-03 & 1.298 E-02 \\ 4.826 E-03 & 3.708 E-02 \\ 3.323 E-02 & 1.200 E-01 \\ 7.25 O E-O 2 & 4.722 E-01 \\ 6.901 E-02 & 1.530 E+O O \\ 5.538 E-02 & 8.378 E+O O\end{array}$

GROUP 12 2. 2 TO 2.4 MEV

$\begin{array}{cc}\text { ALPHA } & \text { LAMBDA } \\ 1.455 E-07 & 2.008 E-05 \\ 8.004 E-07 & 5.01 E E-05 \\ 1.207 E-05 & 4.515 E-04 \\ 3.110 E-05 & 1.081 E-03 \\ 1.133 E-04 & 3.628 E-03 \\ 6.488 E-04 & 1.326 E-02 \\ 1.536 E-03 & 3.563 E-02 \\ 9.87 O E-03 & 1.295 E-01 \\ 2.234 E-02 & 5.873 E-01\end{array}$

GROUP 16

4. IO 5 O MEV

$\begin{array}{cc}\text { ALPHA } & \text { LAMBDA } \\ 2.986 E-10 & 7.322 E-06 \\ 5.341 E-07 & 6.456 E-05 \\ 1.165 E-07 & 9.254 E-05 \\ 2.717 E-06 & 5.900 E-04 \\ 4.975 E-06 & 1.186 E-03 \\ 1.498 E-04 & 4.534 E-03 \\ 6.276 E-O 4 & 1.271 E-02 \\ 2.549 E-03 & 4.519 E-02 \\ 2.529 E-02 & 1.301 E-01 \\ 4.986 E-O 2 & 5.006 E-01 \\ 4.849 E-02 & 1.834 E+O 0\end{array}$




\author{
GROUP 1 \\ O.O TO .1 MEV
}

\section{ALPHA}

1. $945 E-08$

4. $412 \mathrm{E}-08$

5. $925 \mathrm{E}-07$

3. 308E-06

1. $279 E-05$

4. $020 \mathrm{E}-04$

1. $791 E-04$

LAMPDA

3. $284 E-O 6$

5. $731 \mathrm{E}-05$

$.667 \mathrm{E}-04$

$.001 \mathrm{E}-03$

$238 \mathrm{E}-02$

2. $628 \mathrm{E}-02$

9. 534E-O 1

GROUP 5

$$
.6 \text { TO } 8 \text { MEV }
$$

ALPHA

9. $667 \mathrm{E}-08$

5. $472 \mathrm{E}-07$

1. $.486 \mathrm{E}-05$

4. $458 \mathrm{E}-05$

2. $787 \mathrm{E}-04$

3. $320 \mathrm{E}-\mathrm{O} 3$

6. $178 \mathrm{E}-03$

3. $229 \mathrm{E}-\mathrm{O} 2$

$-1.721 E-02$

1.721E-02

$-3.152 E-04$
LAMBDA

1. 547E-06

5. $881 \mathrm{E}-06$

2. 303E-O5

$.682 \mathrm{E}-04$

.787E-04

3. $52 \mathrm{OE}-03$

$.948 E-02$

5. 298E-01

.012E-01

3. $372 \mathrm{E}+\mathrm{OO}$

$2.047 E-02$

$$
\text { GROUP } 2
$$

1 TO . 2 MEV

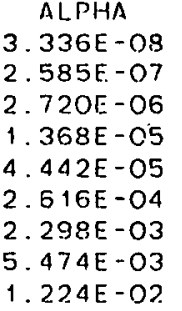

LAMEDA

3. $343 E-O 6$

7. $208 \mathrm{E}-05$

2. $575 E-04$
8. $146 E-04$

3. $251 \mathrm{E}-\mathrm{O} 3$

1. $286 E-02$

5. $928 \mathrm{E}-\mathrm{O} 2$

2. $609 \mathrm{E}-01$

9. $219 E-O 1$

GROUP 6

3 TO $1.0 \mathrm{MEV}$

ALPHA

1.722E-O7

2. $920 E-06$

5. 105E-O5

2. $008 E-04$

$.293 \mathrm{E}-04$

$2.075 E-03$

1. $038 \mathrm{E}-02$

7. $078 E-03$
$1.761 E-02$
LAMBDA

$6.812 \mathrm{E}-06$

G. $338 \mathrm{E}-05$

2. $194 \mathrm{E}-\mathrm{O} 4$

1. $762 E-03$

3. $302 \mathrm{E}-03$

3. $529 \mathrm{E}-02$

1. $176 E-O 1$

3. $471 E-01$

9. $036 \mathrm{E}-01$
GROUP 3
.2 TO . 4 MEV

ALPHA

4. O49E-O7

2. $605 \mathrm{E}-\mathrm{O} 7$

2. $436 E-05$
i. $310 E-O 4$

1. $532 \mathrm{E}-03$

$4.078 \mathrm{E}-03$

1. $548 \mathrm{E}-02$

6. $938 \mathrm{E}-05$

LAMBOA
$8.887 E-06$
$4.069 E-05$
$4.048 E-04$
$8.680 E-04$
$1.159 E-02$
$4.463 E-02$
$2.608 E-01$
$1.198 E+00$
$8.405 E-04$

GROUP 7

1.O TO $1.2 \mathrm{MEV}$

$\begin{array}{cc}\text { ALPHA } & \text { LAMEDA } \\ 4.369 E-07 & 1.516 E-05 \\ 2.265 E-O 6 & 6.077 E-05 \\ 2.854 E-05 & 3.288 E-04 \\ 1.165 E-04 & 1.601 E-03 \\ 4.929 E-04 & 1.273 E-02 \\ 1.394 E-03 & 4.070 E-02 \\ 2.431 E-03 & 1.084 E-O 1 \\ 1.626 E-02 & 5.220 E-01\end{array}$

GROUP 4

.4 TO .6 MEV

ALPHA

5.396E-07 9.120E-06

LAMBDA

1. $903 E-06 \quad 5.736 \mathrm{E}-05$

2.775E-05 3.350E-O

8.349E-05 1.225E-03

1. $.898 E-04 \quad 4.103 E-03$

8. $465 \mathrm{E}-\mathrm{O} 4$ 1. $436 \mathrm{E}-\mathrm{O}$.

2. $384 \mathrm{E}-\mathrm{O} 3 \quad 4.646 \mathrm{E}-\mathrm{O} 2$

1. $380 E-02$

2. $468 \mathrm{E}-02$ A. $114 \mathrm{E}-01$

GROUP 8

\begin{tabular}{|c|c|}
\hline ALPHA & L.AMBDA \\
\hline $1.793 E-09$ & $2.656 E-06$ \\
\hline $2.135 E-07$ & $1.029 E-05$ \\
\hline $3.738 \mathrm{E}-06$ & $5.678 E-05$ \\
\hline $1.511 E-05$ & $1.788 E-04$ \\
\hline $1.645 E-04$ & $1.071 \mathrm{E}-03$ \\
\hline 1. $540 E-03$ & 1. $252 E-02$ \\
\hline $3.993 E-03$ & $7.554 \mathrm{E}-\mathrm{O} 2$ \\
\hline $4.614 \mathrm{E}-01$ & $6.030 E-01$ \\
\hline $4.499 E-01$ & $6.175 \mathrm{E}-01$ \\
\hline $2.436 E-02$ & $2.262 E+O O$ \\
\hline$-7.736 E-05$ & $1.081 E-03$ \\
\hline $9.855 E-06$ & $1.471 \mathrm{E}-\mathrm{O} 4$ \\
\hline
\end{tabular}

1.2 TO 1.4 MEV 
TABLE A-XI (Cont)

GROUP 9 1.4 TO $1.6 \mathrm{MEV}$

ALPHA

4. $330 \mathrm{O}-08$

9. $460 E-O 7$

5. $063 \mathrm{E}-05$

1. $222 \mathrm{E}-03$

1. $075 E-03$

2. $892 \mathrm{E}-03$

7. $954 \mathrm{E}-03$

$-1.380 E-05$

\begin{abstract}
LAMEDA
187E-06

$.78 \mathrm{SE}-05$

1 OETE-O2

3. $509 \mathrm{E}-\mathrm{O} 2$

1. $866 \mathrm{E}-01$

E -01

5. 9OTE-O4
\end{abstract}

GROUP 13

2. 2 TO $2.4 \mathrm{MEV}$

ALPHA

8. 204E-O9

2. $055 E-06$

9. $232 \mathrm{E}-\mathrm{O} 6$

1. $920 E-O 5$

4. $452 \mathrm{E}-04$

$7.904 \mathrm{E}-04$

4. $135 E-03$

$-9.172 E-O G$
LAMBDA

. 297E-06

$7.854 E-05$

2. $439 \mathrm{E}-04$

$124 E-02$

1. $373 E-01$

8. $480 E-01$

$275 E-O 4$
GRDUP 10 1.5 TO $1.8 \mathrm{MEV}$

ALPHA
4. $212 E-0.7$
$1.110 E-0 \equiv$
$1.195 E-05$
$5.541 E-05$
1. $834 E-04$
$5.101 E-04$
$6.933 E-03$
$-4.018 E-0.3$
$3.482 E-03$

LAMBDA

2. 196E-O5

6. $292 \mathrm{E}-05$

3. $202 \mathrm{E}-04$

1. $179 \mathrm{E}-03$

7. $911 \mathrm{E}-03$

2. $207 E-02$

9. 196E-O2

1. $127 \mathrm{E}-\mathrm{O}$

5. $263 \mathrm{E}-\mathrm{O}$

GROUP 14

2.4 TO 2.6 MEV

$\begin{array}{cc}\text { ALPHA } & \text { LAMBDA } \\ 7.427 E-C 9 & 6.187 E-06 \\ 3.876 E-C 7 & 6.948 E-05 \\ 3.475 E-C 6 & 1.564 E-04 \\ 2.56 E E-C 5 & 8.616 E-04 \\ 4.154 E-C 4 & 1.185 E-02 \\ 6.329 E-C 5 & 3.227 E-02 \\ 3.434 E-C .1 & 1.518 E-01 \\ 2.102 E-C .3 & 7.196 E-01 \\ 4.931 E-C 16 & 8.273 E-04\end{array}$

GROUP 11 1.8 TO $2.0 \mathrm{MEV}$

- ALPHA 2.917E-O8 9. $867 E-07$

4. $864 \mathrm{E}-06$

4. $678 \mathrm{E}-05$

5. $893 E-04$

4. $039 \mathrm{E}-03$

$8.641 E-03$

$-1.691 E-05$

GROUP 15

2.6 TO $3.0 \mathrm{MEV}$

ALPHA
$8.679 E-11$
$1.199 E-09$
$1.479 E-06$
$7.860 E-06$
$3.619 E-05$
$1.236 E-02$
$-1.35 O E-02$
$2.079 E-03$
$3.274 E-03$
$3.994 E-03$
$-1.117 E-02$
$7.805 E-04$

LAMBDA

2. 587E-07

1. $972 E-05$

$1.092 E-04$

3. O3OE-O4

1. $483 \mathrm{E}-03$

I. $04+E-02$

1.09

$1.094 \mathrm{E}-02$

1. $602 \mathrm{E}-02$

2. $568 \mathrm{E}-01$

9. $743 \mathrm{E}-01$

3. $684 E+00$

1. $989 \mathrm{E}+\mathrm{OO}$
GROUP 12 2.0 TO 2.2 MEV

\begin{tabular}{|c|c|}
\hline ALPHA & LAMBDA \\
\hline $1.932 \mathrm{E}-08$ & $7.906 E-06$ \\
\hline 1. $214 \mathrm{E}-06$ & $7.513 E-05$ \\
\hline 4. $110 E-06$ & $1.823 E-04$ \\
\hline $7.056 E-05$ & $9.329 E-04$ \\
\hline 4. $141 \mathrm{E}-04$ & 1. $316 \mathrm{E}-\mathrm{O} 2$ \\
\hline $5.881 E-04$ & $1.495 E-01$ \\
\hline $2.077 E-03$ & $5.858 E-01$ \\
\hline $1.699 E-05$ & $1.027 \mathrm{E}-03$ \\
\hline
\end{tabular}

GROUP 16

3.0 TO $4.0 \mathrm{MEV}$

ALPHA

7. 29OE- 11

1. $422 E-06$

$1.667 E-06$

2. $194 \mathrm{E}-05$

6. $853 \mathrm{E}-05$

$7.706 E-04$

7.

$7.560 \mathrm{E}-03$

7. $403 E-03$

LAMBDA

6. $499 \mathrm{E}-06$

1. $138 E-04$

2. $149 E-04$

8. 356E-O4

3. $288 \mathrm{E}-\mathrm{O} 3$

1. $332 \mathrm{E}-\mathrm{O} 2$

. $710 E-O 2$

1. 869E-O 1

$455 E-O 1$ 
TABLE A-XI (Cont)

GROUP 17 4.O TO 5.0 MEV

$\begin{array}{cc}\text { ALPHA } & \text { LAMBDA } \\ 8.668 E-O 9 & 6.835 E-O 5 \\ 2.215 E-O 8 & 1.485 E-O 4 \\ 1.448 E-07 & 5.547 E-O 4 \\ 4.094 E-O 5 & 4.145 E-0.3 \\ 2.741 E-04 & 1.278 E-02 \\ 4.149 E-04 & 7.034 E-02 \\ 3.770 E-03 & 4.690 E-01\end{array}$

GROUP is 5.0 TO $6.0 \mathrm{MEV}$

$\begin{array}{cc}\text { ALFHA } & \text { LAMBDA } \\ 1.042 E-19 & 4.165 E-O 6 \\ 3.149 E-15 & 2.024 E-04 \\ 1.625 E-12 & 6.875 E-04 \\ 2.392 E-07 & 2.967 E-03 \\ 7.731 E-06 & 5.322 E-03 \\ 7.698 E-05 & 1.366 E-02 \\ 1.264 E-04 & 6.170 E-02 \\ 4.953 E-04 & 2.121 E-01 \\ 2.154 E-04 & 1.288 E+O O\end{array}$


TABLE A-XII

FITS TO ${ }^{239}$ PU THERMAL PULSE BETAS

FOR JNDC/ENDF DATA

\begin{tabular}{|c|c|c|}
\hline \multicolumn{3}{|c|}{ GROUP 1} \\
\hline $0.0 \mathrm{TO}$ & 2 & MiE'J \\
\hline ALPHA & & LAMBDA \\
\hline $1.622 \mathrm{E}-07$ & & $5.814 \mathrm{E}-$ \\
\hline $5.964 E-07$ & & $5.545 E-$ \\
\hline $3.891 E-O E$ & & 3. 33OE - \\
\hline 1. $179 \mathrm{E}-05$ & & $9.733 \mathrm{E}-$ \\
\hline $3.497 E-05$ & & $5.011 E-$ \\
\hline $1.506 E-0 \angle$ & & $2.676 \mathrm{E}-$ \\
\hline 4. $111 E-04$ & & $1.511 \mathrm{E}-$ \\
\hline $6.213 E-04$ & & $9.855 E-$ \\
\hline
\end{tabular}

GROUP 5

8. TO $1.0 \mathrm{MEV}$

ALPHA
$1.023 E-07$
$8.471 E-O 7$
$2.084 E-O 6$
$1.439 E-05$
$4.237 E-05$
$8.996 E-05$
$4.832 E-O 4$
$1.143 E-03$
$4.123 E-03$
$2.861 E-02$
$-2.72 O E-02$

LAMBDA

4.387E-O6

2. $678 \mathrm{E}-05$

1. O3OE-O4

3. $277 \mathrm{E}-04$

9. $322 \dot{E}-04$

3. $353 \mathrm{E}-03$

1. $31 \mathrm{OE}-\mathrm{O} 2$

3. $561 \mathrm{E}-02$

1. $710 E-01$

1. $377 E+O O$
2. $\supset 12 E+O O$

\begin{tabular}{|c|c|}
\hline \multicolumn{2}{|c|}{ GROUP 2} \\
\hline $.2 \mathrm{TO}$ & $4 \mathrm{MEV}$ \\
\hline ALPHA & LAMBDA \\
\hline $.333 \equiv-07$ & $3.547 \mathrm{E}-\mathrm{OQ}$ \\
\hline $.283 E-07$ & 2. $259 \mathrm{E}-05$ \\
\hline $1.564 \mathrm{E}-06$ & 1. $191 \mathrm{E}-04$ \\
\hline $9.773 \mathrm{E}-06$ & $3.768 \mathrm{E}-04$ \\
\hline $2.914 E-05$ & $9.231 E-04$ \\
\hline $4.985 \mathrm{E}-05$ & $4.56 \ni E-03$ \\
\hline $.745 E-04$ & 2. $066 \mathrm{E}-\mathrm{O}$ \\
\hline $414 E-O 4$ & $8.850 E-02$ \\
\hline $7.682 \mathrm{E}-04$ & 3. $301 E-0$ \\
\hline $634 \mathrm{E}-\mathrm{OA}$ & $9.438 E-0$ \\
\hline
\end{tabular}

IROUP 6

1.O TO $1.2 \mathrm{MEV}$

ALPHA

6. $022 \mathrm{E}-0 \mathrm{O}$

7:028E-07

2. $092 \mathrm{E}-06$

1. $351 E-05$

$4.056 E-05$

9. $262 E-05$

5. $245 \mathrm{E}-04$

1. $297 E-03$

$4.059 \mathrm{E}-03$

$3.611 E-02$

$-2.993 \mathrm{E}-\mathrm{O} 2$
LAMBDA
4. $792 E-C 6$
2. 847 E-O5
1. $01.4 E-O 4$
3. $303 E-04$
3. $25 \bar{E} \mathrm{E}-03$
1. $216 \mathrm{E}-\mathrm{O} 2$
3. $396 \mathrm{E}-02$
1. $305 \mathrm{E}-01$
8. $844 \mathrm{E}-\mathrm{O} 1$

\begin{tabular}{|c|c|}
\hline \multicolumn{2}{|c|}{ GROUP 3} \\
\hline $.4 \mathrm{TO}$ & $6 \mathrm{MEV}$ \\
\hline ALPHA & LAMBDA \\
\hline $1.507 E-07$ & $3.939 \mathrm{E}-06$ \\
\hline $9.619 E-07$ & $2.345 E-05$ \\
\hline $1.892 \mathrm{E}-06$ & 1. $173 \mathrm{E}-\mathrm{OA}$ \\
\hline 1. $246 E-05$ & $3.522 \mathrm{E}-\mathrm{O} 4$ \\
\hline $3.90 \Omega E-05$ & $9.184 \mathrm{E}-04$ \\
\hline $6.056 \mathrm{E}-05$ & $3.497 \mathrm{E}-03$ \\
\hline $4.806 \mathrm{E}-04$ & $1.714 \mathrm{E}-02$ \\
\hline 1. $370 E-03$ & $9.828 E-02$ \\
\hline $3.714 E-03$ & $6.227 E-O 1$ \\
\hline $1.457 \mathrm{E}-03$ & 7. $384 \mathrm{E}-01$ \\
\hline
\end{tabular}

$-1.457 \mathrm{E}-03$
GROUP 7 1.2 TO 1.4 MEV

\section{GROUP 4 .6 TO $.8 \mathrm{MEV}$}

\begin{tabular}{|c|c|}
\hline ALPHA & LAMBDA \\
\hline $1.503 E-07$ & 4. $390 E-C$ \\
\hline $9.232 E-07$ & $2.447 \mathrm{~B}$ \\
\hline $2.151 E-06$ & 1. $045 E-C$ \\
\hline $1.342 E-05$ & $3.387 \mathrm{E}-\mathrm{C}$ \\
\hline $.325 E-05$ & $9.055 E-C$ \\
\hline $7.431 \mathrm{E}-05$ & $3.427 \mathrm{E}-\mathrm{C}$ \\
\hline 3. $995 E-04$ & 1. $328 \mathrm{E}-\mathrm{C}$ \\
\hline 3. $333 E-04$ & $3.984 E-C$ \\
\hline $2.020 E-03$ & $1.472 E-C$ \\
\hline $6.131 E-03$ & $6.667 \mathrm{E}$ \\
\hline
\end{tabular}

\begin{tabular}{|c|c|}
\hline ALPHA & LAMBDA \\
\hline $.025 E-08$ & $4.520 E-O$ \\
\hline $5.280 E-07$ & $2.860 E-C$ \\
\hline $1.876 \mathrm{E}-06$ & $1.026 \mathrm{E}-\mathrm{O}$ \\
\hline 1. $33 \mathrm{OE}-05$ & $3.362 \mathrm{E}-0$ \\
\hline 4. 195E-05 & $1.002 E-0$ \\
\hline $1.051 E-04$ & 3. $386 \mathrm{E}-\mathrm{C}$ \\
\hline $5.294 \mathrm{E}-04$ & $1.212 \mathrm{E}-\mathrm{C}$ \\
\hline $1.243 E-03$ & $3.063 E-0$ \\
\hline $5.255 E-03$ & $1.208 E-C$ \\
\hline $.015 E+00$ & $1.351 E+C$ \\
\hline $8 E+00$ & $373 E+C$ \\
\hline
\end{tabular}

GROUP 8 1.4 TO $1.6 \mathrm{MEV}$

\section{$\wedge$ LPHA}

$2.614 \mathrm{E}-08$

6. $264 \mathrm{E}-07$

1. $311 \mathrm{E}-\mathrm{O6}$

1. $323 \mathrm{E}-05$

4. $210 E-05$

1. $054 \mathrm{E}-04$

5. $802 E-04$

1. $714 \mathrm{E}-03$

7. 4 19E-O3

6. $991 \mathrm{E}-\mathrm{O} 2$

$-7.172 \mathrm{E}-\mathrm{O} 2$
LAMBDA

3. $112 E-05$

9. $339 E-05$

1. $013 E-03$

. $250 \mathrm{E}-\mathrm{O}$

1. $234 \mathrm{E}-\mathrm{O} 2$

3. $372 \mathrm{E}-\mathrm{O} 2$

1. $195 \mathrm{E}-01$

7. 159E-01

8. $842 E-01$

1. $812 \mathrm{E}+\mathrm{OO}$ 
GROUP 9 1.6 TO $1.8 \mathrm{MEV}$
LAMBD

$5.369 E-06$

3. $230 E-05$

9. $338 \mathrm{~F}-05$

$3.584 \mathrm{E}-04$

1.024E-03

3. $237 E-03$

1. $214 \mathrm{E}-02$

3. $340 E-02$

1. $262 E-01$

6. $814 \mathrm{E}-\mathrm{O} 1$

$8:-393 E-01$

1. $831 E+O O$

GROUP 13

2.4 TO $2.6 \mathrm{MEV}$

\begin{tabular}{|c|c|}
\hline ALPHA & LAMBDA \\
\hline $787 E-09$ & 6. $055 E-06$ \\
\hline $2.849 E-07$ & $3.763 E-05$ \\
\hline $7.954 E-08$ & $6.015 E-05$ \\
\hline $7.431 E-O G$ & $4.329 E-04$ \\
\hline $3.630 E-05$ & $1.038 E-03$ \\
\hline $8.757 E-.05$ & $3.358 E-03$ \\
\hline $5.033 E-04$ & 1. $237 E-02$ \\
\hline $1.361 E-03$ & 3. $382 E-O 2$ \\
\hline $6.384 \mathrm{E}-03$ & 1. $238 E-01$ \\
\hline $6.943 E-02$ & $7.287 E-01$ \\
\hline $5.699 E-02$ & $8.866 E-01$ \\
\hline
\end{tabular}

1. $868 \mathrm{E}-\mathrm{O} 2$

GRDUP 10 1.8 TO 2.0 MEV

ALPHA

1. O33E-O8

4. $927 \mathrm{E}-07$

1. 1O6E-05

4. $074 \mathrm{E}-05$

1. OGOE-O4

$5.475 E-04$

1. $488 \mathrm{E}-03$

6. $271 \mathrm{E}-03$

$3.578 \mathrm{E}-02$

$2.715 \mathrm{E}-02$

1. $056 \mathrm{E}-\mathrm{O} 2$
GROUP 11

2.0 TO 2.2 MEV

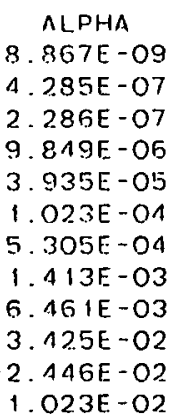

LAMBDA

LAMEDA

$5.525 \mathrm{E}-06$

3. $343 \mathrm{E}-05$

$.51 .3 \mathrm{E}-05$

1.

3. $245 \mathrm{E}-03$

1. $220 E-02$

3. $357 \mathrm{E}-\mathrm{O} 2$

1. $259 \mathrm{E}-\mathrm{O} 1$

$.238 E-01$
$.331 E-01$

1. $847 E+00$

GROUP 14

2.6 TO $3.0 \mathrm{MEV}$

AL.PHA

2.673E-09.5.091E-06

5. $246 \mathrm{E}-07 \quad 4.442 \mathrm{E}-05$

2.731E-O8 4.436E-O5

1. O8AE-O5 4. $440 E-04$

6. 393E-O5. 1.078E-O3

1. $452 \mathrm{E}-\mathrm{O} \quad 3.383 \mathrm{E}-\mathrm{O} 3$

9.003E-O4 $1.228 E-02^{\prime}$

2. $513 \mathrm{E}-\mathrm{O} 3 \quad 3.362 \mathrm{E}-\mathrm{O} 2$

1. $194 \mathrm{E}-02 \quad 1.219 \mathrm{E}-01$

$3.418 \mathrm{E}-01 \quad 8.733 \mathrm{E}-01$

$3.714 E-01 \quad 9.939 E-01$
6. $48.7 \mathrm{E}-06$

3. $412 \mathrm{E}-05$

$7.036 E-05$

3. $953 E-04$

$1.061 E-03$

3. $278 E-03$

1. 219E-O?

3. $376 \mathrm{E}-\mathrm{O} 2$

1. $257 \mathrm{E}-\mathrm{O}^{1}$

6. 109E-01

7. $903 E-01$

1. $842 E+O O$

GROUP 15

3.0 TO $4.0 \mathrm{MEV}$

ALPHA
$2.45 O E-09$
$4.212 \mathrm{E}-07$
$5.021 \mathrm{E}-07$
$1.824 \mathrm{E}-05$
$8.103 \mathrm{E}-05$
$1.915 \mathrm{E}-04$
$1.457 \mathrm{E}-03$
$4.271 \mathrm{E}-03$
$2.343 \mathrm{E}-02$
$2.564 \mathrm{E}-01$
$2.372 \mathrm{E}-01$
$6.642 \mathrm{E}-02$

LAMBDA

6. $380 E-O G$

4. $835 \mathrm{E}-05$

3. $434 \mathrm{E}-0.5$

5. $309 E-01$

1. $138 \mathrm{E}-\mathrm{O} 3$

3. $639 \mathrm{E}-03$

1. $224 \mathrm{E}-02$

$3.419 E-02$

1. $227 E-O$

7. $451 E-01$

$9.092 \mathrm{E}-\mathrm{O}$

1. $888 E+O O$
GROUP 12

2.2 TO 2.4 MEV

GROUP 17

5.0 TO $6.0 \mathrm{MEV}$

$\begin{array}{cc}\text { ALPHA } & \text { LAMBDA } \\ 2.618 E-10 & 1.091 \mathrm{E}-05 \\ 1.769 E-09 & 3.753 E-05 \\ 5.220 E-09 & 8.550 E-05 \\ 8.780 E-07 & 1.475 E-03 \\ 1.860 E-05 & 4.831 E-03 \\ 1.012 E-04 & 1.224 E-02 \\ 6.765 E-04 & 1.250 E-02 \\ 8.308 E-03 & 1.232 E-01 \\ 1.007 E-02 & 4.134 E-01 \\ 1.346 E-02 & 1.041 E+00\end{array}$


TABLE A-XIII

FITS TO

\section{$235^{U}$ THERMAL PULSE GAMMAS}

FOR UK DATA

\begin{tabular}{|c|c|}
\hline GI & 1 \\
\hline 0.0 & 1 MEV \\
\hline ALPHA & LAMBDA \\
\hline $5.532 E-14$ & 4. 393E-09 \\
\hline 1. $605 E-13$ & $1.499 E-08$ \\
\hline 2. $140 E-12$ & $\Xi .258 E-08$ \\
\hline $5.700 E-10$ & $\epsilon .738 E-07$ \\
\hline $4.672 E-09$ & $1.596 E-06$ \\
\hline $4.482 E-10$ & $6.209 E-06$ \\
\hline $2.872 E-07$ & $2.248 E-04$ \\
\hline 1. $100 E-06$ & $? .456 \mathrm{E}-04$ \\
\hline 2.403E-O6 & $2.493 E-03$ \\
\hline 1. $644 \mathrm{E}-05$ & $\because 822 \mathrm{E}-03$ \\
\hline $6.580 E-05$ & $2.633 \mathrm{E} \cdot 02$ \\
\hline $2.690 E-04$ & $8.388 E-0 ?$ \\
\hline $1.595 E-04$ & $1.001 E-01$ \\
\hline $1.016 E-05$ & $3.450 E-01$ \\
\hline $2.236 E-O 5$ & $1.864 E+00$ \\
\hline$-4.941 E-06$ & 3. $902 E+O O$ \\
\hline $.222 E-10$ & 1. $136 \mathrm{E}-05$ \\
\hline
\end{tabular}

GROUP 5

6 TO $8 \mathrm{MEV}$
GROUP 2

1 TO :2 MEV

ALPHA

3. $833 \mathrm{E}-14$

4. $305 E-12$

2. $273 E-11$

$.211 E-09$
$.943 E-08$

1. $943 E-08$

1. $.845 E-08$

5. $323 E-06$

1. $663 \mathrm{E}-05$

1. $322 \mathrm{E}-04$

9. $419 E-04$

2. $716 \mathrm{E}-03$

$-2.597 \mathrm{E}-04$

$-1.556 E-04$

$-6.143 E-09$
LAMBDA
$4.567 E-O 9$
$1.959 E-O 8$
$3.391 E-O 8$
$2.668 E-07$
$2.557 E-06$
$6.309 E-06$
$1.127 E-O 4$
$4.057 E-O A$
$1.607 E-O 3$
$1.503 E-O 2$
$6.863 E-O 2$
$6.912 E-O 1$
$2.145 E+O O$
$4.916 E-O 2$
$5.485 E-04$
$6.128 E-O 6$
GROUP 6

8 TO 1.0 MEV

ALPHA

1. 39 IE- 17

3. $1 \mathrm{H} 2 \mathrm{E}-13$

$1.097 E-13$

1. $556 E-O B$

$3.475 \mathrm{E}-03$

4. $214 E-07$

3. $323 E-06$

4. $703 E-05$

2.7 $33 E-04$

4. $036 E-03$

$2.851 E-02$

$-1.519 E-02$

1. $257 \mathrm{E}-02$

$-1.479 E-04$
- AMBDA

A. $554 \mathrm{E}-10$

2. $132 E-O B$

3. $303 E-08$

$6.287 \mathrm{E}-07$

$2.694 \mathrm{E}-06$

2. $379 E-05$

7. $360 \mathrm{OE}-05$

2. $051 E-04$

2. $091 E-03$

1. $562 \mathrm{E}-\mathrm{O} 2$

9. $226 \mathrm{E}-\mathrm{O} 2$

9. $233 \mathrm{E}-01$

9. $772 E-01$

4. $964 E+00$

7. $190 E+O 0$

g. $024 \mathrm{E}-\mathrm{O} 3$
GROUP 3

2 TO $4 \mathrm{MEV}$

ALPHA

1. $631 \mathrm{E}-14$

5. $665 E-15$

3. $709 \mathrm{E}-14$

5. $448 \mathrm{E}-09$

1. $283 E-08$

4. $147 \mathrm{E}-08$

2. $675 \mathrm{E}-07$

1. $291 \mathrm{E}-07$

1. $467 \mathrm{E}-05$

4. $669 \mathrm{E}-05$

3. $084 \mathrm{E}-04$

9.2AOE-CA

$3.093 E-03$

1. $121 \mathrm{E}-02$

$-6.084 \mathrm{E}-03$

$3.001 \mathrm{E}-03$

$-1.792 \mathrm{E}-03$
7. $882 \mathrm{E}-12$

GROUP

4 TO 6 MEV

$\because$ ALPHA

3. 21 IE- 14

2. $232 \mathrm{E}-12$

9. $274 \mathrm{E}-12$

3. $338 E-09$

3. $537 \mathrm{E}-08$

7. $147 \mathrm{E}-07$

1. $233 \mathrm{E}-06$

2. $881 \mathrm{E}-05$

1. $013 E-04$

2. $466 \mathrm{E}-04$

1. $076 \mathrm{E}-03$

9. 557E-O3

5. $298 \mathrm{E}+00$

$-5.671 E+O O$

4. $777 \mathrm{E}-01$

$-9.812 E-02$

$-6.864 \mathrm{E}-09$

$6.953 E+0 O$

GROUP 7
1. 0 TO $1.2 \mathrm{MEV}$

ALPHA

9. $511 E-18$

1. $814 \mathrm{E}-12$

3. $413 E-1 A$

$7.578 \varepsilon-12$

1. $328 E-10$

9. $608 \mathrm{E}-09$

1. $213 E-O 7$

1. $392 E-06$

1. $553 \mathrm{E}-05$

1. 07 IE-O4

2. $430 \mathrm{OE}-03$

5. 558E-02

$-4.790 E-02$

$6.521 \mathrm{E}-03$

$-1.642 E-03$

-4. $519 E-04$

$-1.395 E-05$
LAMBDA

7. 138F-10

$172 \mathrm{E}-08$

3. $156 \mathrm{E}-\mathrm{OS}$

3. $216 \mathrm{E}-07$

B.
$593 E-06$

1. $183 \mathrm{E}-05$

2. $892 \mathrm{E}-05$

2. $054 E-04$

8. 836E-04

. $811 \mathrm{E}-\mathrm{O} 2$

6. $466 \mathrm{E}-\mathrm{O} 1$

7. 70.3E-01

$1.621 E+00$

4. $475 E+O O$

8. $911 \mathrm{E}-03$

$5.668 \mathrm{E}-04$
LAMBDA

2. $864 \mathrm{E}-\mathrm{OS}$

1. $21 \mathrm{GE}-08$

2. $790 E-08$

2. 14OE -07

8. O9OE-O7

1. $335 \mathrm{E}-\mathrm{O} 5$

$6.011 E-05$

3. $0565-04$

1. $502 \mathrm{E}-03$

6. $564 \mathrm{E}-03$

2. $866 \mathrm{E}-\mathrm{O} 2$

1. 151E-O 1

1. $240 E+00$

2. $227 \mathrm{E}+\mathrm{OO}$

2. $227 E+O O$

5. $814 \mathrm{E}-\mathrm{O} 7$ 
TABLE A-XIII (Cont)

GROUP 9 1.4 TO $1.6 \mathrm{MEV}$

ALPHA

2. 2OEE- 18

4. $906 E-12$

1. $529 \mathrm{E}-07$

. $122 E-06$

1. $241 \mathrm{E}-04$

2. $054 \mathrm{E}-03$

1. $838 E-03$

4. $751 \mathrm{E}-03$

$-1.139 E-03$

$-1.317 E-04$

1. 303E-04

$-1.921 E-07$

1. $145 E-07$

$-1.355 \mathrm{E}-\mathrm{O} 7$

2. $695 E-O 7$

$757 E$
LAMBDA

5. $396 \mathrm{E}-10$

2. $629 \mathrm{E}-08$

$7.071 \mathrm{E}-07$

1. $445 \mathrm{E}-\mathrm{OA}$

5. $352 \mathrm{E}-\mathrm{OA}$

1. $436 E-O 2$

9. $255 E-02$

2. $565 \mathrm{E}+\mathrm{OO}$

8. $181 \mathrm{E}-\mathrm{O} 4$

1. $229 \mathrm{E}-06$

$6.095 \mathrm{E}-\mathrm{OF}$

1. $491 \mathrm{E}-05$

GROUP 13

2. 2 TO 2.4 MEV

$\begin{array}{cc}\text { ALPHA } & \text { LAMBDA } \\ 8.778 E-14 & 2.179 E-08 \\ 3.097 E-13 & 2.483 E-08 \\ 8.927 E-10 & 6.255 E-07 \\ 2.737 E-11 & 9.813 E-07 \\ 7.409 E-10 & 2.578 E-06 \\ 1.598 E-06 & 6.100 E-05 \\ 4.059 E-06 & 1.175 E-04 \\ 1.868 E-05 & 3.958 E-04 \\ 4.157 E-04 & 9.608 E-03 \\ 3.893 E-04 & 2.698 E-02 \\ 6.374 E-04 & 1.402 E-01 \\ 2.548 E-03 & 7.842 E-01 \\ 1.588 E-02 & 2.532 E+00 \\ -7.185 E-03 & 3.907 E+00 \\ -2.582 E-06 & 2.054 E-04\end{array}$

GROUP 10 1.6 TO $1.8 \mathrm{MEV}$

ALPHIA
$1.256 E-11$
$9.024 E-14$
$4.696 E-15$
$4.124 E-14$
$1.595 E-12$
$1.326 E-09$
$1.811 E-08$
$7.147 E-O 7$
$9.331 E-07$
$4.320 E-06$
$3.24 O E-O 4$
$2.656 E-O 3$
$1.046 E-03$
$9.490 E-04$
$-4.423 E-04$
$-2.767 E-04$
$1.847 E-04$
$5.509 E-04$

LAMBDA
$7.543 E-10$
$2.158 E-08$
$3.089 E-08$
$2.123 E-07$
$8.242 E-07$
$2.487 E-06$
$1.111 E-05$
$2.921 E-05$
$1.079 E-04$
$2.012 E-04$
$1.327 E-03$
$5.943 E-02$
$2.713 E-01$
$9.917 E-01$
$1.385 E+00$
$1.425 E-03$
$5.993 E-03$
$2.279 E-02$

GROUP 14 2.4 TO 2.6 MFV

$\begin{array}{cc}\text { ALPHA } & \text { LAMBOA } \\ 4.45 G E-14 & 2.179 E-O 8 \\ 2.433 E-19 & 1.590 E-08 \\ 1.917 E-18 & 3.291 E-08 \\ 4.062 E-09 & 6.273 E-07 \\ 3.740 E-10 & 3.036 E-06 \\ 6.101 E-06 & 1.000 E-04 \\ 2.665 E-05 & 1.226 E-03 \\ 3.425 E-04 & 8.762 E-03 \\ 5.417 E-04 & 2.455 E-02 \\ 5.549 E-04 & 1.181 E-01 \\ 5.973 E-03 & 1.062 E+00 \\ -5.223 E-03 & 1.252 E+00 \\ 9.848 E-O 4 & 4.937 E+00 \\ -5.834 E-04 & 7.152 E+0 O \\ -3.835 E-06 & 9.972 E-05 \\ 5.187 E-06 & 2.906 E-04 \\ -3.605 E-09 & 4.383 E-05\end{array}$

GROUP 11 1.8 TO 2.0 MEV

\begin{tabular}{|c|c|}
\hline ALPHA & LAMBDA \\
\hline $5.177 E-14$ & 2. $137 \mathrm{E}-08$ \\
\hline $1.291 E-14$ & $2.447 \mathrm{E}-08$ \\
\hline 2. $356 E-11$ & $5.642 \mathrm{E}-07$ \\
\hline $1.132 E-09$ & 2. $141 \mathrm{E}-0 \mathrm{G}$ \\
\hline $1.732 E-09$ & $3.347 E-O 6$ \\
\hline $3.658 E-08$ & $1.658 E-05$ \\
\hline S. $943 E-07$ & 5. 292E-05 \\
\hline $3.093 E-06$ & $1.178 E-04$ \\
\hline $2.569 E-06$ & $2.672 \mathrm{E}-04$ \\
\hline $2.225 E-05$ & $1.080 E-03$ \\
\hline $3.913 E-05$ & $4.055 \mathrm{E}-03$ \\
\hline $5.416 E-04$ & 1. $308 E-02$ \\
\hline $2.365 E-O 4$ & $3.432 \mathrm{E}-02$ \\
\hline $3.772 E-03$ & $1.927 E-01$ \\
\hline $9.819 \mathrm{E}-03$ & $6.341 E-01$ \\
\hline 1. $352 E+00$ & $9.332 \mathrm{E}+00$ \\
\hline 1. $313 E+00$ & $9.760 E+O O$ \\
\hline
\end{tabular}

GROUP 15 2.6 TO $3.0 \mathrm{MEV}$

ALPHA
$2.861 E-14$
$5.394 E-15$
$8.749 E-11$
$3.824 E-07$
$2.893 E-O 6$
$1.531 E-05$
$3.960 E-04$
$5.358 E-02$
$-1.001 E-01$
$5.345 E-02$
$-6.184 E-03$
$5.859 E-03$
$-2.609 E-03$
$1.554 E-03$
LAMBDA 2. 2O2E-OB 3. $612 \mathrm{E}-08$ 6. $286 E-07$ 6. $286 \mathrm{E}-07$ 1. $.738 \mathrm{E}-\mathrm{OS}$ 1. $527 \mathrm{E}-\mathrm{OA}$ 4. $701 \mathrm{E}-\mathrm{OA}$

5. 185E-O3

$6.064 \mathrm{E}-\mathrm{O} 2$

7. $638 \mathrm{E}-\mathrm{O} 2$

1. O4OE-O 1

4. 291E-O1

$7.075 E-O$

4. $598 E+O D$

4. $598 E+00$
$6.820 E+O O$
GROUP 12 2.O TO $2.2 \mathrm{MEV}$

ALPHA

1. $312 E-11$

$.145 \mathrm{E}-1$

. $315 E-10$

3. $929 E-O 9$
7. $444 E-O B$

7. $444 \mathrm{E}-08$
3. $036 \mathrm{E}-\mathrm{O}$

7. 19OE-O6

$6.659 E-05$

3. $888 \mathrm{E}-04$

8. $481 \mathrm{E}-\mathrm{O} 4$

2. $156 \mathrm{E}-03$

1. $397 E-03$

8. 283E-O4

$-8.925 \mathrm{E}-05$

LAMBOA

2. $585 E-O B$

3. $084 E-08$

1. $160 E-O 6$

2. 972 E-OG

2. $730 \mathrm{E}-05$

8. $789 \mathrm{E}-05$

3. $638 E-04$

9. $797 \mathrm{E}-\mathrm{OA}$

$1.313 E-02$

6. $114 \mathrm{E}-\mathrm{O} 2$

1. $20 O E+O O$

5. $200 E+O O$

7. $360 E+O O$

2. $766 \mathrm{E}-\mathrm{O}$ ?
GROUP 16

3.0 TO $4.0 \mathrm{MEV}$

ALPHA
$6.536 E-15$
$3.090 E-21$
$4.347 E-11$
$4.809 E-15$
$5.836 E-07$
$3.229 E-06$
$4.331 E-05$
$3.463 E-04$
$1.073 E-03$
$1.955 E-03$
$1.368 E-02$
$3.731 E-03$
$5.551 E-03$
$2.387 E-03$ LAMEDA 2. $179 E-O B$ 2. $519 E-09$ 6. $273 E-07$ 9. $268 \mathrm{E}-07$ $9.268 E-07$ 9. $427 E-05$ 1. $754 \mathrm{E}-04$ 1. $144 \mathrm{E}-03$ 4. $789 \mathrm{E}-\mathrm{O} 3$ 1. $553 \mathrm{E}-\mathrm{O} 2$ 6. 866E-O2 2. $503 \mathrm{E}-01$ 3. $460 E-01$ 3. $185 \mathrm{E}+0 \mathrm{O}$ 5. $689 \mathrm{E}+0 \mathrm{O}$ 
TABLE A-XIII (Cont)

GROUP 17 4. O. TO 5.O MEV

$\triangle L$ PA 2. $07 D E-08$

2.71.0E-O8

6. $05 \exists E-07$

1. $64.2 \mathrm{E}-04$

3. $745 E-04$

4. $181 \mathrm{E}-\mathrm{OA}$

3. 11 19E-OA

7. $432 \mathrm{E}=\mathrm{O} 4$

2. $69 B E-O 3$

$-1.705 E-03$

3. $600 \mathrm{E}-\mathrm{O}$

\section{LAMBDA}

$6.782 E-05$

1. $38 O E-O 4$

7. $190 \mathrm{E}-01$

3. $900 \mathrm{E}-\mathrm{O} 3$

8. $346 \mathrm{E}-\mathrm{O} 3$

3. $400 \mathrm{E}-02$

1. $085 E-01$

3. $631 \mathrm{E}-\mathrm{O} 1$

$1.006 E+00$

2. $110 E+O 0$

4. $888 \mathrm{E}+0 \mathrm{O}$
GROUP 18 $5.0106 .0 \mathrm{MEV}$

At_PHA

2. $773 E-07$

3. $095 \mathrm{E}-05$

8. 399E-05

1. $088 E-04$

1. 309E-03

$7.110 E-04$

5. 194E-O5

1. 122E-O5

$-3.916 E-O 5$
- LAMBDA

2. $687 \mathrm{E}-\mathrm{O} 3$

4. $533 \mathrm{E}-\mathrm{O} 3$

1. OBAE-O2

1. $756 \mathrm{E}-02$

$1.677 E-01$

4. $086 E-01$

1. $415 E+O O$

4. $195 E+00$

2. $028 E-02$ 
TABLE A-XIV

FITS TO ${ }^{235} \mathrm{U}$ THERMAL PULSE BETAS

FOR UK DATA

$\begin{array}{cc}\text { GROUP } & 1 \\ 0.0 \text { TO } & .2 \text { MEV } \\ & \\ \text { ALPHA } & \text { LAMBDA } \\ 6.039 E-12 & 7.768 E-10 \\ 1.750 E-11 & 9.490 E-09 \\ 1.343 E-10 & 3.234 E-08 \\ 2.430 E-09 & 1.498 E-07 \\ 1.761 E-O B & 1.132 E-06 \\ 6.278 E-08 & 5.306 E-06 \\ 3.212 E-07 & 3.225 E-05 \\ 1.479 E-06 & 1.536 E-04 \\ 1.103 E-05 & 7.294 E-04 \\ 4.239 E-05 & 6.510 E-03 \\ 9.331 E-05 & 6.268 E-02 \\ 1.939 E-04 & 4.293 E-01 \\ -8.171 E-05 & 5.205 E-01 \\ 2.882 E-05 & 4.576 E+O O \\ -1.736 E-O 5 & 6.812 E+0 O \\ -3.866 E-06 & 1.341 E-03\end{array}$

GROUP 5
.8 TO $1.0^{\mathrm{ME}}$
$2 \mathrm{TROUP}$
.2
$2 \mathrm{MEV}$

ALPHA

9. $908 \mathrm{E}-12$

1. $913 E-12$

6. $156 E-11$

1. $875 E-09$

1. $562 \mathrm{E}-08$

3. $72 A \mathrm{~A}-07$

3. $724 \mathrm{AE}-07$

4.654E-O7

$2.044 E-06$
$7.993 E-O 6$

3. $993 \mathrm{E}-\mathrm{OC}$

8. 696E-05

2. $238 \mathrm{E}-04$

3. $488 \mathrm{E}-04$

1. $599 \mathrm{E}+01$

$-1.600 E+01$

8. $098 \mathrm{E}-03$

$-4.811 \mathrm{E}-\mathrm{O} 3$

GROUP 6

1.0 TO $1.2 \mathrm{MEV}$

ALPHA

6. $57 \mathrm{OE}-12$

6.570E-12

1. $240 E-10$

8. $539 \mathrm{E}-11$
$2.934 \mathrm{E}-09$

$2.934 \mathrm{E}-\mathrm{Og}$
$1.074 \mathrm{E}-08$

2. $142 \mathrm{E}-07$

1. $116 \mathrm{E}-\mathrm{OC}$

2. $903 \mathrm{E}-06$

1. $357 E-05$

4. $179 \mathrm{E}-05$

1. $391 \mathrm{E}-04$

5. $893 E-04$
1. $290 E-03$

3. $155 \mathrm{E}-03$

3. $322 \mathrm{E}-03$

2. $795 E-03$

$-2.397 \mathrm{E}-03$

$-8.584 E-10$

\begin{abstract}
LAMBDA
.698E-10

8. $930 E-09$
3. $135 E-08$

1. $565 \mathrm{E}-07$

6. $318 \mathrm{~F}-07$

3.367E-OG

3. $609 \mathrm{E}-05$

1. $120 E-04$

3. $373 E-04$

9. $715 E-O 1$

$5.227 \mathrm{E}-03$

$1.03 \mathrm{E}-01$

1. $820 E+00$

$.821 E+00$

5. $240 E+O O$

$7.163 E+00$
\end{abstract}

$\begin{array}{cc}\text { GROUP } & 3 \\ .4 \text { TO } & .6 \text { MEV } \\ \text { ALPHA } & \text { LAMBDA } \\ 4.454 E-12 & 7.866 E-10 \\ 2.804 E-12 & 1.080 E-08 \\ 7.566 E-11 & 3.140 E-08 \\ 2.557 E-09 & 1.698 E-07 \\ 1.760 E-08 & 7.817 E-07 \\ 6.381 E-08 & 4.059 E-06 \\ 5.623 E-07 & 1.426 E-05 \\ 7.498 E-07 & 4.263 E-05 \\ 6.833 E-06 & 1.857 E-04 \\ 5.222 E-05 & 7.832 E-04 \\ 2.066 E-04 & 6.789 E-03 \\ 4.447 E-04 & 2.843 E-02 \\ 7.519 E-04 & 1.105 E-01 \\ 7.449 E-03 & 7.097 E-01 \\ -8.074 E-03 & 8.669 E-01 \\ 2.108 E-03 & 1.882 E+00 \\ -4.939 E-04 & 4.899 E+00 \\ -3.182 E-06 & 2.696 E-04\end{array}$

GROUP 7

1.2 TO 1.4 MEV

LAMBDA

7. $542 \mathrm{E}-10$

2. $544 E-C 8$

3. $681 E-08$

2. $291 \mathrm{E}-06$

1. 189E-05

3. $695 \mathrm{E}-05$

1. $182 E-04$

3. $697 \mathrm{E}-04$

3. $958 \mathrm{E}-03$

1. $237 E-0.2$

3. $650 \mathrm{E}-\mathrm{O} 2$

1. $296 E-01$

5. $714 \mathrm{E}-\mathrm{O} 1$

7. $109 E+00$

1. $932 \mathrm{E}-07$ $\begin{array}{ll}\text { GROUP } & 4 \\ 6 \text { TO } & 8\end{array}$

8 MFV

\begin{tabular}{|c|c|}
\hline & \\
\hline $569 E-12$ & $7.54 A E-10$ \\
\hline $2.7+1 E-11$ & $2.073 E-08$ \\
\hline $9.993 \mathrm{E}-11$ & $3.424 E-08$ \\
\hline $3.586 E-09$ & $1.755 E-07$ \\
\hline $1.899 E-08$ & 1. $066 E-05$ \\
\hline $1.568 E-07$ & $6.632 E-O G$ \\
\hline $7.22 .3 E-07$ & 1. $.994 E-05$ \\
\hline 1. $985 E-06$ & $7.563 E-05$ \\
\hline $4.842 E-05$ & 4. 206E-04 \\
\hline $2.909 E-03$ & $1.056 E-02$ \\
\hline $1.798 \mathrm{E}-03$ & $1.491 E+O O$ \\
\hline 4. $245 E-04$ & $3.268 E+O 0$ \\
\hline $2.441 \mathrm{E}-03$ & 1. $108 E-02$ \\
\hline $1.284 \mathrm{E}-03$ & 5. $372 E-02$ \\
\hline $1.792 \mathrm{E}-03$ & $2.729 E-01$ \\
\hline$-4.331 E-06$ & $2.971 E-04$ \\
\hline $5.719 E-10$ & $1.578 E-07$ \\
\hline
\end{tabular}

GROUP 8

1. 4 TO $1.6 \mathrm{MEV}$

\begin{tabular}{|c|c|}
\hline ALPHA & LAMBDA \\
\hline $6.014 E-12$ & $7.543 E-10$ \\
\hline $1.635 \mathrm{E}-10$ & $2.560 E-08$ \\
\hline $1.001 \mathrm{E}-10$ & 3. $686 \mathrm{E}-08$ \\
\hline $1.619 E-09$ & $6.846 E-07$ \\
\hline $2.769 \mathrm{E}-07$ & $1.627 E-05$ \\
\hline $2.216 \mathrm{E}-06$ & $5.429 E-05$ \\
\hline $2.132 \mathrm{E}-05$ & $3.946 E-04$ \\
\hline $6.315 E-05$ & 1. $391 \mathrm{E}-03$ \\
\hline 3. $538 E-04$ & $6.766 E-03$ \\
\hline $2.301 \mathrm{E}-03$ & $2.888 E-02$ \\
\hline $5.461 \mathrm{E}-03$ & $1.562 E-01$ \\
\hline 1. $155 \mathrm{E}-02$ & $7.558 \mathrm{E}-01$ \\
\hline $6.756 \mathrm{E}-03$ & $9.166 E-01$ \\
\hline $2.626 \mathrm{E}-03$ & $4.716 \mathrm{~F}+00$ \\
\hline $1.586 E-03$ & $6.946 E+00$ \\
\hline $4.585 E-10$ & 6. $145 E-07$ \\
\hline
\end{tabular}


TABLE A-XIV (Cont)

GROUP 9
9 TO $1.8 \mathrm{M} V$

ALPHA

4. $547 \mathrm{E}-12$

. $866 \mathrm{E}-10$

$8.47 O E-11$

. $161 E-10$

.533E-O9

$.989 E-07$

$2.541 E-06$

2.04 1E-03

8. $470 \mathrm{OE}-\mathrm{O} 2$

$-1.550 E-02$

- $318 E-03$

$-2.202 E-03$

. $416 \mathrm{E}-\mathrm{O} 4$

1. $609 \mathrm{E}-03$

$-1.503 E-11$

GROUP 13

2.4 TO $2.6 \mathrm{MEV}$

\begin{tabular}{|c|c|}
\hline ALPHA & LAMBDA \\
\hline $1.174 E-11$ & 2. $198 E-08$ \\
\hline $9.904 E-11$ & $2.921 E-08$ \\
\hline 1. $666 \mathrm{E}-07$ & 2. $429 \mathrm{E}-05$ \\
\hline 1. $561 E-06$ & $6.981 E-05$ \\
\hline $3.467 E-05$ & $7.946 E-04$ \\
\hline $9.57 \mathrm{BE}-05$ & 3. $394 \mathrm{E}-03$ \\
\hline $5.159 \mathrm{E}-04$ & $1.215 E-0 ?$ \\
\hline 1. $533 E-03$ & 3. $233 \mathrm{E}-02$ \\
\hline $6.433 E-03$ & 1. $153 \mathrm{E}-01$ \\
\hline $3.932 E-02$ & $6.475 E-01$ \\
\hline $3.499 E-02$ & 8. $296 \mathrm{E} \cdot 01$ \\
\hline 1.275E-02 & $1.929 E+\infty 0$ \\
\hline $2.528 E-03$ & 4. $71 O E+00$ \\
\hline $4.393 E-07$ & $5.336 \mathrm{E}-05$ \\
\hline $1.759 E-11$ & $3.899 E-08$ \\
\hline $4.824 \mathrm{E}-12$ & $7.193 E-08$ \\
\hline & $1.521 E-07$ \\
\hline & \\
\hline
\end{tabular}

GROUP 10
7. $543 E-10$
2. $596 \mathrm{E}-\mathrm{OS}$
$3.737 \mathrm{E}-\mathrm{O} 8$
1. $436 \mathrm{E}-05$
7. $114 \mathrm{E}-06$
2. $107 \mathrm{E}-05$
$6.938 \mathrm{E}-05$
$1.066 \mathrm{E}-03$
4. $006 \mathrm{E}-01$
. $027 \mathrm{E}-01$
4. $442 E+00$
$6.656 \mathrm{E}+00$
1. $129 \mathrm{E}-03$
2. $225 \mathrm{E}-03$
1. $767 E-02$ 1.8 TO 2.0 MEV

GROUP 11 2.O TO 2.2 MEV

\begin{tabular}{|c|c|}
\hline ALPHA & LAMBDA \\
\hline 8. $156 E-13$ & $7.543 E$ \\
\hline 1. $360 E-10$ & $2.559 E$ \\
\hline 7. $699 E-11$ & $3.713 \mathrm{E}-\mathrm{C}$ \\
\hline 1. $.090 E-07$ & $1.685 \mathrm{E}$ \\
\hline $1.025 E-06$ & 4 \\
\hline $4.765 \mathrm{E}-08$ & $8.494 \mathrm{E}$ \\
\hline $1.071 E-05$ & $3.716 E-C$ \\
\hline $4.048 E-05$ & $1.019 \mathrm{E}$ \\
\hline 1. $177 E-04$ & $3.786 \mathrm{E}$ \\
\hline $6.388 E-04$ & 1. $333 \mathrm{E}$ \\
\hline $1.652 E-03$ & $3.444 E-C$ \\
\hline $5.838 E-03$ & 1. $142 E-C$ \\
\hline 2. $286 E-02$ & $5.674 E-$ \\
\hline $1.698 \mathrm{E}-02$ & $7.72 O E-C$ \\
\hline $7.879 E-03$ & 1. $921 E+C$ \\
\hline $1.527 E-03$ & $4.703 E$ \\
\hline$=-11$ & \\
\hline $1.532 E-11$ & $6.421 \mathrm{E}$ \\
\hline
\end{tabular}

GROUP 14

2 . 5 TO 3 .O MEV

\begin{tabular}{|c|c|}
\hline$\triangle L P H A$ & LAMBDA \\
\hline $1.366 E-11$ & 2. $186 \mathrm{E}-\mathrm{O} 8$ \\
\hline $5.050 E-11$ & $2.919 E-08$ \\
\hline $3.087 E-07$ & $3.266 \mathrm{E}-05$ \\
\hline 2. $303 E-06$ & $7.247 E-05$ \\
\hline $5.735 \mathrm{E}-05$ & $8.223 E-04$ \\
\hline $1.683 E-04$ & $3.472 \mathrm{E}-03$ \\
\hline $9.322 E-04$ & 1. 22OE-O2 \\
\hline $2.776 \mathrm{E}-03$ & $3.229 E-02$ \\
\hline 1. $303 E-02$ & 1. $178 E-01$ \\
\hline $3.518 E-01$ & 8. $705 E-01$ \\
\hline $3.869 E-01$ & $9.897 \mathrm{E}-01$ \\
\hline 8. $370 E-02$ & $1.998 E+00$ \\
\hline$-1.737 \mathrm{E}-\mathrm{O} 2$ & $4.778 E+00$ \\
\hline$-6.34 A E-07$ & $5.767 E-05$ \\
\hline$-8.875 E-12$ & $3.895 \mathrm{~F}-08$ \\
\hline $2.421 E-12$ & 7. $186 \mathrm{E}-08$ \\
\hline $6.115 E-13$ & 1. $530 \mathrm{OE}-07$ \\
\hline & \\
\hline
\end{tabular}

\begin{abstract}
LAMRDA
1. $664 \mathrm{E}-08$

1. $533 E-05$

4. $069 E-05$

9. $522 E-05$

$3.621 E-04$

$1.013 \mathrm{E}-03$
3. $802 \mathrm{E}-03$

1. $335 E-02$

3. $465 \mathrm{E}-02$

1. $143 \mathrm{E}-01$

5. $722 \mathrm{E}-01$

$.770 E-01$

4. $691 E+O O$

8. $176 \mathrm{E}-08$

6. $920 E-07$
\end{abstract}

\section{GROUP 15}

3.0 TO $4.0 \mathrm{MEV}$

\begin{tabular}{|c|c|}
\hline ALPHA & LAMBDA \\
\hline $3.975 E-12$ & 2. $179 E-08$ \\
\hline $4.466 E-17$ & $2.254 \mathrm{E}-\mathrm{OB}$ \\
\hline 1. OOOE - 11 & $1.767 \mathrm{E}-07$ \\
\hline $6.747 E-07$ & $4.823 E-05$ \\
\hline $2.490 E-05$ & 8. $608 E-05$ \\
\hline $6.204 E-05$ & $7.973 E-04$ \\
\hline $2.382 E-04$ & $3.431 E-03$ \\
\hline $1.450 E-03$ & $1.151 E-02$ \\
\hline A. $880 E-03$ & $3.201 E-02$ \\
\hline $2.826 E-02$ & $1.223 E-01$ \\
\hline $3.071 E-01$ & $7.411 E-01$ \\
\hline $2.979 E-01$ & $9.012 E-01$ \\
\hline 8. $947 E-02$ & 1. $.96 \% E+O D$ \\
\hline$-1.799 E-02$ & 4. $744 E+O O$ \\
\hline$-4.066 E-07$ & $6.346 E-05$ \\
\hline $1.000 E-11$ & $1.767 E-07$ \\
\hline 1. $169 E-10$ & $7.981 E-06$ \\
\hline
\end{tabular}

GROUP 12 2.2 TO 2.4 MEV

ALPHA

2. $591 E-14$

1. $026 E-10$

6. $055 \mathrm{E}-11$

2. $259 \mathrm{E}-07$

1.764E-06

3.65OE-05

9. $981 E-05$

5. $173 \mathrm{E}-04$

1. $6.30 E-O 3$

6. 192E-O3

. $457 E-02$

$-1.791 \mathrm{E}-\mathrm{O} 2$

8. 564E-O3

$-1.654 \mathrm{E}-03$

$-4.361 \mathrm{E}-07$

$-1.302 E-11$

1. $436 \mathrm{E}-12$

LAMBDA

7. $543 E-10$

2. $54 O E-.08$

3. $713 E-08$

2. $249 \mathrm{E}-05$

$6.921 \mathrm{E}-05$

$7.471 E-04$

3. $229 \mathrm{E}-\mathrm{O} 3$

3. $199 \mathrm{E}-\mathrm{O} 2$

1. $134 \mathrm{E}-01$

$5.729 E-O 1$

7. $750 E-01$

1. $934 E+O O$

4. $715 \mathrm{E}+O O$

$4.625 E-05$

5. $860 \mathrm{O}-\mathrm{OS}$

4. $578 \mathrm{E}-07$

3. $884 \mathrm{E}-\mathrm{O}$

GROUP 16

4.0 TO 5.0 MEV

ALPHA

$6.836 \mathrm{E}-07$

3. $980 E-08$

LAMBDA

2. $362 E-O 6$

2. $690 \mathrm{E}-\mathrm{OS}$

1. $109 \mathrm{E}-\mathrm{OA}$

. .

$5.948 \mathrm{E}-04$

1. $980 \mathrm{OE}-03$

2. $095 \mathrm{E}-02$

4. $681 \mathrm{E}-02$

1. 163E-O2

6.780 - 05

$.257 E-04$

$1.2515-03$

4. $522 \mathrm{E}-\mathrm{O} 3$

1. $269 \mathrm{E}-\mathrm{O} 2$

3. $605 \mathrm{E}-\mathrm{O} 2$

1. $298 \mathrm{E}-01$

5. $067 E-01$

GROUP 17

5.0 TO 6.0 MEV

$\begin{array}{cc}\text { ALPHA } & \text { LAMBDA } \\ 1.827 E-O 8 & 6.909 E-05 \\ 2.867 E-O 5 & 4.548 E-O 3 \\ 1.026 E-O 4 & 1.275 E-O 2 \\ 6.397 E-O 4 & 3.976 E-O 2 \\ 1.237 E-02 & 1.308 E-01 \\ 8.416 E-03 & 4.070 E-O 1 \\ 1.783 E-02 & 1.151 E-O O \\ 4.151 E-03 & 1.799 E+O O \\ 1.475 E-O 3 & 4.881 E+O O \\ 4.295 E-09 & 7.522 E-O 5 \\ 5.537 E-09 & 6.761 E-04\end{array}$


This appendix contains sets of alpha, lamba parameter pairs derived (from experimental data) by using the FITPULS code, as described in Section VI. Since the method used does nct result in unique sets of parameters, confidence limits were placed on each set. Tables B-I through B-IV give the confidence limits to be associated with the sets of parameter pairs in Tables B-V through B-VIII. An index to the tables in Appendix $B$ follows.

Table B-I Confidence Limits of Experimental Fits for ${ }^{239} \mathrm{U}$ Thermal Pulse Gammas

Table B-II Confidence Limits of Experimental Fits for ${ }^{239} \mathrm{U}$ Thermal Pulse Betas

Table B-III Confidence Limits of Experimental Fits for ${ }^{239} \mathrm{Pu}$ Thermal Pulse Gammas

Table B--IV Confidence Limits of Experimental Fits for ${ }^{239} \mathrm{Pu}$ Thermal Pulse Betas

Table B-V Experimental Fits for ${ }^{235}$ Thermal Pulse Gammas

Table B-VI Experimental Fits for $235 \mathrm{U}$ Thermal Pulse Betas

Table B-VII Experimental Fits for ${ }^{239} \mathrm{Pu}$ Thermal Pulse Gammas

Table B-VIII Experimental Fits for ${ }^{239} \mathrm{Pu}$ Thermal Pulse Betas. 
CONFIDENCE LIMITS OF EXPERIMENTAL FITS FOR $235_{\text {U THERMAL PULSE GAMMAS }}{ }^{\text {. }}$

\begin{tabular}{|c|c|c|c|}
\hline Group No. & Confidence & Limit (\%) & Comment \\
\hline 1 & 19.0 & & includes al1 points \\
\hline 2 & 19.0 & & includes all points \\
\hline 3 & 15.0 & & includes all points \\
\hline 4 & 24.0 & & includes all points \\
\hline 5 & 7.0 & & includes all points \\
\hline 6 & 20.0 & & includes all points \\
\hline 7 & 12.0 & & includes all points \\
\hline 8 & 41.0 & & includes all points \\
\hline 9 & 56.0 & & includes all points \\
\hline 10 & 45.0 & · & includes all points \\
\hline 11 & 62.0 & & includes all points \\
\hline 12 & 65.0 & & includes all points \\
\hline 13 & 77.0 & : & exclude pt. at $1.2+04 \mathrm{~s}(134 \%)$ \\
\hline 14 & 31.0 & & includes all points \\
\hline 15 & 36.0 & & exclude pt. at $1.0+5$ s $(81 \%)$ \\
\hline 16 & 23.0 & & includes all points \\
\hline 17 & 32.0 & & exclude data above $1000 \mathrm{~s}$ \\
\hline 18 & 57.0 & & exclude data above $1000 \mathrm{~s}$ \\
\hline
\end{tabular}

aNote: Gamma Fits are from $2 \mathrm{~s}$ to $1.5 \times 10^{5} \mathrm{~s}$ cooling time.

TABLE B-II

CONFIDENCE LIMITS OF EXPERIMENTAL FITS FOR 235 U THERMAL PULSE BETASa

\begin{tabular}{ccc} 
Group No. Confidence Limit $(\%)$ & Comment \\
\cline { 1 - 3 } 1 & 25.0 & \\
2 & 18.0 & includes all points \\
3 & 8.0 & includes all points \\
4 & 8.0 & includes all points \\
5 & 10.0 & includes all points \\
6 & 10.0 & includes all points \\
7 & 10.0 & includes all points \\
8 & 9.0 & includes all points \\
9 & 10.0 & includes all points \\
10 & 11.0 & includes all points \\
11 & 10.0 & includes all points \\
12 & 22.0 & includes all points \\
13 & 17.0 & includes all points \\
14 & 15.0 & includes all points \\
15 & 25.0 & includes all points \\
16 & 33.0 & includes all points \\
17 & 39.0 & includes all points
\end{tabular}

aNote: Beta Fits are from $2 \mathrm{~s}$ to $1.2 \times 10^{4} \mathrm{~s}$ 
CONFIDENCE LIMITS OF EXPERIMENTAL FITS FOR ${ }^{235}$ PU THERMAL PULSE GAMMASa

\begin{tabular}{|c|c|c|c|}
\hline Group & No. & Confidence Limit (\%) & Comment \\
\hline 1 & & 15.0 & includes all points \\
\hline 2 & & 10.0 & includes all points \\
\hline 3 & & 9.0 & includes all points \\
\hline 4 & & 7.0 & includes all points \\
\hline 5 & & 8.0 & includes all points \\
\hline 6 & & .13 .0 & includes all points \\
\hline 7 & & 13.0 & includes all points \\
\hline 8 & & 15.0 & includes all points \\
\hline 9 & & 33.0 & includes all points \\
\hline 10 & & 27.0 & includes all points \\
\hline 11 & & 16.0 & includes all points \\
\hline 12 & & 28.0 & exclude pt. at $1.5+05 \mathrm{~s}(42 \%)$ \\
\hline 13 & & 24.0 & includes all points \\
\hline 14 & & 14.0 & includes all points \\
\hline 15 & & 59.0 & exclude pt. at $1.5+05$ s $(92 \%)$ \\
\hline 16 & & 19.0 & includes all points \\
\hline 17 & & 24.0 & exclude points above $1000 \mathrm{~s}$ \\
\hline 18 & & 61.0 & exclude points above $500 \mathrm{~s}$ \\
\hline
\end{tabular}

aNote: Gamma Fits are from $2 \mathrm{~s}$ to $1.5 \times 10^{5} \mathrm{~s}$ cooling time.

TABLE B-IV

CONFIDENCE LIMITS OF EXPERIMENTAL FITS FOR ${ }^{239}$ PU THERMAL PULSE BETASa

\begin{tabular}{ccc} 
Group No. Confidence Limit $(\%)$ & \multicolumn{1}{c}{ Comment } \\
\cline { 2 - 3 } 1 & 44.0 & includes all points \\
2 & 25.0 & includes all points \\
3 & 15.0 & includes all points \\
4 & 6.0 & includes all points \\
5 & 6.0 & includes all points \\
6 & 7.0 & includes all points \\
7 & 8.0 & includes all points \\
8 & 10.0 & includes all points \\
9 & 8.0 & includes al1 points \\
10 & 6.0 & includes all points \\
11 & 9.0 & includes all points \\
12 & 8.0 & includes all points \\
13 & 14.0 & includes all points \\
14 & 17.0 & includes all points \\
15 & 7.0 & exclude point at $1.2 \mathrm{x} 10^{4} \mathrm{~s}$ \\
16 & 13.0 & exclude point at $1.2 \mathrm{x} 10^{4} \mathrm{~s}$ \\
17 & 13.0 & exclude point at $1.2 \mathrm{x} 10^{4} \mathrm{~s}$
\end{tabular}

aNote: Beta Fits are from $2 \mathrm{~s}$ to $1.2: \times 10^{4} \mathrm{~s}$ 
EXPERIMENTAL FITS FOR ${ }^{235} \mathrm{U}$ THERMAL PULSE GAMMAS

\begin{tabular}{|c|c|c|c|}
\hline \multicolumn{2}{|c|}{ GROUP 1} & \multicolumn{2}{|c|}{ GROUP 2} \\
\hline O.O TO & .1 MEV & .1 TO & 2 MEV \\
\hline ALPHA & LAMBDA & ALPHA & 'LAMBDA \\
\hline $1.228 E-13$ & $8.579 E-10$ & 4. O9OE-14 & $4.802 E-09$ \\
\hline $4.447 E-13$ & 1. $275 E-08$ & $2.485 \mathrm{E}-12$ & 2. $080 E-08$ \\
\hline $9.405 E-12$ & $3.172 E-08$ & 2. $304 E-11$ & $3.117 E-08$ \\
\hline $3.022 E-10$ & $3.403 E-07$ & 1. $295 \mathrm{E}-09$ & $2.722 \mathrm{E}-07$ \\
\hline $6.528 E-09$ & $1.314 E-06$ & $2.774 \mathrm{E}-08$ & 2. $963 \mathrm{E}-06$ \\
\hline $3.318 E-O B$ & $5.054 E-06$ & $4.529 E-08$ & 1. $461 \mathrm{E}-05$ \\
\hline $9.476 \mathrm{E}-07$ & $3.283 E-04$ & $6.728 \mathrm{E}-07$ & $9.231 E-05$ \\
\hline $7.533 E-06$ & 1. $426 \mathrm{E}-03$ & $5.744 E-06$ & 4. $102 \mathrm{E}-04$ \\
\hline $6.507 E-05$ & $1.041 \mathrm{E}-\mathrm{O} 2$ & $9.158 E-06$ & 1. $158 \mathrm{E}-03$ \\
\hline $4.818 E-04$ & 4. $514 \mathrm{E}-02$ & 1. $127 E-05$ & 3. $266 \mathrm{E}-03$ \\
\hline $8.863 E-04$ & 3. $187 E-01$ & 1. $192 E-04$ & $1.323 E-02$ \\
\hline$-2.132 \mathrm{E}-04$ & 4. 56 IE-D2 & $7.323 \mathrm{E}-04$ & 4. $193 E-02$ \\
\hline$-3.858 E-06$ & $1.425 \mathrm{E}-03$ & 1. $619 E-03$ & 1. $259 \mathrm{E}-01$ \\
\hline$-3.226 E-O 8$ & $6.742 \mathrm{E}-06$ & 9. $\triangle 4 O E-O 3$ & $7.269 \mathrm{E}-01$ \\
\hline $4.742 E-08$ & $3.595 E-05$ & $2.279 E-04$ & $1.045 E+0:$ \\
\hline & & $-4.289 E-09$ & $4.334 \mathrm{E}-06$ \\
\hline
\end{tabular}

\begin{tabular}{|c|c|}
\hline \multicolumn{2}{|c|}{ GROUP 5} \\
\hline . 6 TO & $8 M \equiv V$ \\
\hline ALPHA & LAMBDA \\
\hline $2.574 E-11$ & $7.376 E-10$ \\
\hline $7.418 E-12$ & $1.713 E-08$ \\
\hline $2.867 E-11$ & $4.871 \mathrm{E}-08$ \\
\hline $1.984 E-C 8$ & $1.228 E-07$ \\
\hline $2.611 \mathrm{E}-\mathrm{G} .7$ & $2.894 E-06$ \\
\hline $1.350 E-06$ & 1. $.485 \mathrm{E}-05$ \\
\hline $1.972 E-05$ & $1.964 E-04$ \\
\hline $7.089 E-05$ & 1. $152 \mathrm{E}-03$ \\
\hline 3. $109 E-04$ & $4.265 E-03$ \\
\hline $2.301 E-03$ & $2.561 \mathrm{E}-02$ \\
\hline $8.318 E-03$ & 1. $481 E-01$ \\
\hline $1.851 E+00$ & $1.395 E+00$ \\
\hline$-1.906 E+00$ & $1.437 E+00$ \\
\hline $1.591 \mathrm{E}-01$ & $3.249 E+0 O$ \\
\hline$-G .489 E-O 2$ & $4.622 E+0 O$ \\
\hline$-1.156 \mathrm{E}-08$ & $1.979 E-07$ \\
\hline
\end{tabular}

GROUP 6

E TO $1.0 \mathrm{MEV}$

\begin{tabular}{|c|c|}
\hline$A L D H A$ & LAMBDA \\
\hline 1. $259 E-17$ & $5.695 \mathrm{E}-10$ \\
\hline $2.939 E-13$ & $2.122 \mathrm{E}-08$ \\
\hline $9.255 E-14$ & $3.302 E-08$ \\
\hline $7.414 E-09$ & $5.605 E-07$ \\
\hline $1.273 E-08$ & $8.313 E-07$ \\
\hline 4. $374 E-08$ & $4.035 E-06$ \\
\hline $1.052 E-06$ & 3. $179 \mathrm{E}-05$ \\
\hline 2. $150 E_{-}-05$ & $1.608 E-04$ \\
\hline $2.559 E-05$ & $2.116 \mathrm{E}-04$ \\
\hline $2.235 E-04$ & $1.521 E-03$ \\
\hline $8.837 E-04$ & 1. $108 \mathrm{E}-02$ \\
\hline $3.410 E-03$ & $4.970 E-02$ \\
\hline 1. $101 \mathrm{E}-02$ & 2. $147 \mathrm{E}-01$ \\
\hline $4.631 E-02$ & $9.452 E-01$ \\
\hline $2.531 \mathrm{E}-02$ & $4.542 E+O O$ \\
\hline
\end{tabular}

\begin{tabular}{|c|c|c|}
\hline GROUP & 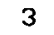 & \\
\hline 2 TO & .4 & MEV \\
\hline ALPHA & & LAMBDA \\
\hline 4. $262 E-15$ & & 5. $144 \mathrm{E}-09$ \\
\hline $1.991 E-14$ & & $9.623 E-09$ \\
\hline 3. $188 E-16$ & & $1.542 E-07$ \\
\hline $6.465 E-12$ & & 1. $262 \mathrm{E}-07$ \\
\hline $5.067 E-09$ & & $5.485 E-07$ \\
\hline 1. $193 E-08$ & & 1. $179 \mathrm{E}-06$ \\
\hline $5.075 E-08$ & & $3.726 \mathrm{E}-06$ \\
\hline $1.227 E-07$ & & $2.662 E-05$ \\
\hline $1.918 E-07$ & & $1.312 E-05$ \\
\hline $1.984 E-05$ & & $3.288 E-04$ \\
\hline $5.503 E-05$ & & 1. $102 E-03$ \\
\hline 1. $187 E-04$ & & $7.011 \mathrm{E}-03$ \\
\hline $9.778 \mathrm{E}-04$ & & 1. $899 E-02$ \\
\hline $3.131 E-03$ & & 9. $157 \mathrm{E}-02$ \\
\hline i. $475 \mathrm{E}-02$ & & $3.912 \mathrm{E}-01$ \\
\hline $2.059 E-04$ & & $1.463 E+01$ \\
\hline & & $4.043 E-01$ \\
\hline & & \\
\hline
\end{tabular}

GROUP 7 1.O TO 1.2 MEV
ALPHA
$9.554 \mathrm{E}-18$
1. $803 E-12$
2. $164 E-14$
1. $910 E-11$
3. $362 \mathrm{E}-10$
1. $093 \mathrm{E}-08$
2. $442 \mathrm{E}-07$
$7.977 \mathrm{E}-07$
1. $458 E-05$
$1.037 E-04$
3. $971 E-04$
2. $181 E-03$
$5.714 E-03$
1. $870 \mathrm{OE}-02$
3. $736 \mathrm{E}-\mathrm{O} 2$
$-6.221 E-02$
4. $891 \mathrm{E}-02$

GROUP 4

.4 TO .6 MEV

ALPHA

2. $064 E-14$

8. $636 \mathrm{E}-13$

9. $578 \mathrm{E}-12$

3. $139 E-O 9$

3. $769 \mathrm{E}-08$

$5.032 \mathrm{E}-07$

1. $039 E-06$

2. $068 \mathrm{E}-05$

8. $651 \mathrm{E}-05$

1. $204 \mathrm{E}-03$

7. $462 \mathrm{E}-03$

1. $001 \mathrm{E}-01$

$-8.124 E-02$

1. $455 \mathrm{E}-\mathrm{O}$

$-1.232 \mathrm{E}-\mathrm{O}$

$-1.243 E-O B$

LAMBDA

2. $121 E-09$

9. $932 E-O 9$

2. $363 \mathrm{E}-08$

2. $110 E-07$

7. 255E-O7

1. $045 E-05$

4. $414 \mathrm{E}-05$

2. $598 \mathrm{E}-\mathrm{O} 4$

1. $443 E-03$

7. $951 E-02$

4. 185E-O

4. $654 \mathrm{E}-01$

2. $092 E+O O$

2. $209 E+O O$

7. $486 \mathrm{E}-07$
GROUP 8

1. 2 TO $1.4 \mathrm{MEV}$

\section{ALPHA}

2. $433 E-17$

3. $457 \mathrm{E}-14$

1. $720 E-13$

3. $215 E-11$

3. $094 \mathrm{E}-09$

2:218E-O8

8. $842 E-08$

3. $442 E-O 6$

1. $351 \mathrm{E}-05$

1. $040 E-04$

2. $014 \mathrm{E}-03$

7. $000 \mathrm{E}-03$

1. $128 E-O 1$

$-3.390 E-02$

$5.434 E-0.1$

$-5.846 E-0$

$-1.887 E-04$
LAMBDA.

1. $824 E-O 9$

2. $029 E-08$

1. $4203 E-08$

1. $420 E-07$

2. $891 E-06$

1. $268 \mathrm{E}-05$

5. $066 \mathrm{E}-05$

2. $003 E-04$

1. $186 \mathrm{E}-0.3$

1. 179E-O2

9.864E-O2

8. $032 \mathrm{E}-01$

7. $183 E-01$
$2.027 E+00$

1. $897 \mathrm{E} \div \mathrm{OO}$

1. $082 E-O 2$ 


\begin{tabular}{|c|c|}
\hline $2.657 \mathrm{E}-18$ & $4.328 E-10$ \\
\hline $4.743 E-12$ & $2.620 E-08$ \\
\hline $2.442 E-12$ & $3.741 E-08$ \\
\hline 1. $499 E-07$ & $6.916 \mathrm{E}-07$ \\
\hline $1.019 E-05$ & $1.507 \mathrm{E}-\mathrm{OA}$ \\
\hline $1.913 E-O A$ & $6.732 E-04$ \\
\hline $1.784 \mathrm{E}-03$ & 1. $162 \mathrm{E}-02$ \\
\hline $8.929 E-03$ & $2.032 E-01$ \\
\hline 1. $433 E-02$ & $1.520 E+O O$ \\
\hline$-6.409 E-03$ & 3. $379 E-02$ \\
\hline $8.391 E-03$ & $3.717 E-02$ \\
\hline$-2.153 E-04$ & $8.070 E-04$ \\
\hline 1. $150 E-04$ & $1.756 \mathrm{E}-03$ \\
\hline$-2.028 E-07$ & $8.980 E-07$ \\
\hline $1.274 \mathrm{E}-07$ & $1.065 E-06$ \\
\hline$-1.911 \mathrm{E}-07$ & $8.004 E-06$ \\
\hline $7.048 E-07$ & $2.568 E-05$ \\
\hline
\end{tabular}

GROUP 13

2. 2 TO 2.4 MEV
GROUP 10 1.6 TO $1.8 \mathrm{MEV}$.

ALPHA
$2.671 E-19$
$1.056 E-13$
$4.417 E-14$
$1.072 E-12$
$1.159 E-09$
$1.383 E-09$
$4.823 E-07$
$3.281 E-06$
$1.291 E-05$
$4.864 E-04$
$3.784 E-03$
$1.598 E-02$
$-1.040 E-01$
$1.049 E-01$
$-2.317 E-06$
$-4.039 E-04$
$5.889 E-04$
$2.100 E-03$

LAMBDA 6. $182 E-11$ 2. $175 \mathrm{E}-08$ 2. $117 E-O$ ? 8. $332 \mathrm{E}-\mathrm{O}$ ? 2. $118 E-06$ 5. $228 \mathrm{E}-06$ 2. $323 \mathrm{E}-05$ 1. $063 \mathrm{E}-04$ 4. $402 \mathrm{E}-04$ 1. $501 \mathrm{E}-03$ 1. $246 \mathrm{E}-\mathrm{O}$ 4. $091 \mathrm{E}-\mathrm{O}$ : 1. $520 E+00$ 1. $693 \mathrm{E}+00$ . $745 \mathrm{E}+01$ 1. $485 \mathrm{E}-03$ 1. $012 \mathrm{E}-\mathrm{O} 2$
3. $991 \mathrm{E}-\mathrm{O} 2$
ROUP 11 1.8 TO 2.0 MEV

ALPHA

$2.024 E-19$

5. $844 E-14$

6. $540 E-11$

1. 507E-O9

2. $069 \mathrm{E}-09$

2. $169 \mathrm{E}-08$

2. $723 \mathrm{E}-07$

2. $706 \mathrm{E}-06$

1. $521 \mathrm{E}-05$

5. $338 \mathrm{E}-05$

1. $569 \mathrm{E}-04$

6. $287 E-O 4$

1. $160 \mathrm{E}-03$

$6.638 \mathrm{E}-03$

2. $948 \mathrm{E}-02$

LAMBOA
$9.974 E-11$
$2.208 E-08$
$5.904 E-07$
$2.846 E-06$
$2.872 E-O 6$
$2.110 E-O 5$
$2.734 E-05$
$1.085 E-04$
$4.563 E-04$
$1.452 E-03$
$6.788 E-03$
$1.403 E-02$
$3.474 E-02$
$1.469 E-O 1$
$6.451 E-01$
$1.739 E+00$

GROUP 15

2.6 TO 3 O MEV

2. 4 TO $2.6 \mathrm{MEV}$

ALPHA
$4.55 O E-14$
$2.863 E-15$
$3.77 A E-10$
$4.319 E-09$
$4.902 E-07$
$2.073 E-06$
$5.159 E-05$
$1.950 E-04$
$1.111 E-03$
$3.164 E-03$
$6.179 E-03$
$1.502 E-05$
$3.600 E-05$
$2.081 E-09$

LAMBDA

2. $174 \mathrm{E}-\mathrm{OB}$

8. $104 E-08$

9. $897 \mathrm{E}-07$

6. $300 E-07$

5. $834 \mathrm{E}-05$

9. $839 E-05$

$6.065 E-04$

4.739E-03

$2.031 \mathrm{E}-02$

9. $449 E-02$

3. $370 E-O 1$

1. $394 \mathrm{E}+01$

$6.874 \mathrm{E}-04$

2. $182 \mathrm{E}-06$
ALPHA

2. 195E-1

7. $280 \mathrm{E}-15$

$7.767 \mathrm{E}-11$

3. $281 \mathrm{E}-07$

3. O6OE -O6

7. $557 \mathrm{E}-06$

1. $161 E-04$

1. $366 \mathrm{E}-03$

3. $349 \mathrm{E}-03$

1. $577 \mathrm{E}-02$

$1.207 \mathrm{E}-03$

$3.044 \mathrm{E}-02$

3. $383 \mathrm{E}-02$

5.577 E -05

2. 000 E -07
GROUP 12 2.0 TO $2.2 \mathrm{MEV}$

$\begin{array}{cc}\text { ALPHA } & \text { LAMBDA } \\ 2.671 E-13 & 2.274 E-O 8 \\ 3.418 E-11 & 2.879 E-08 \\ 2.562 E-09 & 2.204 E-06 \\ 3.248 E-10 & 2.203 E-06 \\ 3.678 E-07 & 4.780 E-05 \\ 2.663 E-06 & 1.152 E-O 4 \\ 2.568 E-05 & 1.940 E-04 \\ 8.103 E-05 & 2.200 E-03 \\ 1.192 E-03 & 1.736 E-O 2 \\ 4.033 E-03 & 9.531 E-02 \\ 8.527 E-O 3 & 3.754 E-O 1 \\ 1.476 E-O 1 & 4.271 E+O O \\ -1.415 E-01 & 4.296 E+00 \\ -1.026 E-11 & 2.996 E-08\end{array}$

$-1.026 E-11 \quad 4.296 E+O O$

2.306E-O2 3.206E+O0

-2 OOOE - O7

GROUP 16

3. O TO $4.0 \mathrm{MEV}$

$\begin{array}{cc}\text { ALPHA } & \text { LAMBDA } \\ 6.508 E-15 & 2.174 E-O 8 \\ 8.05 O E-20 & 8.327 E-08 \\ 8.104 E-13 & 4.45 O E-O 7 \\ 3.771 E-11 & 6.403 E-07 \\ 1.187 E-07 & 7.160 E-05 \\ 2.892 E-06 & 1.594 E-04 \\ 3.430 E-05 & 8.621 E-04 \\ 1.745 E-04 & 2.875 E-O 3 \\ 1.598 E-03 & 1.195 E-O 2 \\ 4.916 E-03 & 5.149 E-02 \\ 1.957 E-02 & 1.941 E-01 \\ 4.009 E-02 & 6.943 E-01 \\ 2.377 E-02 & 9.153 E-O 1 \\ 7.220 E-04 & 9.215 E+O O \\ -5.709 E-13 & 5.423 E-07 \\ -2.457 E-10 & 6.617 E-O 6 \\ 1.001 E-06 & 1.100 E-05 \\ 9.999 E-07 & 1.100 E-05\end{array}$


TABLE B-V (Cont)

GROUP 17

4.O TO 5.O MEV

GROUP 18

5.0 TO $6.0 \mathrm{MEV}$

\begin{tabular}{|c|c|}
\hline$A L P H A$ & LAMBOA \\
\hline 1. $736 E-19$ & 4. $125 E-05$ \\
\hline 4. $261 E-08$ & $7.408 E-05$ \\
\hline $1.936 E-08$ & $7.432 E-05$ \\
\hline 7. $3 \subseteq 4 E-07$ & $3.419 E-04$ \\
\hline $4.780 E-05$ & $2.673 E-03$ \\
\hline $5.669 E-04$ & $7.308 E-03$ \\
\hline 7. 997E-04 & 3. $194 \mathrm{E}-\mathrm{O} 2$ \\
\hline $3.627 E-03$ & 1. $005 \mathrm{E}-01$ \\
\hline 2. $18.0 E-02$ & $4.891 E-01$ \\
\hline $4.398 E-03$ & $1.939 E+O 1$ \\
\hline $1.711 E-05$ & $2.426 E-02$ \\
\hline $1.227 E-07$ & 1. $182 E-04$ \\
\hline $1.002 E-02$ & $9.738 E-02$ \\
\hline$-1.023 E-02$ & $1.056 E-01$ \\
\hline
\end{tabular}

$\triangle L P H A$

8. $501 E-20$

2. $175 E-14$

2. $197 E-12$

1. OA7E-OG

8. $733 \mathrm{E}-\mathrm{Or}$

2. $89 O E-O A$

2. $027 E-01$

1. $995 E-01$

4. 202E-OJ

$5.210 E-03$

2. $836 \mathrm{E}-03$

$-5.322 E-04$

$-6.367 E-21$

2. $549 E-03$

$-1.841 E-03$

$1.000 E-21$

LAMBDA

5. $76 O E-O 6$

1. $006 E-04$

3. 18GE-OA

1. $377 E-03$

3. 395E-03

1. $086 \mathrm{E}-02$

2. $032 E-01$

$2.023 E-01$

2. 607 E- 01

3. $716 E-01$

9. O9OE-O 1

1. $638 E+00$

$6.629 E-06$

4. $224 E-02$

1. OOOE-O6 


\begin{tabular}{|c|c|}
\hline \multicolumn{2}{|c|}{ GROUP 1} \\
\hline 0.0 TO & 2 MEV \\
\hline ALPHA & LAMBOA \\
\hline $434 E-12$ & $7.896 E-10$ \\
\hline $913 E-11$ & $9.474 E-09$ \\
\hline $578 E-10$ & 3. $256 \mathrm{E}-08$ \\
\hline $530 E-09$ & 1. $501 E-07$ \\
\hline $708 E-08$ & 9. $199 E-07$ \\
\hline $206 E-08$ & $3.307 E-06$ \\
\hline $834 E-07$ & $1.780 E-05$ \\
\hline O05E-07 & $7.042 E-05$ \\
\hline $179 E-06$ & 1. $454 \mathrm{E}-04$ \\
\hline $087 \varepsilon-06$ & $4.018 E-04$ \\
\hline $306 E-05$ & 1. $345 E-03$ \\
\hline $554 E-05$ & $7.228 \mathrm{E}-03$ \\
\hline $491 E-04$ & $3.395 \mathrm{E}-02$ \\
\hline $1.982 \mathrm{E}-03$ & $1.833 E-01$ \\
\hline $1.696 E-03$ & $6.551 \mathrm{E}-01$ \\
\hline $758 \mathrm{E}-04$ & $8.562 E-01$ \\
\hline $6.054 E-04$ & $8.475 E+00$ \\
\hline $326 E-04$ & 4. $550 E+0 O$ \\
\hline
\end{tabular}

GROUP 5

8 TO $1.0 \mathrm{MEV}$

\begin{tabular}{|c|c|}
\hline ALPHA & LAMBDA \\
\hline $6.292 E-12$ & $7.685 E-10$ \\
\hline 1. $042 E-10$ & $2.614 \mathrm{E}-08$ \\
\hline $6.666 E-11$ & $3.809 E-08$ \\
\hline $2.504 E-09$ & $1.591 E-07$ \\
\hline 1. $152 \mathrm{E}-08$ & $1.020 E-06$ \\
\hline $6.957 E-07$ & $8.643 E-06$ \\
\hline 1. $044 E-05$ & $1.924 E-04$ \\
\hline $6.635 \mathrm{E}-05$ & $9.142 \mathrm{E}-04$ \\
\hline $1.760 E-02$ & $1.071 E-02$ \\
\hline $2.071 E-02$ & $4.203 E+00$ \\
\hline$-2.346 \mathrm{~F}-\mathrm{O} 2$ & $3.437 \mathrm{E}+00$ \\
\hline$-1.872 E-02$ & 1. $116 \mathrm{E}-\mathrm{O} 2$ \\
\hline $3.23+E-03$ & $1.991 E-02$ \\
\hline $6.294 E-03$ & $1.267 \mathrm{E}-01$ \\
\hline 1. $352 E-O 2$ & $1.096 E+00$ \\
\hline$-5.361 E-07$ & $9.227 E-06$ \\
\hline 1. $231 E-06$ & $3.095 \mathrm{E}-05$ \\
\hline
\end{tabular}

$\operatorname{lin}_{\text {GROUP }}^{2}$ T 4 MEV

ALPHA

1. O62E-11

1. $890 E-12$

$6.351 E-11$

2. $015 E-09$

1. $576 E-08$

$6.061 \mathrm{E}-07$

$9.710 E-07$

3. $984 E-06$

$.727 \mathrm{E}-05$

. $401 E-05$

2. $774 \mathrm{E}-04$

8. $341 \mathrm{E}-04$

$5.944 \mathrm{E}-03$

$-2.499 E-02$

2. $153 E-O 2$

1. $110 E-02$

$-1.126 E-02$

LAMBDA
$7.807 E-10$
$1.148 E-08$
$3.184 E-08$
$1.585 E-07$
$6.529 E-07$
$3.463 E-06$
$1.731 E-05$
$6.245 E-05$
$1.701 E-04$
$4.936 E-01$
$1.393 E-03$
$9.581 E-03$
$3.740 E-02$
$1.121 E-01$
$4.593 E-01$
$7.693 E-01$
$8.770 E-01$
$1.010 E+01$
$9.738 E+00$

GROUP 6

1.0 TO 1.2 MEV

\begin{tabular}{|c|c|}
\hline ALPHA & LAMBDA \\
\hline 7. $+12 \mathrm{E}-12$ & $7.706 E-10$ \\
\hline $1.540 E-10$ & $2.641 E-O B$ \\
\hline $6.938 \mathrm{E}-11$ & $4.577 E-O S$ \\
\hline 2. $156 \mathrm{E}-09$ & $1.623 E-07$ \\
\hline $5.464 \mathrm{E}-03$ & $9.591 E-07$ \\
\hline 6. 190E -08 & $7.049 E-05$ \\
\hline $4.927 E-07$ & $2.044 E-05$ \\
\hline $2.253 E-06$ & $6.548 E-05$ \\
\hline $1.857 E-05$ & $3.281 E-04$ \\
\hline $6.168 E-05$ & $1.229 E-03$ \\
\hline $2.965 \bar{E}-04$ & $6.261 E-03$ \\
\hline $1.57 \mathrm{AE}-03$ & $1.967 E-02$ \\
\hline $3.578 E-01$ & $1.663 E-01$ \\
\hline 3. $68 G E-01$ & $1.708 E-01$ \\
\hline $2.491 E-02$ & $2.903 E-01$ \\
\hline $7.847 \mathrm{E}-03$ & $3.439 E+O D$ \\
\hline $9.409 E-03$ & $1.017 E+01$ \\
\hline $4.072 E-10$ & $1.777 \mathrm{E}-07$ \\
\hline
\end{tabular}

\begin{tabular}{|c|c|}
\hline GROUP & 3 \\
\hline $4 \mathrm{TO}$ & $.6 \mathrm{MFV}$ \\
\hline ALPHA & LAMBDA \\
\hline $4.750 E-12$ & $7.305 E-10$ \\
\hline $2.357 \varepsilon-12$ & 1. $191 \mathrm{E}-08$ \\
\hline $7.888 E-11$ & 3. $140 E-O B$ \\
\hline $2.391 E-09$ & $1.698 E-07$ \\
\hline $1.854 E-08$ & $7.808 E-07$ \\
\hline $8.220 E-08$ & $4.453 E-06$ \\
\hline $6.783 E-07$ & $1.624 E-05$ \\
\hline 1. $3 A O F-O 6$ & $6.349 E-05$ \\
\hline $9.950 E-06$ & $1.951 E-04$ \\
\hline $6.032 E-05$ & $9.275 E-01$ \\
\hline $3.861 E-04$ & $7.555 \mathrm{E}-03$ \\
\hline 1. $226 E-03$ & $3.455 \mathrm{E}-02$ \\
\hline $2.435 E-03$ & $1.381 \mathrm{E}-01$ \\
\hline $2.501 E-03$ & $3.703 E-01$ \\
\hline $5.654 E-03$ & $1.792 E+00$ \\
\hline $5.239 E-03$ & $5.809 E+00$ \\
\hline $8.991 E-03$ & $3.458 E+\infty 0$ \\
\hline $1.611 E-06$ & 1. $178 E-04$ \\
\hline
\end{tabular}

GROUP 7

1.2 TO $1.4 \mathrm{MEV}$

ALPHA

$1.605 E-10 \quad 2.619 E-08$
$8.736 E-11$

$8.736 E-11 \quad 3.811 E-08$

8.811E-10 1.811E-07

3.714E-O9 1.336E-O6

1. $754 \mathrm{E}-07$ 1.290E-05

1.339E-O6 3.986E-O5

1. $399 \varepsilon-04$

1. $466 E-05 \quad 3.666 E-04$

$\begin{array}{ll}4.227 E-O 5 & 1.039 E-O 3 \\ 1.311 E-04 & 4.132 E-03\end{array}$

$8.081 E-04 \quad 1.239 E-02$

$1.912 E-03 \quad 3.473 E-O 2$

5.576E-O3 1.258E-O 1

3. $57 \mathrm{OE}-03 \quad 1.675 \mathrm{E}-01$

$2.204 \mathrm{E}-02 \quad 9.831 \mathrm{E}-01$

$1.783 E+00$

$\begin{array}{rr}8.132 E-03 & 4.127 E+00 \\ -4.068 E-11 & 2.837 E-06\end{array}$
GROUP 1

6 TO 8 MFV

\begin{tabular}{|c|c|}
\hline ALPHIA & LAMBDA \\
\hline 1. $883 E-12$ & $7.499 \mathrm{~F}-1$ \\
\hline $.903 E-11$ & $2.138 E-C$ \\
\hline $.872 E-11$ & $3.127 \mathrm{E}-\mathrm{C}$ \\
\hline . $300 E-09$ & $1.626 E-O$ \\
\hline $1.432 \mathrm{E}-08$ & $7.559 E-0$ \\
\hline 1. $350 F-07$ & $5.469 E-O$ \\
\hline $9.369 E-07$ & $2.151 \mathrm{E}-$ \\
\hline $.395 E-06$ & $1.349 E-O$ \\
\hline $7.592 E-05$ & $5.565 E-0$ \\
\hline 1. $308 E-03$ & $9.635 E-C$ \\
\hline $2.671 E-03$ & 4. $199 \mathrm{E}-0$ \\
\hline $9.315 E-03$ & $3.322 \mathrm{E}-\mathrm{O}$ \\
\hline $7.551 E-04$ & 1. $20 G E+C$ \\
\hline $7.696 E-03$ & $8.195 E-0$ \\
\hline $9.081 E-03$ & $1.442 E+C$ \\
\hline $5.847 E-04$ & $9.493 E-C$ \\
\hline $.231 E-05$ & $6.673 \mathrm{E}$ \\
\hline $8.844 \mathrm{E}-05$ & $1.281 \mathrm{E}$ \\
\hline $824 E-09$ & $1.742 \mathrm{E}$ \\
\hline
\end{tabular}

GROUP 8

\begin{tabular}{|c|c|}
\hline ALPHA & LAMBDA \\
\hline 6. $463 E-12$ & $7.583 E-10$ \\
\hline $1.825 E-10$ & $2.675 E-08$ \\
\hline $8.885 E-11$ & 3.901 \\
\hline $3.097 E-10$ & $3.983 E-07$ \\
\hline 8. $137 E-10$ & $9.840 E-07$ \\
\hline 2. $905 E-09$ & $3.216 E-O G$ \\
\hline 1. $905 E-07$ & 1. $486 \mathrm{E}-O$ \\
\hline 1. $107 \mathrm{E}-06$ & $4.059 E-05$ \\
\hline 1. $110 E-05$ & $8.726 E-05$ \\
\hline 1.73IE-05 & $3.789 E-04$ \\
\hline 4. $208 E-05$ & $1.079 E-0$ \\
\hline $9.869 E-05$ & $3.565 E-O$ \\
\hline $8.968 E-04$ & $1.219 E-O$ \\
\hline $2.568 E-03$ & $4.522 \mathrm{E}-\mathrm{O}$ \\
\hline $5.091 E-03$ & $1.086 E-0$ \\
\hline $1.612 \mathrm{E}-\mathrm{O} 2$ & $3.837 E-0$ \\
\hline $3.812 E-02$ & $3.853 E+O$ \\
\hline 3.097E-02 & $4.879 E+C$ \\
\hline
\end{tabular}


TABLE B-VI (Cont)

\begin{tabular}{|c|c|}
\hline \multicolumn{2}{|c|}{ GROUP 9} \\
\hline $1.5 \mathrm{TO}$ & 3 MEV \\
\hline ALPHA & LAMBDA \\
\hline $4.849 E-12$ & $7.317 E-10$ \\
\hline 2. $136 E-10$ & $2.655 E-08$ \\
\hline $6.448 E-11$ & 5. $16.1 E-08$ \\
\hline $1.028 E-09$ & 1. $133 E-06$ \\
\hline $6.465 E-08$ & 1. $113 E-05$ \\
\hline $1.052 E-O G$ & $3.50 D E-05$ \\
\hline $2.872 E-06$ & $1.536 E-04$ \\
\hline 2. $114 E-03$ & 1. $07 \mathrm{BE}-03$ \\
\hline $1.843 E-02$ & $1.263 E-01$ \\
\hline$-7.584 E-03$ & $1.502 \mathrm{E}-01$ \\
\hline $2.210 E-O 2$ & $7.820 E-01$ \\
\hline$-2.356 E-03$ & $1.131 \mathrm{E}-03$ \\
\hline $3.988 E-04$ & $1.823 E-03$ \\
\hline $1.578 E-03$ & $1.764 \mathrm{E}-02$ \\
\hline$-1.75 I E-11$ & 4. $980 E-08$ \\
\hline
\end{tabular}

GROUP 10

1.8 TO $2.0 \mathrm{MEV}$

\begin{tabular}{|c|c|}
\hline ALPHA & LAMBDA \\
\hline 2. $949 E-12$ & $7.714 \mathrm{E}-10$ \\
\hline 1. $980 E-10$ & $2.751 E-08$ \\
\hline $6.559 E-11$ & $3.731 E-08$ \\
\hline 5. $338 E-10$ & $1.322 E-06$ \\
\hline 8. $-19 E-08$ & $1.422 E-05$ \\
\hline $1.207 E-06$ & $4.057 E-05$ \\
\hline 2. $281 E-05$ & $4.868 E-04$ \\
\hline 5. ع 28,E-05 & $1.670 E-03$ \\
\hline A. ESGE-OA & 8. $908 E-03$ \\
\hline $9.572 E-03$ & $4.377 E-02$ \\
\hline 1. $438 \mathrm{E}-02$ & $1.733 E-01$ \\
\hline $2.216 \mathrm{E}-02$ & 1. $193 E+O O$ \\
\hline$-6.902 E-03$ & 4. $579 \mathrm{E}-02$ \\
\hline$-9.159 E-08$ & $2.355 E-03$ \\
\hline$-2.522 E-11$ & 4. $412 E-08$ \\
\hline
\end{tabular}

GROUP IA

2.6 TO $3.0 \mathrm{MEV}$

$=4$ TO 26 ME

$\begin{array}{ll}\text { ALFHA } & \text { LAMBDA } \\ 1.577 E-13 & 7.277 E-10 \\ 8.363 E-11 & 2.623 E-08 \\ 2.375 E-11 & 4.445 E-08 \\ 4.104 E-08 & 1.752 E-05 \\ 6.387 E-07 & 4.300 E-05 \\ 2.477 E-05 & 6.432 E-04 \\ 1.345 E-03 & 3.34 O E-03 \\ 7.314 E-O 4 & 1.420 E-02 \\ 4.027 E-03 & 6.914 E-02 \\ 3.552 E-02 & 2.643 E-01 \\ 2.066 E-02 & 2.914 E-01 \\ 2.439 E-02 & 1.245 E+O O \\ 1.287 E-03 & 3.420 E-03 \\ 6.659 E-12 & 4.485 E-08 \\ 7.127 E-11 & 2.409 E-06\end{array}$

ALFHA

1. $138 \mathrm{E}-11$

1. 706F- 11

1. $0.45 E-11$

1. $495 E-10$

1. $24 O E-08$

1. $340 E-05$

$2.917 E-05$

5. $145 \mathrm{E}-05$

4. 355E-O4

1. $236 \mathrm{E}-\mathrm{O} 2$

4. $517 \mathrm{E}-02$

4. $57 \mathrm{OE}-\mathrm{O} 2$

$-2.425 E-02$

$-2.114 E-02$

2. $968 \mathrm{E}-\mathrm{O} 2$

$-4.287 E-O \%$
LAMBDA

$7.243 E-10$ 2. $441 \mathrm{E}-08$ 3. $570 E-08$ 2. $323 E-07$ 3. $553 \mathrm{E}-06$ 1. $635 E-05$ 4. $797 E-05$ 5. $905 E-04$ 1. $357 \mathrm{E}-03$ 6. $814 \mathrm{E}-\mathrm{O} 3$ 4. $479 \mathrm{E}-\mathrm{O} 2$ $6.053 E-0$ 3. $446 \mathrm{E}+00$ 4. $152 \mathrm{E}+\mathrm{OO}$ 6. 305E-02

8. $224 \mathrm{E}-05$
GROUP 11 2.0 TO 2.2 MEV

\begin{tabular}{|c|c|}
\hline ALPHA & LAMBDA \\
\hline $.020 E-12$ & $7.529 E-10$ \\
\hline $1.452 \mathrm{E}-10$ & $2.621 \mathrm{E}-08$ \\
\hline $7.995 E-11$ & $3.554 E-08$ \\
\hline 2. $193 E-10$ & $2.239 E-06$ \\
\hline 2. $169 \mathrm{E}-07$ & $2.054 \mathrm{E}-05$ \\
\hline $1.707 E-06$ & $5.446 E-05$ \\
\hline $2.067 E-05$ & $5.119 E-O 4$ \\
\hline $7.755 E-05$ & $2.029 E-03$ \\
\hline $6.905 E-04$ & 1. $264 \mathrm{E}-\mathrm{C} 2$ \\
\hline $2.517 \mathrm{E}-03$ & $4.546 E-02$ \\
\hline 1. $2.33 \mathrm{E}-02$ & $1.633 E-01$ \\
\hline $2.177 \mathrm{E}-\mathrm{O} 2$ & $7.341 E-01$ \\
\hline 4. $179 \mathrm{E}-03$ & $8.797 E+O 0$ \\
\hline $1.870 E-04$ & $6.310 E-02$ \\
\hline $8.830 E-07$ & $6.605 E-05$ \\
\hline $1.946 E-11$ & $3.456 \mathrm{E}-08$ \\
\hline
\end{tabular}

GROUP 12 2.2 TO $2.4 \mathrm{MEV}$

ALPHA
$1.903 E-13$
$1.072 E-10$
$5.483 E-11$
$1.553 E-10$
$1.454 E-07$
$1.201 E-06$
$1.695 E-O 5$
$5.651 E-O 5$
$3.952 E-04$
$4.120 E-03$
$7.799 E-03$
$1.116 E-02$
$2.257 E-02$
$-2.236 E-03$
$-1.368 E-06$
$-6.888 E-12$

LAMBDA 7. $383 E-10$ 3. $435 \varepsilon-08$ 2. $998 E-O G$ 2. $031 \mathrm{E}-05$ 5. $467 \mathrm{E}-05$ 4. $681 \mathrm{E}-\mathrm{OA}$ 1. $594 \varepsilon-03$ 9. $282 E-03$ 4. 844E-O2 2. $477 \mathrm{E}-01$ 1. $378 \mathrm{E}+00$ 8. $750 \mathrm{E}-02$ 1. $320 \mathrm{E}-\mathrm{O}$ 2. 175E-O8
GROUP 15 3.0 TO 4 O MEV

ALPIHA 4. $153 \mathrm{E}-13$ 3. $579 E-12$ 1. $346 E-12$ 1. $425 \mathrm{E}-11$ 3. $418 \mathrm{E}-10$ 8. $996 \mathrm{~F}-07$ 2. $150 E-06$ $4.837 E-05$ 9. $929 E-05$

3. $157 \mathrm{E}-04$ 2. $987 \mathrm{E}-03$ 3. $174 \mathrm{E}-\mathrm{O} 2$ 1. $002 \mathrm{E}-01$ 4. $835 \mathrm{E}-\mathrm{OA}$ $-3.577 E-02$

9. $45.3 \mathrm{E}-02$ 1. $804 \mathrm{E}-06$
LAMBDA

7. O98E- 10 2. $083 \mathrm{E}-08$ 6. $657 \mathrm{E}-08$ 2. $455 E-07$ 5. $361 E-06$ 3. $918 \mathrm{E}-05$ 5. $184 E-05$ 6. $238 E-O 4$ 1. $948 E-03$ 6. $540 E-03$ 2. $109 E-O$ ? 1. $171 E-O 1$ 4. $571 \mathrm{E}-01$

3. $940 E+O O$

4. $790 E-01$

1. $663 \mathrm{E}+00$ 4. 392 E-O5
GROUP 16

4.0 TO $5.0 \mathrm{MEV}$

ALPHA 1. $35 O E-13$ 2. $872 E-12$

3. $918 \mathrm{E}-10$

1. $941 \mathrm{E}-\mathrm{OT}$

5. $200 E-O G$

4. $277 E-05$

3. $132 \mathrm{E}-04$

1. $.951 \mathrm{E}-01$

$-4.793 E-01$

3. $067 \mathrm{E}-\mathrm{O} 1$

7. $505 \mathrm{E}-02$

4. $923 \mathrm{E}-02$

$-2.039 E-02$.

$-8.067 E-13$

5. $0.15 E-12$
LAMBDA

7. $006 E-10$

2. $105 E-07$

9. $775 \mathrm{E}-06$

5. 23OE-O4

3. $298 \mathrm{E}-01$

9. $81 G E-03$

7. $07.2 \mathrm{E}-\mathrm{O} 2$

7. $851 E-02$

8. $639 \mathrm{E}-02$

$6.381 \mathrm{E}-01$

1. $712 \mathrm{E}+\mathrm{OO}$

7. $458 \mathrm{E}-01$

4. $439 \mathrm{E}-07$

1. $375 \mathrm{E}-\mathrm{O} 6$
GFOUN 17 5.0 TO 6.0 MEV

AIPHA

3. $333 \mathrm{~F}-11$

5. O2.5E- 11

1. $891 E-13$

1. $251 \mathrm{E}-10$

7.343E-

1 Inge-cis

$2780 \mathrm{E}-\mathrm{C} 5$

1. $55 O E-O$

1. 4775.62

2. $050 \mathrm{C}-\mathrm{C}$

1. $423 \mathrm{E}-(\because)$

2. $480 F-C ?$

$-5.153 E-C O$
I. AMEDA

$1.89: \varepsilon .00$

1. $121 E-05$

3. 5 F E - OS

1. $750 \mathrm{E}-03$

4. $623 \mathrm{t}-0.3$

2.0965 o?

1. 39OE- 01

$0.032 t-01$

2. 4 ISE BO

3. $6 \% A \mathrm{~A}$ tOn

7. $165 \mathrm{~F}-\mathrm{Or}$ 


\begin{tabular}{|c|c|}
\hline \multicolumn{2}{|c|}{ GROUPP 1} \\
\hline $.0 .0 \mathrm{TO}$ & $1 \mathrm{MEV}$ \\
\hline$\wedge L P H A$ & LAMBDA \\
\hline $1.575 E-13$ & $1.053 E-09$ \\
\hline $5.868 E-13$ & $7.491 E-09$ \\
\hline 6. $533 E-12$ & 3. 193E-O8 \\
\hline $1.563 E-10$ & $2.533 E-07$ \\
\hline $2.942 \mathrm{E}-09$ & $9.501 E-07$ \\
\hline $1.025 E-08$ & 2. $326 \mathrm{E}-\mathrm{O}$ \\
\hline $7.436 E-09$ & $9.554 E-06$ \\
\hline $3.483 E-08$ & $9.956 \mathrm{E}-05$ \\
\hline $9.955 E-07$ & $3.260 E-04$ \\
\hline $4.669 E-06$ & $1.120 E-03$ \\
\hline $2.70 G E-05$ & $6.438 E-03$ \\
\hline $1.908 E-04$ & $1.786 E-02$ \\
\hline $5.654 E-04$ & $9.085 E-02$. \\
\hline $6.856 E-02$ & $1.582 E+O O$ \\
\hline$-7.029 E-02$ & $1.659 E+O O$ \\
\hline $4.682 E-03$ & $4.954 E+00$ \\
\hline$-2.124 E-03$ & $7.501 E+00$ \\
\hline
\end{tabular}

GROUP 5

6 TO .8 MEV

\begin{tabular}{|c|c|}
\hline ALPHA & LAMBDA \\
\hline $2.743 E-11$ & $7.278 E-10$ \\
\hline 1. $232 E-11$ & $1.087 E-08$ \\
\hline $7.873 E-11$ & $2.966 \mathrm{E}-08$ \\
\hline 1. $462 \mathrm{E}-08$ & 1.24OE - O7 \\
\hline $3.050 E-07$ & $2.826 \mathrm{E}-0 \mathrm{O}$ \\
\hline $8.594 E-07$ & $1.520 E-05$ \\
\hline $2.487 E-00$ & $6.046 E-05$ \\
\hline $2.047 E-05$ & $2.516 E-04$ \\
\hline $3.840 E-05$ & $9.024 E-04$ \\
\hline $1.538 E-04$ & $2.905 \mathrm{E}-03$ \\
\hline $4.903 E-04$ & $1.092 E-02$ \\
\hline $2.285 E-03$ & $4.341 E-02$ \\
\hline $1.239 E-02$. & $2.716 E-01$ \\
\hline $5.805 E-02$ & $2.337 E+00$ \\
\hline $1.241 E-01$ & $4.39 .3 E+00$ \\
\hline $7.718 E-02$ & $5.731 E+00$ \\
\hline $8 E-04$ & $2.642 E-01$ \\
\hline $.299 t-19$ & 1.969E - \\
\hline
\end{tabular}

$$
\begin{aligned}
& \text { GROUP } \\
& .1 \\
& \text { TO }
\end{aligned}
$$

ALPHA

1. $895 \mathrm{E}-13$

7. $624 \mathrm{E}-13$

1. $603 \mathrm{E}-11$

1. $104 \mathrm{E}-09$

$5.213 \mathrm{E}-08$

7. $553 E-07$

5. $556 \mathrm{E}-06$
1. $684 \mathrm{E}-05$

1. $681 \mathrm{E}-05$

8. $412 \mathrm{E}-\mathrm{OA}$

2. $436 \mathrm{E}-03$

2. $005 \mathrm{E}-02$

8. 527E-03

$-4.437 E-09$

\section{LMEDA}

4. $578 E-09$

1. $647 E-08$

2. $997 E-08$

2. $903 E-06$

1. $534 E-05$

1. $357 E-04$

$4.019 E-04$

1. $534 \mathrm{E}-03$

$7.615 E-03$

$.544 E-02$

1. $396 E+O O$

$596 E+00$

5. $917 E-06$
GROUP 6

\& TO $1.0 \mathrm{MEV}$

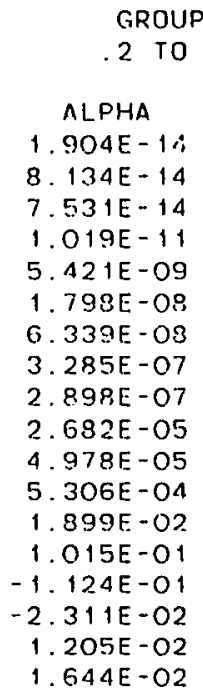

ROUP 3

MEV

LAMBDA

$6.098 \mathrm{E}-09$

$1.012 \mathrm{E}-08$

3. $884 \mathrm{E}-08$

1. $499 \mathrm{E}-07$

G. 605E-07

1. $235 \mathrm{E}-06$

4. $014 \mathrm{E}-0 \mathrm{OG}$

1. 36GE-05

3. $175 \mathrm{E}-05$

4. $061 E-01$

8. $420 E-04$

$9.422 \mathrm{E}-03$

8. $051 \mathrm{E}-\mathrm{O} 2$

7. 403

6. $864 \mathrm{E}+\mathrm{OO}$

9. $396 \mathrm{E}-02$

1. $646 E-01$
2. $363 E+O O$

GROUP 7

1.O TO $1.2 \mathrm{MEV}$

ALPHA

3. $386 \mathrm{E}-16$

1. 8 ! $1 E-11$

1. $05 E-12$

5. $91,6 E-10$

1. $4 \backslash 8 E-09$

1. $405 E-08$

9. $464 \mathrm{E}-08$

9. $313 \mathrm{E}-07$

1. 396E-O5

1.

7. $180 E-05$

1. $907 E-04$

1. $327 \mathrm{E}-03$

4. $988 \mathrm{E}-03$

2. $417 E-02$

$-1.155 E-02$

$-6.802 \mathrm{E}-05$
LAMBDA

1.872E-O9

2. $159 \mathrm{E}-\mathrm{O}$

3. $497 \mathrm{E}-08$

$5.608 \mathrm{E}-07$

$1.414 E-06$

3. $147 E-06$

1. $136 E-05$

3. $355 E-05$

2. $250 E-04$

$9.838 E-01$

4. $337 \mathrm{E}-03$

2. $133 \mathrm{E}-\mathrm{O} 2$

1. OOOE-O

$5.331 E-01$

1. $364 E+O O$

2. $902 \mathrm{E}+\mathrm{OO}$

$3.011 E-02$
GROUP 4

\begin{tabular}{|c|c|}
\hline ALPHA & LAMBDA \\
\hline $.580 E-13$ & 4. $501 E-09$ \\
\hline $1.981 E-11$ & 1. $\triangle 1 O E-O B$ \\
\hline $081 E-10$ & $2.817 t$ \\
\hline $.883 E-09$ & $2.249 E-O 7$ \\
\hline $3.127 E-08$ & $8.420 E-07$ \\
\hline $183 E-07$ & 1. $010 E-05$ \\
\hline $.132 E-06$ & A. $560 E-O$ \\
\hline $1.938 E-05$ & $2.835 E-O$ \\
\hline $.860 E-05$ & $9.431 E-O$ \\
\hline $1.030 E-04$ & $3.519 E-O$ \\
\hline $5.790 E-04$ & 1. $204 \mathrm{E}-\mathrm{O}$ \\
\hline $6.223 E-04$ & $2.756 \mathrm{E}-\mathrm{O} 2$ \\
\hline $.028 E-02$ & 1. $147 \mathrm{E}-\mathrm{O}$ \\
\hline $3.843 E-02$ & $5.050 E-O$ \\
\hline $1.5 \wedge 8 E-02$ & $5.633 E-O$ \\
\hline $805 E-03$ & $2.563 E+O$ \\
\hline $382 E-03$ & $4.641 E+0$ \\
\hline $.746 \mathrm{E}-09$ & $7.773 \mathrm{E}$ \\
\hline
\end{tabular}
4 TO . $6 \mathrm{MEV}$

GROUP 8

2 TO 1.4 MEV

ALPHA

1.035E-15 2.421E-O9

$1.086 E-13 \quad 1.670 E-08$

3. $401 E-13$ 3. $130 E-08$

1. $555 \mathrm{E}-11 \quad 1.495 \mathrm{E}-07$

$3.557 \mathrm{E}-10 \quad 6.177 \mathrm{E}-07$

2.170E-O8 2. $425 E-O G$

2. $566 \mathrm{E}-08 \quad 5.153 E-06$

1.673E-06 $4.161 E-05$

9.010E-OG $1.913 E-O 4$

$4.957 E-O 5 \quad 7.425 E-O 4$

1.26OE-O4 $7.425 E-04$

$2.879 E-03$

1. $326 \mathrm{E}-\mathrm{O} \quad 1.422 \mathrm{E}-\mathrm{O} 2$

$2.244 E-O 3 \quad 6.297 E-O 2$

2.506E-03 2.560E-01

$1.261 E-O 4$. $1.514 E+O 1$ 
TABLE B-VII (Cont)

GROUP 9

1.4 TO $1.6 \mathrm{MEV}$

\begin{tabular}{|c|c|}
\hline ALPHA & LAMBDA \\
\hline $6.011 E-17$ & $1.414 E-09$ \\
\hline $3.490 E-12$ & $2.207 E-08$ \\
\hline $3.876 E-12$ & $3.063 E-08$ \\
\hline $6.253 E-07$ & $7.4140 E-07$ \\
\hline 7. $373 E-05$ & $3.949 E-04$ \\
\hline 1. $356 E-03$ & $1.522 E-02$ \\
\hline $1.885 E-03$ & $7.589 \mathrm{E}-02$ \\
\hline $6.279 E-03$ & $2.278 E-01$ \\
\hline $1-381 E-02$ & $7.323 E-01$ \\
\hline $7.309 E-03$ & $5.955 E-01$ \\
\hline $2.441 F-03$ & 1. $.533 E+00$ \\
\hline 4. $.071 \mathrm{E}-03$. & $2.331 \mathrm{E}+00$ \\
\hline $2.959 E-05$ & $4.123 E-04$ \\
\hline $1.626 \mathrm{E}-04$ & $3.979 E-03$ \\
\hline $1.617 E-06$ & 8. $158 E-07$ \\
\hline $9.953 E-07$ & $8.456 E-07$ \\
\hline $8.030 E-07$ & A. $587 \mathrm{E}-05$ \\
\hline $2.093 E-07$ & $1.344 \mathrm{E}-06$ \\
\hline 1. $985 E-C 7$ & 1. $394 E-06$ \\
\hline
\end{tabular}

GROUP 13

2. 2 TO 2.4 MEV

ALPHA

9. $396 E-13$

2. $560 E-16$

1. $045 \mathrm{E}-12$

8. $002 E-10$

2. $344 E-10$

1. $830 E-09$

7. $367 E-07$

O. $824 \mathrm{E}-\mathrm{OG}$

ङ. $303 E-05$

2. $582 \mathrm{E}-\mathrm{OA}$

1. $420 \mathrm{E}-\mathrm{O}$

5. $593 \mathrm{E}-\mathrm{O} 3$

4. $160 \mathrm{E}-03$

4. $263 \mathrm{E}-03$

$-5.712 \mathrm{E}-\mathrm{O} 3$

2. $179 E-08$

3. $071 \mathrm{E}-08$

3. 544E-O7

6. $192 E-07$

1. $211 E-06$

5. $950 E-O 5$

2. $018 E-04$

. $124 \mathrm{E}-$

7. $439 E-03$

2. 534E-O2

2. $142 \mathrm{E}-\mathrm{O} 1$

6. $752 E-O 1$

4. $459 E+00$

1. $683 \mathrm{E}-\mathrm{OA}$
GROUP 10

1.6 TO $1.8 \mathrm{MEV}$

ALPHA

1. $420 \mathrm{E}-18$

1. $126 \mathrm{G}-12$

2. $791 E-13$

1. $761 E-09$

2. $\mathrm{C} 82 \mathrm{E}-\mathrm{OB}$

A. $11 E-07$

4. $14 \mathrm{E}-\mathrm{OS}$

. 14 E 06

1. $441 E-05$

5. $855 \mathrm{E}-05$

2. $359 \mathrm{E}-04$

1. $169 \mathrm{E}-03$

$1.270 \mathrm{O}-02$

$-8.152 E-03$

8. $864 \mathrm{E}-\mathrm{O} 3$

5. $294 \mathrm{E}-03$

2. $934 \mathrm{E}-03$

1. $4.3 E-03$
LAMEDA
$E-10$
2. $180 E-08$
$2.003 E-07$
7. $512 \mathrm{E}-07$
2. $556 \mathrm{E}-\mathrm{O} 5$
121E-05
$.763 E-05$
1.758E-O4
5. $645 E-04$
$182 E-03$
$.098 \mathrm{E}-03$
2. 469E-02
1. $117 \mathrm{E}-01$
1. $193 E-01$
3. $794 E-01$
4. $467 E+00$
3. $307 E+00$

GROUP 14

2. 4 TO 2.6 MEV

ALCHA

4. $848 E-13$

1. $252 \mathrm{E}-15$

3. $612 E-16$

$3.374 \mathrm{E}-09$

1. $407 E-07$

4. $232 \mathrm{E}-06$

4. $572 E-05$

$5.481 E-04$

7. $497 E-04$

4. $713 E-03$

3. $493 \mathrm{E}-03$

1. $039 \mathrm{E}-03$

$6.771 \mathrm{E}-\mathrm{OA}$

$5.545 E-04$

1. $469 \mathrm{E}-05$

1. $990 E-0^{\circ}$

$-2.0 C 4 E-07$

AMBDA

2. 17.8E-O8

2. $253 E-08$

2. $254 E-08$

.253E-05

1. $602 E-04$

8. $998 E=04$

1. $206 E-02$

. $243 E-02$

2.018E-01

$1.277 E+O O$

2. $275 E+0 O$

3. $738 E+00$

1. $692 \varepsilon-06$

1. $705 E-06$
GROUP 11

.1 .8 TO 2.O MEV

ALPHA
$9.695 E-19$
$6.832 E-13$
$1.720 E-10$
$3.996 E-09$
$4.361 E-08$
$6.644 E-07$
$7.149 E-O 6$
$4.754 E-O 5$
$1.041 E-04$
$7.792 E-04$
$1.092 E-03$
$4.851 E-03$
$1.016 E-O 2$
$4.740 E-03$
$3.880 E-03$

LAMEOA

9.565E- 11

2. $180 E-08$

$5.658 \mathrm{E}-07$

$2.702 E-06$

1. $756 E-05$

6. $116 E-05$

2. $874 \mathrm{E}-04$

1. $.009 \mathrm{E}-03$

4. $623 \mathrm{E}-03$

1. $667 \mathrm{E}-02$

3.861E-0?

1. $740 E-O$

5. $.496 E-01$

1. $163 E+O O$

2. $173 E+O O$
GROUP 12

2. $O$ TO 2.2 MEV

\begin{tabular}{|c|c|}
\hline ALPHA & LAMBOA \\
\hline $9.394 E-12$ & $2.465 E-08$ \\
\hline 5. $163 E-16$ & $3.071 E-08$ \\
\hline 1. $838 E-12$ & $9.914 E-08$ \\
\hline $9.985 E-11$ & 3. $122 \mathrm{E}-07$ \\
\hline $5.056 E-12$ & 1. 2 GOE -06 \\
\hline $3.573 E-09$ & $2.072 \mathrm{E}-\mathrm{OG}$ \\
\hline $3.964 E-07$ & $5.483 E-05$ \\
\hline $9.3 \mathrm{OOE}-\mathrm{O} 6$ & 2. $2.80 E-04$ \\
\hline 4. $799 E-05$ & $8.095 E-04$ \\
\hline 1. $216 E-04$ & $4.200 E-03$ \\
\hline 1. $386 E-03$ & $2.219 E-02$ \\
\hline $5.089 E-03$ & $1.688 E-01$ \\
\hline 3. $932 \mathrm{E}-03$ & $5.132 E-01$ \\
\hline 4. $930 \mathrm{O}-\mathrm{O} 3$ & $3.755 E+O O$ \\
\hline 5. $688 E-03$ & $2.049 E+00$ \\
\hline $.144 E-06$ & $1.94 \mathrm{CE}-04$ \\
\hline
\end{tabular}

GROUP 16

GROUP 15

2.6 TO 3 O MEV

3.O TO 4.0 MEV

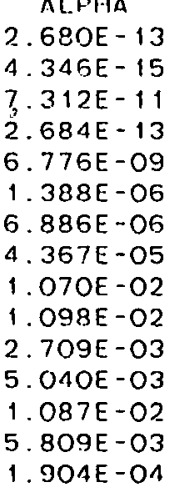

LAMBDA
2. $179 \mathrm{E}-\mathrm{OS}$

2. $553 E-O 8$

6. $240 \mathrm{E}-07$

$6.835 \mathrm{E}-06$

1. $993 \mathrm{E}-05$

1. 158E-04

3. $099 \mathrm{E}-04$

1. 240E-O3

$1.038 \mathrm{E}-02$

1. $074 \mathrm{E}-02$

2. $116 \mathrm{E}-\mathrm{O} 2$

1. $682 \mathrm{E}-\mathrm{O}$

5. 767E-01

1. $301 \cdot E+O O$
ALPHA

6. $976 E-14$

6. $465 \mathrm{E}-17$

3. $321 E-11$

1. $827 E-07$

1. $733 \mathrm{E}-06$

3. $355 E-05$

1. 392E-O

2.059E-O3

3. $501 \mathrm{E}-03$

1. $461 \mathrm{E}-\mathrm{O} 2$

$-1.852 E-11$
LAMBDA

2. 179E-OB

3. $507 E-08$

$9.524 E-05$

$.474 E-O 4$

$3.629 E-03$

1. $508 \mathrm{E}-02$

2. $323 E-01$

3. $354 \mathrm{E}-\mathrm{O} 6$
5. $809 E-03$

1. $304 \mathrm{E}-04$
1. $162 E+O 1$ 
TABLE . B-VII (Cont)

GROUP 17 4.0 TO 5 O MEV

ALPHA $7.777 \mathrm{E}-19$

1. $75 \mathrm{OE}-\mathrm{OB}$

1. $593 \mathrm{E}-0 \mathrm{~S}$

143E-O7

1. $224 \mathrm{E}-05$

2. $356 \mathrm{E}-0.1$

8. $390 E-0.4$

2. $194 \mathrm{E}-03$

4. $094 \mathrm{E}-03$

4. $702 \mathrm{E}-05$

2. $463 E-05$
LAMEDA
4. 142E-OG
3. $393 E-05$
6. $406 E-05$
7. $133 \mathrm{E}-\mathrm{OA}$
1. $602 \mathrm{E}-03$
7. $705 E-03$
$3.049 E-02$
. $559 E-01$
2. $862 E-0.1$
9. $94.3 E-01$
1. $620 E+01$

GROUP 18 G. O TO G.O MFV

$\begin{array}{cc}\text { NLPHA } & \text { LAMBDA } \\ 1.200 E-20 & 8.577 E-O 6 \\ 3.001 E-16 & 4.044 E-O 4 \\ 1.177 E-13 & 1.308 E-03 \\ 2.247 E-09 & 5.877 E-03 \\ 7.189 E-07 & 9.483 E-03 \\ 8.904 E-05 & 9.483 E-03 \\ 2.099 E-04 & 3.293 E-02 \\ 1.326 E-03 & 1.699 E-01 \\ 1.352 E-03 & 9.456 E-01 \\ -1.81 O E-19 & 2.973 E-06\end{array}$


EXPERIMEITAL FITS FOR ${ }^{239}$ PU THERMAL PULSE BETAS

\begin{tabular}{|c|c|c|}
\hline \multicolumn{3}{|c|}{ GROUP 1} \\
\hline 0.0 TO & .2 & MEV \\
\hline ALPHA & & LAMP,DA \\
\hline $119 E-12$ & & 3. $882 E-10$ \\
\hline $897 E-: 1$ & & 1. $583 E-08$ \\
\hline $550 E-10$ & & $8.552 E-08$ \\
\hline $890 E-O 9$ & & $2.910 \mathrm{E}-07$ \\
\hline $120 E-08$ & & $1.431 E-06$ \\
\hline $983 E-08$ & & 6. $194 \mathrm{E}-06$ \\
\hline $280 E-07$ & & $2.573 E-05$ \\
\hline $645 E-06$ & & 1. $800 E-04$ \\
\hline $900 E-05$ & & $3.218 E-04$ \\
\hline $929 E-05$ & & 4. 258E-03 \\
\hline $4 O E-04$ & & $1.513 E-02$ \\
\hline $475 E-04$ & & 3. $165 E-02$ \\
\hline $21 \mathrm{E}-05$ & & $1.433 \mathrm{E}-01$ \\
\hline $1 E-05$ & & $4.497 E$ \\
\hline 10 & & $9.689 \mathrm{E}$ \\
\hline
\end{tabular}

GROUP 5

8 TO $1.0 \mathrm{NEV}$
GROUP 2

2 TO 4 MEV

ALPHA

6. $815 E-12$

$5.074 E-11$

8. $539=-10$

6. $740 \equiv-09$

$2.546 \equiv-09$

$2.057 \equiv-07$

1. $.088 \equiv-06$

7. $335 \equiv-06$

$6.070 \equiv-05$

1. $277 \mathrm{E}-04$

$5.421 \mathrm{E}-04$

1. $033 \mathrm{E}-03$

8. $253 \mathrm{E}-\mathrm{OA}$

LAMEDA
$7.591 E-10$
$2.618 E-08$
$1.405 E-07$
$4.525 E-07$
$1.392 E-06$
$7.443 E-06$
$3.189 E-05$
$1.980 E-04$
$8.686 E-04$
$5.066 E-03$
$1.791 E-02$
$5.746 E-02$
$2.753 E-01$
$9.173 E-01$
$4.499 E+00$

GROUP 6

1.0 TO 1.2 MEV

ALPHA

2. $630 E-12$

LAMBDA

2. $006 \mathrm{E}-10$

2. $809 E-10$

1. $345 E-09$
$247 E-09$

6. $247 E-09$
4. $608 E-08$

3. $230 E-07$

1. $579 E-06$

1. $667 \mathrm{E}-05$

6. $8.38 E-05$

5. $1 \div 1 \mathrm{E}-\mathrm{OA}$

1. $826 \mathrm{E}-03$

3. $938 \mathrm{E}-03$

$6.447 \mathrm{E}-\mathrm{O} 3$

1. $507 \mathrm{E}-03$
7. $524 \mathrm{E}-10$

2. $402 E-08$

9. $519 E-08$

3. 138E-07

1. $343 \mathrm{E}-06$

6. $853 \mathrm{E}-06$

1. \& 19E-05

6. 169E-05

3. $381 \mathrm{~F}-04$

1. $311 E-03$

7. $685 \mathrm{E}-03$

2. $827 E-02$

1. $140 E-01$

4. $672 \mathrm{E}-\mathrm{OI}$

2. $453 \mathrm{E}+\mathrm{OO}$
GROUP 3

4 TO .6 MEV

ALPHA

2. $331 E-12$

6. $773 \mathrm{E}-11$

$4.448 E-10$

$6.469 E-09$

2. $265 E-08$

9. $492 E-07$

2. $378 \mathrm{E}-06$

2. $535 \mathrm{~F}-05$

8. $596 \mathrm{E}-\mathrm{OS}$

4. 259E-O4

1. $130 E-03$

$1.605 \mathrm{E}-03$

$2.016 E-03$

$4.068 \mathrm{E}-04$

LAMBDA
$7.817 E-10$
$2.413 E-08$
$1.174 E-07$
$4.460 E-07$
$1.391 E-06$
$7.015 E-06$
$2.461 E-05$
$1.012 E-04$
$3.937 E-01$
$1.494 E-03$
$8.519 E-03$
$3.219 E-02$
$8.691 E-02$
$5.182 E-01$
$2.517 E+O O$

GROUP 7

1.2. TO 1. 4 MEV

ALPHA

2. $669 E-12$

2. $368 E-10$

1. $117 E-10$

$6.499 E-10$

3. $244 \mathrm{E}-09$

2. $113 \mathrm{E}-08$

2. $830 E-07$

1. $313 E-06$

1. $476 \mathrm{E}-05$

6. $597 E-05$

1. 800 - 04

. $807 \mathrm{E}-04$

1. $977 E-03$

5. $113 \mathrm{E}-\mathrm{O} 3$

8. $198 \mathrm{E}-03$

1.718E-03
LAMBDA

7. $529 \mathrm{E}-10$

2. $395 \mathrm{E}-08$

7. $533 \mathrm{E}-\mathrm{OS}$

3. $016 \mathrm{E}-07$

1. $357 E-O G$

6. 895E-06

1. $905 E-05$

5. $995 E-05$

3. $3+4 \mathrm{E}-\mathrm{OA}$

1. $306 \mathrm{E}-\mathrm{O}$

7. $605 \mathrm{E}-03$

2. $859 \mathrm{E}-02$

1. $199 \mathrm{E}-\mathrm{O}$

4. $470 E-01$
GROUP 4 .6 TO $.8 \mathrm{MEV}$

ALPHA

2. O49E-12

5. $264 E-10$

4. $655 \mathrm{E}-09$

$2.002 \mathrm{E}-08$

1. $850 E-07$

$825 \mathrm{E}-07$

. 569E-06

3. $391 \mathrm{E}-05$

$6.498 \mathrm{E}-0.5$

4. 854E-O4

$.538 \mathrm{E}-03$

3. $867 \mathrm{E}-\mathrm{O}$

7. $133 E-06$

LAMBDA

2. $418 \mathrm{E}-08$

4. $219 E-07$

1. $460 \mathrm{O}-O 6$

7. 192E-OG

2. $458 \mathrm{E}-05$

1. $158 \mathrm{E}-\mathrm{O} 4$

4. $870 E-O A$

1. $587 \mathrm{E}-03$

$7.846 \mathrm{E}-0.3$

2. $731 \mathrm{E}-\mathrm{O} 2$

1. $339 E-01$

3. $199 \mathrm{E}-\mathrm{O} 1$

6. $246 E-01$
1. 4 TO $1.6 \mathrm{MEV}$

ALPHA

2. $420 E-12$

2. $604 E-10$

3. $715 E-11$

3. $381 E-10$

1. $968 \mathrm{E}-09$

1. $364 E-08$

2. $439 \mathrm{E}-07$

1. $116 \mathrm{E}-\mathrm{OG}$

. $347 E-05$

6. $335 E-05$

4. $102 \mathrm{E}-04$

. $905 E-03$

7. $426 \mathrm{E}-03$

1. $102 E-02$
2. $431 E-03$
LAMEDA

7. $532 \mathrm{E}-10$

2. $386 \mathrm{E}-\mathrm{OS}$

5. $222 \mathrm{E}-\mathrm{O} 8$

3. $842 \mathrm{E}-\mathrm{O} 7$

1. $474 \mathrm{E}-O \mathrm{OE}$

7. $069 \mathrm{E}-06$

1. $943 \mathrm{E}-05$

3. $417 \mathrm{E}-\mathrm{OA}$

1. $313 E-03$

7. $243 E-03$

2. $757 \mathrm{E}-02$

1. $317 E-01$

5. $374 \mathrm{E}-01$

1. $742 \mathrm{E}+\mathrm{OO}$ 
GROUP 9 $1.6 \mathrm{TO} \mathrm{i} .8 \mathrm{MEV}$

$\begin{array}{ll}\text { ALPHA } & \text { LAMBDA } \\ 1.878 E-12 & 7.537 E-10 \\ 2.680 E-10 & 2.377 E-03 \\ 3.369 E-11 & 5.089 E-08 \\ 1.866 E-10 & 4.034 E-07 \\ 1.196 E-09 & 1.600 E-06 \\ 6.57 O E-09 & 6.887 E-O 5 \\ 1.778 E-07 & 1.972 E-05 \\ 8.040 E-07 & 4.701 E-05 \\ 1.244 E-05 & 3.563 E-04 \\ 6.067 E-05 & 1.310 E-03 \\ 3.749 E-04 & 7.270 E-03 \\ 1.892 E-03 & 2.882 E-O 2 \\ 7.177 E-03 & 1.275 E-01 \\ 1.117 E-02 & 4.606 E-01 \\ 2.441 E-03 & 2.457 E+00\end{array}$

GROUP 10 1.8 TO 2.0 MEV

ALPHA
1. $158 E-12$
$2.582 E-10$
$3.229 E-11$
$9.044 E-11$
$5.239 E-10$
$3.076 E-09$
$1.604 E-07$
$6.059 E-07$
$1.017 E-05$
$5.633 E-05$
$3.146 E-04$
$1.642 E-03$
$7.810 E-03$
$1.161 E-02$
$4.786 E-03$

LAMBDA

7. $549 \mathrm{E}-10$

2. $352 E-O 8$

4. $904 \mathrm{E}-08$

3. $593 \mathrm{E}-07$

1. $570 E-06$

6. 899E-06

2.091E-05

4.8.10E-O5

$3.897 \mathrm{E}-04$

1. $238 \mathrm{E}-0.3$

$7.345 \mathrm{E}-03$

2. $806 \mathrm{E}-02$

1. $257 \mathrm{E} \cdot 01$

4. $593 \mathrm{E}-01$

4. $158 \mathrm{E}+00$
GROUP 11

2.O TO 2.2 MEV

\begin{tabular}{|c|c|}
\hline$A L P H A$ & LAMBDA \\
\hline $893 E-13$ & $7.587 E-10$ \\
\hline $324 E-10$ & $2.344 E-08$ \\
\hline $818 E-11$ & 4. $668 \mathrm{E}-08$ \\
\hline $249 E-11$ & $2.829 \mathrm{E}-07$ \\
\hline $059 F-10$ & 1. $664 E-06$ \\
\hline $47 O E-09$ & 8. $128 E-06$ \\
\hline $398 E-07$ & 2. $152 E-05$ \\
\hline $286 E-07$ & $4.695 \mathrm{E}-05$ \\
\hline $132 \mathrm{E}-06$ & $4.246 E-04$ \\
\hline A56E-05 & $1.236 \mathrm{E}-03$ \\
\hline $526 E-04$ & 7. $192 \mathrm{E}-03$ \\
\hline $547 \mathrm{E}-03$ & $2.789 E-02$ \\
\hline $177 \mathrm{E}-03$ & $1.323 E-01$ \\
\hline $.284 \mathrm{E}-\mathrm{O} 2$ & $4.483 E-01$ \\
\hline $.237 E-03$ & 4. $122 E+\infty 0$ \\
\hline
\end{tabular}

GROUP 12 2. 2 TO 2. 4 MEV

$\begin{array}{ll}\text { ALPHA } & \text { LAMBDA } \\ 1.915 E-13 & 7.652 E-10 \\ 1.95 O E-10 & 2.320 E-08 \\ 2.300 E-11 & 5.096 E-08 \\ 2.236 E-11 & 3.528 E-07 \\ 2.488 E-10 & 3.786 E-O 6 \\ 3.744 E-08 & 1.540 E-05 \\ 3.702 E-07 & 3.900 E-05 \\ 8.964 E-O 6 & 4.644 E-O 4 \\ 5.010 E-05 & 1.274 E-03 \\ 1.958 E-04 & 6.800 E-0.3 \\ 1.476 E-03 & 2.764 E-02 \\ 7.887 E-O 3 & 1.371 E-01 \\ 1.339 E-02 & 4.143 E-01 \\ 4.395 E-03 & 3.473 E+00\end{array}$

GROUP 13 2. 4 TO 2.6 MEV

ALPHA

$1.474 E-10$

1. $56: E-1$

$1.592 E-11$

1. $887 E-10$

2. $011 E-O B$

3. O1OE-OT

9. $338 E-O G$

4. $301 E-O 5$

1. $512 \mathrm{E}-\mathrm{O} 3$

7. $586 \mathrm{E}-03$

1. $418 \mathrm{E}-\mathrm{O} 2$

$4.085 E-0.3$
GROUP 14 2. 6 TO 3.0 MEV

LAMBDA
$7.606 E-10$
$2.289 E-09$
$4.910 E-08$
$2.551 E-07$
$4.225 E-06$
$1.492 E-05$
$4.040 E-05$
$5.009 E-04$
$1.338 E-03$
$5.592 E-03$
$2.749 E-02$
$1.422 E-01$
$4.899 E-01$
$3.028 E+00$

ALPHA

3. COBE-13.

$1.55 T E-10$
$1.037 E-11$

2. $433 E-11$

2. $786 E-10$

$9.032 \mathrm{E}-09$

. 663E-07

1. $672 \mathrm{E}-05$

6. $538 E-05$

2. $303 E-04$

2. $097 \mathrm{E}-03$

$.452=-02$

2. $618 E-02$

\begin{tabular}{|c|c|c|}
\hline DA & A-PHA & LAMBDA \\
\hline $7.514 E-10$ & $4.543 E-13$ & $7.371 E-10$ \\
\hline $2.221 E-08$ & $3.983 E-11$ & $2.121 E-08$ \\
\hline 4. $785 E-03$ & $8.334 E-12$ & $9.686 E-08$ \\
\hline $2.477 \mathrm{E}-07$ & $2.808 \mathrm{E}-11$ & 2. $72.2 \mathrm{E}-07$ \\
\hline $4.257 E-06$ & 1. $159 E-10$ & $3.451 E-05$ \\
\hline 1.2.70E - 05 & $6.576 E-09$ & 1.2.11E-05 \\
\hline 4. 199E-05 & $5.397 E-07$ & 5. $192 E-O$ \\
\hline $5.579 E-04$ & $2.329 E-05$ & $5.555 E-O 4$ \\
\hline $1.284 E-03$ & $8.706 E-05$ & $1.414 E-0$ \\
\hline 6. $216 \mathrm{E}-03$ & 4. $345 E-04$ & $7.91+E-O$ \\
\hline $2.640 \mathrm{E}-\mathrm{O} 2$ & $3.394 \mathrm{E}-03$ & 3. $107 \mathrm{E}-02$ \\
\hline $1.376 \mathrm{E}-01$ & $3.286 E-02$ & $1.565 E-O$ \\
\hline $4.9+8 E-01$ & $5.802 E-02$ & $7.539 E-0$ \\
\hline 3. OOOE +OO & $1.363 E-02$ & $1.432 \mathrm{E}+\mathrm{O}$ \\
\hline
\end{tabular}

GROUP 15

3.0 TO $4.0 \mathrm{MEV}$

GROUP 16

4.0 TO 5.0 MEV

GROUP 17

5.0 TO $6.0 \mathrm{MEV}$

ALPHA

4. $564 E-14$

4. $211 E-12$

$3.013 E-12$

4. $142 \mathrm{E}-11$

1. $354 E-09$

6. $663 \mathrm{E}-09$

8. $362 E-O B$

3. $096 E-06$

1. $182 \mathrm{E}-05$

1. $822 \mathrm{E}-04$

1. $352 E-03$

$.583 \mathrm{E}-02$

2. $73 \mathrm{OE}-\mathrm{O} 2$

2. 598E-O2
LAMBDA

3. $656 E-10$

4. $358 E-08$

4. 2 IOE -OT

4. $476 \mathrm{E}-\mathrm{OG}$

1. $329 E-05$

$5.033 E-05$

5. $676 E-04$

1. $052 E-02$

1. $55 \mathrm{OE}-\mathrm{O} 1$

$7.876 \mathrm{E}-01$

1. $O 7 O E+O O$
ALPHA

3. $739 E-14$

1. $458 \mathrm{E}-13$

1. $334 \mathrm{E}-10$

1. $500 E-08$

1. $720 \mathrm{~F}-\mathrm{O}$

1. $720 F-05$

2. 297E-OS

$9.674 E-O 3$

3. $306 \mathrm{E}-\mathrm{O} 2$

1. $414 E-0$ ?

6. $814 \mathrm{E}-03$

$-3.575 E-03$

$-1.544 \mathrm{E}-08$

$-1.54 O E-12$

1. $413 \mathrm{E}-12$
LAMBDA

7. $272 \mathrm{E}-10$

6. 886 E- 07

2. $232 E-05$

6.238F-O5

1. $171 \mathrm{E}-03$

6.793E-03

9. $484 E-02$

2. $365 \mathrm{E}-\mathrm{O} 1$

1. $046 F+00$

$.786 E-01$

2. $725 \mathrm{E}+00$

6. $362 E-05$

5. $61.6 E-07$

1. $552 \mathrm{E}-07$ 


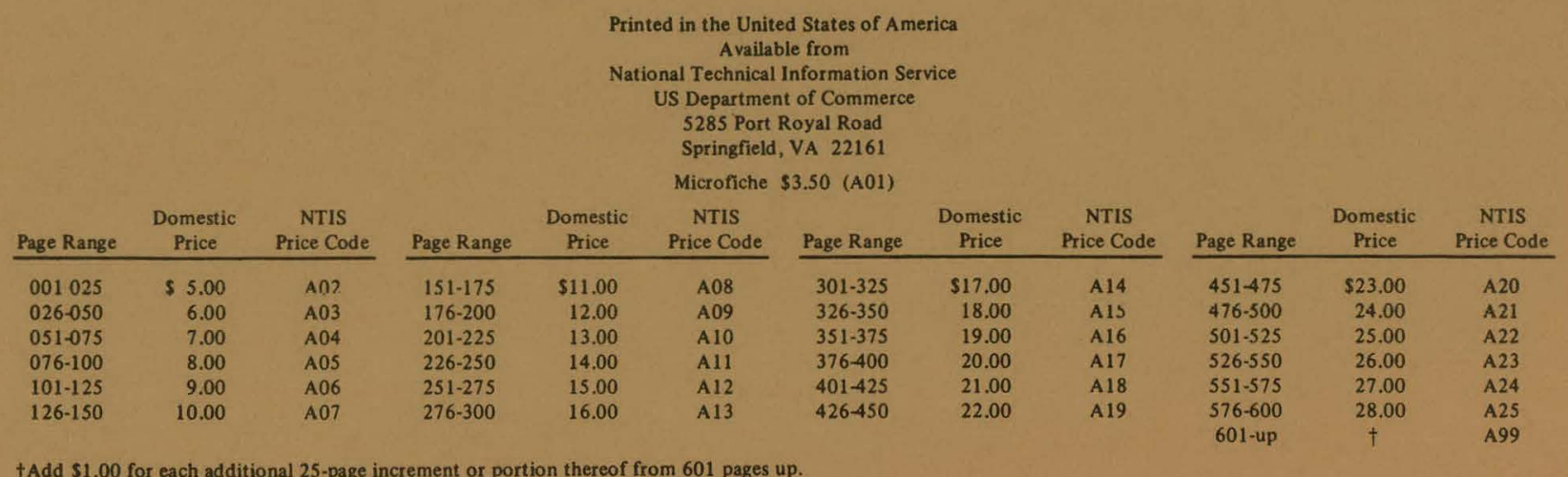

†Add $\$ 1.00$ for each additional 25 -page increment or portion thereof from 601 pages up. 
- range 